\title{
GENERAL DYNAMICS
}

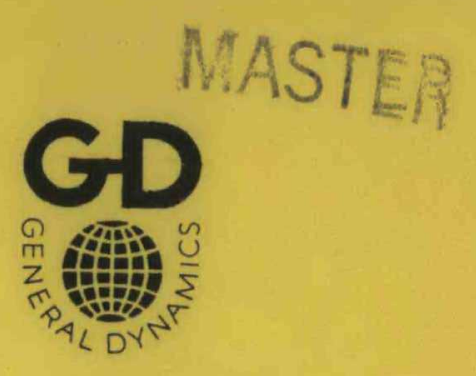

GA-1099

MARITIME GAS-COOLED REACTOR PROGRAM

QUARTERLY PROGRESS REPORT

FOR THE PERIOD ENDING JUNE 30, 1959

Contract A T(04-3)-187

U.S. ATOMIC ENERGY COMMISSION

and

MARITIME ADMINISTRATION

GENERAL ATOMIC and

ELECTRIC BOAT DIVISIONS 


\section{DISCLAIMER}

Portions of this document may be illegible in electronic image products. Images are produced from the best available original document. 


\section{LEGAL NOTICE}

This report was prepared as an account of Government sponsored work. Nelther the United States, nor the Commission, nor any person acting on behalf of the Commission:

A. Makes any warranty or representation, expressed or implied, with respect to the accuracy, completeness, or usefulness of the information contained in this report, or that the use of any information, apparatus, method, or process disclosed in this report may not infringe privately owned rights; or

B. Assumes any liablities with respect to the use of, or for damages resulting from the use of any information, apparatus, method, or process disclosed in this report.

As used in the above, "person acting on behalf of the Commission" includes any employee or contractor of the Commission, or employee of such contractor, to the extent that such employee or contractor of the Commission, or employee of such contractor prepares, disseminates, or provides access to, any information pursuant to his employment or contract with the Commission, or his employment with such contractor.

Printed in USA. Price $\$ 3.50$.

Available from the Office of Technical Services,

Department of Commerce, Washington $25, \mathrm{D}$. C. 


\section{GENERAL DYNAMICS

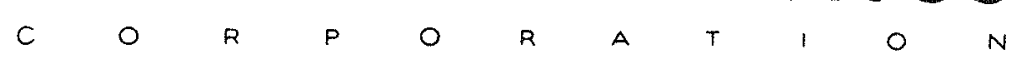

GA-1099

Reactors-Power TID-4500 (15th ed.)

MARITIME GAS-COOLED REACTOR PROGRAM

QUARTERLY PROGRESS REPORT

FOR THE PERIOD ENDING JUNE 30, 1959

Contract AT(04-3)-187

U.S. ATOMIC ENERGY COMMISSION

$$
\text { and }
$$

MARITIME ADMINISTRATION

GENERAL ATOMIC and

ELECTRIC BOAT DIVISIONS

$G$

EB

CU.

$\operatorname{LCC}$

C-L

象

ED

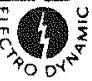

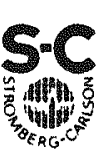


GA-744-October, November, December 1958

GA-1030-January, February, March, 1959 


\section{SUMMARY}

\section{REACTOR DEVELOPMENT}

A code is being developed for the IBM 704 in order to incorporate the effects of actual three-dimensional flux shapes. This code will be used to calculate temperatures, pressure drop, and coolant channel orifice distribution in the core. The IBM 704 code "Peg," developed for the determination of the temperature distribution in the semihomogeneous fuel element, was completed early in the quarter. This has been used to obtain information for the Hanford loop test element.

Assembly of the air-flow test stand was completed, and the testing of a mockup of a 13-rod fuel-element bundle was begun. Initial tests were run to check out the operation of the loop. General agreement was found between a preliminary heat balance and the flow indicated by a flow nozzle. Subsequently, runs were made to determine isothermal friction factors and to determine the existence of hot spots by the use of temperature-sensitive paints.

Preliminary runs with temperature-sensitive paints indicated that there are no local hot spots created by the nonuniform flow path produced by the rod bundle.

A preliminary experiment has been designed and is being fabricated to determine whether it is possible to use water as an emergency coolant in place of an inert gas. The purpose of the experiment is to determine the rate at which various sections of the core can be cooled by water.

During this quarter, the design requirements necessary for a highpressure, high-temperature helium loop for the rmal testing of fuel assemblies have been established.

Experiments performed on the Hanford test pile indicate tiat a heat flux of $110,000 \mathrm{Btu} /(\mathrm{hr})\left(\mathrm{ft}^{2}\right)$ can be expected at the surface of the 1/2-in. diam pellet. Temperature and pressure cycling tests have been run on a 
number of tubes that contained pellets. In all cases, tubes with approximately 0.003 -in. diametral clearance and no axial restraint did not show any cladding failures. Similar experiments run with axial restraint have always ended in failure at the end-cap weld. Seal-ring tests have also been run throughout the quarter.

A complete test-element assembly was fabricated and shipped to Hanford. It included mock fuel and mock thermocouples, the 20 -ft-long support tube, and the end closure seal of the in-pile tube.

Attempts have been made to devise a method of predicting the thermal conductivity of fibrous insulation under the conditions of use in the reactor. Investigation showed that the mechanisms of heat transfer that are of importance are those of gas conduction and radiation across the pores.

The preliminary design of the pressure vessel with and without internal insulation was developed. An analysis was made to determine the effect of thermal shock on the pressure vessel during emergency cooling.

A program was organized to outline the development of conceptual designs to justify the selection of a preliminary design for the core and internals. Ten concepts of core support structures have been studied and evaluated. Highlights of the investigations to date are given and sketches of pertinent concepts are shown.

Studies have been conducted to determine the required thickness of internal biological shielding material and the weight needed to reduce gamma radiation intensity to a level that is tolerable to personnel working near the head of the reactor and that will not induce activation in the head assembly. Results of these studies are given.

The design of fuel reloading equipment was continued, with emphasis placed on a study of the advantages and limitations of a "gas cover" refueling operation and subsequent handling procedures for spent fuel, as opposed to a water cover for these operations. 


\section{FLUID SYSTEMS AND PLANT ARRANGEMENT}

Investigation into reactor heat dump systems showed that an aircooled helium heat exchanger, located outside the containment vessel, is required during reactor heat dump operation.

An experimental program for a four-phase heat-exchanger test loop was layed out and started. Two phases of the experiment, the air isothermal pressure-drop tests and the helium isothermal pressure-drop tests, have been completed.

A survery and detailed evaluation of existing valve technology is being conducted pertinent to the functional requirements of valves for isolating the reactor from propulsion machinery. Fifteen preliminary designs were presented and are described.

An experiment to verify the performance of the concentric-duct heat barrier was developed and preliminary design studies were made for flanged mechanical joints in the main coolant ducting.

A number of possible steam generator and jet pump combinations were investigated, as were computer programs for calculating the steadystate performance. A steady-state analysis that has been performed indicates that the plant may be operated at constant compressor shaft speed over most of its operating range. This opens the possibility of placing the electrical generator on the compressor shaft without using a variable-speed drive and of requiring the low-pressure turbine bypass steam generator to act only as a heat sink.

Revision of the system transient equations have been taking place during the entire quarter. Equations to account for bleed flows have been added, as well as accumulator equations and equations for the reactor outlet temperature control system and reactor power-level control system.

Engineering for the main coolant system included a detailed investigation of the pressure and temperature ratings for the system and a tentative selection of the material and stress codes. Studies of the exhaust 
venturi method and the regenerator bypass method were also made to determine the most efficient system for supplying heat to the bypass steam generator. There appears to be a definite improvement in basic cycle efficiency by connecting the bypass steam generator in parallel with the shell side of the regenerator.

Experimental work is continuing to establish steady-state impurity tolerances. This is part of the over-all study of coolant purification and analysis. In order to set a quantitative limit on steady-state helium impurities, further experiments will be necessary. The critical reaction involved in graphite transport is $2 \mathrm{CO} \rightarrow \mathrm{C}+\mathrm{CO}_{2}$, which may occur either in the region from the reactor outlet to the high-pressure turbine outlet or in the cooler parts of the reactor core.

Various methods of purifying helium were studied, and a proposal was prepared for the construction of a purification plot plant. A lowtemperature adsorption system was selected as the most satisfactory purification method. Reasons for this selection are given.

During the latter part of the reporting period, the concept of an ac power distribution system closely resembling a shipboard installation was modified to one aimed at fulfilling the requirements of the prototype only. A revised load analysis has been completed.

The present arrangement of the main machinery compartment for the MGCR has been analyzed from the points of view of pipe stress and pressure drop. The pipe stress analysis of the main coolant system has been completed. Based on Marine Engineering Regulations and Material Specifications, CG-115 (March 1, 1958), all main coolant piping, with the exceptions of the low-pressure turbine bypass line and the bypass boiler inlet and outlet lines, have acceptable stress values.

A pressure-drop analysis has peer completed for the entire main coolant system. It includes not only pipe-line losses, but also all inlet and outlet velocity head losses, heat-exchanger losses, and rotatingmachinery head losses. The results are given. 
Design of primary and secondary shielding for the prototype plant continued. The specific activity of primary coolant under abnormal conditions is currently being calculated for the case of fuel-pin failures. The preparation of computer codes for designing primary shields has been started.

\section{ROTATING MACHINERY}

Studies of the low-pressure turbine have continued. There is an optimum combination of turbine and marine-type reduction gear because lower turbine cost, resulting from higher turbine speed, is counterbalanced by increasing cost of the reduction gear. In order to select this optimum, a series of turbines with speeds ranging from 6,000 to $10,000 \mathrm{rpm}$ is being studied.

Casing studies have indicated that horizontal joints will be satisfactory in most sections of the machine from the standpoints of tightness, strength, and total length of joint. This construction is greatly preferred for reasons of access and assembly. The high-pressure compressor and turbine are combined in a horizontally split section of casing. A design has been worked out to avoid four-corner joints but still to provide access to all parts of the machine. The low-pressure compressor and lowpressure turbine retain vertically split, or barrel-type, casings except at the bearings.

The development of efficient bearings, seals, and associated systems for application to the prototype gas turbine, and the selection of the lubricating oil best suited to the particular working conditions of this machine are also part of the over-all work on rotating machinery.

The initial work in the study of lubricants was the tabulation of pertinent physical properties of various lubricating oils, as furnished by their manufacturers. In some instances, the reported properties for similar oils differed. In all instances, the effect on properties of using 
the oils in a helium environment was unknown.

In order to resolve discrepancies in the reported data and to determine the effect of helium on the properties, a lubricating oll test program has been initiated.

A revised version of the digital computer program used to predict off-design plant performance was completed. Provisions now exist for determining part-load performance with two bleed flows, power turbine bypass, and a steam generator. The part-load performance characteristics for the flant arrangement were generated using the program.

\section{REACTOR PHYSICS}

Based on the established design parameters, a semihomogeneous graphite core was developed to be equivalent to the present preliminary design heterogeneous core, Reactivitv, burnup, and fuel cycle cost estimates were obtained for the equivalent semihomogeneous core for comparison with the current heterogeneous design. In making estimates, a semiempirical relation was used to obtain the resonance escape probability for the semihomogeneous design. The disadvantage factor was evaluated analytically。 Results are given.

Initial calculations were made to investigate the potential gains in performance from the use of $\mathrm{BeO}$ as a moderator in future maritime reactors. Two BeO systems were considered, the first being the same as the current design for the heterogeneous core with a direct substitution of BeO for graphite. The second is a semihomogeneous system with BeO and $\mathrm{UO}_{2}$ intumately mixed in 0.788-in.-diameter tubes, with 19 tubes arranged in a bundle surrounded by a BeO shroud. Preliminary data are given。

The effect on MGCR shielding caused by recently recommended revisions to the AEC's "Standards for Protection Against Radiation" was investigated. Preliminary estimates are being made of the weight of the 
shielding cask for fuel element removal for both the heterogeneous and semihomogeneous designs.

The main problem associated with the hazards analysis for the critical facility concerned the attainment of some kind of inherent shutdown mechanism which would limit the magnitude of the excursion following a credible accident. It was decided that melting of the uranium-aluminum alloy fuel plates into a less reactive configuration within the core was the only inherent shutdown mechanism available for the flexible critical assembly。

Calculations for the critical assembly were made to determine the magnitude of the expected shutdown coefficient and to decide on an optimum loading pattern for fuel and poison in the core, independent of actual concentrations, which would yield the maximum shutdown coefficient and minimum energy release following an accidental excursion. The final loading configuration chosen is shown schematically.

The second important aspect concerning the hazards analysis for the critical facility was the classification of all possible accidents. Because of the poor structural properties of an unrestrained graphite assembly and because of the Califorma location of the MGCR critical facility, a great deal of attention was pald to the investigation of earthquake hazards.

In connection with the critical experiment safeguards report, dose rates from the operating and shutdown assembly have been calculated and are given. As an appendix to the safeguards report, a section on emergency procedures was drafted.

\section{MATERIALS DEVELOPMENT}

It is anticipated that the fuel bodies for the MGCR will consist of a mixture of particles of the fuel phase dispersed in a nonfissionable phase. The fuel materials under consideration are $\mathrm{UO}_{2}, \mathrm{UC}$, and $\mathrm{UC}_{2}{ }^{\circ}$ During the past quarter, investigations concerning the development of fabrication 
viii

techniques for use in the production of fuel-containing bodies from the materials listed above was pursued both at General Atomic and at Battelle Memorial Institute. A study was also made of how several impurityadditions to high-purity aluminum affected the sintering behavior of compacts. Results are given.

In order to understand the chemistry of fuel systems containing uranium and oxygen, the ternary system aluminum-uranium-oxygen is being studied.

Studies of fission-product retention by fuel bodies were centered around the release of $\mathrm{Xe}^{133}$ from samples of sintered $\mathrm{UO}_{2}$ and from specimens of fused $\mathrm{UO}_{2}$. The amount of xenon released was found to be inversely related to the particle diameter for the conditions of the experiment (annealing for $20 \mathrm{hr}$ at $1,400^{\circ} \mathrm{C}$ ).

The first MGCR fuel irradiation capsule was inserted into the Battelle research reactor and irradiation was begun. No unusual behavior of the capsule occurred during irradiation. The post-irradiation measurements include dimensional determinations of the fuel claddings, density determinations of the clad specimens, dimensional measurement of the individual fuel pellets, collection and analysis of the fission gas that had accumulated in the several claddings, and metallography of the fuel pellets and of the pellet claddings. Results of some of these measurements are given.

Two experiments to determine the influence of precipitated carbon on the ductility of Monel and "A" nickel are almost complete. Carburization of Monel caused an increase in strength of $1 \%$ without a loss in ductility. A number of creep curves for " $A$ " nickel are being obtained, in vacuum, in the range of $1,000^{\circ}$ to $1,600^{\circ} \mathrm{F}$. These tests are being conducted to check the vacuum and gas-handling systems on the creep equipment.

Experiments were continued on the effect of coolant and impurities in the coolant on materials, and further data on the effects of impurities, such as CO, on metals are given. Studies of the disproportionation of CO 
in helium plus $1 \%$ carbon monoxide and of $\mathrm{CO}$ in 1 atm of carbon monoxide were continued, and results are shown.

Materials investigation and testing are being conducted to ensure proper selection and handling of nonreactor structural alloys, and the selection of safe design stresses. Materials are undergoing elevatedtemperature creep-rupture tests, in high-purity helium, to determine the effect on their strength properties. A number of creep-rupture tests were first performed in air on the se materials to establish suitable comparison data for the helium tests. Resultant data are given.

An experiment to determine whether or not helium penetrates through the walls of $1-1 / 4 \mathrm{Cr}-1 / 2$ Mo steel piping was conducted. Helium penetration could not be detected within the sensitivity limits of the vacuum decay measurements and measurements with a mass spectrometer leak detector.

Tests to study the irradiation effects on coolant and impurities in the coolant have been made and data compiled. 
0 


\section{MGCR DESIGN DATA}

The preliminary core design parameters listed below have been selected for the heterogeneous and semihomogeneous cores. They are based on the cycle conditions presented in the previous quarterly reports, which are as follows:

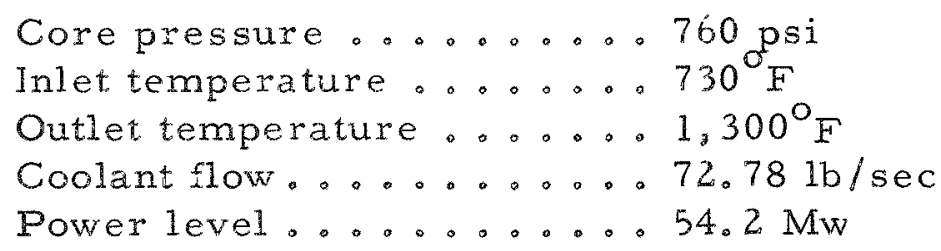

\section{DESIGN PARAMETERS FOR HETEROGENEOUS CORE}

Fuel-element diameter, including cladding... $0.25 \mathrm{in}$.

Number of fuel elements per hexagonal as sembly ................... 19

Fuel-element spacing, triangular pitch .... $0.050 \mathrm{in}$

Distance across flats of as sembly ...... 1.39 in.

Active (fueled) length of assembly ..... $6.37 \mathrm{ft}$

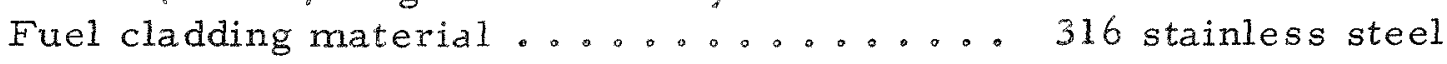

Fuel cladding thickness .................. 0.010 in.

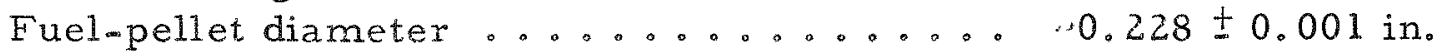

Number of assemblies in core ........ 440

Number of moderator elements ....... 88

Number of fuel assemblies in each moderator element ................... 5

Size of moderator element ......... $7 \times 7$ in. sq., $88.5 \mathrm{ft}$

Diameter of fuel assembly holes in moderator

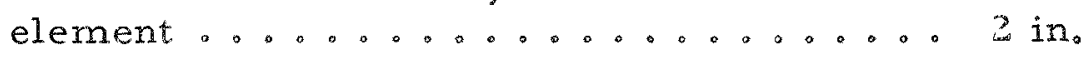

Nominal core diameter ...........66.37 ft

Maximum (design) surface temperature of fuel cladding ....................... $1,500^{\circ} \mathrm{F}$

The maximum central temperature of the fuel pellet is based on a $0.25-\mathrm{mil}$ gap of xenon gas between the cladding and the fuel pellet. The conductivity of xenon is taken to be $\left.0.03 \mathrm{Btu} /(\mathrm{hr})(\mathrm{ft}) \mathrm{l}^{\mathrm{O}} \mathrm{F}\right)$ and the conductivities of the fuel body materials axe assumed to be 10,4 , and 1.5 $\mathrm{Btu} /(\mathrm{hr})(\mathrm{ft})\left({ }^{\circ} \mathrm{F}\right)$ for graphite, $\mathrm{BeO}$, zid $\mathrm{Al}_{2} \mathrm{O}_{3}$, respectively。 
Maximum (design) central temperature of fuel pellet

$\mathrm{BeO} \ldots \ldots \ldots \ldots \ldots \ldots \ldots \ldots 0^{\circ} \mathrm{F}$

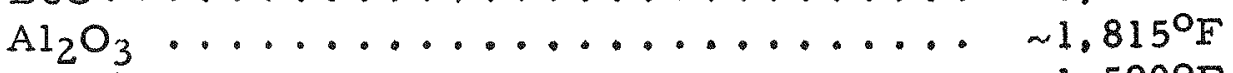

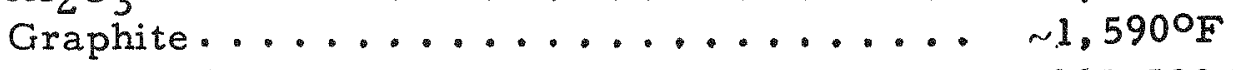

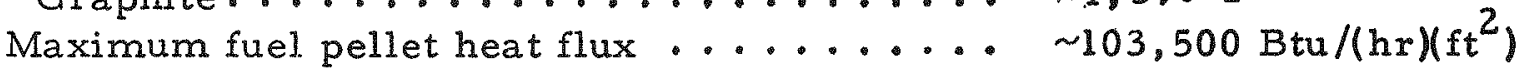

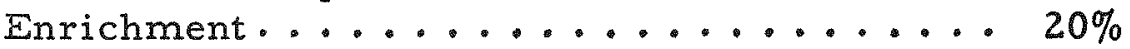

Fuel loading in pellets ................................. $1.43 / \mathrm{cm}^{3}$ fuel

\section{DESIGN PARAMETERS FOR SEMIHOMOGENEOUS CORE}

Fuel-element diameter including cladding

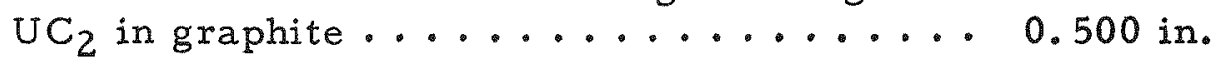

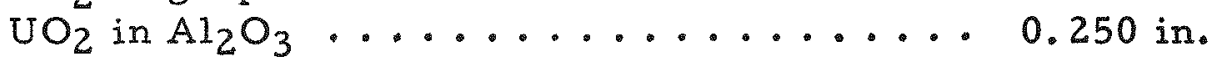

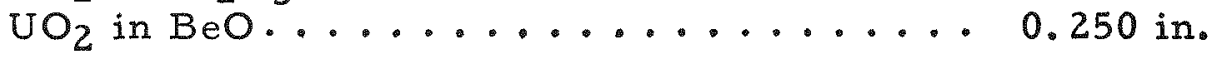

Number of fuel elements per plate

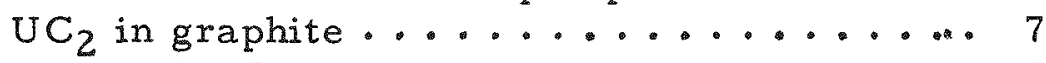

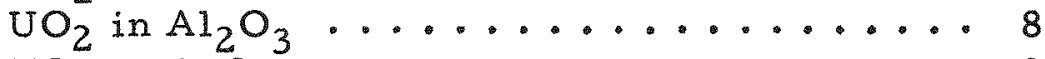

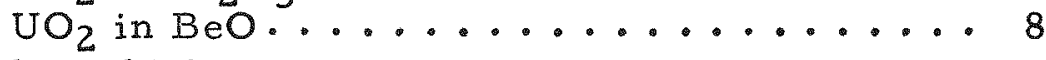

Plate thickness

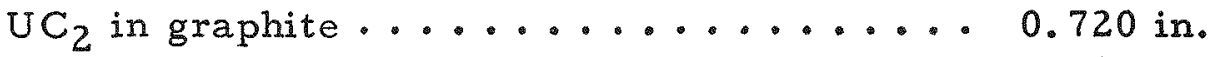

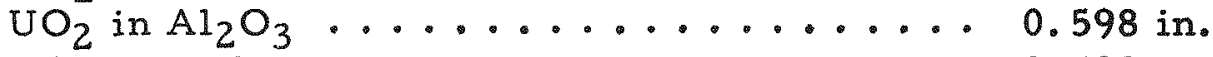

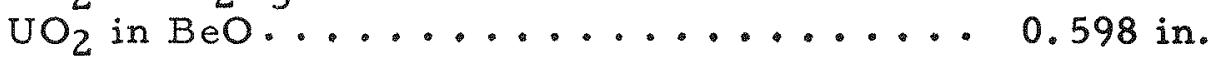

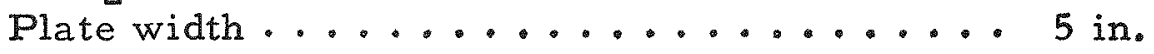

Number of plates per box

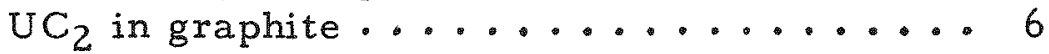

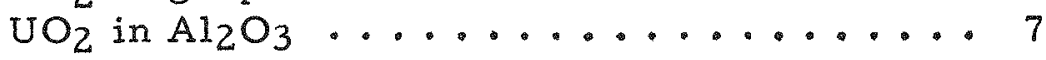

$\mathrm{UO}_{2}$ in $\mathrm{BeO} \ldots \ldots \ldots \ldots . \ldots \ldots$

Size of fuel box........................... 7 x 7 in. sq., $8.5 \mathrm{ft}$

Fuel cladding thickness............................. 005 to 0.010 in.

Fuel cladding material ............. "A" nickel

Number of fuel-box assemblies in core .... 88

Number of fuel-rod elements in core,

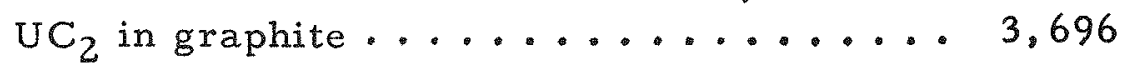

* The maximum central temperature of the fuel pellet is based on a 0.25-mil gap of xenon gas between the cladding and the fuel pellet. The conductivity of xenon is taken to be $\left.0.03 \mathrm{Btu} /(\mathrm{hr})(\mathrm{ft}){ }^{\circ} \mathrm{F}\right)$ and the conductivities of the fuel-body materials are assumed to be 10,4 , and 1.5 $\mathrm{Btu} /(\mathrm{hr})(\mathrm{ft})\left({ }^{\mathrm{O}} \mathrm{F}\right)$ for graphite, $\mathrm{BeO}$, and $\mathrm{Al}_{2} \mathrm{O}_{3}$, respectively. 
Maximum plate (graphite) surface

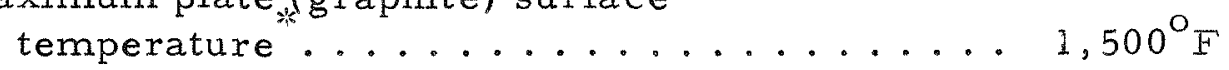

Maximum temperature on inner cladding surface $e^{*}$

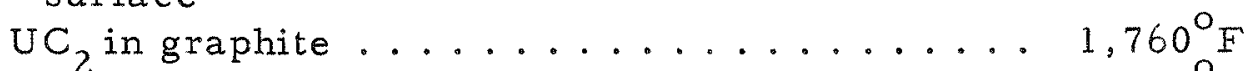

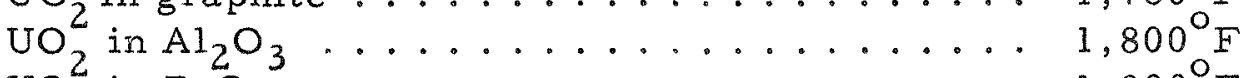

$\mathrm{UO}_{2}^{2}$ in $\mathrm{BeO} \ldots \ldots \ldots \ldots . \ldots . \ldots . \ldots . \ldots . \ldots . \ldots 0^{\circ} \mathrm{F}$

Maximum central temperature of fuel

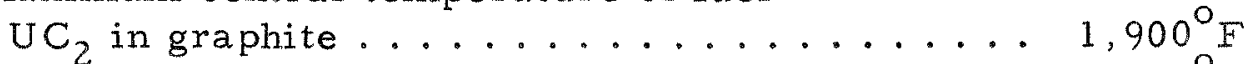

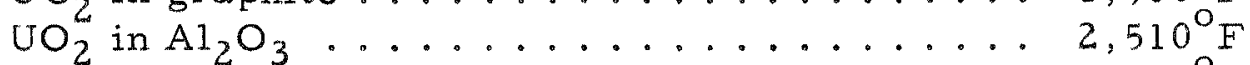

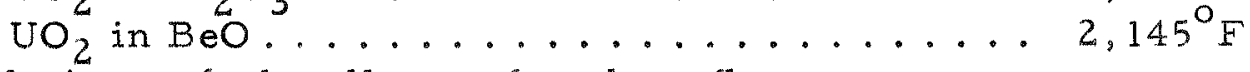

Maximum fuel-pellet surface heat flux

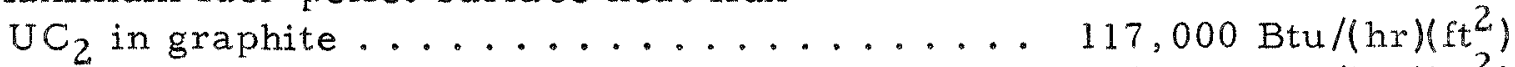

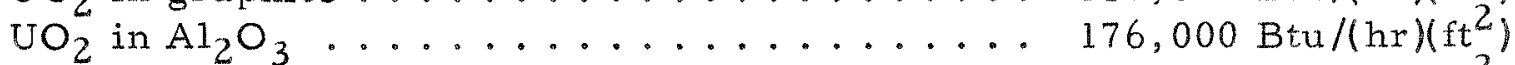

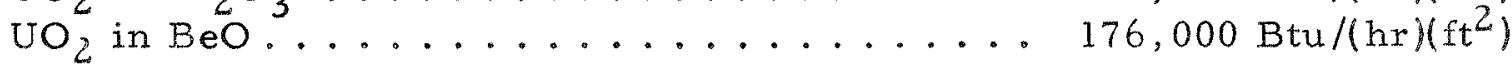

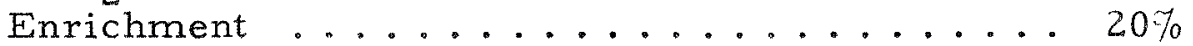

Fuel loading in pellets

$\mathrm{UC}_{2}$ in graphite................................................ $\mathrm{g} \mathrm{cm}^{3}$ fuel

$\mathrm{UO}_{2}$ in $\mathrm{Al}_{2} \mathrm{O}_{3} \ldots \ldots \ldots . \ldots . \ldots . . \ldots \mathrm{g} \mathrm{U} / \ldots \mathrm{cm}^{3}$ fuel

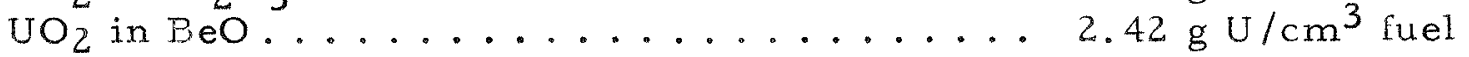

The maximum central iuel temperature is based on a 0.25 -mil gap of xenon between the fuel pellet and clad and a 2 -mil gap of helium between the clad and graphite. The conductivity of helium is assumed to be $0.197 \mathrm{Btu} /(\mathrm{hr})(\mathrm{ft})\left({ }^{\circ}\right)$ and the conductivities of xenon, graphite, and the fuel materials are the same as for the heterogeneous calculation. 


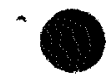




\section{CONTENTS}

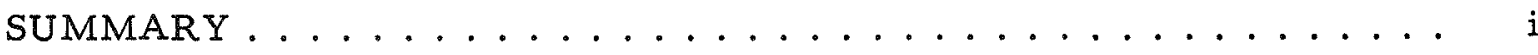

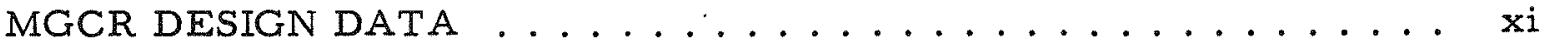

I. REACTOR DEVELOPMENT ................. 1

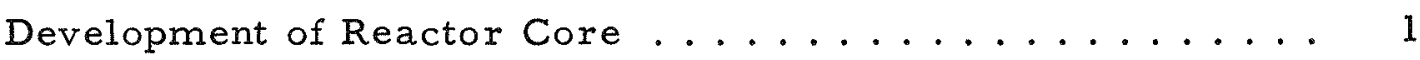

Thermal Analysis of Reactor Core.............. 1

Mechanical Design of Reactor Core .............. 1

Fuel-element Development ................. 2

Calculations for Semihomogeneous Fuel Element ....... 2

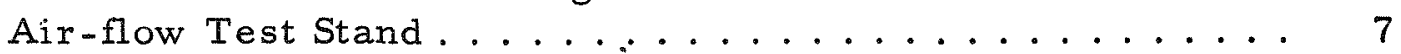

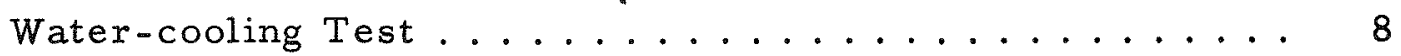

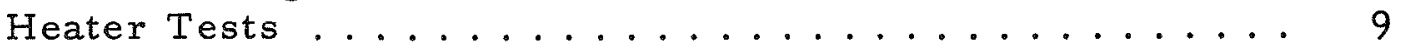

Helium Loop ............................ 10

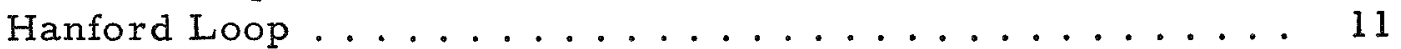

Internal Insulation ...................... 13

Pressure Vessel and Core Internals ............. 15

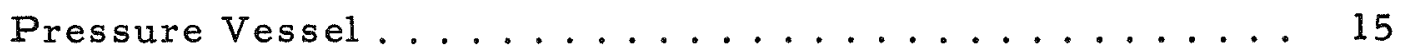

Design of Pressure-vessel Internals ............ 24

Support of Core..................... 25

Biological Shielding of Pressure Vessel ........... 29

Control-rod Drives ..................... 31

Design of Fuel Reloading Equipment............. 40

Design of Reactor Controls and Instrumentation ......... 45

II. FLUID SYSTEMS AND PLANT ARRANGEMENT . . . . . . . . 46

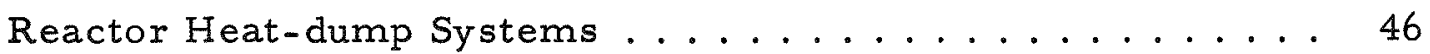

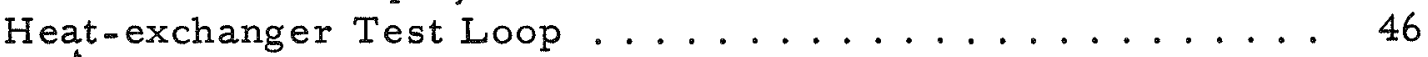

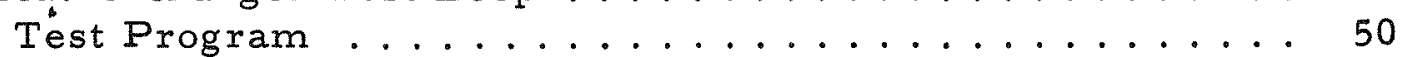

Data Reduction and Analysis ............... 50

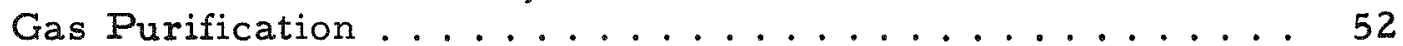

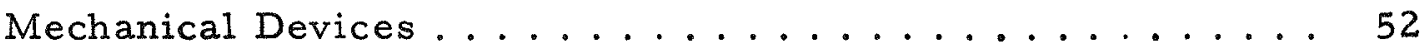

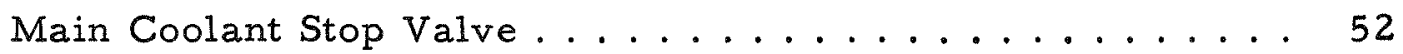

Design, Development, and Testing of Ducts......... 55

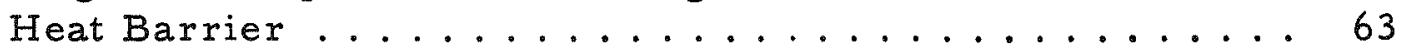

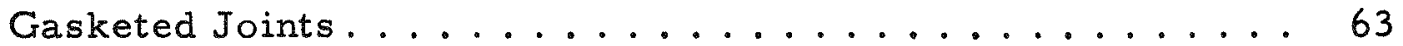

Preliminary Design of Plant Control System ......... 66

Low-pressure Turbine Bypass System ............. 66

System Transient Studies ................. 67

Heat-exchanger Analysis and Preliminary Design ....... 68

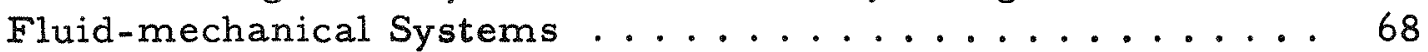

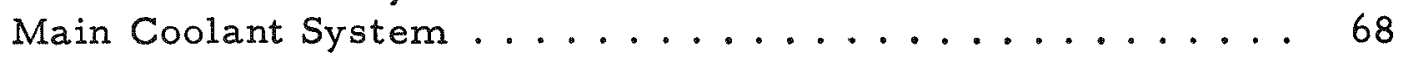

Coolant Charging and Storage System ........... 70 


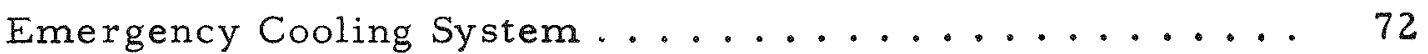

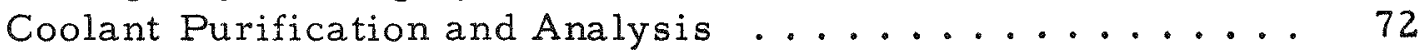

Development of Propulsion-plant Electrical Systems . . . . 77

Design Studies for Power - plant Arrangement and Structure . 78

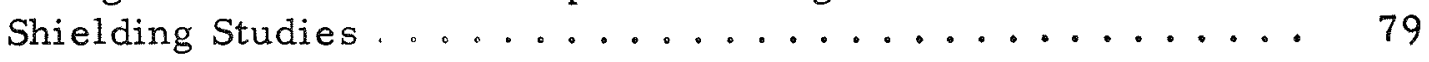

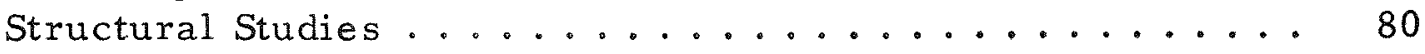

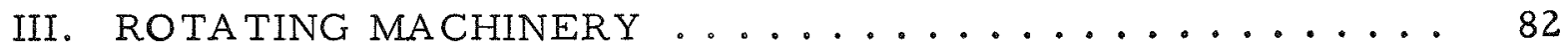

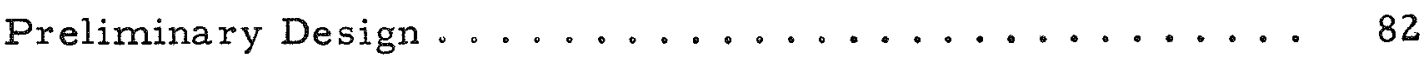

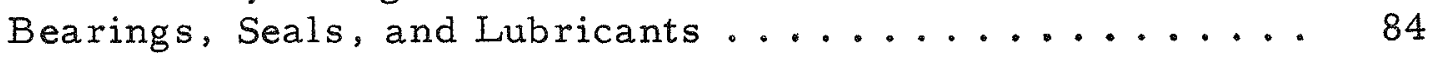

Seal Test Program: First Series ................... 85

Bearings and Seal Tests: Second Series ................. 93

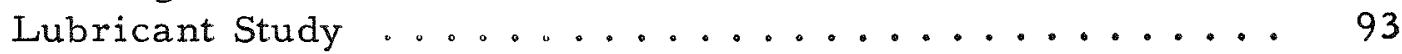

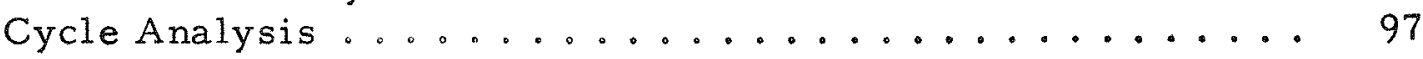

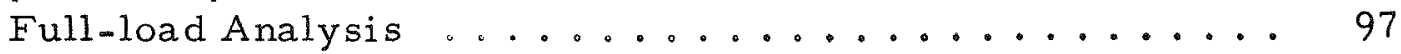

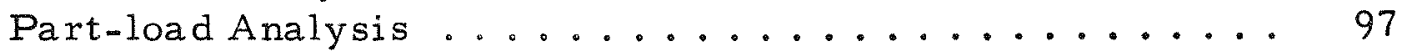

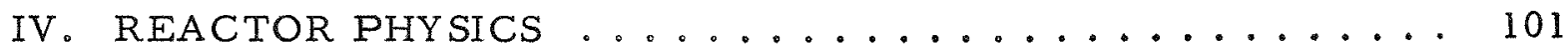

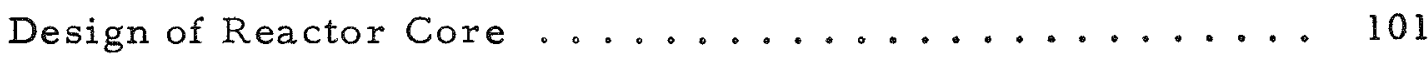

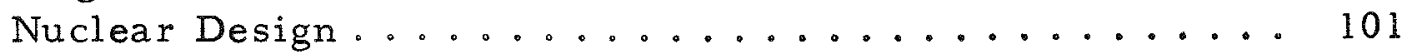

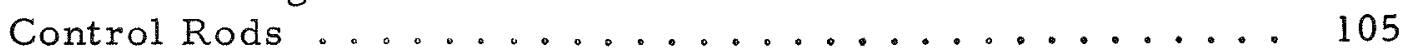

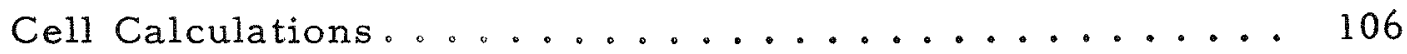

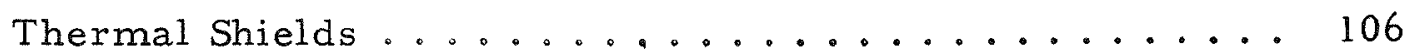

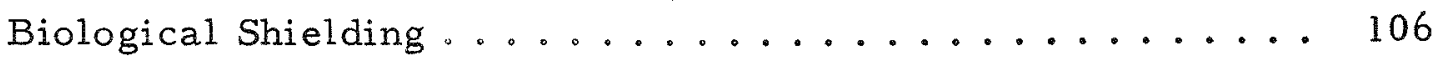

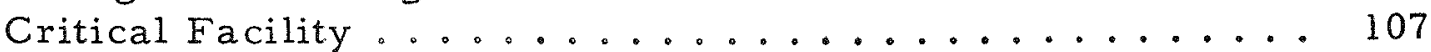

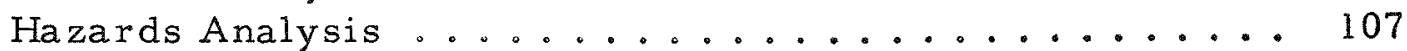

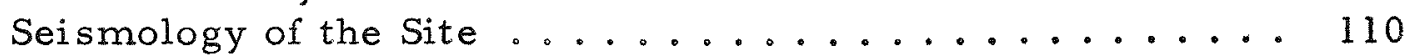

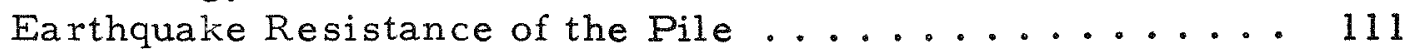

Thermal Insulation of Fuel Elements ........... 112

Heat Transfer from Molten Fuel ............. 113

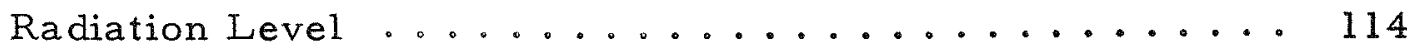

V. MATERIALS DEVELOPMENT ................. 120

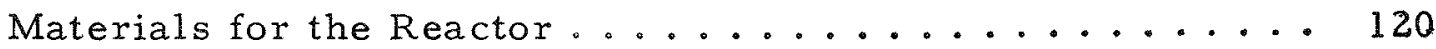

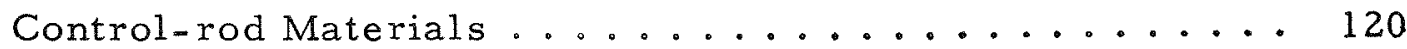

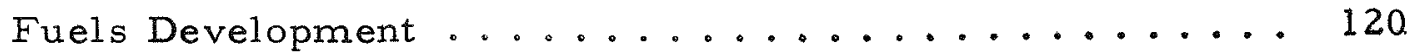

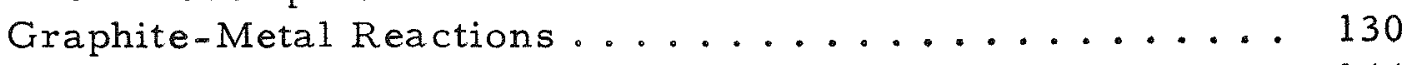

Moderator-Coolant Compatibility ............. 144

Strength and Oxidation-resistance of Fuel Cladding

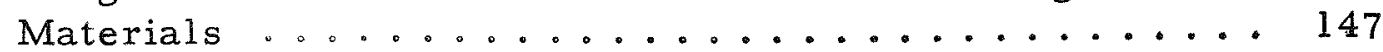

Materials for the Propulsion Plant ............ 150

Creep, Stress-rupture, and Fatigue of Turbine and

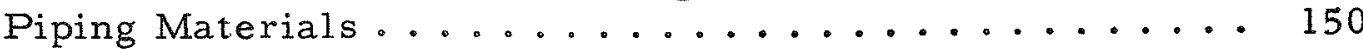

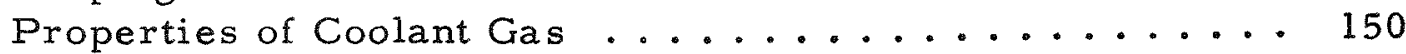

Effect of coolant and Impurities in Coolant on Materials . . 15 I

Studies of Disproportionation of $\mathrm{CO}$ in

Helium $+1 \%$ Carbon Monoxide .............. 159 
Studies of Disporportionation of $\mathrm{CO}$ in 1 Atm Carbon

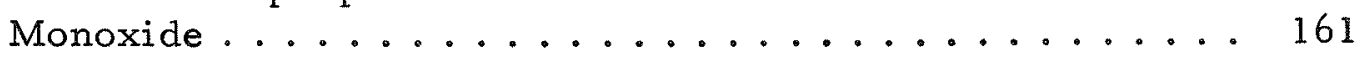

Effects of Irradiation on Corrosion by Coolant or

Coolant-carried Impurities ................ 164

Investigation and Test of Nonreactor Structural

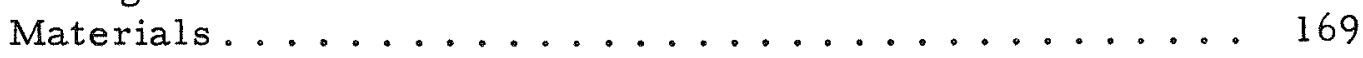




\section{REACTOR DEVELOPMENT}

DEVELOPMENT OF REACTOR CORE (S. A. Bernsen)

Thermal Analysis of Reactor Core (R. Katz and T. Rogers)

In order to incorporate the effects of actual three-dimensional flux shapes on the performance of the core, a computer code is being developed for the IBM 704. This code will permit calculation of the following core conditions:

1. Orifice distribution required to obtain an exit temperature for a given geometry, cycle condition, and flux distribution. Pressure drop will also be calculated.

2. Orifice distribution required to maintain a constant hot-spot temperature in each fuel channel for a given geometry, cycle condition, and flux distribution. Pressure drop will also be calculated.

3. Local temperature of fuel and coolant, local mass flow, and core pressure drop for a given orifice distribution, flux distribution, coolant inlet temperature, and total core mass flow.

A flow diagram and detailed formulas have been developed for the code, and programming is now in progress. A preliminary hand calculation is under way which will check the procedures to be used by the code and will serve as a test problem for it.

Mechanical Design of Reactor Core (R. Bean)

A study group has been established to perform a design evaluation of various reactor and vessel internal arrangements. This is a cooperative activity involving personnel responsible for the reactor vessel and internal structures, as well as those responsible for the reactor core proper. A preliminary discussion of the work performed thus far is presented in this section. 
A drawing of the layuut of the propose- semihomogeneous reactor core has been completed and is included as I'ig. 1.1 The geometry, but not the fabrication details, for the semihomogeneous fuel assemblies are shown in Figs. 1.2 and 1.3 . These preliminary drawings show only the fuel portion of the elements. Details of the end fittings will be determined by present studies of core-support and fuel-handling techniques. A program describing the recommended analytical and design studies required to develop the semihomogeneous fuel element has been evolved.

\section{EUEL-ELEMENT DEVELOPMENT (S A. Bernsen)}

Calculations for Seminomogeneous Fuel Element (R. Katz)

The IBM-704 code PEG for determining the temperature distribution in the semihomogeneous fuel element was completed early in the quarter. This code has been used to obtain information for the Hanford loop test element. The input parameters and pertinent results for a representative case are listed in Table 1.1 .

Table 1.1

INPUT PARAMETERS AND RESULTS FOR TYPICAL SEMIHOMOGENEOUS FUEL ELEMENT

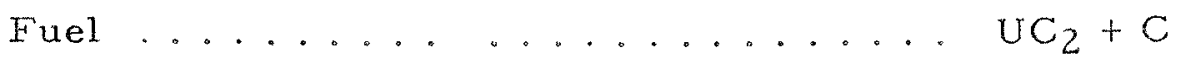

Sample width.................. $3 / 4 \mathrm{in}$

Sample thickness.............................

Number of fuel pellets ........... 2

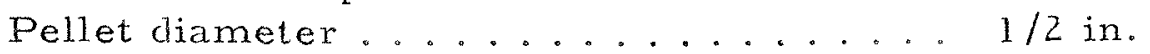

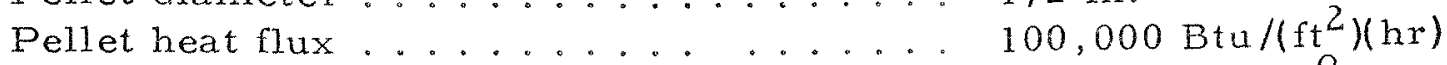

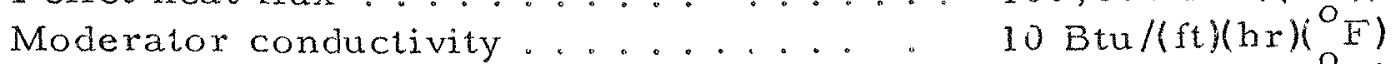

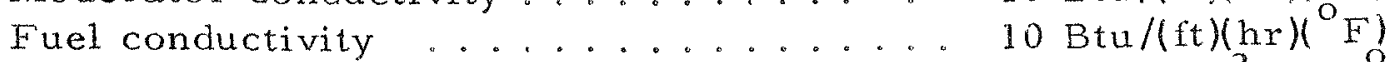

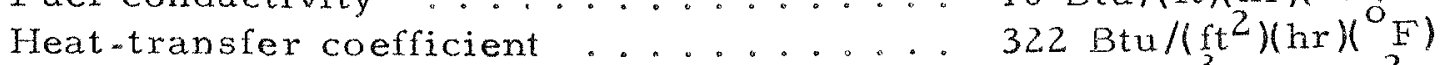

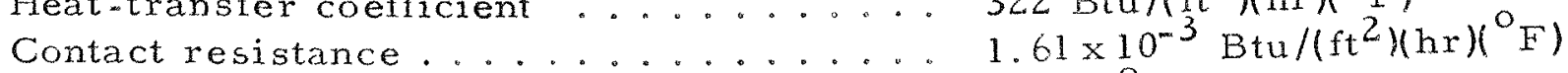

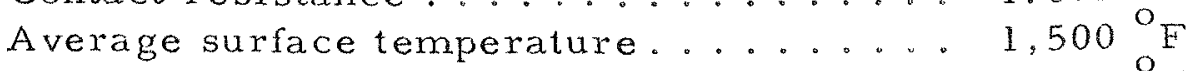

Maximum clad temperature ............................ $1,793^{\circ} \mathrm{F}$

Maximum fuel temperature ... ... $1,917^{\circ} \mathrm{F}$ 


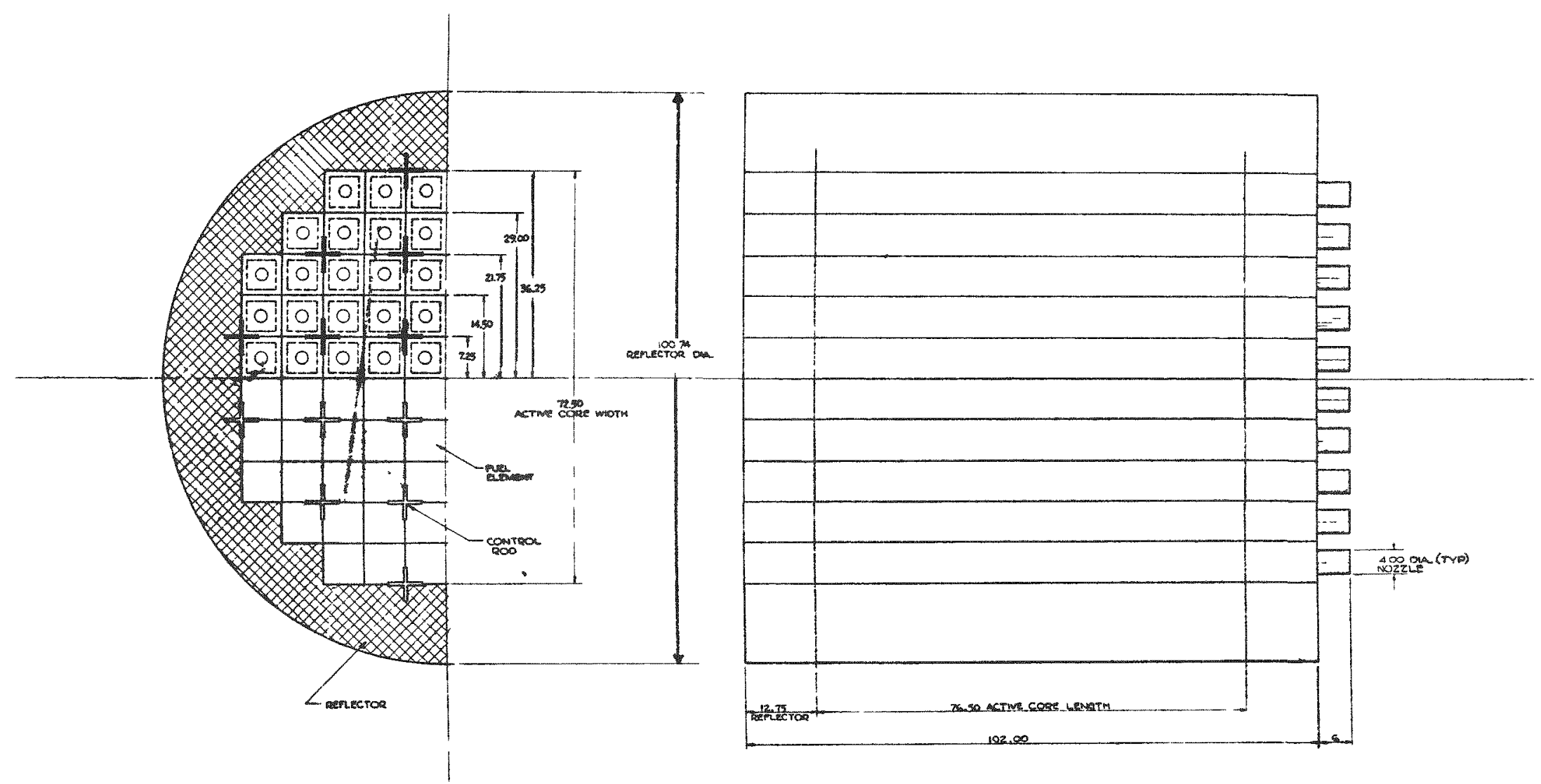

Fig. 1.1--Preliminary layout of MGCR core 

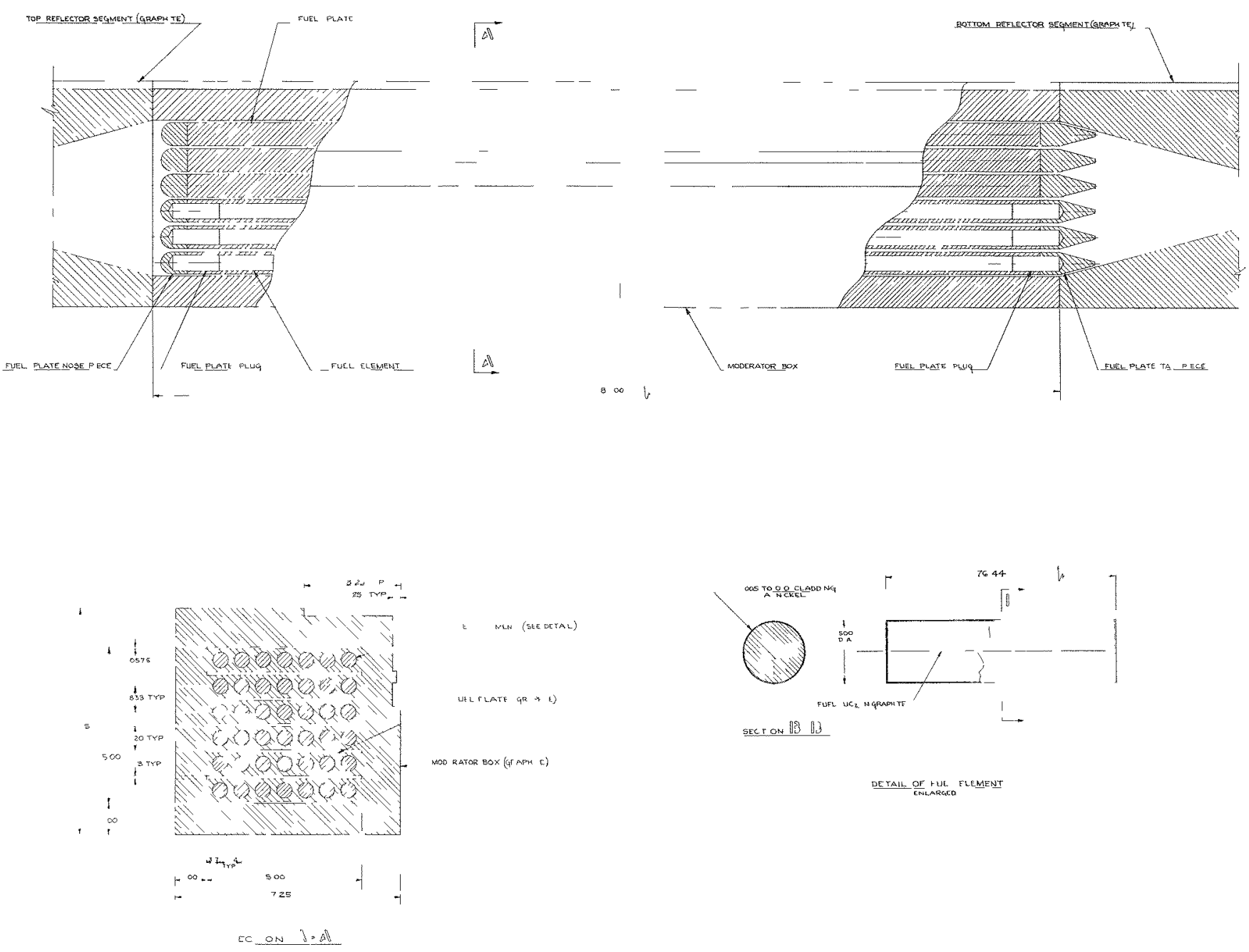

Fig. 1.2--Fuel box assembly for semihomogeneous core; $\mathrm{UC}_{2}$ in graphite 

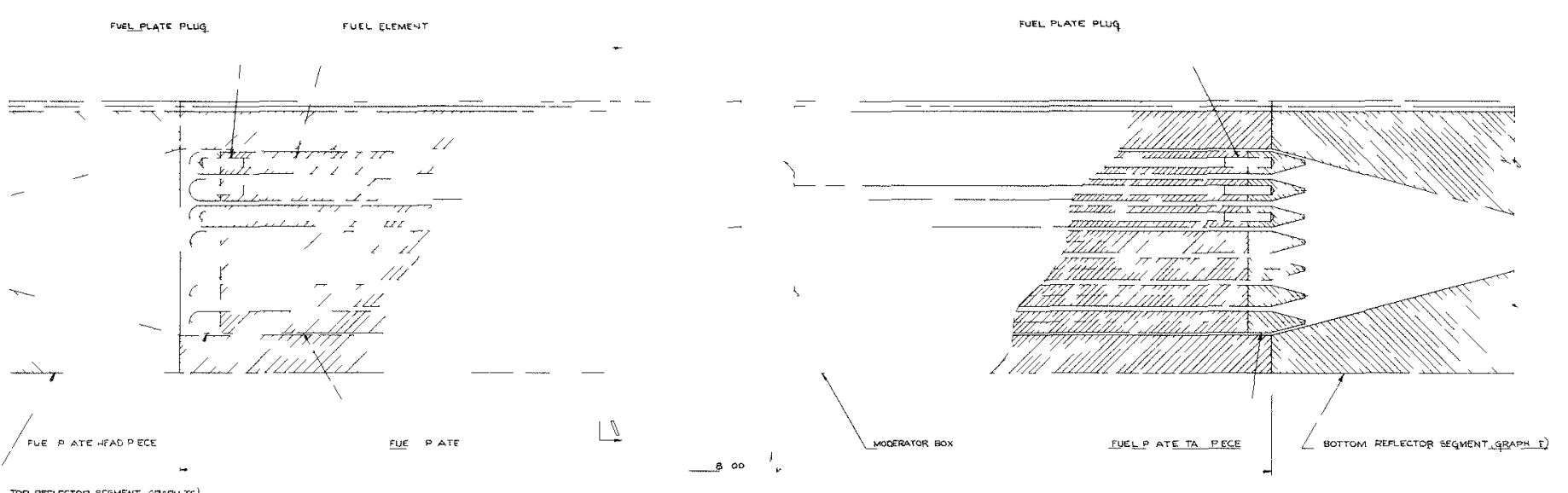

TOO REF RECTOR SEGMENT,GRAPH TS
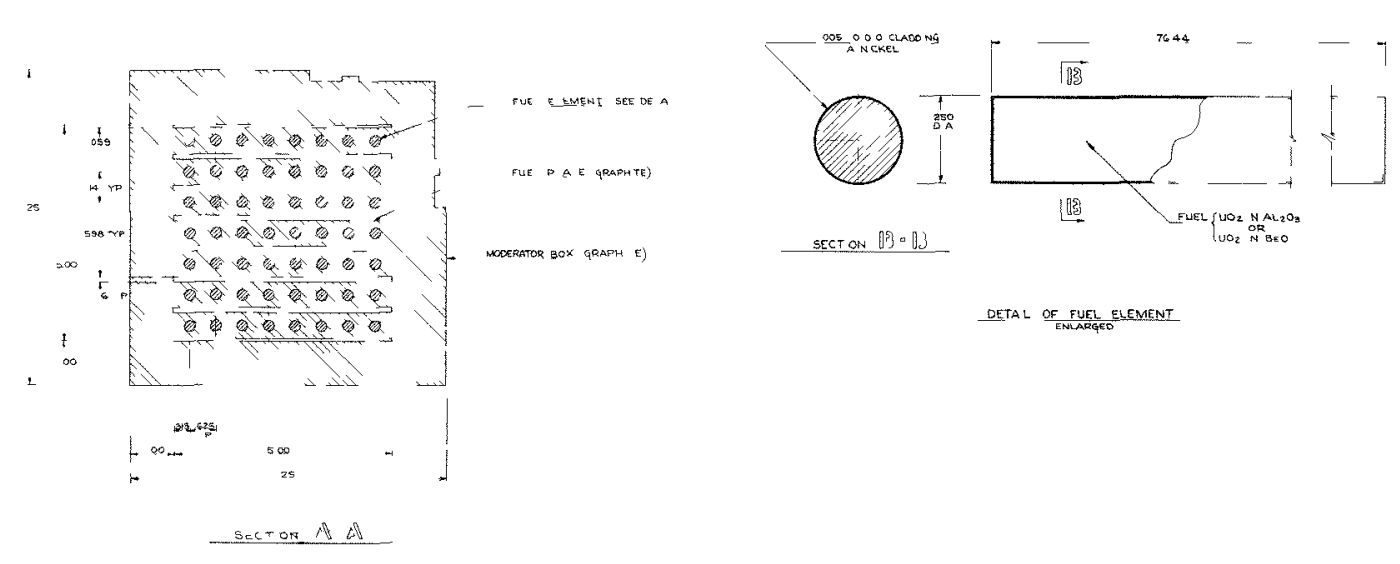

DETAL OF FUEL ELEMENT

Fig. 1.3--Fuel box assembly for semihomogeneous core; $\mathrm{UO}_{2}$ in $\mathrm{Al}_{2} \mathrm{O}_{3}$ or $\mathrm{BeO}$ 
The contact resistance was determined by assuming a 2 -mil helium gap on the moderator side and a $0.25=\mathrm{mil}$ xenon gap on the fuel side of a 15-mil "A" nickel cladding. Conductivities of 30, 0.19, and $\left.0.03 \mathrm{Btu} /(\mathrm{ft})(\mathrm{hr}) \mathrm{C}^{\mathrm{O}} \mathrm{F}\right)$ were assumed for the cladding, helium, and xenon, respectively. These temperatures are proportional to the heat flux, conductivity, and heatwtransfer coefficient. Therefore, temperatures for other values of these parameters may be found by linear interpolation.

The code for computing the thermal stresses in the semihomogeneous fuel element was completed and checked out during the quarter. It has been used in calculations of the thermal stresses in the Hanford loop test element. Results of some calculations based on the conditions given in Table 1.1 may be briefly summarized as follows:

1. The maximum compressive and tensile stresses occur along the section of minimum thickness from the fuel pellet to the coolant surface. A compressive stress of 493 psi occurs at the pellet surface and a tensile stress of 509 psi occurs at the coolant surface.

2. The shear stresses are all low - in the order of 10 psi.

3. The maximum tensile and compressive stresses are significantly larger than those calculated for an equivalent thick-walled cylinder with the same temperature difference $\left(110^{\circ} \mathrm{F}\right)$ and with inner and outer diameters equal to the fuel-pellet diameter and the plate thickness, respectively. For the Hanford element, an equivalent cylinder will have a 270 -psi tensile stress and a 350.psi com pressive stress.

The stress calculations for the graphite bodies as sume conservative values for Young's modulus, $1.29 \times 10^{6} \mathrm{psi}$, and for the coefficient of thermal expansion, $\left.3.25 \times 10^{-6} \mathrm{in} . /(\mathrm{in} .)^{\circ} \mathrm{F}\right)$. Since the thermal stresses are directly proportional to Young's modulus, the coefficient of thermal expansion, and the heat flux. stresses for other values of these parameters may readily be found. 
Air-flow Test Stand (H. C. Hopkins, Jr.)

Assembly of the air-flow test stand was completed during the quarter, and testing was begun on a mockup of a 13-rod fuel-element bundle. This mockup bundle, which is a scale model $2-1 / 2$ times the reactor element, has the properties given in Table 1.2 .

Table 1.2

PROPERTIES OF MOCKUP FUEL-ELEMENT BUNDLE

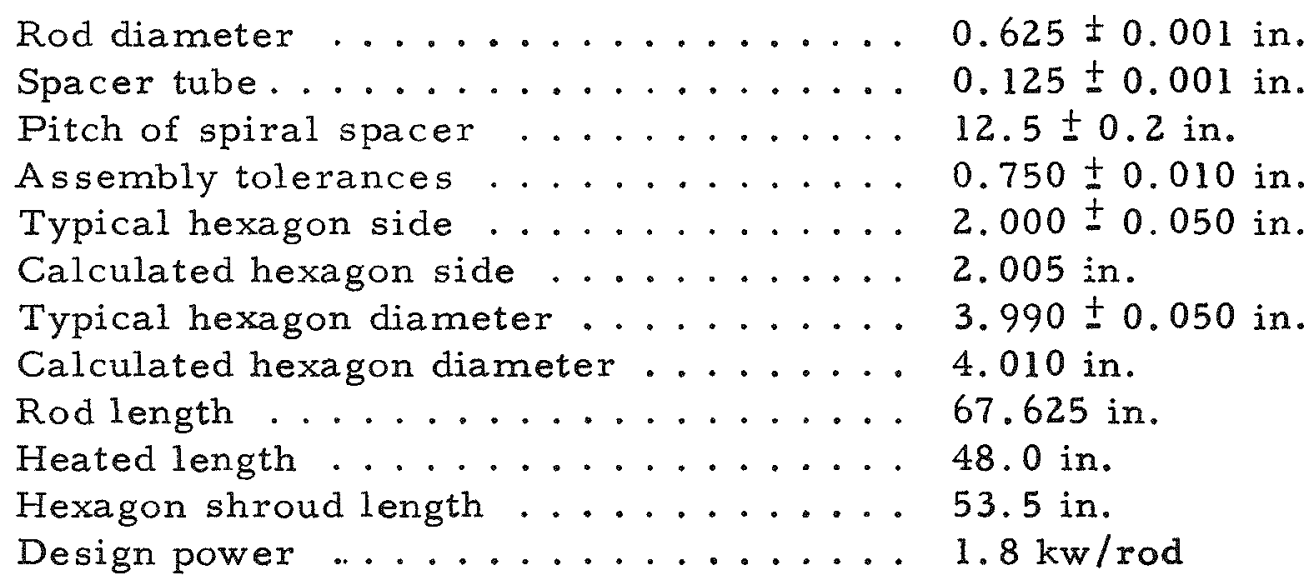

Initial tests were run to check out the operation of the loop. General agreement was found between a preliminary heat balance and the flow indicated by a flow nozzle. Subsequently, runs were made to determine isothermal friction factors and to determine the existence of hot spots by the use of temperature-sensitive paints.

Experimental friction factors all seemed to be lower than those which were calculated for flow in a smooth pipe, and it was suspected that leakage in the system and manometer connections contributed to these anomolous results. Investigation showed that the manometer setup was not completely tight and that the resultant leakage produced low pressuredrop readings of the order of $4 \%$ to $5 \%$.

In order to check for system leakage, the rod-bundle assembly was removed and an auxiliary flat-plate orifice was installed instead. A seal 
was installed on the blower shaft, and runs were made to check for additional flow errors. The results indicated that some leakage was still present. To correct this, the flow nozzle has been moved closer to the test section. Also, a new permanent manometer bank has been installed. These changes should ensure that virtually all errors in the flow measurement will be eliminated.

Preliminary runs with temperature-sensitive paints indicated that no local hot spots would be created by the nonuniform flow path produced by the rod bundle. However, there was a marked increase in coolant temperature from the outer perimeter to the center of the bundle. This was conm sidered to be a direct result of the fact that the coolant-flow area per rod decreases from the outside to the center of the bundle. Further experiments, which will be run with radial flux shapes anticipated throughout the bundle, are expected to reduce this apparent hot spot. Additional improvement may be needed in the form of minor modification of the geometry of the bundle.

A high-current power supply and a hollow stainless steel tube have been obtained, so that one of the solid heaters in the rod-bundle assembly can be replaced with the hollow tube heater. This will permit measurement of local heater-surface temperature by means of a movable, internal thermocouple probe.

Water-cooling Test $(H . C$. Hopkins, Jro)

Preliminary experimental equipment has been designed and is being fabricated to determine whether it is possible to use water as an emergency coolant in place of an inert gas. The present emergency cooling system, visualized for use if a loss of helium occurs, employs an inert gas, such as nitrogen, to cool the core to some intermediate temperature, and further cooling is by air circulation. Since an exothermic reaction is likely to occur between air and graphite in the temperature range $700^{\circ}$ to $800^{\circ} \mathrm{F}$, air cannot be used as a coolant until the temperature of the graphite is below this point. If water is employed for the initial cooling, the reaction 
is endothermic and cooling can be obtained over the entire temperature range of the reactor core. Although some chemical attack would be expected, this probably could be tolerated in an emergency.

Water injection could be employed only in conjunction with the semihomogeneous core, because the violent initial vaporization of water would prevent complete cooling of the core for several minutes. Since it is estimated that the semihomogeneous core can remain uncooled for at least 15 to $20 \mathrm{~min}$ in the shutdown state, it is quite possible that sufficient time would have elapsed to permit boiling to cool all portions of the core.

The purpose of the experiment is to determine the rate at which various sections of the core can be cooled by water. A test element consisting of two concentric, cylindrical sections of graphite, each 24 in. long, will be heated to high tcmperatures in an inert-gas atmosphere. The sections are assembled with an annular gap equivalent to the coolant channel in the semihomogeneous element. The mass of graphite surrounding the annular space is equivalent to the same mass in the semihomogeneous design. Water can either be sprayed on the test section or be allowed to flow in from below it. Thermocouples will be located at various spots in the test section. The entire experimental setup will be mounted on a movable cart. Instrumentation, control, and service power will be supplied by long-lead connection, so that the experiment can be performed at a safe distance from all personnel. The first tests will be run during the next quarter.

Heater Tests (R. C. Howard and H. C. Hopkins, Jr.)

Experimental heaters have been obtained which are expected to duplicate the full power and temperature performance of typical MGCR fuel elements. (Such experiments might be performed in the thermal test loop described under "Helium Loop" below.) A flexible test setup to prove the performance of the heaters has been designed and is being fabricated. 
Helium Loop (H. C. Hopkins, Jr.)

The design requirements for a high-pressure, high-temperature helium loop for the thermal testing of fuel assemblies have been established. The requirement that an adequate test be made of the semihomogeneous fuel element sets the maximum design conditions for the loop. The parameters listed in Table 1.3 have been employed to determine the loop requirements.

Table 1.3

PARAMETERS FOR HELIUM LOOP

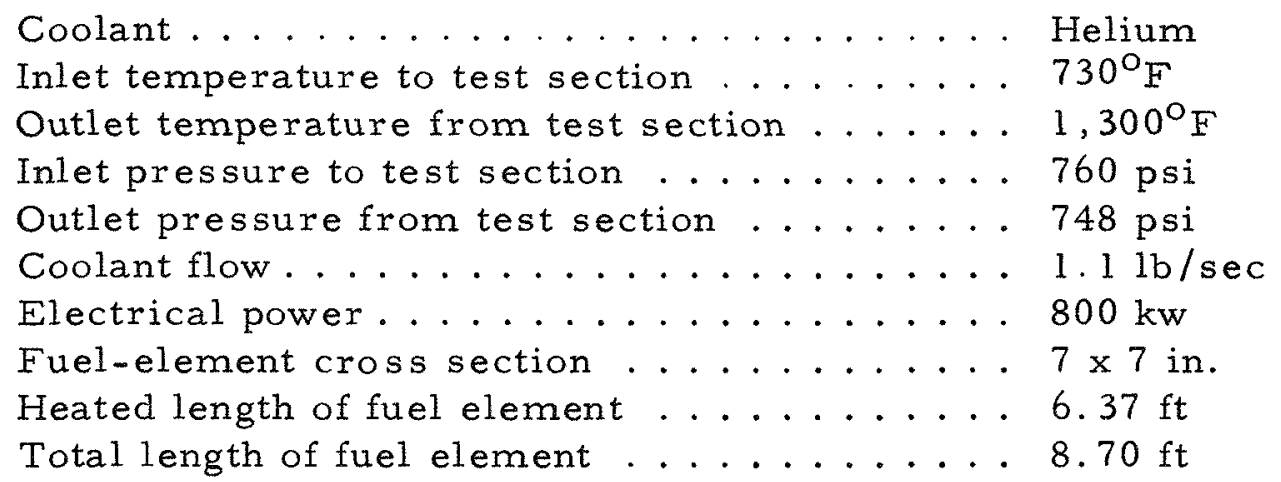

The possibility of reducing the length and cross section of the fuel element will be considered later to determine what savings might be effected in the facility. Thus far, the loop design has only been developed to a point at which an accurate cost estimate can be obtained.

It is expected that a significant saving can be realized by employing some of the equipment assembled by Electric Boat Division for its heatexchanger test loop. The scheduled program for that facility will terminate early enough to make this feasible. A loop design based on modifications of the Electric Boat loop has been made to fit the fuel-element test requirements. If this proves feasible, the existing space at Electric Boat would be utilized. 
Hanford Loop (S. A. Bernsen and R. C. Howard)

Experiments performed on the Hanford test pile indicate that a heat flux of $110,000 \mathrm{Btu} /\left(\mathrm{ft}^{2}\right)(\mathrm{hr})$ can be expected at the surface of the $1 / 2 \mathrm{~min}$.diam fuel pellet. In order to assure safe operation of the test, a value of $150,000 \mathrm{Btu} /\left(\mathrm{ft}^{2}\right)(\mathrm{hr})$ has been recommended for analyzing the safety aspects of the test.

Thermal and pressure-cycling tests have been run on a number of tubes containing fuel pellets. Both graphite-filled nickel tubes (1/2-in. diam) and $\mathrm{Al}_{2} \mathrm{O}_{3}$-filled nickel tubes $(1 / 4-\mathrm{in}$. diam) have been cycled. The tubes have a wall thickness of approximately $0.015 \mathrm{in}$, and $0.012 \mathrm{in}$. , respectively. These tubes were cycled in a 3-ft-long cylindrical block that contained four holes. In some cases, 1/8-in.-diam tubes were connected to one end cap of the simulated fuel tube to permit internal pressurization of the tube. These tubes, contained in the graphite block, were cycled in autoclaves under various conditions of axial and radial restraint.

In all cases, tubes having approximately 0.003-in. diametral clearance and no axial restraint showed no cladding failures. However, some of the 1/4-in.-diam tubes showed some "necking down" of the cladding at a few places along the length. A total of 27 cycles have been performed-14 cycles on $1 / 2-i n$. tubes and 13 cycles on 1/4-in. tubes. The time span for each cycle varied. Included in these tests were runs with maximum temperatures up to $1,850^{\circ} \mathrm{F}$ and internal pressures up to 150 psi (with no external pressure), as well as runs with external pressures of 250 psi and no internal pressure.

To date, similar experiments run with the tubes under axial restraint have always resulted in failure at the end-cap weld. The end caps tested thus far have all been thick plugs set into each end of the tube with an edge weld made at the periphery of the tube end. Failures have occurred at these welds, which indicated that the axial restraint prevents the heavy plugs from moving as the cladding expands axially and as a combined bending and shear load is applied to the welds. It is possible that other end 
closure arrangements will eliminate this problem, but these are not now available. Therefore, the first in-pile test will be run on fuel tubes that are axially unrestrained.

Tests have been run on tubes with no axial or radial restraint. A 1/4-in.-diam tube operated without failure at 150-psi internal pressure for $16 \mathrm{hr}$ at $1,700^{\circ} \mathrm{F}$. During this test, the sample expanded $0.020 \mathrm{in}$. in diameter. Tests were also run on several $1 / 2$-in.-diam tubes, into each of which was inserted a hollow graphite sleeve for internal support; it was hoped that this would be one way to adapt the 1/4-in.-diam ceramic fuel body to a 1/2-in. hole in the graphite. This would have the effect of reducing surface temperatures of the cladding and thermal stresses in the fuel plate without requiring an excessive fuel volume in the core. It was found, however, that the full-length inner tubes forced all the axial expansion of the cladding tube to "pile up" at one end. Severe necking down and crushing of the graphite tube was observed. If the inner graphite tube is segmented, as are the pellets, then performance would be similar to that observed with solid 1/2-in.-diam graphite pellets.

In May, 1959, a complete test-element mockup was fabricated and placed in an autoclave for thermal and pressure-cycling tests. During June, the element received four thermal cycles. Early in June, a power cutoff occurred which caused a loss of the helium atmosphere in the autoclave, and the test element was exposed to an unknown amount of air for 4 to $6 \mathrm{hr}$ at temperatures from $1,700^{\circ}$ to $1,000^{\circ} \mathrm{F}$. The extent of the damage will not be known until the first inspection of the mockup in July.

Seal-ring tests have been in progress throughout this quarterly period. Samples of seal rings made of graphite, beryllium, Type 430 stainless steel, and Type 430 stainless steel coated with tungsten carbide were installed in a sample of the in-pile tube material and are undergoing tests under temperature and loading conditions somewhat in excess of those expected in the loop.

It was not possible to obtain 0.025-in.-diam nickel-sheathed 
thermocouples early enough for use in the first in-pile experiment. Therefore, Inconel-sheathed thermocouples will be used in the first test. No thermocouple failures have been observed thus far.

A test element was shipped to Hanford so that the fit of the element in the in-pile tube could be determined. The element was easily pushed through the inner tube, which indicated that larger seal rings could possibly be used to give a better gas seal and still permit assembly of the element. Other rings have been tested and the best size has been found.

A complete test-element assembly, including mock fuel and mock thermocouples, the 20-ft-long support tube, and the end closure seal of the in-pile tube, was also fabricated and shipped to Hanford. This assembly was used to determine the isothermal pressure drop and to check insta1lation and removal procedures. The measured pressure drops are lower than the conservative estimates on which the fuel-element design is based. This means that from a thermal and hydraulic standpoint, the design of the element is on safe ground.

Because of the interest in various types of graphite and the lack of irradiation data for these graphites under MGCR conditions, the test element will be slightly modified to accommodate a number of graphite specimens. Four tubes 1/4 in. in diameter will be loosely fitted into holes on each end flange. In these tubes will be 1/4-in. rods of the graphite of the same diameter. The types of graphite tested will depend on their immediate availability: however, included among them will be Graphitite. The $1 / 4$-in. rods will also serve as the modification necessary to permit satisfactory performance of Hanford's fuel-removal equipment.

Internal Insulation (H. C. Hopkins, Jr., and J. T. Rogers)

The design and fabrication of the internal-insulation test stand proceeded ahead of schedule during the quarter. By the end of the reporting period, completion of the test stand was only a few weeks away from the first test. A Refrasil insulating blanket is now installed in the autoclave 
and will be tested first Several thermocouples are imbedded in the insulation to determine the conductivity of the Refrasil and the effect, if any, of internal convection on it Stainless steel wool will also be used for insulation testing after the Refrasil tests have been completed. A multilayer, corrugated-metal type of insulation will also be tested.

In order to devise a method of predicting the thermal conductivity of fibrous insulation under the conditions in the test and in the reactor, a theoretical analysis of insulating materials has been attempted. Investigation showed that those mechanisms of heat transfer which are of importance are gas conduction and radiation across the pores Natural convection is of no significance, and there is no decrease in effective conductivity from accommodation-coefficient effects; $i$ e. , the pore size is much greater than the mean free path of the gas under the pertinent conditions The literature indicates that conduction through the insulation material itself should contribute about $5 \%$ to the total effective conductivity for the Refrasil type of insulation

Prediction of the effective conductivity has been based on the following simplified models of the actual insulation

1 Infinite parallel planes

2 In-line cubical pores

3 Staggered cubical pores in three dimensions.

Based on the assumption that only gas conduction and radiation are important and that black-body conditions apply, these models gave results which did not differ greatly and which followed the general trends of the measured conductivity of the Refrasil fairly well, except at the higher temperature By allowing for actual emissivities and geometric factor increases, the agreement between measured and predicted values varied considerably, particularly at the higher temperatures. For example, Model 3--with allowances for gas conduction, gray-body radiation, and solid phase conduction--gave results which were too high at the low 
temperatures (too great a contribution by solid phase conduction) and too low at high temperatures (too small a contribution by radiation)

\section{PRESSURE VESSEL AND CORE INTERNALS (F J。 Liederbach)}

Pressure Vessel (M. Grassmann and R. Kelsey)

The initial preliminary design of the pressure vessel with and without internal insulation was developed and is shown in Fig. 14. Figure 1. 5 is a more detailed version of this concept and shows the pressure vessel, the core and its support, and the control-rod drives in various positions.

An analysis was made to determine the effect of thermal shock on the pressure vessel during emergency cooling. (A report is in preparation.) The analysis is primarily concerned with the relation between cyclic plastic deformations due to high thermal stresses and the possible fatigue failure of the pressure vessel An additional study will be made of the steadystate and transient temperature distribution in the pressure vessel for preliminary evaluation of thermal stresses in the conceptual designs.

The properties of the materials needed for the pressure-vessel design were compiled. The materials investigated were:
A-302 Gr "B'
Type 316
$A-204 \mathrm{Gr}$ " $B$ "
Type $T-1$
A-387 Gr "D"
$\mathrm{HY}-80$
A- $240 \mathrm{Gr}$ "C"
Type 347

Figures 1.6 and 17 were prepared by using calculations that conform to the ASME Code for "POWER BOILERS" and "UNFIRED PRESSURE VESSELS." Figure 1.6 shows the relation between required vessel thickness and temperature for a design pressure of 850 psi. Figure 1.7 shows variation of pressure with temperature for a vessel thickness of 4 in.

Figures 1.8 through 1.10 show internal pressure as a function of temperature for $0.1 \%$ and $1 \%$ creep in $10,000 \mathrm{hr}$, where a $14-\mathrm{ft}$ ID and a 6-in. wall thickness are assumed. 


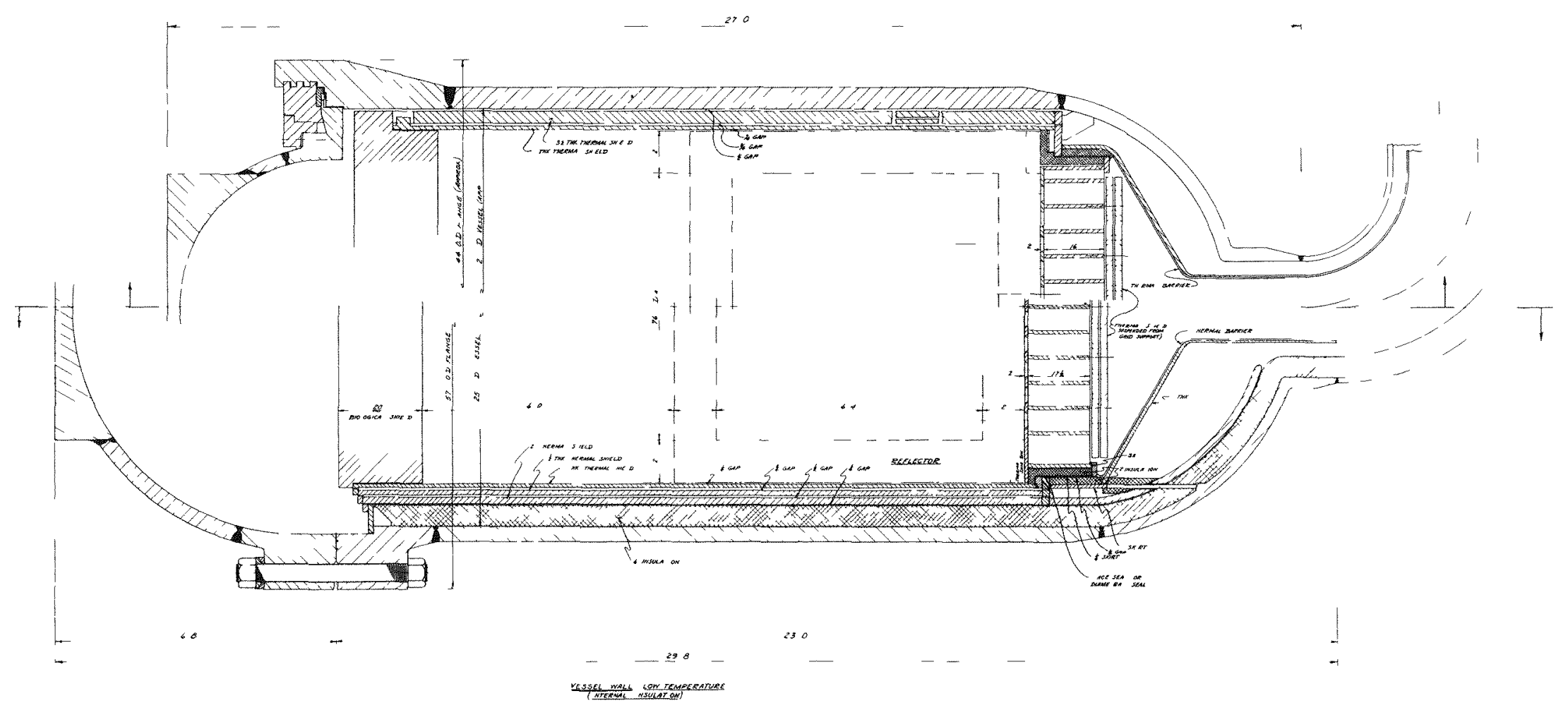

Fig. 1.4--Preliminary layout of graphite reactor 


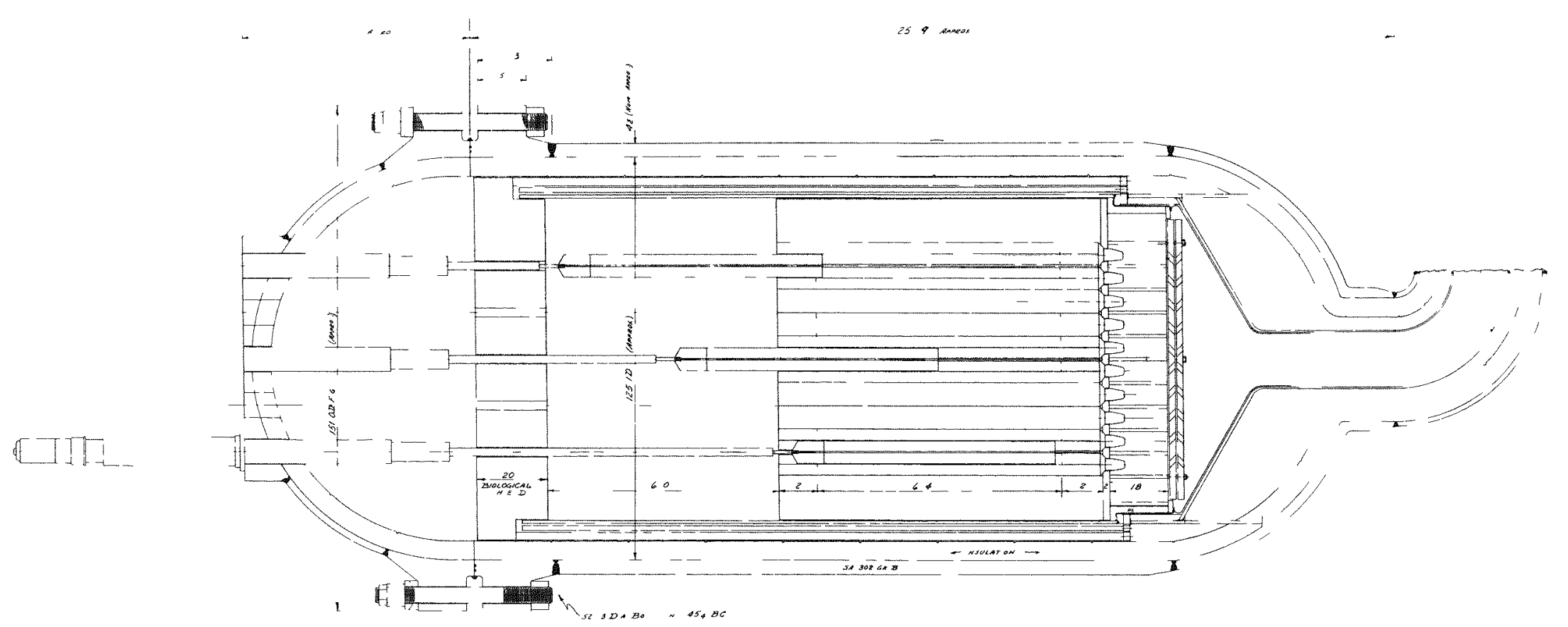

Fig. 1.5--Preliminary layout of reactor pressure vessel 


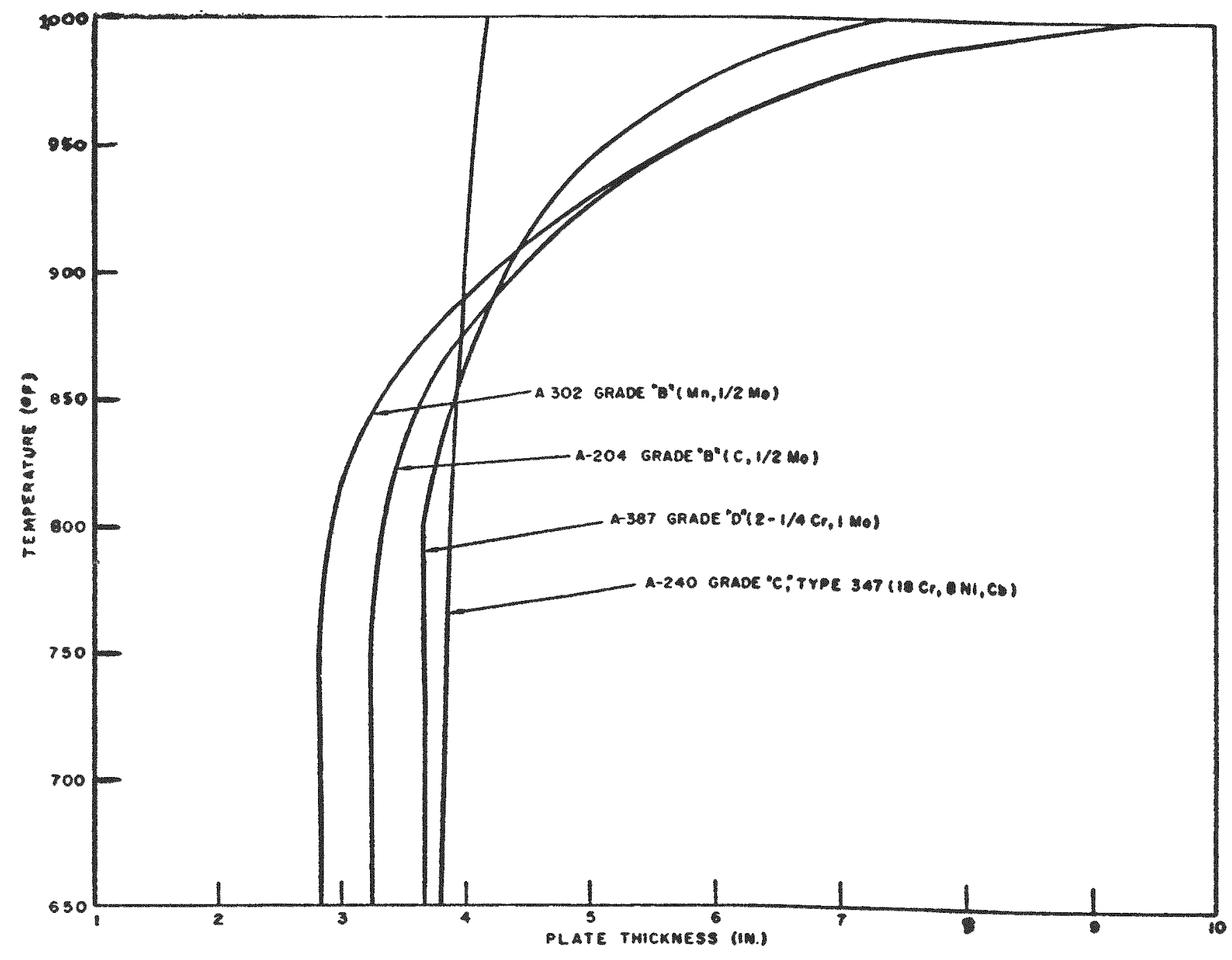

$\infty$

Fig. 1.6--Relationship between thickness and temperature for viou material $(P=850 \mathrm{psi})$ 


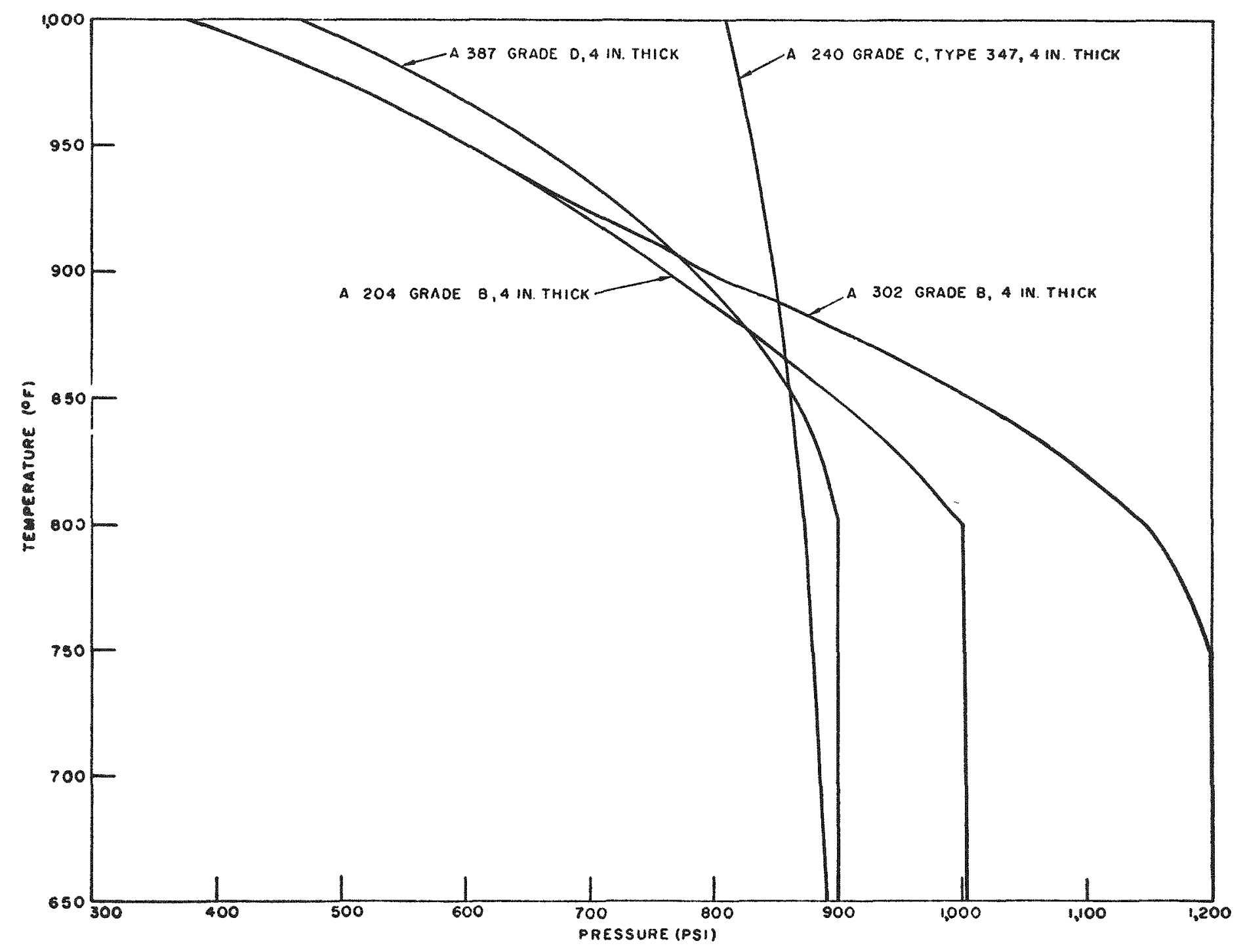

Fig. 1.7--Allowable pressure versus temperature for a 4 -in. wall thickness 


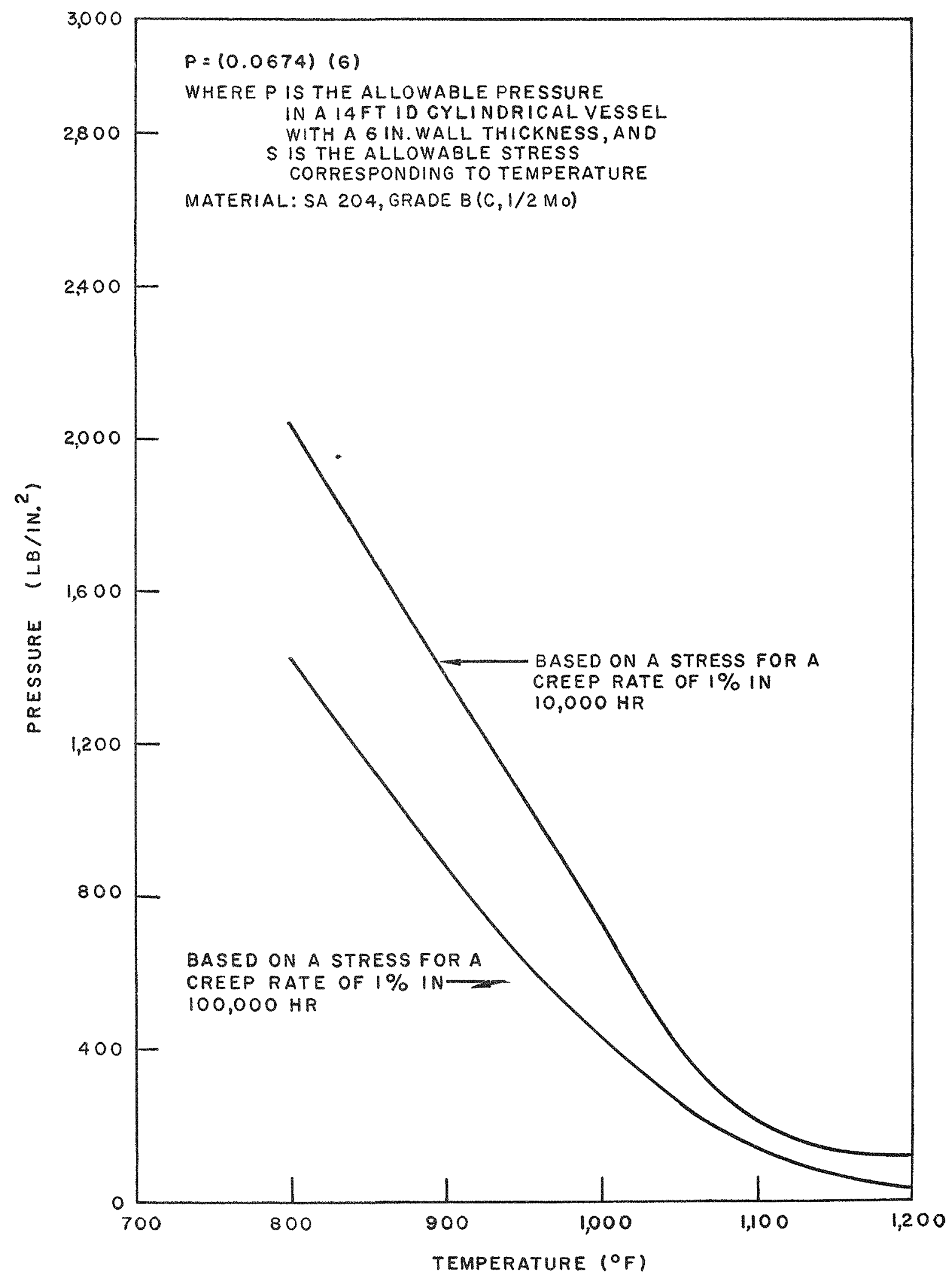

Fig. 1.8--Power boilers, material: SA-204 Grade "B" (C-1/2 Mo) 


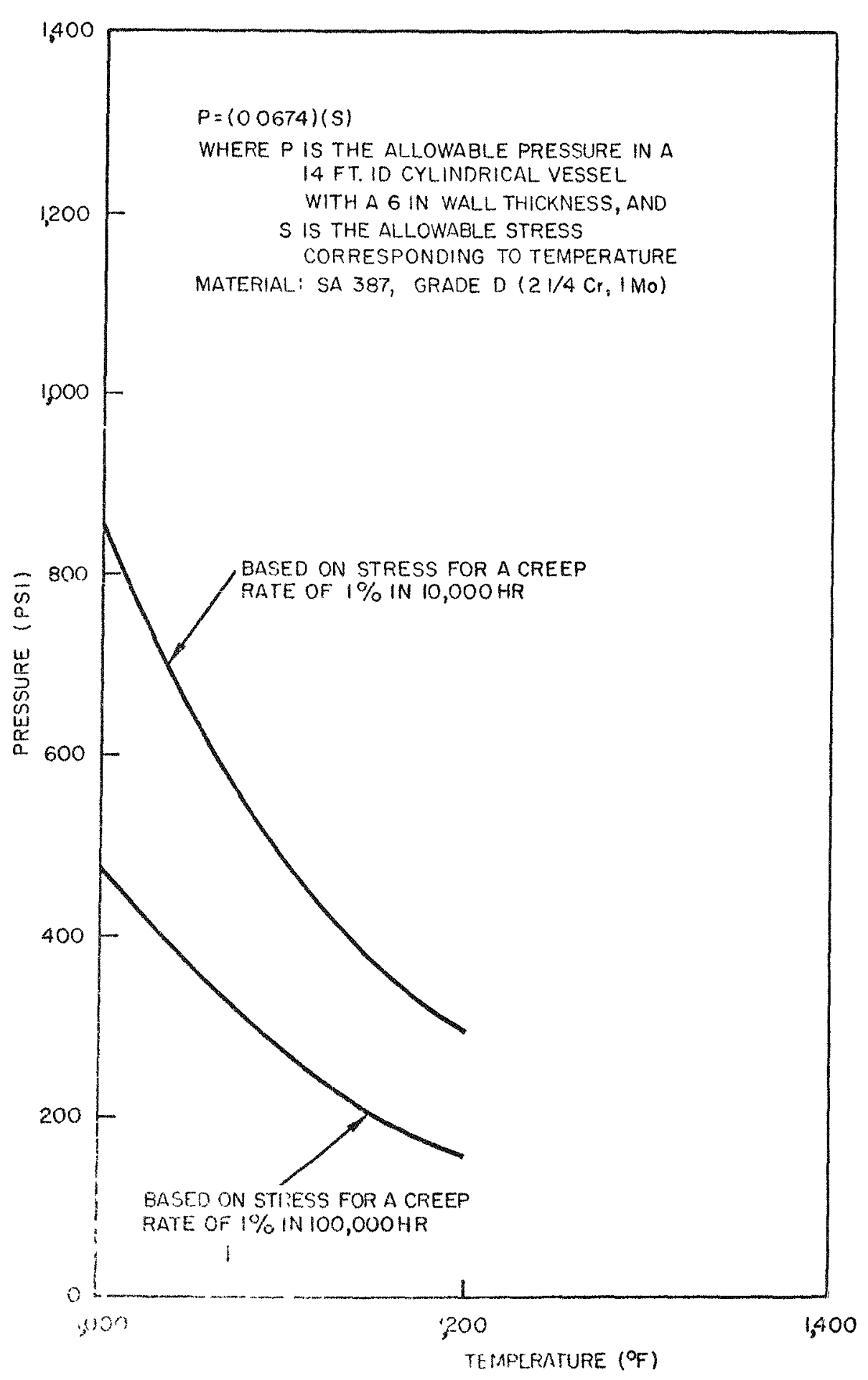

Fig. 1.9--Power boilers; material: SA-387 Grade "D" $(\mathrm{Cr}-1 \mathrm{Mo})$ 


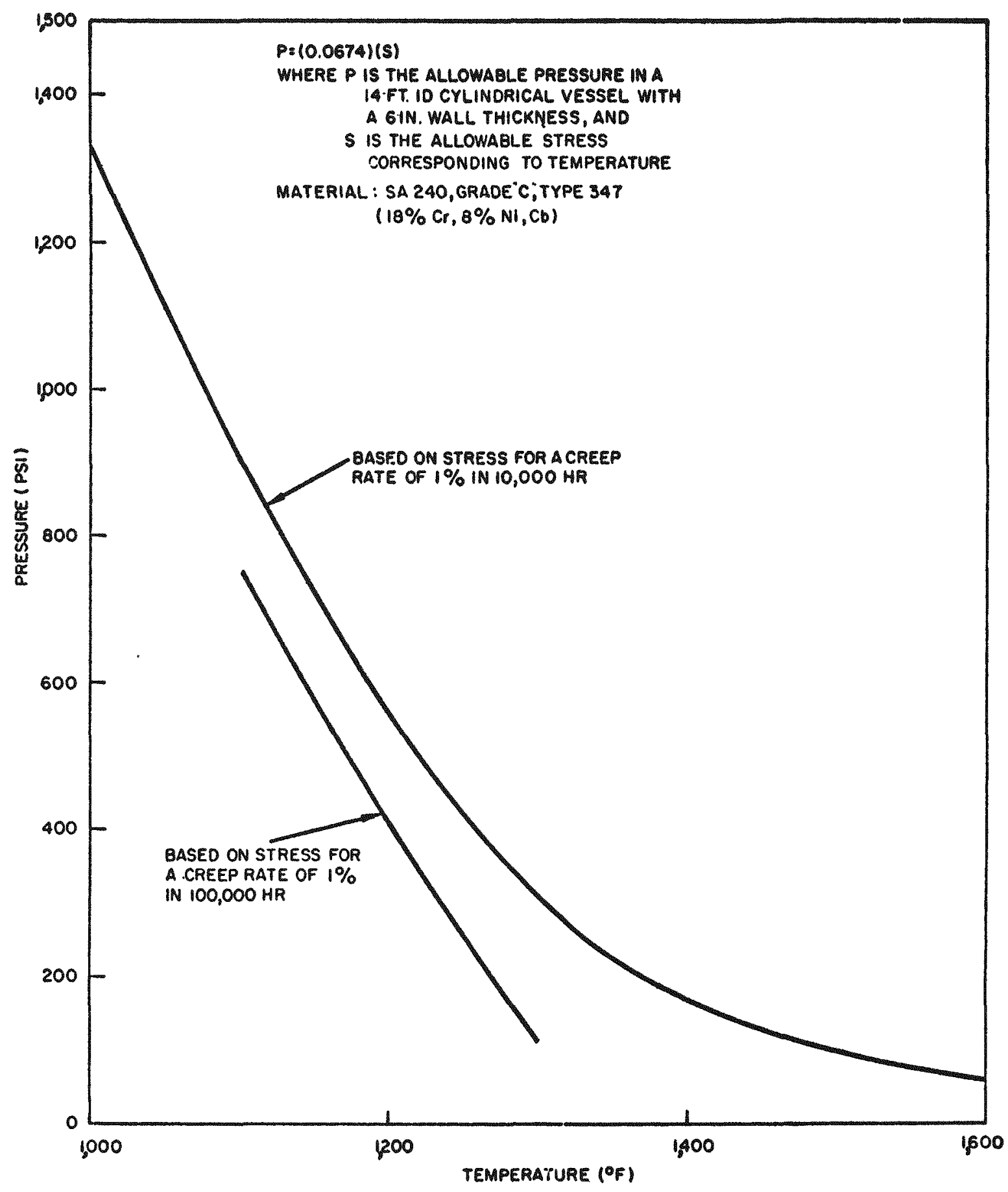

Fig. 1. 10--Power boilers; material: SA-240 Grade "C". Type 347" (18\% $\mathrm{Cr}-8 \% \mathrm{Ni}, \mathrm{Cb})$ 
The conceptual design of a reactor vessel with internal insulation, shown in Fig. 1.5, was developed so that work could proceed on the necessary analyses. The materials chosen for vessel investigations during this quarter were SA-302 Gr "B" and SA-387. SA-302 Gr "B" appears to be the more likely candidate, provided that the vessel wall temperature does not exceed $900^{\circ} \mathrm{F}$ at a pressure of $850 \mathrm{psi}$. To achieve such conditions, it will be necessary (1) to utilize internal insulation within the vessel or (2) to positively direct a portion of the main coolant flow past the vessel walls to ensure adequate cooling or (3) to adopt alternative cooling teçhniques. (Should suitable insulation and/or cooling techniques be developed, it may be possible to use materials which are even less expensive than SA-302 and yet are as widely used as SA-302 Gr "B".)

Calculations indicate that for Type 316 stainless steel, a pressure vessel design to withstand full reactor outlet temperature without internal insulation or other special cooling schemes would require a 12 -in. -thick wall.

For such a thickness, differences in properties of materials, plus other considerations, would make a choice of such materials impractical. Other unique materials for higher-temperature operation are available, but they have been excluded because of high cost, nonconformance to the ASME Code, or lack of long-term high-temperature experience.

Primary decisions still to be made concerning the design of the reactor vessel include the following:

1. Internal insulation versus no internal insulation.

2. External insulation and/or cooling with or without internal insulation.

3. Concentric ducting versus single ducting.

4. Top versus bottom control-rod drive.

5. Best approach to removal of core internals.

6. Head closure problems (bolted flanges versus Alco or other special enclosure approaches) based on maximum diameter restriction. 
7. Single-pass reactor versus two-pass reactor.

Design of Pressure-vessel Internals ( $K$. Trickett, R. Kelsey, R. Bean, T. Rogers, S. Bernsen, and F. Liederbach)

A program for the development of conceptual designs and an analysis for the selection of a preliminary design for the core and internals are in progress. The concepts selected for study were:

1. Metallic bottom support and auxiliary cooling for a $1,700^{\circ} \mathrm{F}$ outlet gas.

2. Metallic top support and no auxiliary cooling for a $1,050^{\circ} \mathrm{F}$ inlet gas.

3. Nonmetallic bottom support and no auxiliary cooling for a $1,700^{\circ} \mathrm{F}$ outlet gas.

4. Metallic bottom support and no auxiliary cooling for a $1,700^{\circ} \mathrm{F}$ outlet gas.

The assumed system parameter for this study include the following:

1. The direction of the working-fluid coolant flow through the core is vertically downward.

2. The maximum inlet-gas temperature and the maximum pressure to the core of $1,050^{\circ} \mathrm{F}$ and 760 psig.

3. The maximum outlet gas temperature and the maximum pressure from the core of $1,700^{\circ} \mathrm{F}$ and $720 \mathrm{psig}$.

4. The control-rod drives are located above the core.

5. The fuel element is removable as a single assembly to a position above the core.

6. To meet dynamic load requirements, component operation and support should withstand the following accelerations:

a. Vertical acceleration, $1.0 \mathrm{~g}$, either up or down. (This means that the foundations must support twice the static weight of the equipment, but that the equipment will not tend to rise off its icunotion.) 
b. Sidemtomside acceleration, $1.1 \mathrm{~g}$.

c Fore-and-aft acceleration, $0.2 \mathrm{~g}$.

7 The head can be removed during refueling.

Further assumptions and detailed problem areas for each of the four concepts were outlined. The results of the analyses of these four designs, and others, are that to date ten concepts of core-support strictures have been studied and evaluated. The most promising concepts are being more thoroughly investigated so as to arrive at a single design. The investigations to date were based on the possible need to handle both the semihomogeneous and heterogeneous fuel elements.

Support of Core

The use of a graphite beam support was considered for one concept of this structure (see Fig. 1.11). This design was rejected because of the high stress levels which are developed in the graphite by the application of mechanical (dead weight, inertial, and pressure drop) loads. Some uncertainty still remains as to whether graphite can withstand long oterm tensile stresses.

Because the graphite beam support proved unacceptable, other nonmetallic core support possibilities were investigated. This resulted in the concept of utilizing a ceramic shape with cored passages to collect the hot outlet gas and discharge it into a single outlet nozzle.

Iop Support. The use of a top support for the core has been evaluated and rejected. This type of support would require that the graphite fuel bodies be in tension, and an examination of the mechanical design has revealed a complex group of problems. Furthermore, the design introduces into the core an additional void, which is undesirable.

Bottnm Support with Auxiliary Cooling. Two systems were investigated: cooling a core support plate with water and cooling a core support plate with gas.

An analysis of the double tube-sheet concept (see Fig. 1.12) showed that large temperature gradients develop when water is used as the auxiliary 


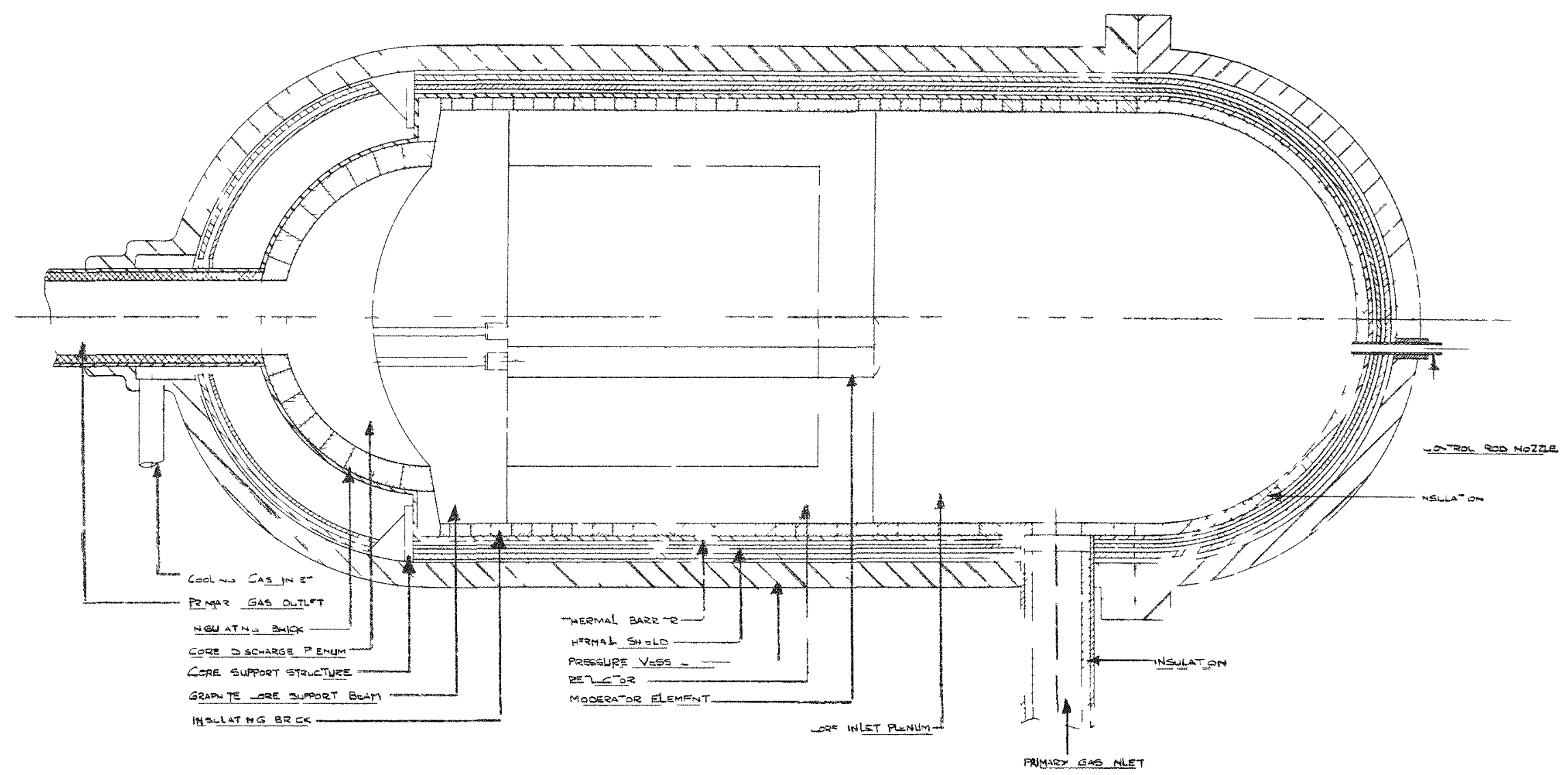

Fig 1 11--MGCR core and internals, concept C, nonmetalinc bottom support without auxiliary cooling 


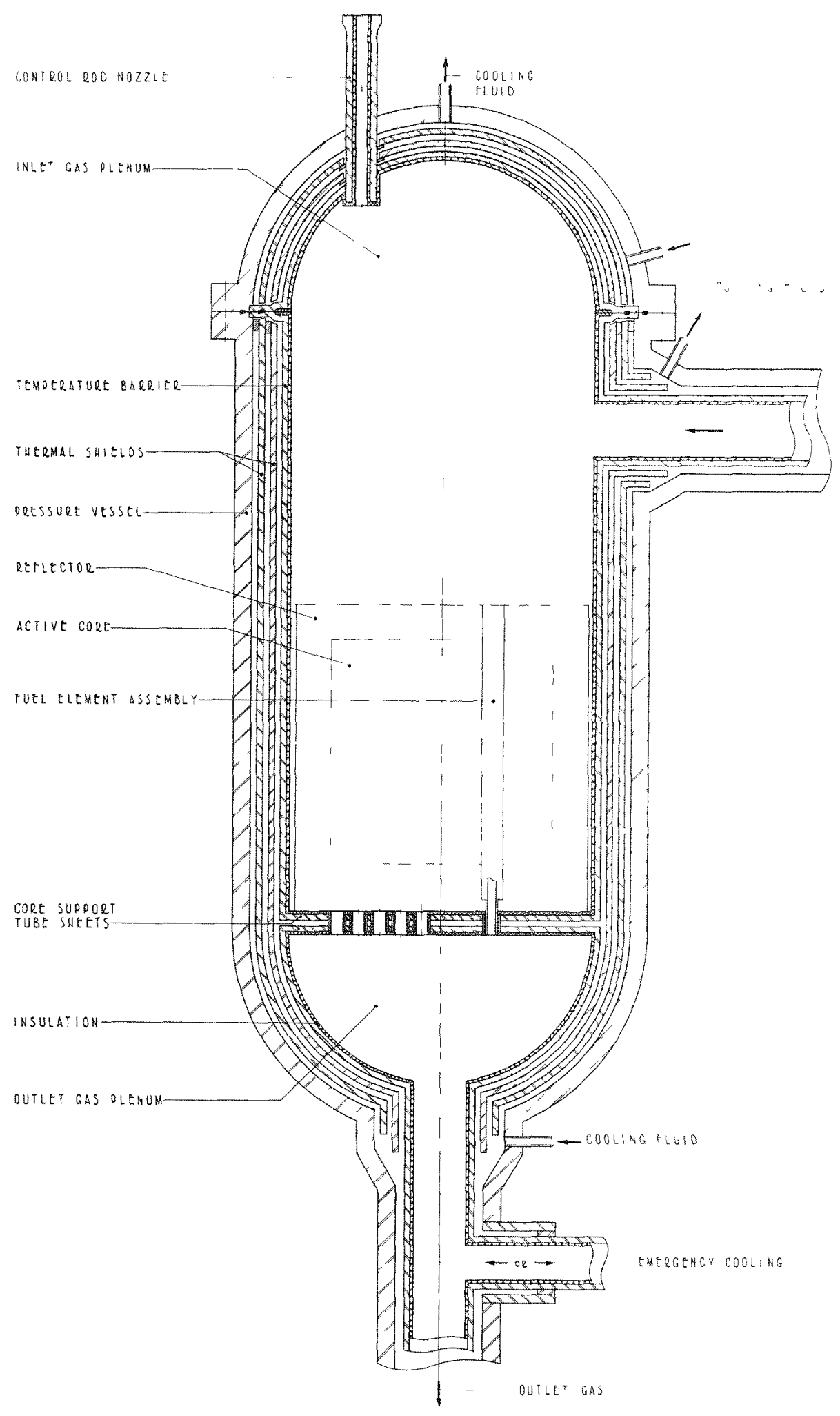

Fig. 1.12--MGCR core and internals, concept $A$; bottom metallic support with auxiliary cooling 
coolant. For this reason, the effects of increasing the insulation thickness are being evaluated, as is the use of other gaseous coolants, including helium.

Bottom Support without Auxiliary Cooling. The design for this type of support (see Fig. 1.11) was originally intended to function at a $1,300^{\circ} \mathrm{F}$ gas temperature, and it is felt that this approach-with either separate or concentric ducts--represents the best design to date. Since the cylindrical core-support skirt is one of the most critical features of this design, an analysis has been made of the mechanical and thermal stresses introduced during steady-state conditions. The results show that with controlled insulation on the skirt, a 3/4-in. -thick skirt about 15 to $18 \mathrm{in}$. in depth will be adequate for the permissible stresses during the lifetime of the core ( 2 to $3 \mathrm{yr}$ ) at a $1.300^{\circ} \mathrm{F}$ outlet temperature. Since helium may have some adverse effects on the stress-rupture properties of the materials being considered it is difficult to ascertain the reliability of this design at higher temperatures; however, data presently available from stress-rupture tests in air indicate that this skirt will be able to withstand limited operation at temperatures up to $1,500^{\circ} \mathrm{F}$. A final evaluation of the skirt will require an experimental program.

Metallic Support Structure. Several designs for a metallic bottom support are being developed. In one a single-duct arrangement for primary gas flow is assumed. The core would be supported by a grid structure fabricated into the base of a long cylinder, supported from above the core. The thermal shield would be cooled by bypassing a small percentage of the working fluid from the main coolant stream that passes through the core. This scheme may have limitations, because bypass cooling reduces the system efficiency.

Another design being considered is one in which a manifold pipe arrangement of five outlet gas pipes compresses the flow into a single outlet duct. The outlet gas from the core is thus collected, and this permits a metallic bottom support to operate at the inlet gas temperature, while still 
retaining the downward flow of working fluid through the core. It is too early to assess the possibilities of this concept, although it appears to have severe limitations imposed by pressure drop.

A hot-plenum, chamber-type core support was also considered, but this design posed other severe mechanical problems and some complexity. The main problem was the possibility that hot spots would be generated in this type of core-support configuration, and that these possible hot spots would contribute to other materials and components problems.

Primary decisions yet to be made concerning the support structure include the following:

1. Top versus bottom fuel-element support.

2. Top versus bottom core support.

3. Internal insulation versus no internal insulation.

4. Various philosophies on removal of core internals.

Nonmetallic Support Structure. One concept was investigated in which the core load and pressure drop are transmitted to the bottom support structure by means of graphite or an insulation material under compressive loading for outlet temperatures up to $1,700^{\circ} \mathrm{F}$. This concept will require extensive analysis before it can be considered as being an acceptable design. Analysis of this concept has been deferred until certain other concepts have been surveyed.

Biological Shielding of Pressure Vessel (K. Trickett and T. Lynxwiler)

Studies have been conducted to determine the internal biologicalshield material, thickness, and weight necessary to reduce the gamma radiation intensity to a level that will be tolerable to personnel working near the head of the reactor and that will not induce activation in the head assembly.

The effects of the numerous control-rod penetrations and coolant passages required in this shield were also considered in calculating the shield efficiency. Whether such a shield is necessary or whether an auxiliary shield may be placed over the core during refueling must be determined before work on the design can continue. 
The functions of an internal biological shield are

1. To act as a thermal shield to protect the vessel head,

2. To reduce induced activation in the head and head components,

3. To act as a biological shield to protect personnel against core shutdown gamma radiation during fuel handling.

The inclusion of an internal biological shield that would perform all of these functions implies (1) that the head would be removed for fuel handling, (2) that there would be some increase in pressure-vessel length. (3) that the shield would have to be rotated for fuel handling, and (4) that there would be possible problems in alignment and thermal mismatch, since control-rod drive extensions must pass through the shield.

An alternative concept of a thermal shield inside the vessel to protect the head has been considered. This shield could be made integral with the head and thus would be removable with it. Such a shield would offer the following advantages:

1. Less thickness would be required in the head to withstand thermal pressure, because the head would be cooler.

2. The refueling operation would be simplified.

3. It would be possible to integrate the optical system and/or closedcircuit television in the external biological shield for viewing vessel internals during refueling operations.

4. Reactor down time would be reduced by reason of a reduction in the number of operations necessary to $r$ efuel.

5. Major manipulating operations, such as the removal of a broken fuel element, would be facilitated. For such operations, an internal biological shield would have to be removed.

6. The possibility of the self-welding of movable parts in an internal biological shield would be obviated.

Further investigations must be carried out to determine whether it is feasible to leave out the biological shield completely, and, if not, what are the additional requirements for it. Questions to be considered are as follows: 
1. What does the additional thickness represent in terms of added pressure-vessel height, weight, and effect on center of gravity?

2. What effect does the internal shield have on primary coolant-flow distribution and pressure drop, assuming (a) that all primary coolant flow passes through the shield and (b) that none of the primary coolant flow passes through the shield?

3. What is the expected frequency of occurrence of inead removal for all causes, including fuel handling, for the prototype and for the operating plant? Is this compatible with a seal weld, should one be required?

4. What length of time would be required for head removal and replacement? What down-time costs does this represent for the prototype and for the operating plant?

5. What are the comparative costs, including comparative down-time costs for the prototype and for shipboard installation, of (a) the internal biological shield, shield rotating and indexing device, and added vessel length, and (b) a fuel-handling machine capable of inserting and removing fuel elements through suitable nozzles in the head?

CONTROL-ROD DRIVES (F. J. Liederbach, B. C. Hawke, and W. Dougherty)

Proposals were requested from vendors for suitable rod drives, together with approximate cost estimates for the design, manufacture, and testing of a control-rod drive unit. In addition, discussions were held with various control-rod drive vendors as part of a survey to ascertain vendors' availability and capability for undertaking the design, development, testing, and production of control-rod drives suitable for application to the MGCR. This information, coupled with a General Atomic design investigation, is to form a basis for an evaluation study, the ultimate objective of which will be to arrive at a "make or buy" decision. 
To date, there is no evidence that an "off-the-shelf" drive exists nor that an existing drive can be easily modified for MGCR application. One company has conducted development work on drives for a closed-cycle, gascooled reactor; however, this work has been associated with bottommounted drives. Some doubt exists as to whether this drive, which is basically a rack and pinion type, can be adapted for top mounting and other MGCR requirements; however, this possibility is being investigated.

Surveys to date also indicate that complete test facilities for hightemperature and high-pressure environmental testing (with helium) are not a vailable.

Also, because of the over-all lack of availability of off-the-shelf drives and of vendor test facilities suitable for application to hightemperature helium environmental testing, an architect-engineer team was obtained to work with us in the preparation of drawings, detailed cost estimates, and a biddable specification for a test facility for a control-roddrive system.

Sketches of two possible test-structure arrangements are shown in Figs. 1.13 and 1.14 .

Both structures are designed to house an autoclave capable of being tilted $30^{\circ}$ to simulate a shipboard inclination. Four graphite blocks and a simulated portion of the core will be included in the test autoclave, which is to be mounted on the test structure. The autoclave will contain one control rod and will be operated to simulate the expected MGCR environment.

The General Atomic concept of the control-rod-drive mechanism is illustrated in Fig.1.15. Our design approach was based on the following as sumptions:

1. Insofar as possible, the mechanism should be designed around known and tried principles.

2. It should be of rugged construction and should be contained within the least possible over-all length and diameter. The diameter, in particular, should be such as to allow sufficient ligament 


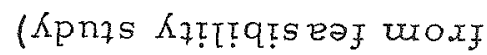

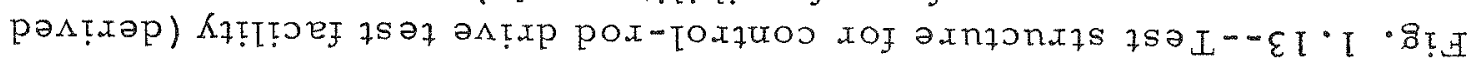

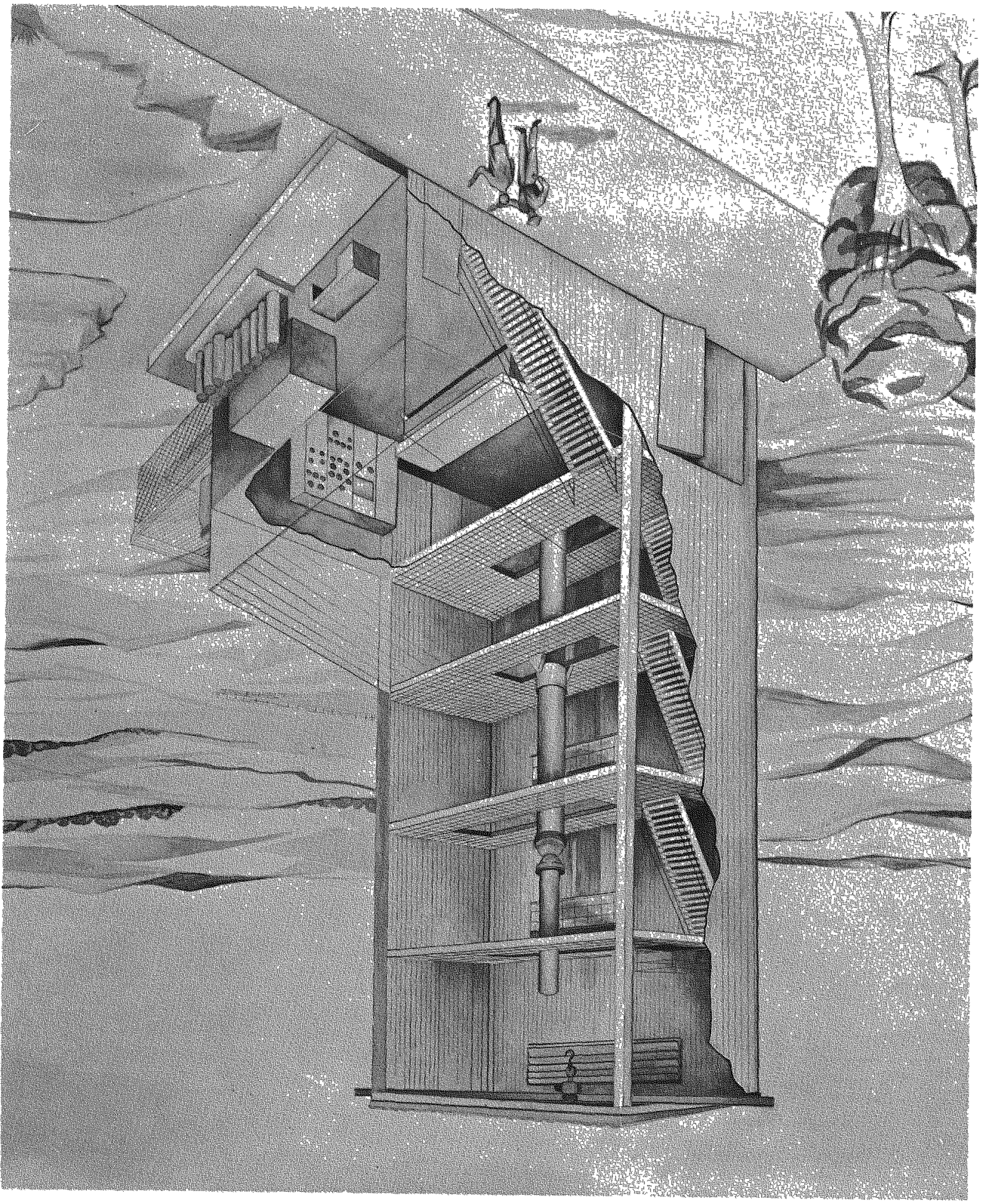




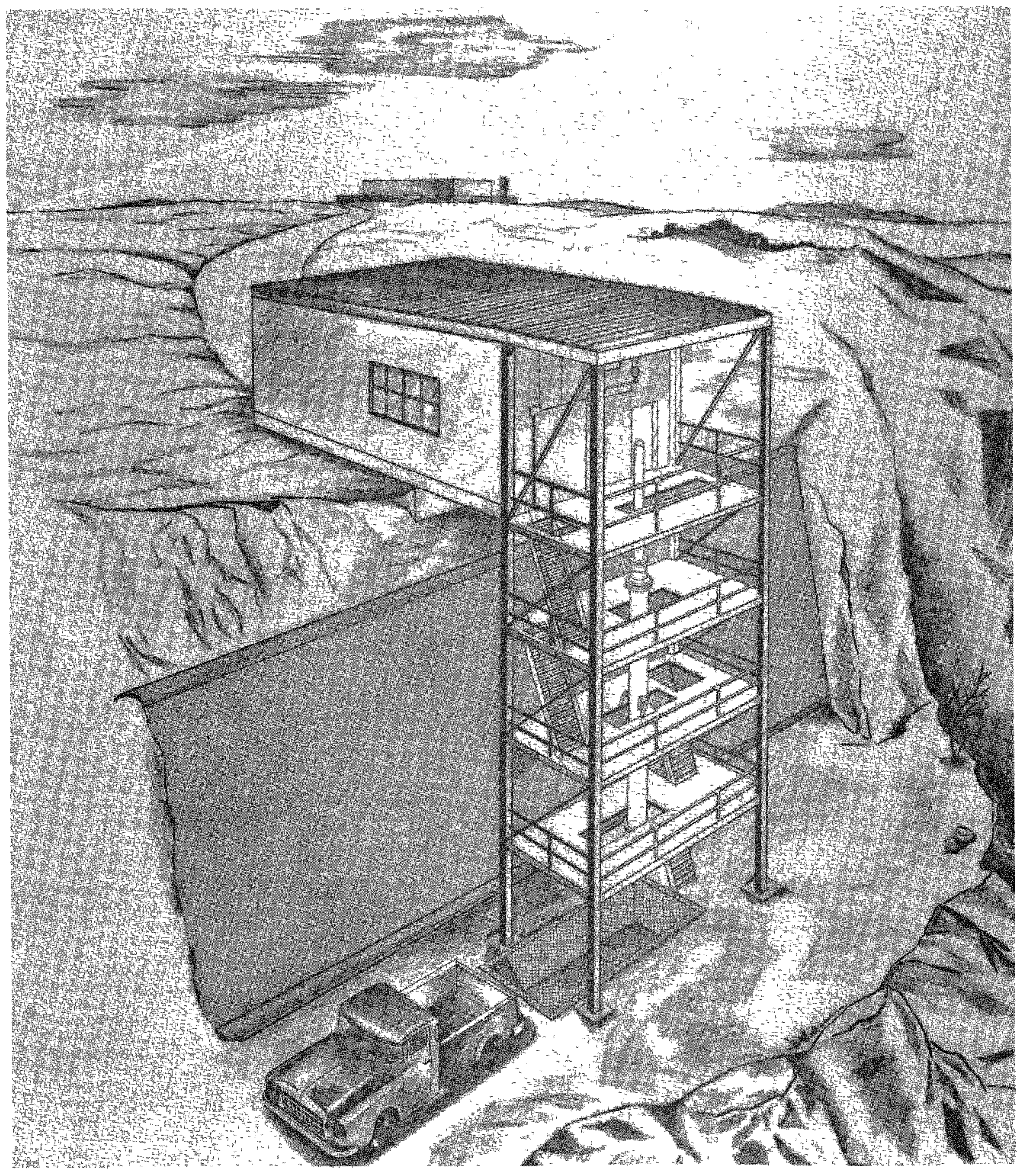

Fig. 1.14--Alternative test structure for control-rod drive test facility (derived from feasibility study) 


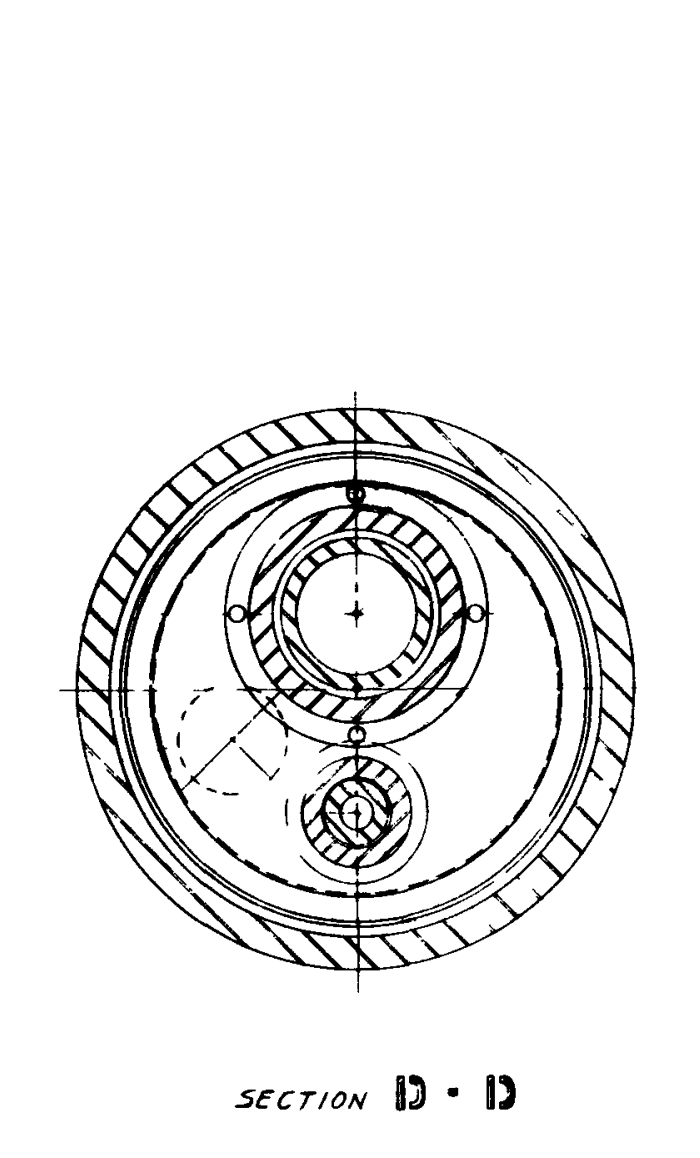

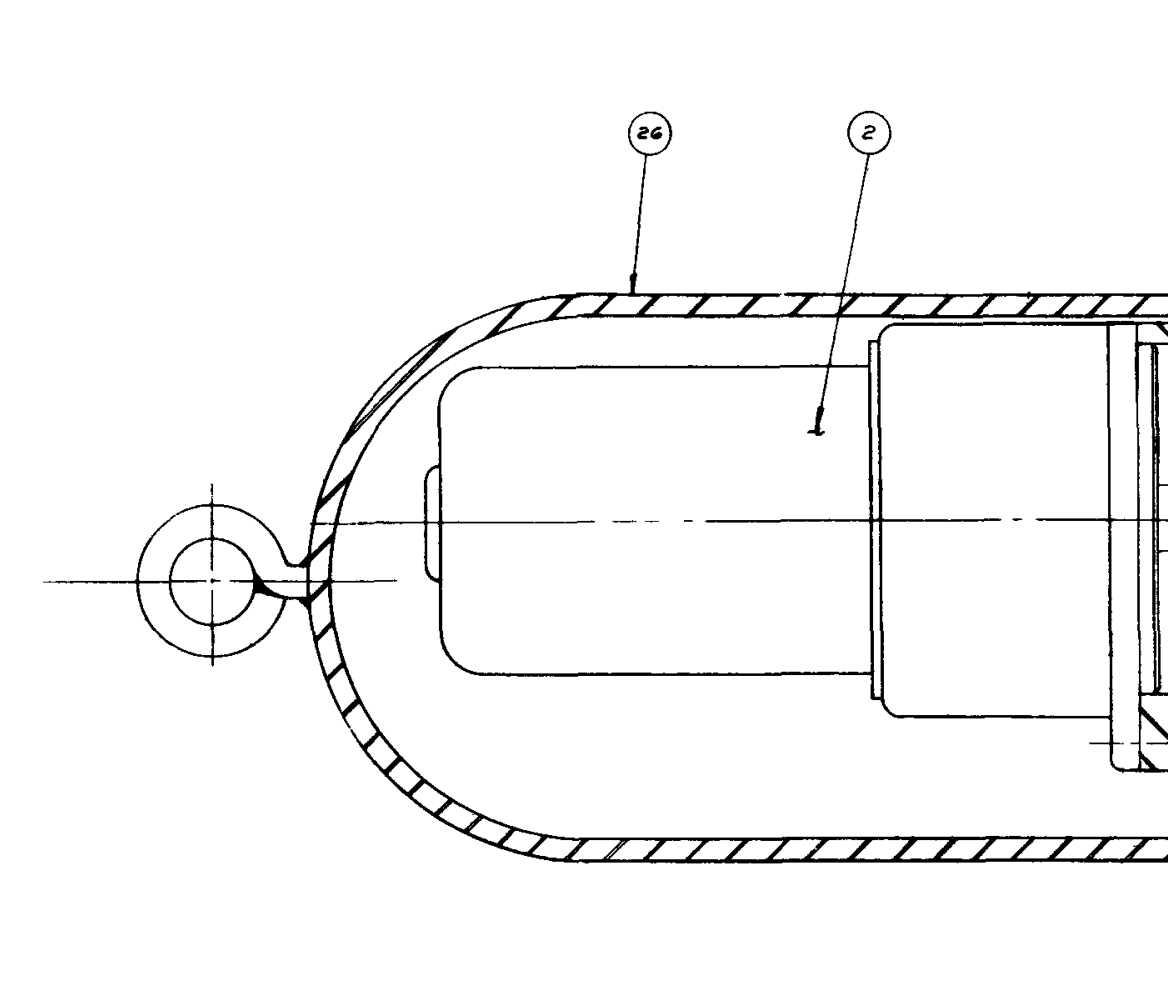

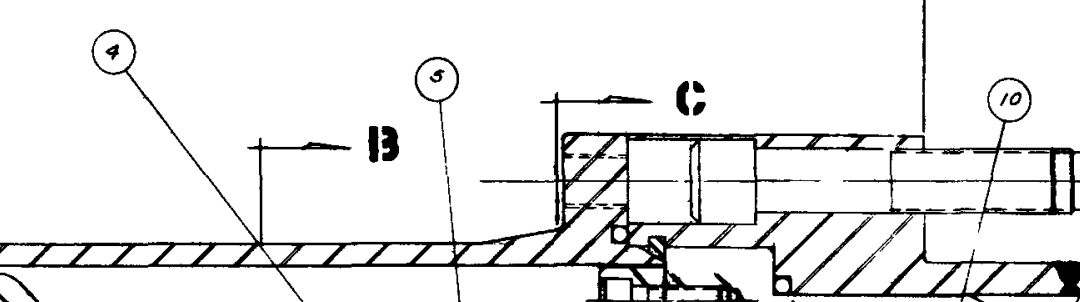

...n

minm

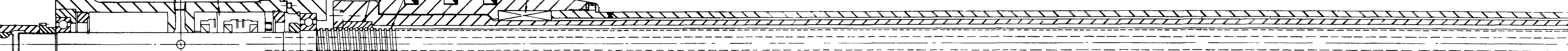

पाem

W 1

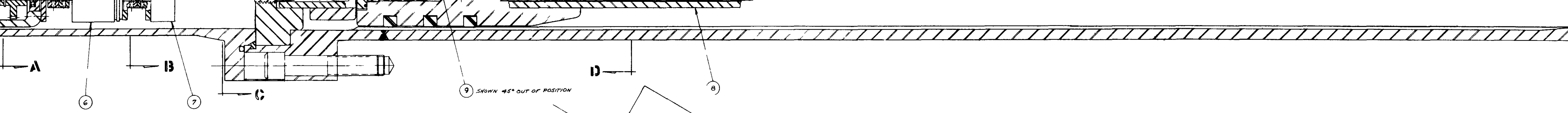

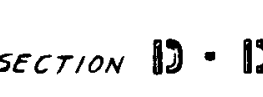
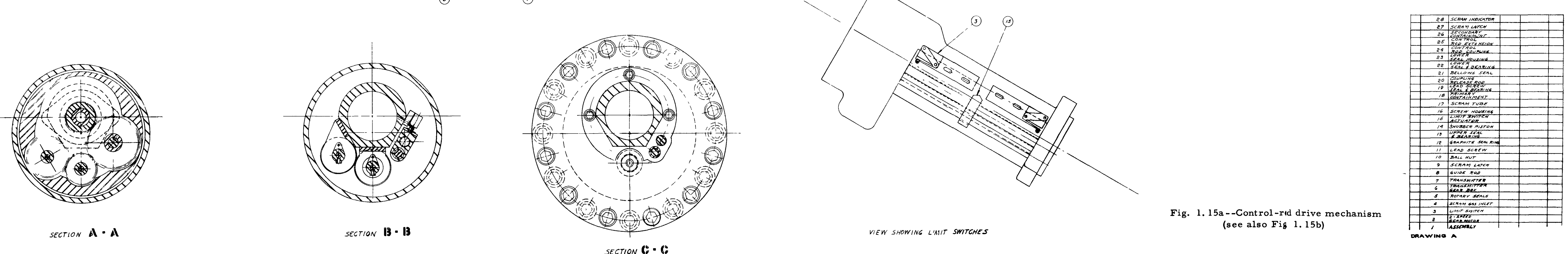
structure at the minimum rod pitch of the design.

3. The mechanism should be totally enclosed in such a manner that failure of any dynamic seal would not allow the reactor coolant to escape to the atmosphere.

4. If possible, the mechanism should be capable of operating at reactor pressure, thereby avoiding the use of a buffer seal and the resultant force which tends to expel the control rod from the reactor core.

5. Some form of forced scram, driven from a separate energy source, should be incorporated in order to overcome such friction forces as may develop in the system, e.g., rod binding in the core due to misalignment.

The following is a description of the drive mechanism shown in Fig. 1.15. Basically, the mechanism is a ball nut and lead-screw actuator that is powered by a two-speed electric-gear motor. Some consideration is, however, being given to use of a gas motor as a power source.

The lead screw (11) is center-bored through its whole length and is plugged at its top end. It operates inside a seal sleeve (16) that is integral with the nut carriage and ball nut (10). There is a dynamic seal (19) between this sleeve and the bottom end of the lead screw.

The tubular drive rod proper (17) is a cylindrical member that carries a seal at its top end (13) and a disconnect at its lower end for attachment of the cruciform control rod. This tubular drive rod is normally free to slide on the seal sleeve (16) and is therefore separable from the nut carriage. However, when the reactor is pressurized, a small differential pressure will cause the latch(9) to engage, thus locking the nut carriage and drive rod together, so that the carriage and rod are simultaneously raised and lowered by rotation of the lead screw. Rotation of the drive rod is prevented by a guide 8 .

Position-indication transmitters, possibly rotary potentiometers, are geared off the lead screw at suitable ratios, as is a small secondary 
lead screw (15) that operates "extremes of travel" limit switches.

Two rotary seals 5 retain reactor pressure and provide an inletporting arrangement for the scram gas.

A secondary containment 26. completely encloses all the electrical components and may serve as a cooling chamber, should one be necessary.

When a scram signal is received. a normally open solenoid valve will allow high-pressure gas from an independent accumulator to flow into the annular space between the two rotary seals, down the center of the lead screw, and into the inside bore of the drive rod. Escape of this pressure to the reactor is prevented by the seals 13) and (19), previously mentioned. The scram pressure is then transmitted to the top side of the latch piston, thus causing the latch to disengage. This latch is cocked by reactor pressure. Loss of both reactor pressure and scram pressure, therefore, will permit a gravity scram; but because of seal friction, roll, pitch, or vertical acceleration forces, gravity scram may occur at a lesser rate than our specification calls for.

The drive rod, being freed by latch disengagement to move independently of the nut carriage, will be accelerated rapidly by the scram pressure. However, after approximately $50 \%$ of full travel, the snubber will enter a closer fitting diameter, thereby causing a pressure build-up below it. The top half of the primary containment cylinder will be opened to allow free gas flow over that portion. This pressure increase as the rod travels downward, which is controlled either by orifices in the primary containment wall or by allowing looser fits, results in a gradual deceleration of the rod velocity.

To maintain the control rod in a "full-in" position in case of ship capsizement, a second latch is provided. This latch is a portion of an assembly that prevents the rod from rotating. The entire assembly consists of a spring-loaded pawl, with the spring load being supplied to the pawl by a follower shaft roller which acts against the cam force of the pawl. When scram action occurs, the snubber-drive-rod assembly 14 and 17 is 
disengaged from the nut carriage (14). which acts as the piston-snubber. At this time, the piston moves down and depresses the extended latch pawl. The pawl springs out into its engagement position when the snubber reaches the bottom of its travel.

This "full-in" latch is automatically released by the nut carriage when it is caused to "follow up" the drive rod.

Engagement of the latch by the snubber and drive causes a signal to be transmitted to the control panel, and thus indicates that a scram stroke has been completed. The magnetic switch which initiates this signal is operated by a rod passing up through the guide tube and into--but sealed from - the secondary containment.

Further consideration of the scram latch has indicated that perhaps a small differential pressure could be utilized to maintain the engagement of the nut carriage and drive rod at all times when the reactor is pres. surized. With this arrangement, the only occasion when the latch would be needed at all would be to pick up a control rod at zero reactor pressure. This feature can be incorporated into the present design.

Investigation has been and is being made into sealing and bearing problems. The results indicate a general lack of vendor experience with seals and bearings for a high-temperature and high-pressure helium environment.

Consideration is also being given to a "rod fully in" indicator after scram, as distinguished from the normal "extreme of travel" indicator required by the tentative design requirements. Problems associated with the disengagement of the control rod and/or extension rod have not been completely resolved, largely because of some degree of uncertainty as to whether or not there is to be a biological shield in the reactor. Further shielding calculations and studies will resolve the questions relative to internal versus external biological shielding requirements and to shielding requirements in general. 
DESIGN OF FUEL RELOADING EQUIPMENT ( $T$. Lynxwiler and F. Liederbach)

The assumptions used in the derivation of our current design philosophy are as follows:

1. Refueling will be accomplished during reactor shutdown.

2. A gas cover above the core will probably be utilized. However, although it is recognized that material-handling devices would be simpler and procedures would be less involved and probably safer if refueling could be accomplished through a liquid shield, it has not been established at this time whether a water cover or a liquid cover is practicable.

3. The gas cover tentatively considered will consist of air inspired during head removal and refueling operations.

4. For present Phase I studies, it is being assumed that a shield to protect personnel who service the reactor during shutdown will be a vessel internal component. With the assumption of a gas cover, it becomes extremely important to know whether this biological shield is to be an integral part of the head and therefore is to be removed from the vessel when the head is removed, or whether it is to remain in the vessel. Until vessel configurations and internal design have been determined, it is impossible to discount the possibility that we may have to utilize a carriageborne external shield, in addition to the carrier plate, to prevent radiation streaming after head removal.

It is contemplated that the carriage, together with its drive and concentric-ring drive, can be made to perform dual service. After the refueling operation has been completed, the carrier plate and coffin may be removed from the carriage by the gantry crane. A fuel-manipulating boom and its mounting may then be fitted into the outer ring bearings of the carrier plate. The new assembly thus becomes the instrument for handling spent fuel elements during underwater inspection, disassembly, and storage operations. 
As previously indicated, the refueling uperation and subsequent spentfuel handling presently assume the probability of a gas cover. However, in an effort to overlook no possible refueling method that might result in safer, more economical, and faster operation, considerable study has been given to the question of a water cover versus a gas cover.

Some of the apparent advantages of a gas cover are as follows:

1. It obviates the necessity for internal cladding of the vessel and for core drying after refueling.

2. It avoids the necessity for draining the reactor and pit after refueling and eliminates the valves, pumps, plumbing, and expansion of the plant demineralization system which would otherwise be required for this operation.

3. It reduces the strength requirements for the reactor-vessel support structure.

4. It eliminates the possibility of reactor core contamination by water-borne foreign matter during refueling.

Some of the apparent limitations of a gas cover are:

1. It accentuates the problem of biological shielding after the vessel head is removed. This entails the use of heavy and complex plates containing plugs which must be indexed over core elements for refueling and control-rod replacement.

2. It may be more hazardous than a water cover because of the possible release of air-borne fission products to the atmosphere during refueling.

3. It requires the inspiration of air and/or the recirculation of coolant gas during refueling to remove decay heat.

4. Fuel-handling equipment must be heavier, bulkier, more expensive, and operationally more complex than would be necessary with a water cover.

5. It cannot be utilized in any operation that requires the removal of internals, such as thermal shields, from a "hot" vessel. 
6. Shielding equipment and refueling procedures have been afforded less design study than have water cover methods during the development of the art, and less experimental background is available on them.

Difficulties have been resolved regarding the geometry of the carrier plate and of the biological shield concentric-eccentric ring system that is used for indexing the coffin over all fuel elements and control rods with respect to control-rod extensions that protrude through the biological shield. It has now been definitely determined that the proposed system for spentfuel replacement is practicable and sufficiently flexible to allow considerable latitude for adaptation to future changes in the vessel, head, and biological-shield design.

Weight studies have been made on most of the major components, and critical as semblies (such as the fuel coffin) are undergoing design analysis to effect optimum weight reduction.

At the present time, refueling mechanisms and handling equipment necessary for the replacement of core internals and for the subsequent disposal of spent fuel elements are divided into the following major assemblies:

1. Carriage assembly.

2. Carrier-plate assembly.

3. Spent-fuel coffin.

4. Control-rod and fuel hoist and hoist housing assembly.

5. Storage pool fuel-manipulating boom adapter for carriage.

6. Underwater saw (or shears) arrangements.

7. Spent-fuel shipping container.

8. Underwater hot-debris press.

9. Hot-debris shipping container.

10. Carriage elevator.

11. Fuel-coffin spreader bar and hoist sling.

12. Gantry crane.

13. Vessel-head spreader bar and hoist sling. 
14. Debris-container spreader bar and hoist sling. (This may be identical with the spent-fuel shipping container hoist sling.)

15. Storage pool fuel-inspection periscope.

16. Seal weld cutting, machining, and rewelding machine.

17. Remote-controlled impact wrench and vessel stud-handling equipment.

18. Heavy-duty, general-purpose, remote-controlled manipulator. In addition to the above items, the following equipment may become necessary (requirement depends on final design of an internal biological shield with relation to the pressure-vessel head):

1. External biological shield and carriage.

2. External biological-shield carriage elevator.

3. Closed-circuit lelevision camera and camera manipulator for viewing vessel internals, fuel hoist engagement with fuel nipples, etc.

4. Head gas-seal grapnel (probably electromagnetic), spider and sling.

Specific hardware design projects that have been undertaken include the following:

1. Carrier-plate and coffin assembly (see Fig. 1.16).

2. Telescoping fuel hoist.

3. Fuel and control-rod grapnel.

4. Plug retractor grapnel.

5. Arrangements of carrier plate and biological-shield carriages and railways.

6. Investigation to adapt a closed-circuit television and/or labyrinth optical system to the carrier plate for the purpose of locating and aligning fresh fuel over its site in the core. 


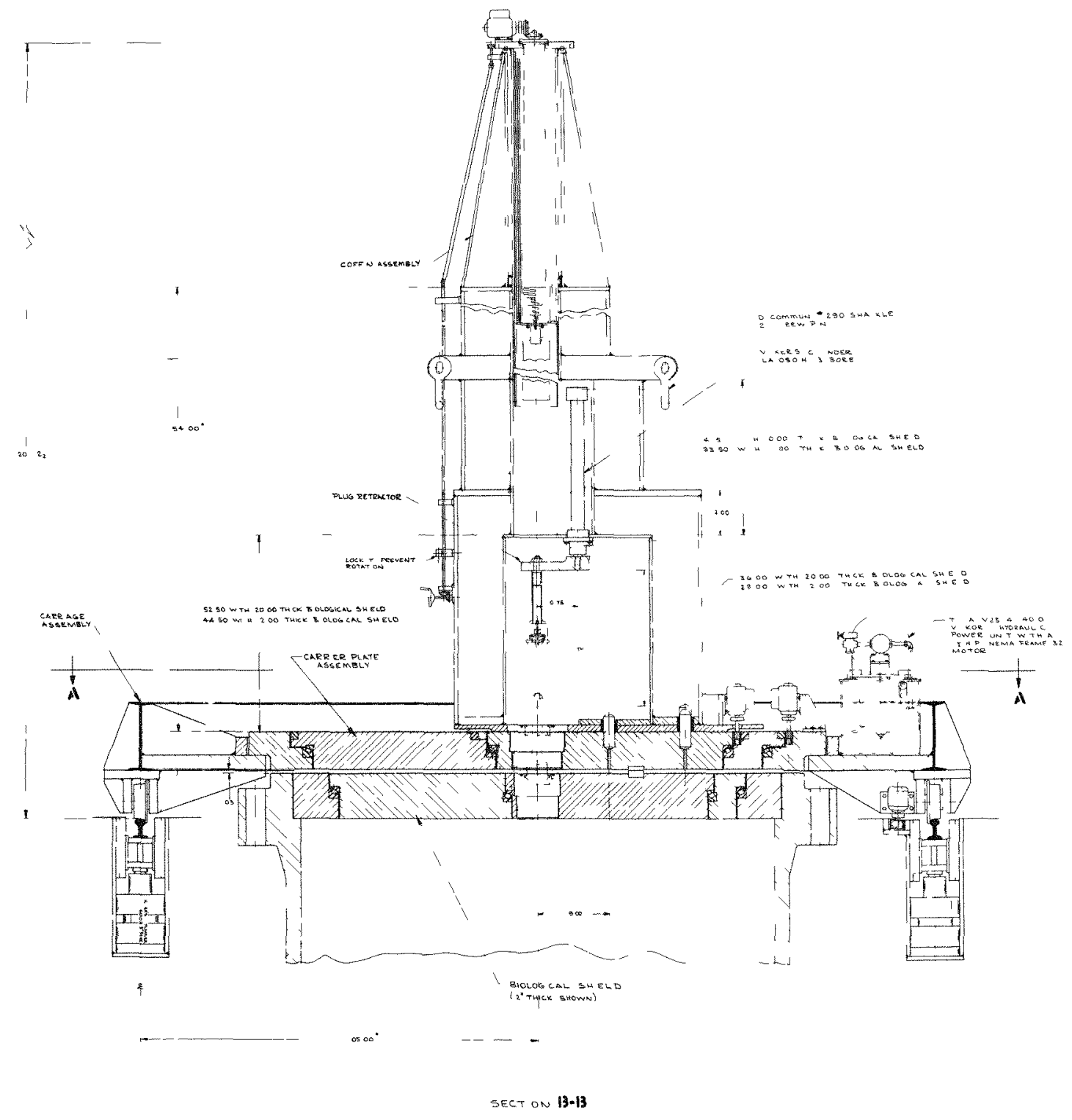

Fig. 1.16--Carrier plate and coffin as sembly 


\section{DESIGN OF REACTOR CONTROLS AND INSTRUMENTATION}

(F. Liederbach and W. Lones)

Preliminary design investigations were started relative to power reactor instrumentation, fuel-failure detection, wire-activation techniques, and other topics pertinent to the reactor plant control and instrumentation system。

Work has been completed on the description, block representation, and preliminary estimating of the following systems:

1.Zero-power start-up instrumentation system.

2. Indicating system for reactor power and rate of temperature change.

3. Power and periodic neutronic trip system.

4. Fuel-failure detection system.

If the basic design criteria are accepted, then extending the conceptual design into the preliminary and final stages of the first three systems will offer no great difficulty. The fuel-failure detection system, however, will require a considerable amount of study, evaluation of experience gained from existing systems, and possibly a great deal of development work. 


\section{FLUID SYSTEMS AND PLANT ARRANGEMENT}

REACTOR HEAT-DUMP SYSTEMS (J. H. Pilliod and B. Lund)

This area of work investigated alternative methods for dissipating up to $40 \%$ of rated reactor power without employing the propulsion plant. Helium-to-water, helium-to-boiling-water, and helium-to-air systems were investigated. Each system was analyzed for development cost, total cost, space, weight, operability, and complexity.

An air-cooled helium heat exchanger, located outside of the containment area, is the most satisfactory system if access within the containment area is required during the reactor heat-dump operation. A system utilizing the installed bypass steam generator would be the most economical and practicable if access within the containment area is not required during reactor heat-dump operation. Other systems investigated were more expensive and required more space, weight, and maintenance.

HEAT-EXCHANGER TEST LOOP (H. C. Paulsen, L. Casellini, F. B. Anderson, and B. Lund)

The objective of this work is to compile and correlate sufficient experimental data for the aerodynamic and thermal design of the prototype main coolant regenerator. This data will also be used in the design of other power-plant exchangers of similar configuration.

The helium heat-exchanger test loop is shown in Figs, 2.1 and 2.2. Figure 2.1 shows the entire test facility, including the model heat exchanger, gas cooler, and gas-circulating blower. Figure 2.2 shows a close-up of the blower system.

The model heat exchanger shown in Fig. 2.3 is of counterflow design. The shell side is unbaffled to allow the flow to be parallel to the tube-bundle axis. The frictional characteristics of the air-foil type of tube supports were compared with those obtained for 3 -ft straight sections of the unsupported 


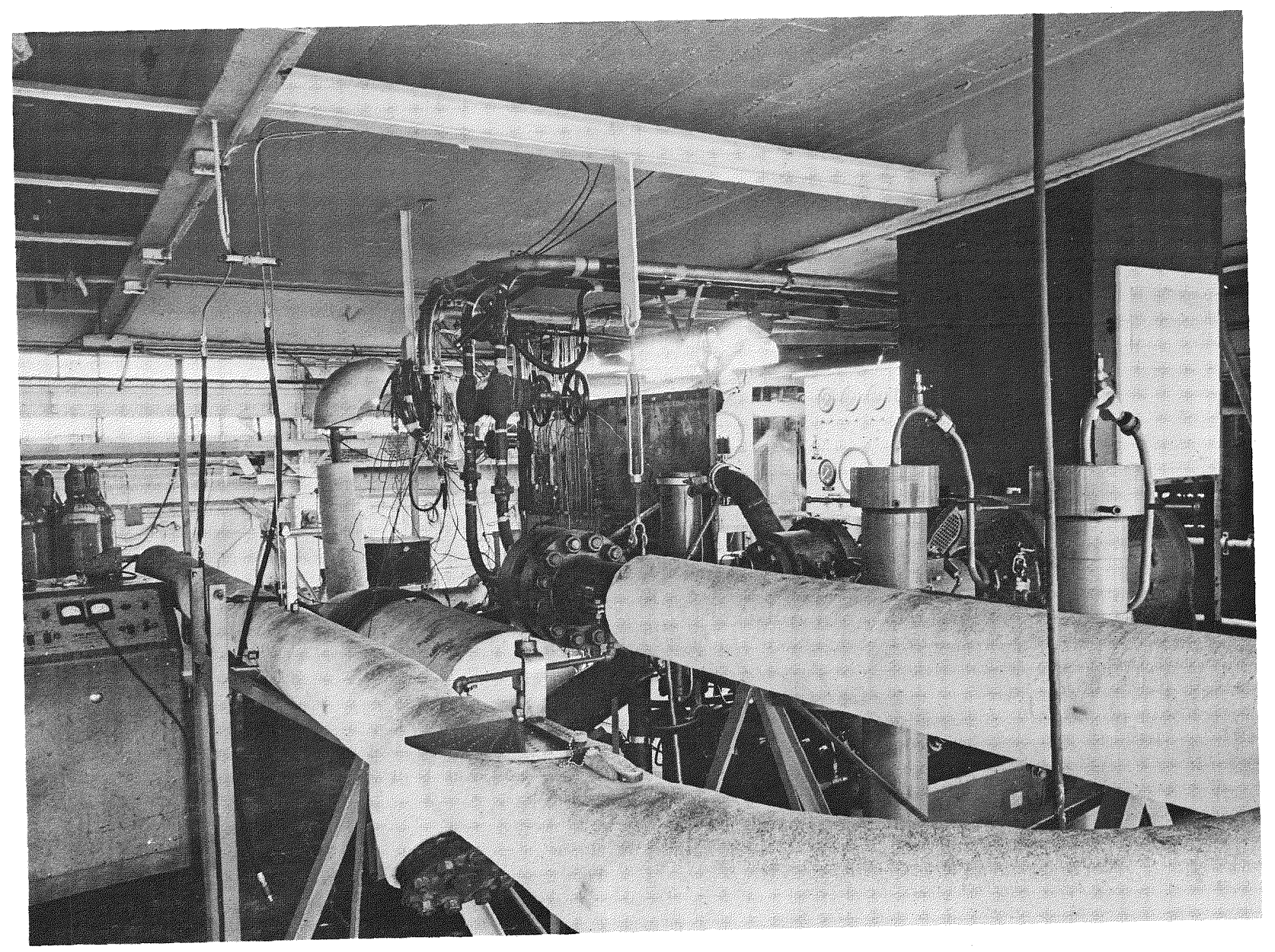

Fig. 2. 1-Helium heat-exchanger test facility 


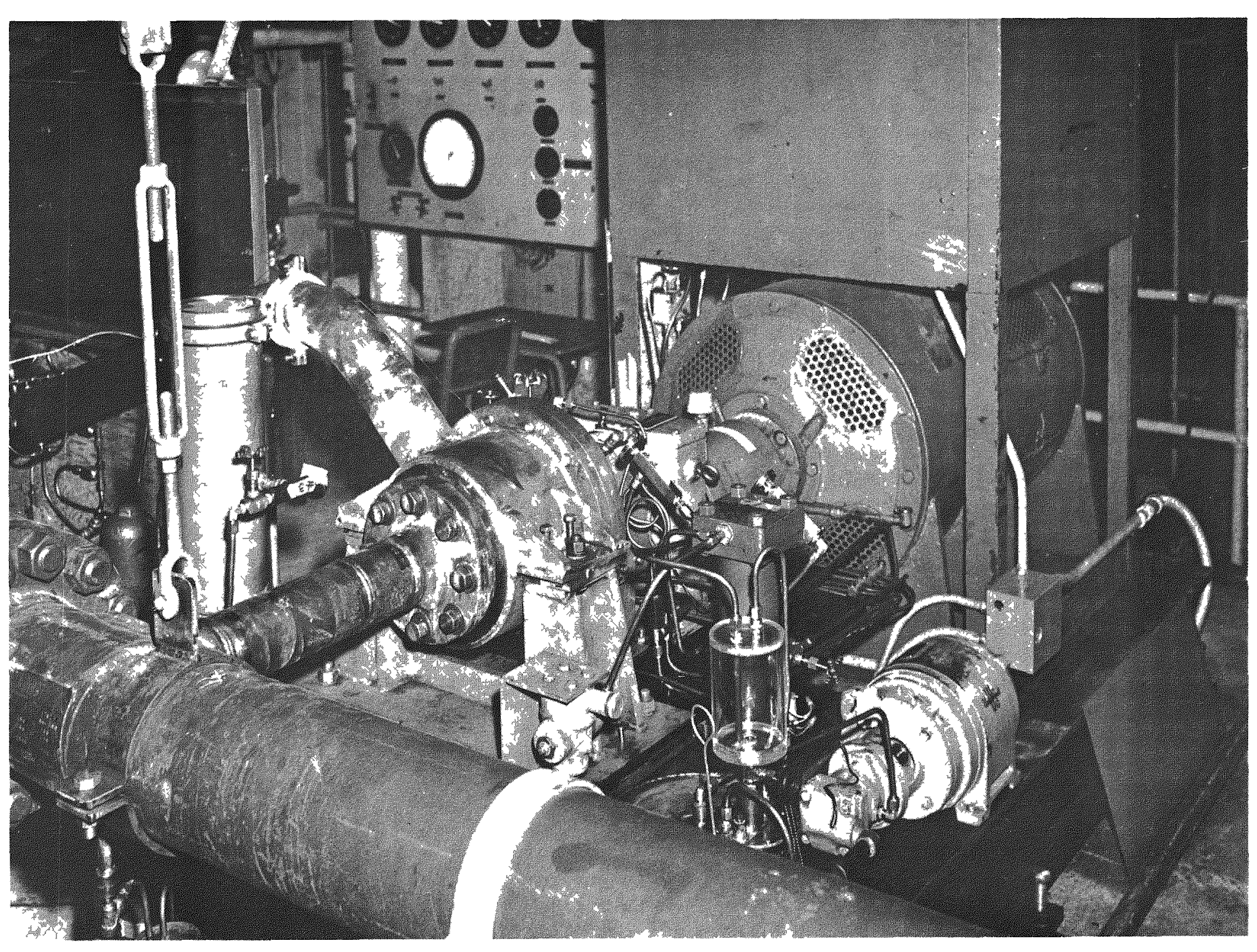

Fig. 2.2--Blower system for the helium heat-exchanger test loop 


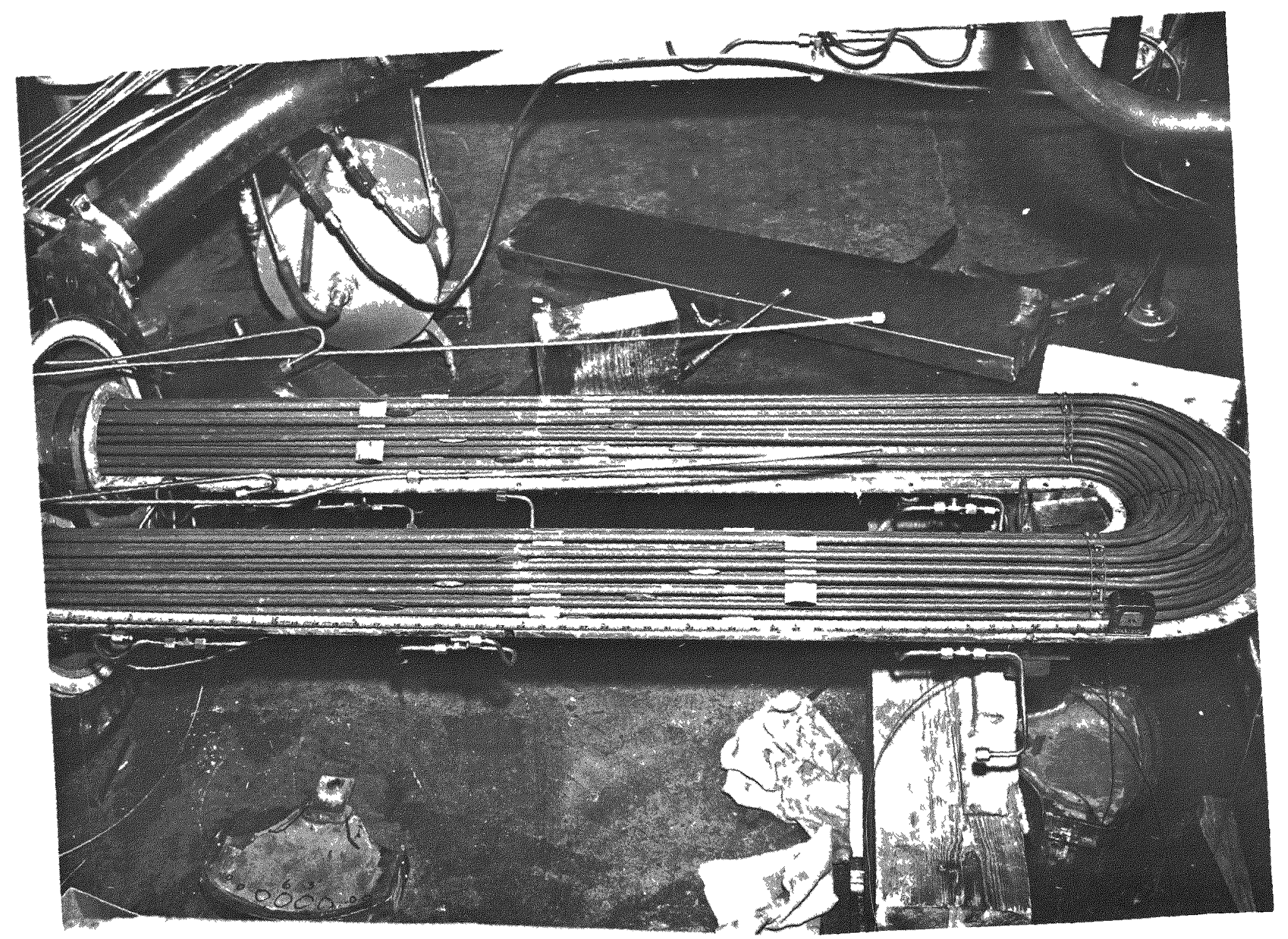

Fig. 2.3--Model heat exchanger 
"bare" bundle. The air-foil supports are designed to offer distributed support and a minimum of increase in pressure loss. These supportelements are installed in the two straight sections. Wire roda installed in the U-bend maintain the proper tube array.

Test Program

The test program consisted of four principal phases:

Phase I: Air isothermal pressure-drop tests.

Phase II: Air heat-transfer tests.

Phase III: Helium isothermal pressure-drop tests.

Phase IV: Helium heat-transfer tests.

Each phase included two series of tests, which differed only in the configuration of tube supports within the model heat exchanger. Formal testing was begun on April 13, 1959. Phase I and Phase III testing (isothermal runs) has been completed. Phase IV testing was started on June 24, 1959; hhowever, after a delay that was caused by a minor difficulty in maintaining heliumstream purity level within specified limits, testing was resumed. Phase II testing will begin at the completion of the Phase IV program. Because Phase II and Phase IV are heat-transfer tests involving tube wall temperatures up to $700^{\circ} \mathrm{F}$. the air tests (Phase II) were deferred to prevent premature tube and shroud scaling.

\section{Data Reduction and Analysis}

The reduction of data from Phase I and Phase III was facilitated by the use of Electric Boat Division's 704 digital computer. The validity of the computer results was checked periodically by comparison with handcalculated data.

Figure 2. 4 shows the shell-side friction-factor variation with Reynolds number in the inlet straight section of the tube bundle. The curves were derived from isothermal tests, with and without foil tube supports. 


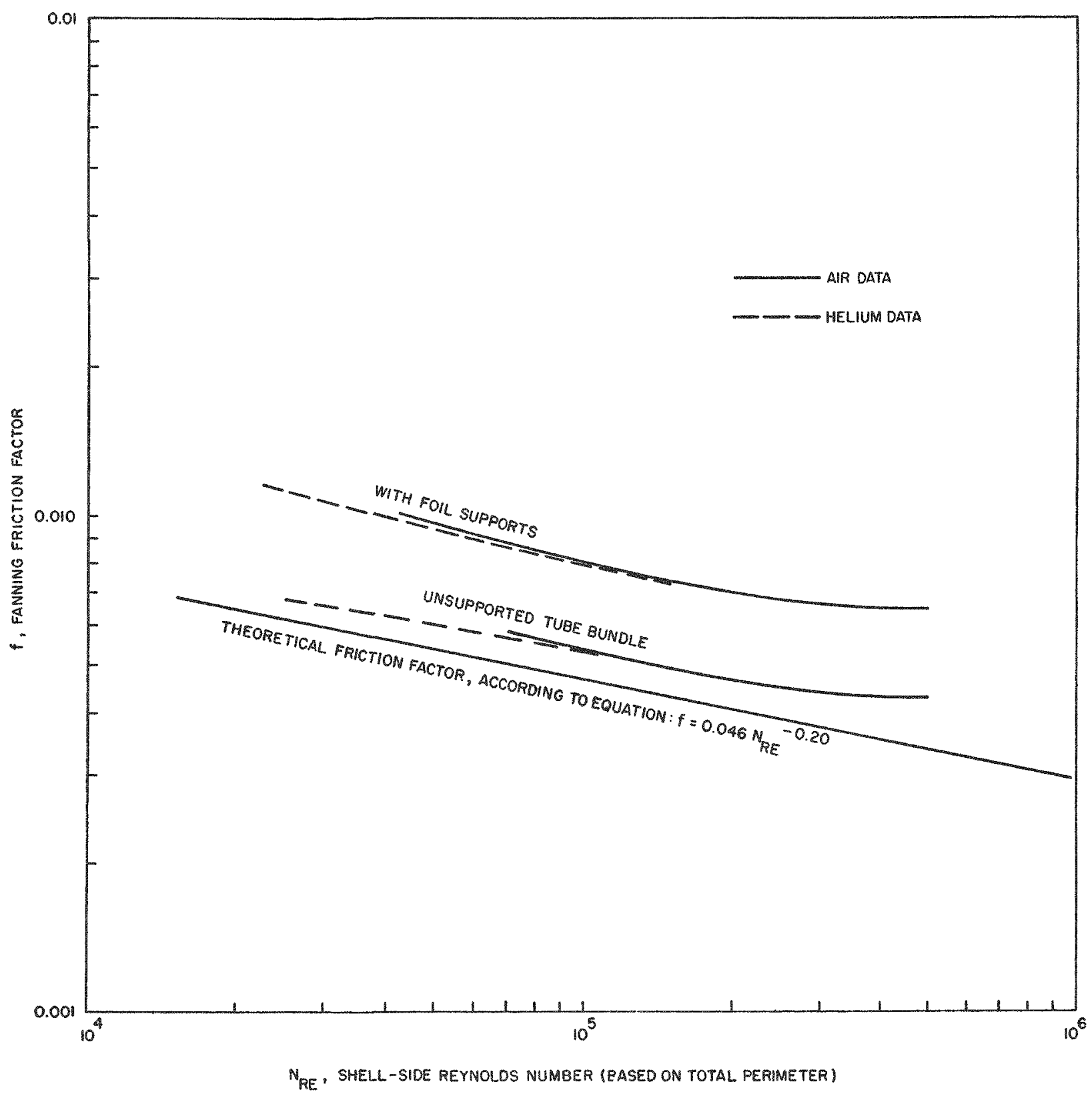

Fig. 2.4--Shell-side friction factor variation with Reynolds number (with and without tube supports) 


\section{Gas Purification}

A small bypass purification loop has been installed to remove oil vapor and water vapor. A schematic diagram of this system is shown in Fig. 2.5. The oil vapor and water vapor concentrations in the gas stream are monitored several times a day to assure satisfactory purity. Steam was admitted to the tube side of the heat exchanger to check out the steam system controls and instrumentation. During these preliminary steam tests, the water vapor concentration in the helium stream gradually increased because of a small water or steam leak. Tests were temporarily interrupted to install two alumina-charged dryers. These dryers maintain the moisture level within an acceptable limit of 1,500 ppm maximum (by weight). This limit was set to prevent the moisture from introducing more than $0.1 \%$ error in the determination of helium properties.

MECHANICAL DEVICES (A. H. Wong, W. M. Hawkes, and B. Lund)

The objectives of this work are to perform engineering design and analysis and to prepare manufacturing drawings for mechanical devices. Included are specially engineered valves, small helium valves, turbine control valves, filters, seals for stationary and rotating penetrations of the containment area, and other devices as required.

Main Coolant Stop Valve

The Crane Company, under subcontract, is conducting a survey and detailed evaluation of existing valve technology pertinent to the functronal requirements of the valve(s) for isolating the reactor from the propulsion machinery. In addition, they are conducting a design study and evaluation of various valve concepts for this application,

As of June 30, 1959, the Crane Company has presented 15 preliminary designs for review and comment:

Design 1. Single piston, parallel seat, double disc, center wedge carrier, with separate inner duct wedge carrier (concentric duct gate). 


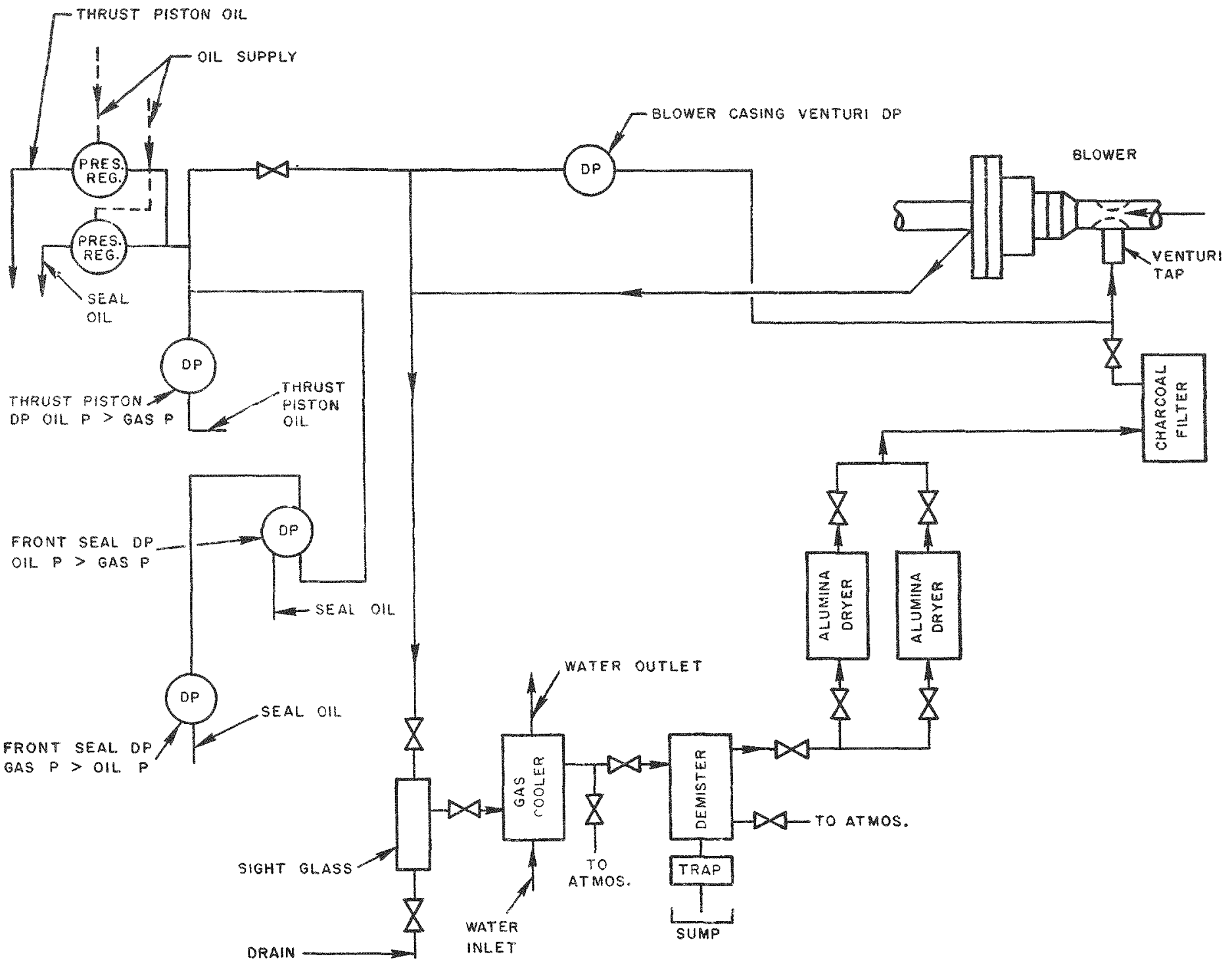

Fig. 2.5--Gas purification system 
Design 2, Single piston, parallel seat, single plate disc, external seat seal, heater bolts for seat loading (concentric duct gate).

Design 3. Triple piston, parallel seat, double disc, single center wedge carrier, with pneumatic latch mechanism to control wedging and dewedging (concentric duct gate).

Design 4. Single piston, single wedge disc, with separate inner duct carrier (concentric duct gate).

Design 5. Double opposing piston, parallel seat, double disc, with single wedge plate for each piston operator (concentric duct gate).

Design 6. Double concentric piston, parallel seat, doubie lisc, with single wedge plate for each piston operator (concentric duct gate).

Design 7. Single piston, single plate disc, pressurized flexible seats (concentric duct gate).

Design 8. Electric motor operator, packed stem, with vacuum leakoff gland (concentric duct gate).

Design 9. Ball valve, rotary vane pneumatic operator (concentric duct).

Design 10. Conical plug valve, rotary vane pneumatic operator (single hot valve).

Design 11. Angle poppet valve, single piston operator, helium-cooled seat (single hot valve).

Design 12. Gate valve, single piston operator, helium-cooled seat (single hot valve).

Design 13. Gate valve, internally insulated, single piston operator, double seat, double disc (single hot valve).

Design 14. Angle poppet valve, internally insulated, single piston operator, helium-cooled seat (single hot valve).

Design 15. Double piston, parallel seat, double disc, combined main coolant and emergency cooling stop valve (single hot gate valve). 
The Crane Company is also studying the following additional designs: (1) concentric duct conical plug valve, (2) concentric duct poppet valve, (3) hot gate valve with outer duct cooling, (4) hot angle-type poppet valve with no internal insulation, (5) Design 2 concept with a mechanical operator in lieu of heater bolts.

Figures 2.6 through 2.10 illustrate several of the valve concepts under study.

The following types of valve actuators are being investigated:

1. Cam piston pneumatic motor-AiResearch Manufacturing Division, Garrett Corporation;

2. Nutating disc pneumatic motor-AiResearch Manufacturing Division, Garrett Corporation;

3. Pneumatic piston and cylinder-Crane Company;

4. Harmonic drive valve actuator-United Shoe and Machinery Company;

5. Limitorque electric motor gear drive-Philadelphia Gear Corporation;

6. Rotary vane pneumatic motor-Crane Company.

The permissible helium leak-rate across the main coolant stop valve disc in the closed position was established as 6.0 scfh. An equivalent air leak-rate of $2.0 \mathrm{scfh}$ for test purposes was also specified. Figures 2.11 and 2.12 show the computed differential pressure build-up across the valve disc during emergency closure to isolate a system leak. The analysis indicated a maximum pressure drop of 90 psi for a 7-in.-diam rupture and a. 1 -sec valve travel.

DESIGN, DEVELOPMENT, AND TESTING OF DUCTS (H. F. Curtis, D. W. Carreau, and B. Lund)

The objective of this work is to design, develop, and test ducting to transport the main coolant between the components of the system at a maximum pressure of 800 psi and a maximum temperature of $1,300^{\circ} \mathrm{F}$. A capability for $1,000 \mathrm{hr}$ of operation at $1,500^{\circ} \mathrm{F}$ is also required.

Most of the ducting operates below $1,000^{\circ} \mathrm{F}$ and will not require special 


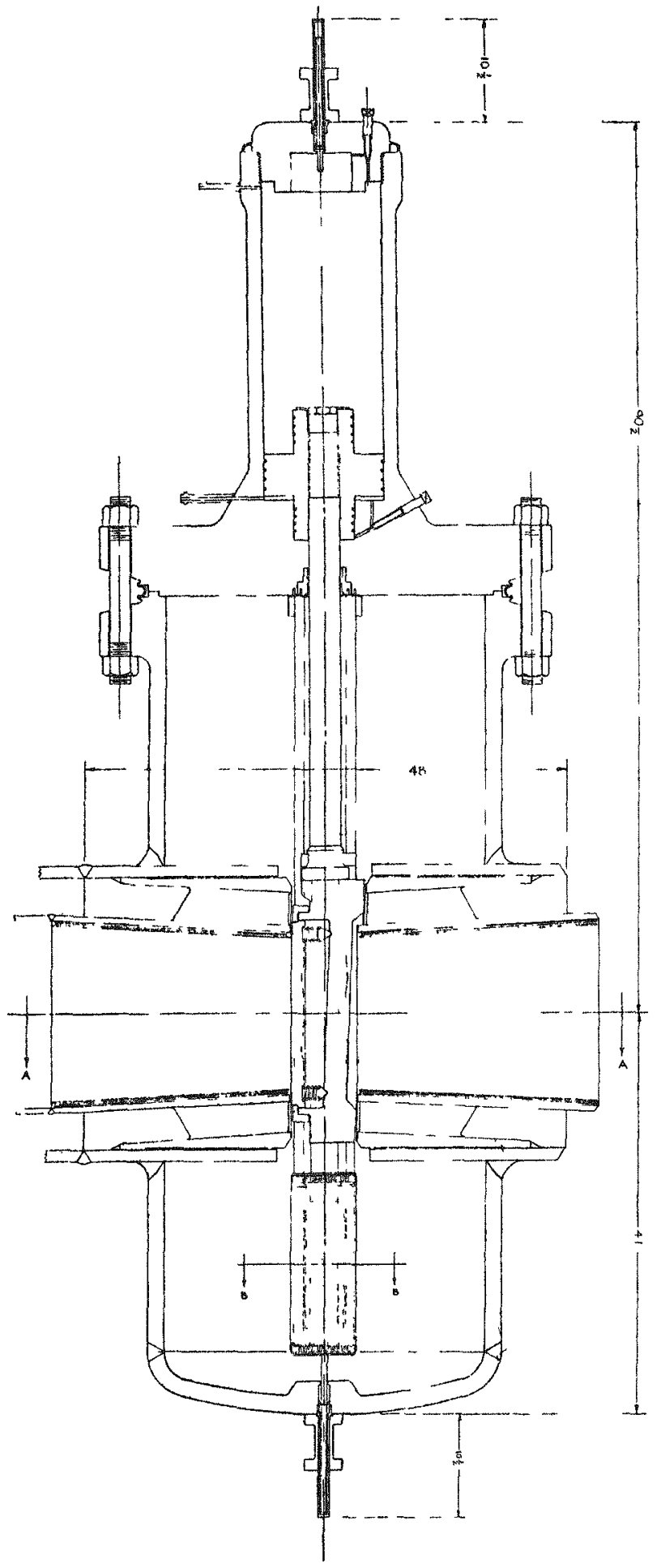

Fig. 2.6--Concentric duct gate valve 


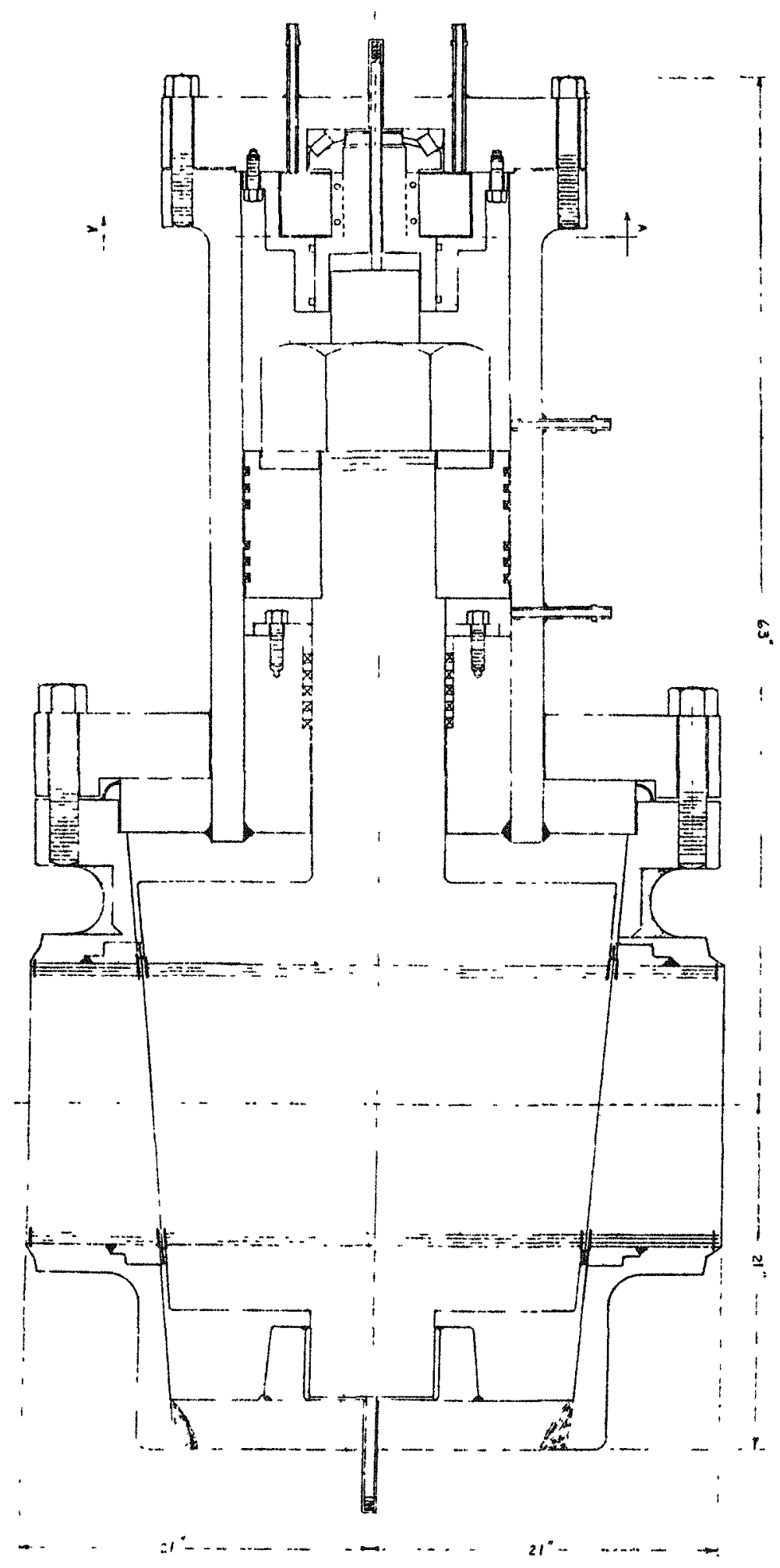

Fig. 2.7--Hot conical plug valve 


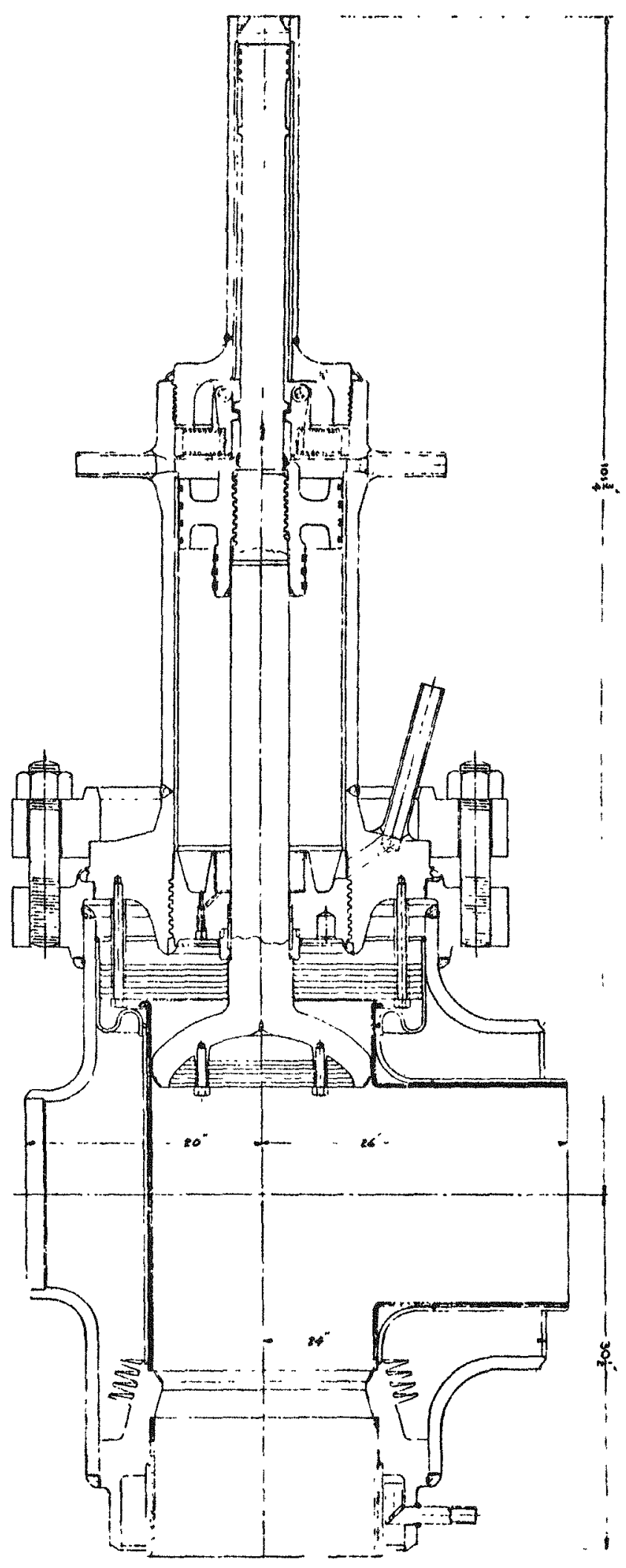

Fig. 2. 8--Hot angle-type poppet valve 


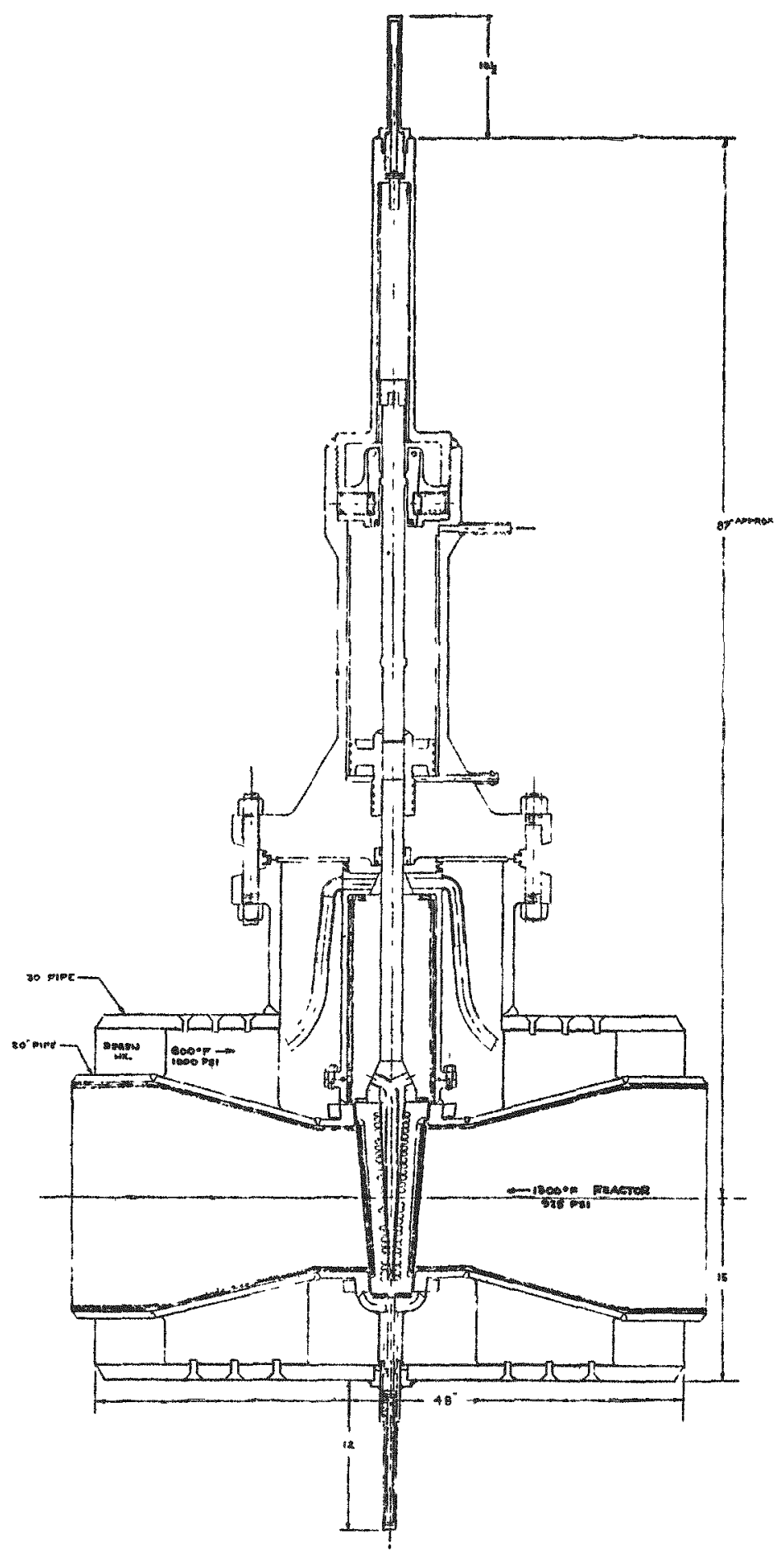

Fig. 2. 9--Hot gate valve (outer duct cooling) 


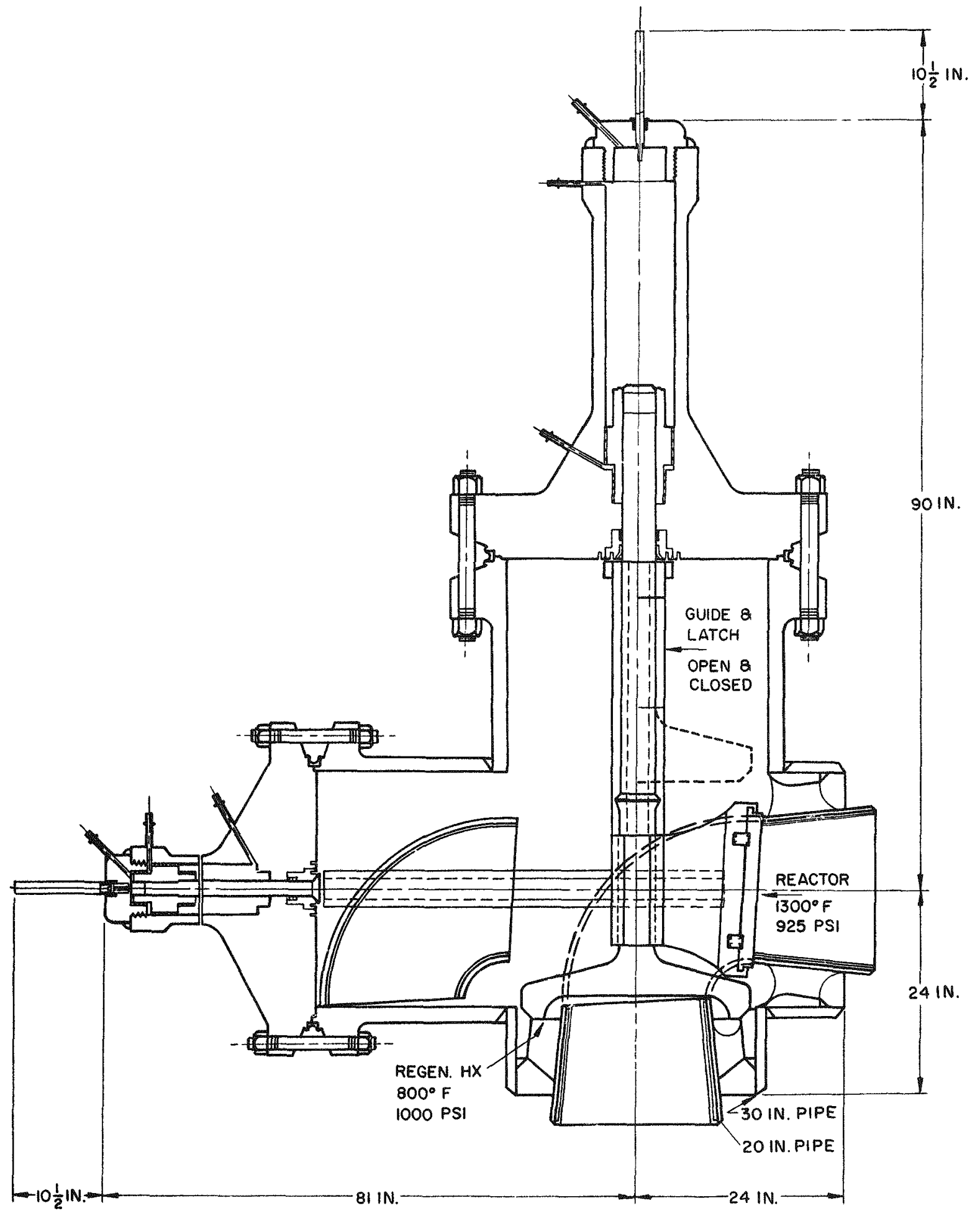

Fig. 2. 10--Concentric duct poppet valve 


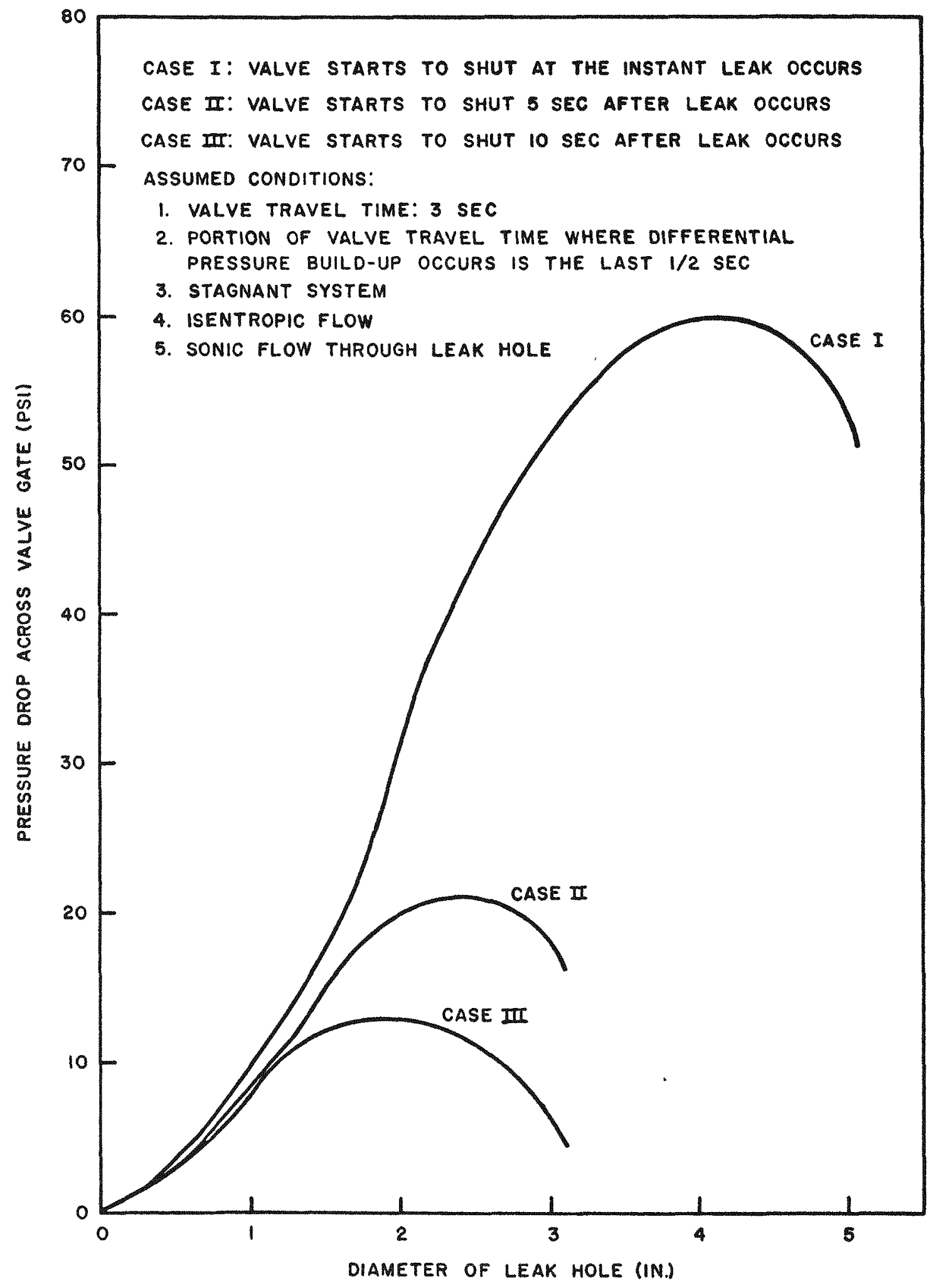

Fig. 2.11--Pressure drop across main coolant stop valve gate versus leak hole diamiter for Cases I, II, and III 


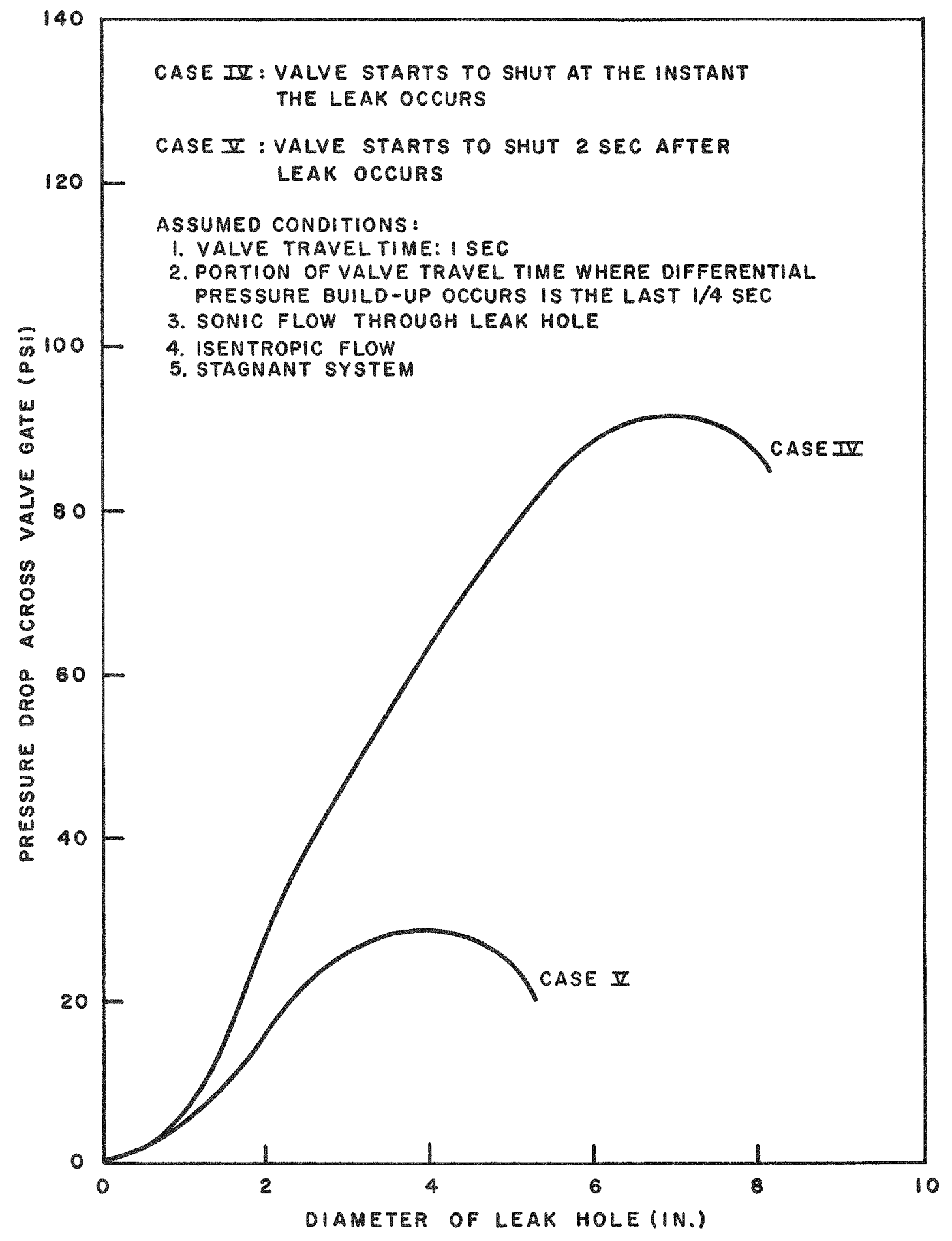

Fig. 2.12--Pressure drop across main coolant stop valve gate versus leak hole diameter for Cases IV and V 
consideration of the high-temperature creep properties of the materials, but the reactor outlet duct and the high-pressure turbine exhaust pipe will reach temperatures of $1,500^{\circ} \mathrm{F}$ and $1,210^{\circ} \mathrm{F}$, respectively. The reactor outlet and inlet flows have been combined into a concentric duct so that the high-temperature gas will pass through the inner duct while the cooler gas will flow in the annulus. The full system pressure load is thus carried only by the outer duct, operating at $800^{\circ} \mathrm{F}$, which is below the high-temperature creep range of the material. A multiple-layer metallic-foil type of heat barrier on the inner skin of the center duct provides enough insulation to permit the structural wall of the center duct to reach a temperature only a few degrees in excess of the $800^{\circ} \mathrm{F}$ gas temperature in the annulus.

The ducting will generally have welded joints, but gasketed flanges will be used where necessary to permit convenient dismantling for inspection, modification, or maintenance of the rotating machinery. All gasketed connections will carry seal welding rings which can be welded if the need arises.

$\underline{\text { Heat Barrier }}$

The heat barrier shown in Fig. 2.13 consists of 0.005 -in. -thick, dimpled, stainless steel sheet coiled to provide stagnant gas spaces. The foil is canned in Inconel $X$ shields that are attached to the inner duct.

An experiment to verify the performance of the concentric-duct heat barrier was developed in May, 1959. Heat insulation characteristics will be determined by passing helium through the inner duct and measuring the rate of heat flow and the temperature gradient through the heat barrier, while maintaining the outer wall of the inner duct at constant temperature.

Detailed drawings of the test apparatus, as shown in Fig. 2. 14, have been completed and all materials and instruments have been ordered. The assembly will be ready for installation in the helium test loop by August, 1959. Gasketed Joints

Preliminary design studies were made for flanged mechanical joints in the main coolant ducting. Minimum flange dimensions were determined 
NOTES:

1. CENTER TUBE BUNDLE (10 IN. INLET)

IS USEO TO COOL LPT BYPASS HELIUM.

2. THE LARGER TUBES SHOWN IN THE ANNULAR BUNDLE (14 IN. INLET) ARE USED TO GENERATE STEAM FOR ELECTRIC POWER GENERATION.
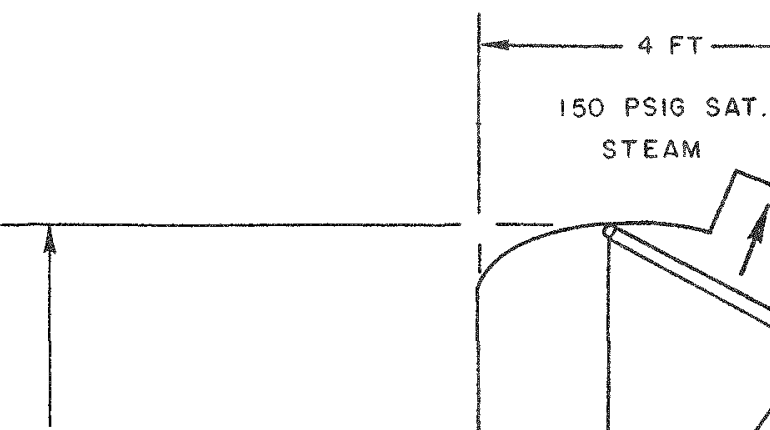

$6 \mathrm{FT}$
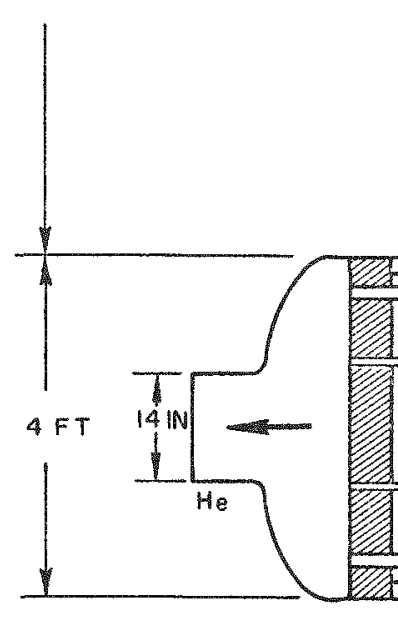<smiles>CCCCCCCCCCC</smiles>

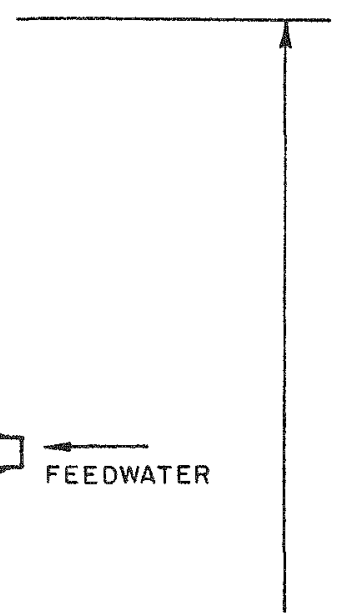

$20 \mathrm{FT}$

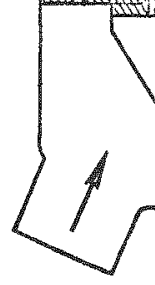

14 IN

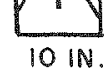

He

Fig. 2. 13--Proposed concentric duct design with heat barrier 


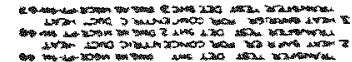 \\ or

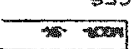

and

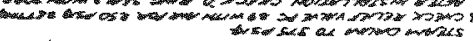

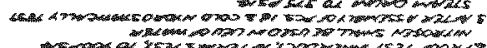

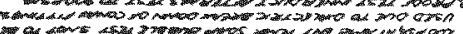
$\rightarrow 0$

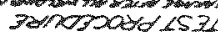

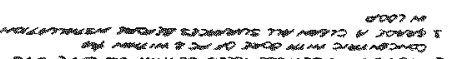

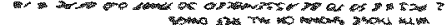

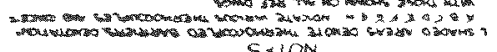

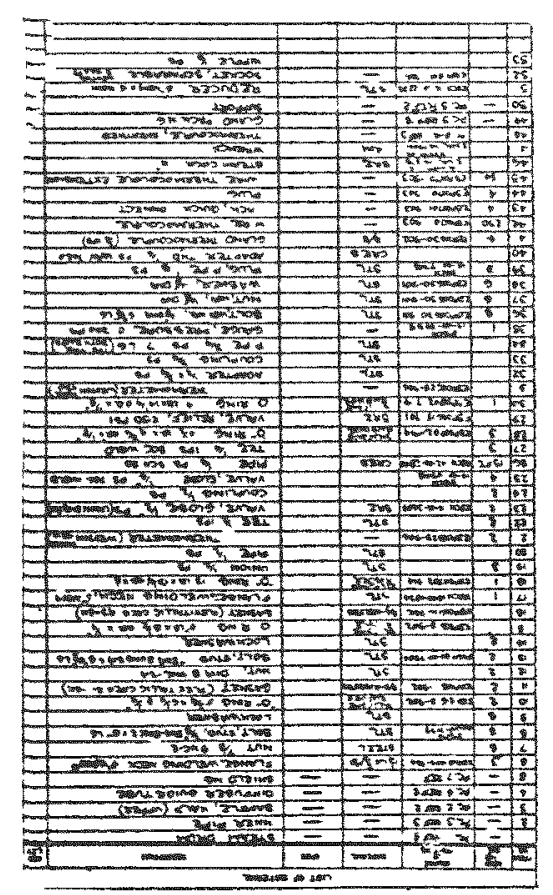

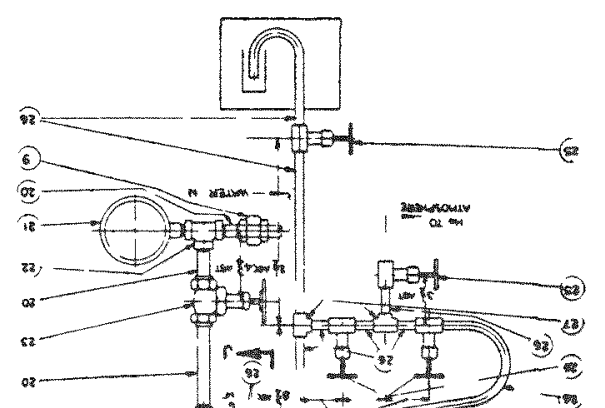

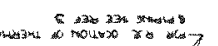
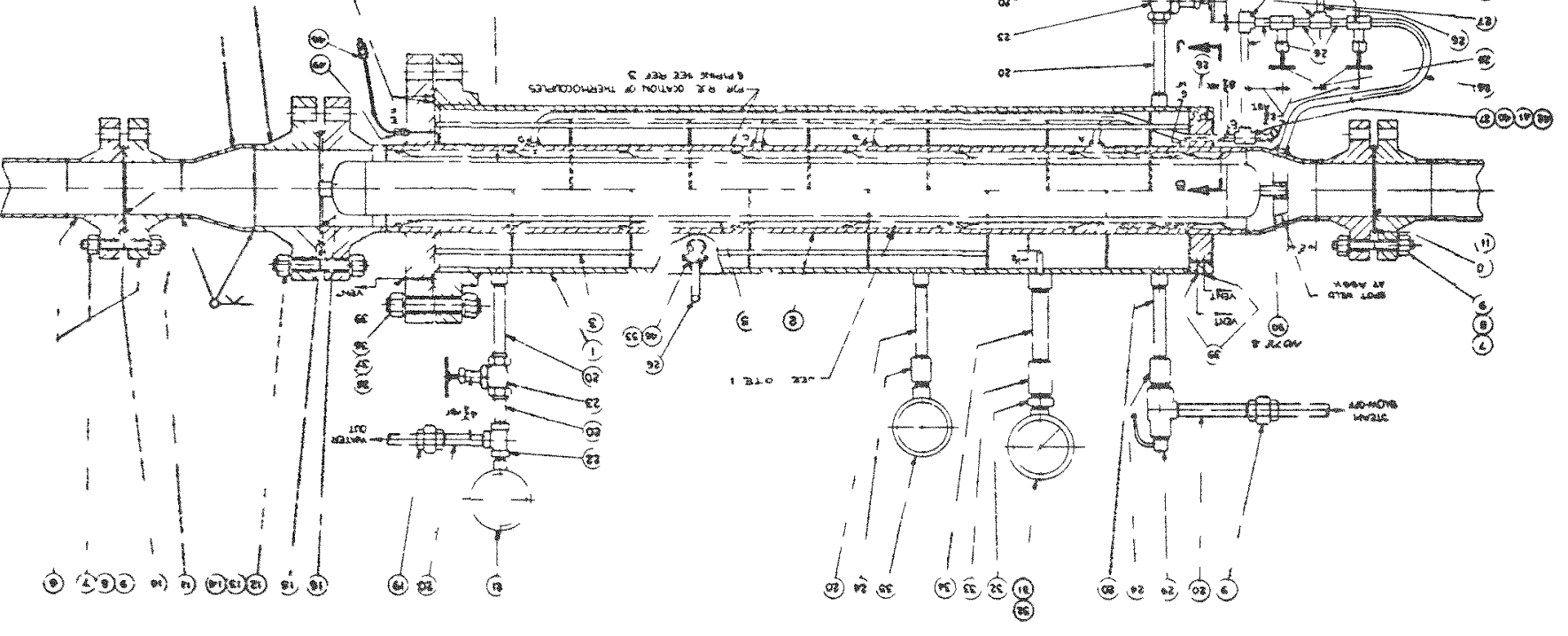

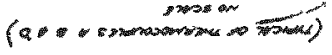

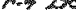

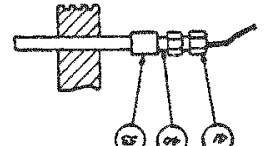

68130

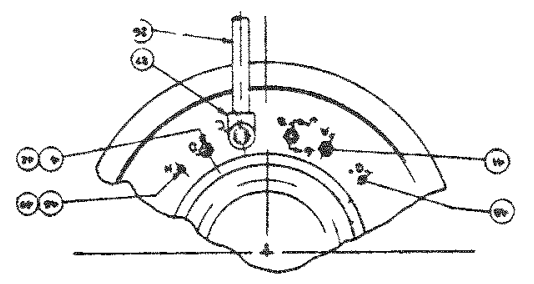


for a 28-in. IPS joint to accommodate a seal weld and, alternately, a spiral-wound, asbestos-filled metallic gasket, or a ring-type gasket.

A survey of industrial experience led to the selection of a spiralwound, asbestos-filled metallic gasket with internal gauge ring and a ringtype metallic gasket, for qualification testing.

PRELIMINARY DESIGN OF PLANT CONTROL SYSTEM (J. J. Kearns, Jr., A. C. McClure, B. S. Ryskiewich, T. M. Silks, and M. P. Wilson, Jr.)

Low-pressure Turbine Bypass System

The previous quarterly report $(G A-1030)$ indicated that it was feasible to use a single steam generator to generate steam for electric power and to act as a heat sink when the low-pressure turbine was being bypassed. This steam generator was placed between the low-pressure turbine and the regenerator in parallel with the low-pressure turbine throttle valve. In addition, consideration was given to developing the pressure drop across the steam generator by means of a jet pump, or venturi, in the low-pressure turbine exhaust line.

During the present quarter, a number of other possible steam generatorjet pump combinations were investigated. Computer programs for calculating the steady-state performance of three different bypass systems have been written:

1. A single steam generator, no venturi, acting as a heat sink and as the source of steam for electric power.

2. A single steam generator, as above, except that during non-bypass operation the pressure drop across the steam generator is developed by a jet pump in the turbine exhaust line.

3. A two-tube-bundle steam generator, one bundle to be used for the generation of steam for electrical purposes and the other bundle to be used as a heat sink. The pressure drop across the "electrical bundle" is developed by a jet pump in the exhaust line. 
It was found that bypass systems which employ a jet pump had two drawbacks:

1. Because the sustained electrical load can be as high as 1,000 kw, even at reduced plant inventory, the venturi had to be designed for this condition. When operated at normal loads and full inventory, too much pressure drop was developed across the venturi and the steam generator and the helium flow in this line had to be throttled. The venturi thus did not furnish as significant a pressure-drop advantage as had been hoped.

2. The jet pumps considered in this installation are of sufficient length to cause severe arrangement problems.

Investigations are currently being made of the feasibility of placing the steam generator, which produces electric power, in parallel with the low mressure side of the regenerator to overcome the disadvantages of the jet pump bypass systems.

Two computer programs, which may be of general interest, were written in the course of the above work: (1) a program which related iet-pump geometry to the generator performance, and (2) a program which calculates the geometry of a steam generator to meet a specific hea" load.

A steady-state analysis has been performed which indicates that the plant may be operated at constant compressor shaft speed over most of its operating range. This leads to the possibility of placing the electric generator on the compressor shaft without using a variable speed drive and requiring the low-pressure turbine bypass steam generator to act only as a heat sink. Such a system would be simpler than those thus far studied.

\section{System Transient Studies}

Revision of the system transient equations has been in process during the entire quarter. Equations to account for bleed flows have been added, as well as accumulator equations, equations for the reactor outlet-temperature control system, and reactor power-level control systems. The Stodola Ellipse equations, previously used to describe the behavior of the turbines, have been 
replaced with turbine maps. An approximate differential equation relating fuel temperature to reactor power and flow rate was added and the total system volume, which was formerly collected into four volumes, has been divided into seven volumes. Equations of the control system for constant compressor-speed operation have been added. Programming and eliminating flaws in the revised equations is almost complete.

HEAT-EXCHANGER ANALYSIS AND PRELIMINARY DESIGN (J. H. Pilliod, J.W. Justusson, and B. Lund)

The objective of this work is to prepare helium heat-exchanger designs for the bypass steam generator, regenerator, precooler, and intercooler. Work began in April, 1959, with the compilation of heat-exchanger performance data.

Preliminary specifications for the precooler and intercooler were prepared in May for review. Design of the bypass steam generator was started in May with the compilation of performance data. Alternative steam generator designs were developed and one is shown in Fig. 2.15.

FLUID-MECHANICAL SYSTEMS (J.H. Pilliod, M. R. Fishkind, and B. Lund)

The objective of this work is to design and develop the prototype power plant fluid-mechanical systems and the equipment comprising the se systems. The scope of engineering work includes (a) preparation of system specifications and detailed engineering diagrams, and (b) identification of the areas of system design which may require experimental verification or special analysis.

Main Coolant System

Preliminary system engineering included the following:

1. Detailed investigation of the pressure and temperature ratings for the system and a tentative selection of the material and stress codes. 


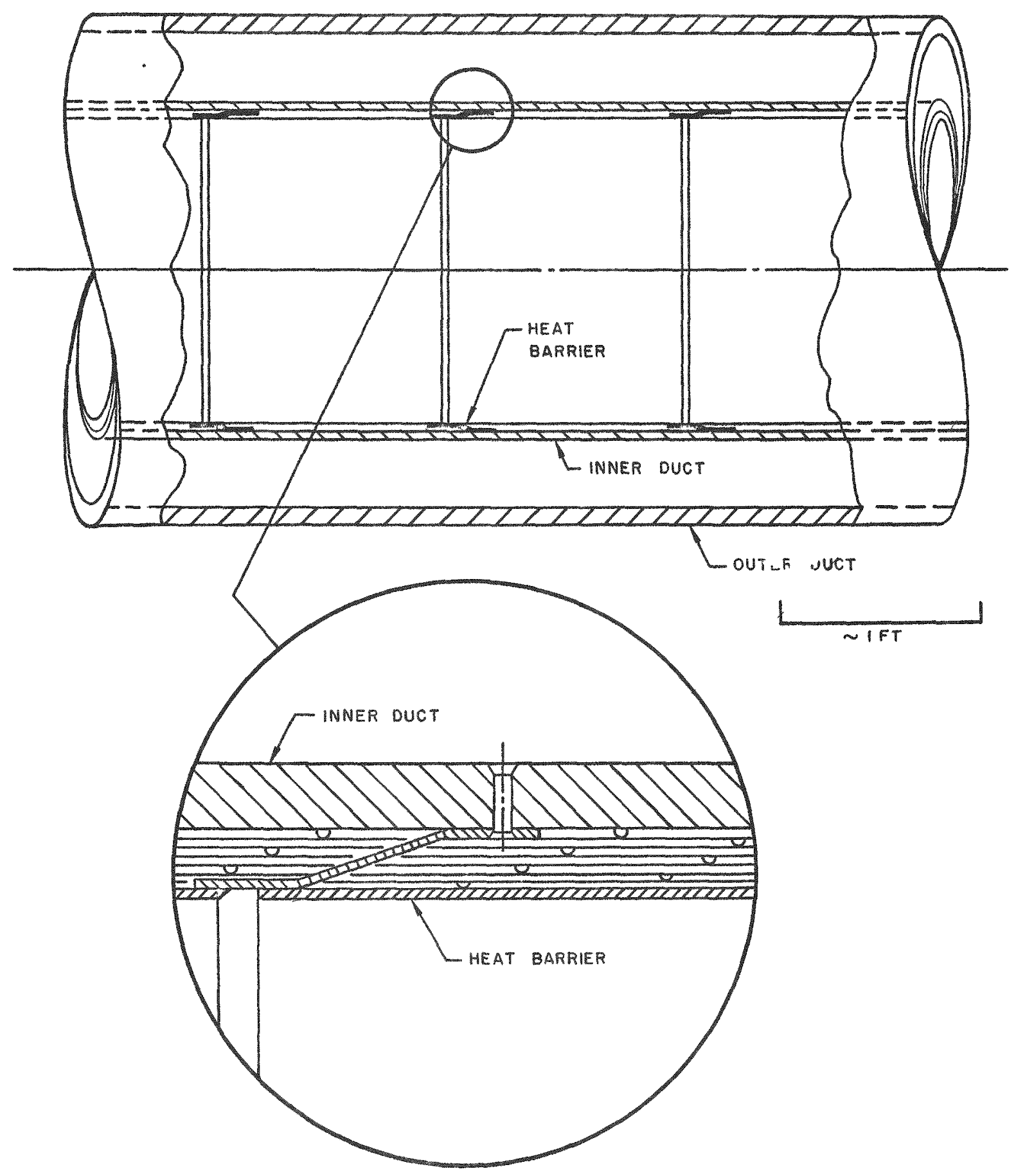

Fig. 2.15--Proposed bypass steam generator 
This work proposes allowable fiber stresses for $1-1 / 4 \mathrm{Cr}-1 / 2 \mathrm{Mo}$ steel. These stresses are shown graphically in Fig. 2.16. Based on these curves, piping thickness for $800^{\circ} \mathrm{F}$ to $1,000^{\circ} \mathrm{F}$ helium service would be greater than that required by other codes.

2. During May and June, the exhaust venturimethod and the regenerator bypass method were studied in order to determine the most efficient system for supplying heat to the bypass steam generator. There appears to be a definite improvement in basic cycle efficiency when the bypass steam generator is connected in parallel with the shell side of the regenerator. This improvement is approximately $0.25 \%$ and is caused by a decrease in the size of the precooler.

\section{Coolant Charging and Storage System}

Preliminary material selection for equipment, such as piping, valves, fittings, and storage flasks, including investigation of corrosion-resistant materials for fabrication of the flasks (parts in contact with helium), were made. Preliminary helium storage capacity requirements for the power plant under normal operating conditions were established (see Table 2. 1).

Table 2.1

TENTATIVE POWER -PLANT COOLANT (HELIUM)

STORAGE CAPACITY REQUIREMENTS

\begin{tabular}{|c|c|c|}
\hline & $\begin{array}{l}\text { Weight } \\
\text { (1b) } \\
\end{array}$ & $\begin{array}{c}\text { Volume } \\
\left(\mathrm{ft}^{3} \text { at } 3,500 \text { psig) }\right. \\
\end{array}$ \\
\hline $\begin{array}{l}\text { Initial main coolant } \\
\text { system charge } \ldots . .\end{array}$ & 262 & 120 \\
\hline $\begin{array}{l}\text { Two spare charges... } \\
\text { Main coolant system }\end{array}$ & 524 & 240 \\
\hline $\begin{array}{l}\text { purging } \ldots . . . . \\
\text { Total power plant } \\
\text { coolant helium }\end{array}$ & 41 & 19 \\
\hline $\begin{array}{c}\text { leakage }(90 \text { days }) \ldots \\
\text { Total .......... }\end{array}$ & - $\frac{112}{939}$ & $\frac{50}{429}$ \\
\hline
\end{tabular}




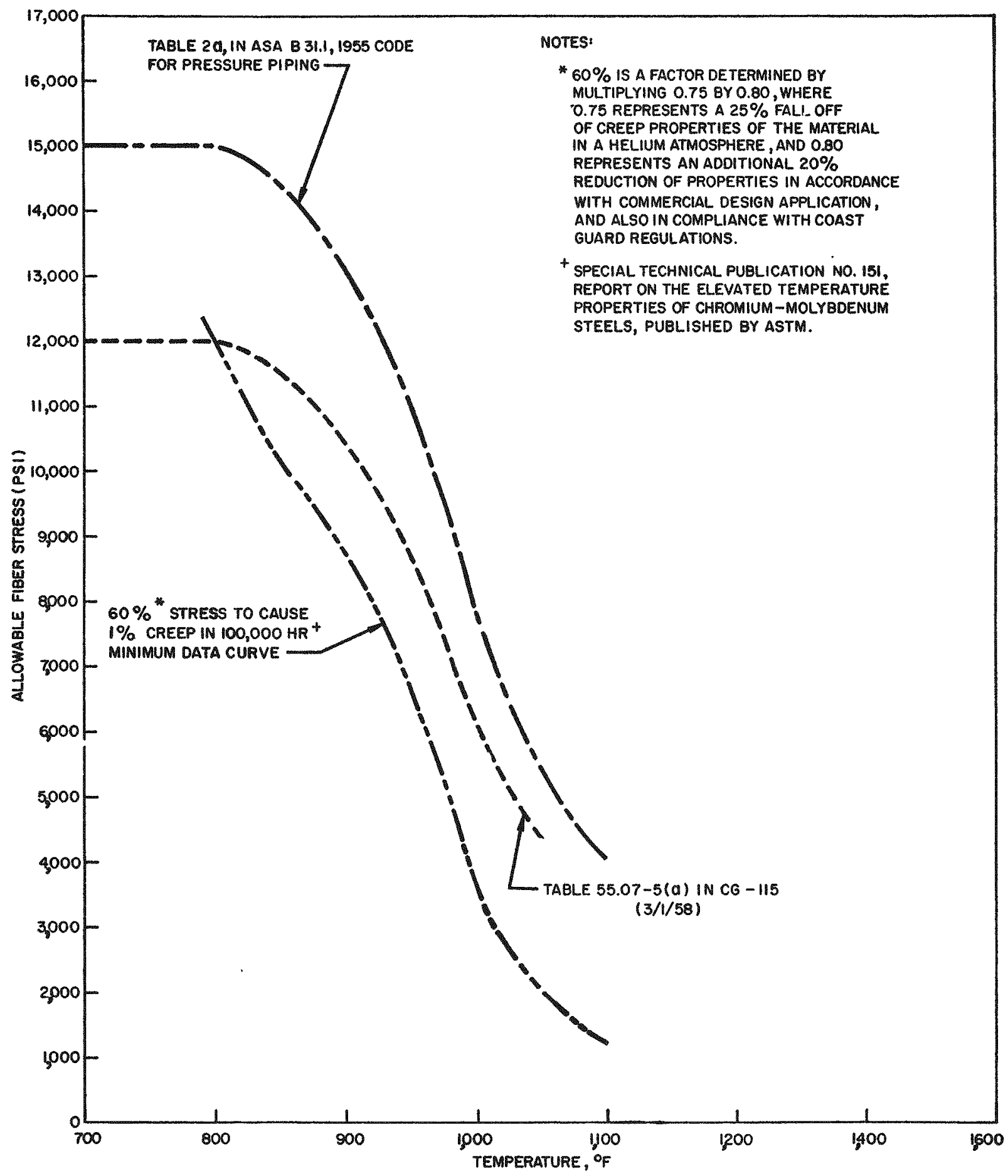

Fig. 2. 16--Comparison of allowable fiber stresses versus temperature 
EMERGENCY COOLING SYSTEM (B. Lund and W. I. Thompson)

System design criteria are being developed by General Atomic for emergency cooling. The Electric Boat Division has studied the design of an emergency cooling system at $3 \%$ of full power and flow. A typical steam generator was designed to meet this rating, and system performance curves were prepared. A rough approximation of the reactor outlet temperature for this case is shown in Fig. 2.17. The reactor decay heat was calculated on the basis of $600 \mathrm{hr}$ at full power prior to shutdown. With these conditions assumed, the reactor outlet cool-down rate may exceed $475^{\circ} \mathrm{F}$ during the first hour after shutdown. As this rate may be excessive, further efforts will proceed on the basis of a system rated at $1 \%$ of full power.

COOLANT PURIEICATION AND ANALYSIS (W. I. Thompson, W. V. Datkiw, and $B$. Lund)

An important function of a gas-purification system is to restrict the transport of graphite from the core by the reversible reaction $2 \mathrm{CO}=\mathrm{CO}_{2}+\mathrm{C}$. For example, a cyclic change in $\mathrm{CO}_{2}$ content of $0.01 \mathrm{ppm}$ would result in graphite transport of about $50 \mathrm{lb} / \mathrm{yr}^{\text {. A A }}$ gas containing $2 \mathrm{ppm}$ of $\mathrm{CO}$ and coming to equilibrium with graphite cyclically at $1,300^{\circ} \mathrm{F}$ and $1,000^{\circ} \mathrm{F}$ would experience a shift in $\mathrm{CO}_{2}$ content of about $0.01 \mathrm{ppm}$. Because very minute cycle changes in $\mathrm{CO}_{2}$ concentrations will result in substantial graphite transport, it is important to determine the appropriate reaction rates as a basis for establishing tolerance levels for oxygen impurity.

Since the required steady-state limit will probably be as low as a few parts per million of oxidizing impurities, and the concentration reached during initial outgassing of the equipment may be as high as 1,500 ppm, the equipment specification may be based primarily on the initial clean-up requirements. Although experimental work is continuing to establish steadystate impurity tolerances, the prototype purification equipment will be sized for the initial clean up. 


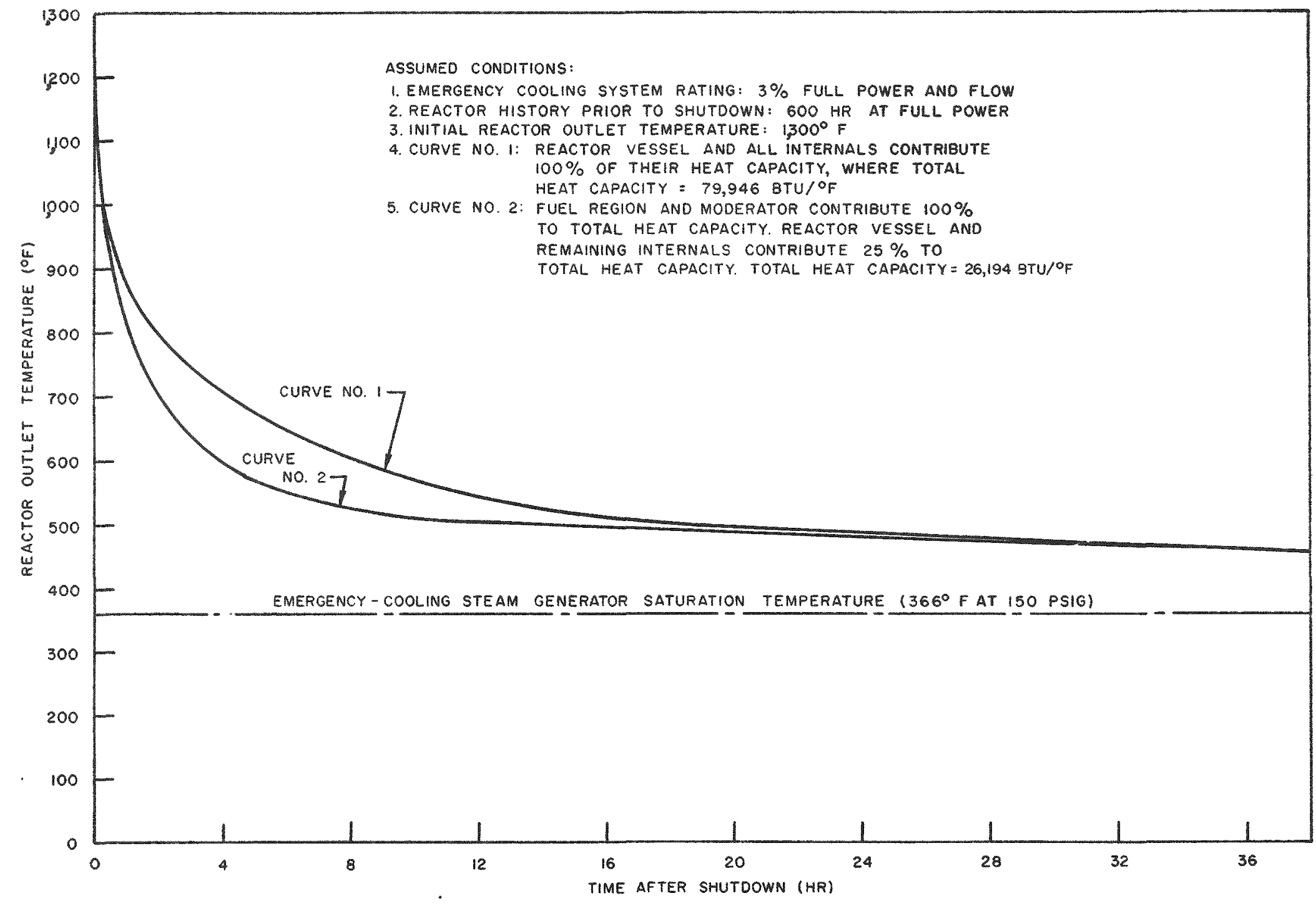

Fig. 2.17--Reactor outlet temperature versus time after shutdown 
The equipment will process continuously a small stream from the main 10op. Because Bureau of Mines helium (purity about $20 \mathrm{ppm}$ ) will be used for make-up, there will be no need for a separate purification system for the feed.

In order to set a quantitative limit on steady-state helium impurities, further experiments will be necessary. The critical reaction involved in graphite transport is $2 \mathrm{CO} \rightarrow \mathrm{C}+\mathrm{CO}_{2}$, which may occur either in the region from the reactor outlet to the high-pressure turbine outlet, or in the cooler parts of the reactor core. It is proposed to explore this reaction rate by low-pressure once-throughexperiments in which carbon monoxide is passed over various materials at different temperatures and the deposit of carbon determined by gas material balances and by weighing the exposed samples. Temperature and partial pressures of carbon monoxide will be varied to determine a relationship from which carbon transport can be estimated. This series of experiments will be done out-of-pile, although some in-pile experiments may be carried out later. The objective of this program is to raise, if possible, the allowable steady-state level of oxidizing impurities above the tentative present limit of about 1 ppm of $C O$.

Other sources of contamination of the reactor coolant may be expected from the following sources: oil from machinery seals, scale from loop walls, erosion particulates, radioactive and nonradioactive reactor fuel-element decomposition products, impurities initially present in the loop (outgassing), and impurities in the initially charged helium. The various methods of purifying helium were studied and a proposal was prepared for the construction of a purification pilot plant.

Preliminary work included obtaining information on purification equipment from manufacturers of low-temperature molecular-sieve adsorbent beds, low-temperature activated charcoal adsorbent beds, high-temperature gettering equipment, and diffusion purification equipment. Low-temperature adsorption was selected as the preferred method. Reasons for selecting the low-temperature adsorption system include the following: 
1. This method is used by the Bureau of Mines to produce helium on a commercial scale. In this process, the impurity level is reduced from 4,000 to 5,000 ppm to about $20 \mathrm{ppm}$ when helium is passed through activated carbon at $-320^{\circ} \mathrm{F}$. Average values obtained on a routine basis at the Exell Plant are

$\begin{array}{ll}\mathrm{Ne} & 13.9 \mathrm{ppm} \\ \mathrm{H}_{2} \mathrm{O} & 1 \text { to } 10 \mathrm{ppm} \\ \mathrm{N}_{2} \text { (and CO) } & 2.2 \mathrm{ppm} \\ \mathrm{CO}_{2} & 0.6 \mathrm{ppm} \\ \mathrm{O}_{2} & 0.3 \mathrm{ppm} \\ \mathrm{H}_{2} & 0.1 \mathrm{ppm} \\ \mathrm{A} & 0.1 \mathrm{ppm}\end{array}$

2. The process is capable of removing a large number of impurities; theoretically, all contaminants will be removed to some extent.

3. The process is relatively "safe" in that it is capable of removing unexpected impurities; furthermore, it is known to be workable on a commercial scale.

4. Both molecular sieves and activated carbon can be regenerated, so storage of chemicals for purification is not required.

5. Liquid-nitrogen generators, or recondensers, are readily available from several sources. Similar equipment has passed all Navy requirements and is used aboard a number of capital ships.

Two reasons for not using one of the other purification methods are

(1) High-temperature getters will not remove chemically inert gases (such as argon, krypton, and xenon) and are not regenerative; hydrogen would not be removed unless a special unit were provided for this purpose.

(2) Diffusion purification is still in the laboratory developmental stage. A preliminary engineering diagram (Fig. 2.18) for a low-temperature adsorption pilot plant, employing a helium flow of $20 \mathrm{scfm}$ lone-twentieth of expected prototype plant size) was prepared.

Engineering progress on the pilot plant, prior to de-activation, is 


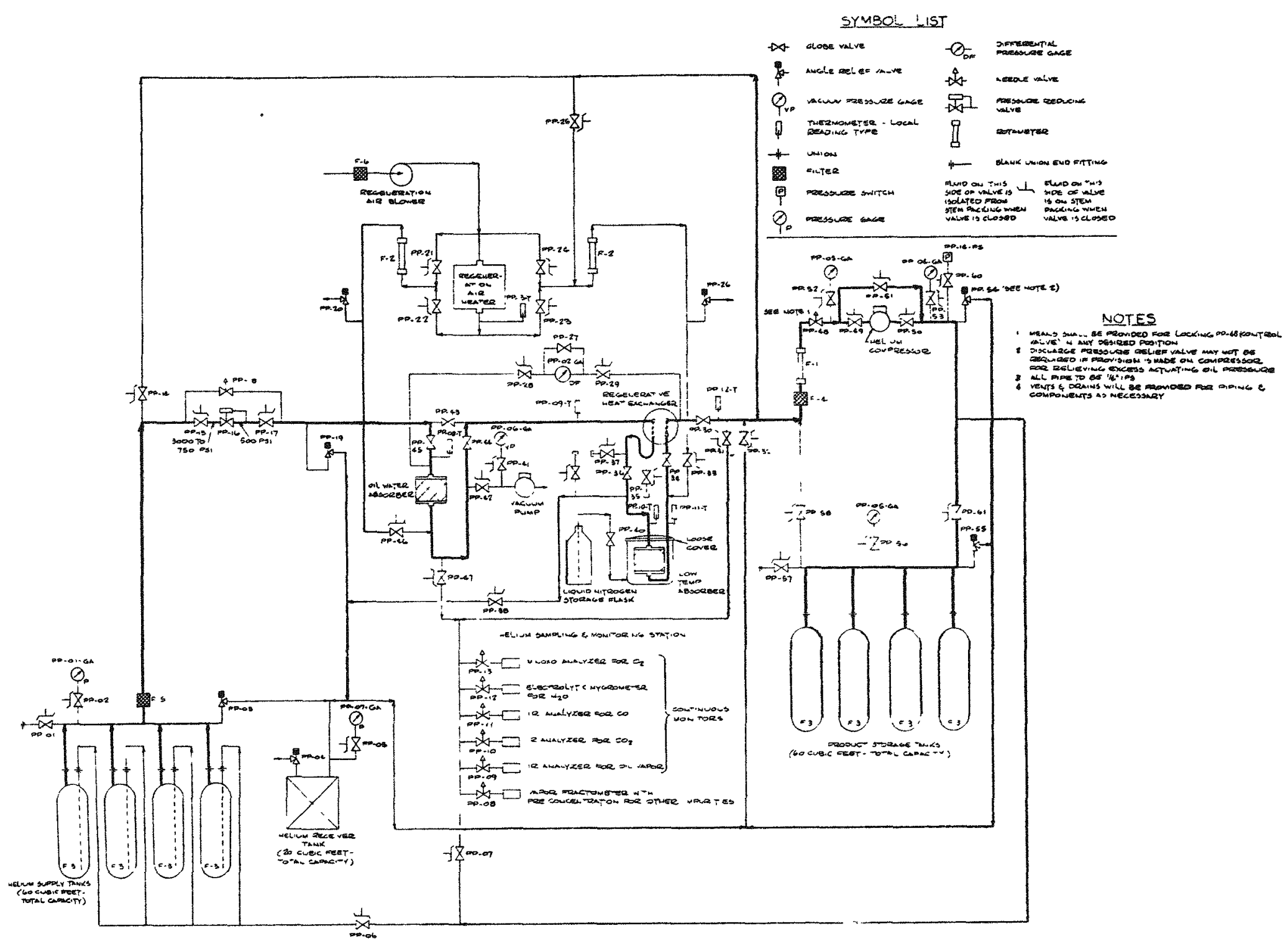

Fig. 2. 18--Proposed helium purification pilot plant 
summarized in Fig. 2.18. The pilot plant would provide design data for the prototype purification units. Areas in which information is needed, or must be established, include the following:

1. The removal efficiency of gases, such as hydrogen, xenon, krypton, and argon.

2. A method for handling frozen solids, such as carbon dioxide.

3. The effect of a mixture of impurities on system operation. Approximately 14 different impurities are anticipated. (Isotherm adsorption data is either incomplete or nonexistent for about half of these impurities.)

4. The design parameters, such as contact time, cycle time, and pressure, of a dynamic, continuous-flow system.

5. The relative efficiency of activated carbon and molecular sieves.

\section{DEVELOPMENT OF PROPULSION-PLANT ELECTRICAL SYSTEMS}

The objectives of the work in this area are (1) to prepare schematic diagrams and system specifications for the propulsion-plant electrical system, (2) to prepare system descriptions, and (3) to identify areas of system design or component construction that may require experimental verification or special analysis.

During the later part of the present reporting period, the concept of an ac power distribution system, closely resembling a shipboard installation, was modified to one aimed at fulfilling the requirements of the prototype only. Work prior to de-emphasis of the ship concept included the preparation of an ac power distribution diagram and a load analysis, both for a shipboard plant. These will be reserved for possible future use. Diagramming of the ac power distribution system for the prototype power plant and site is expected to be completed by October, 1959.

A revised load analysis has been completed, which applies only to the prototype and includes both power plant and site loads. The loads and plant conditions reflect the latest plant philosophy. 
DESIGN STUDIES FOR POWER-PLANT ARRANGEMENT AND

STRUCTURE (I. H. Kabler and A. C. MCClure)

The purpose of the arrangement work is to obtain a proper balance between power plant accessibility, component stresses, shield economy, system pressure drop, compartment size, and power plant weight.

The present MGCR main machinery compartment arrangement has been analyzed from the point of view of pipe stress and pressure drop. The pipe stress analysis of the main coolant system has been completed. Based on Marine Engineering Regulations and Material Specifications, CG-115 (March 1, 1958), all main coolant piping, with the exception of the low-pressure turbine bypass line and the bypass boiler inlet and outlet lines, have acceptable stress values.

The configuration of these lines is dependent on the low-pressure turbine bypass system design and therefore is subject to redesign following the final decision on the low-pressure turbine bypass.

Turbomachinery nozzle reactions and movements have been studied to determine the existing forces, moments, deflections, and rotations imposed on the machinery casings. The low-pressure turbine (power turbine/ has exceptionally high moments acting on it. The lines and anchors in this area have been redesigned to relieve the reactions and reduce the high nozzle moments.

A pressure-drop analysis has been completed for the entire main coolant system. This includes not only pipeline losses, but also all inlet and outlet velocity head losses, heat exchanger losses, and rotating machinery head losses. The results show a slightly higher calculated total fraction pressure drop than has been estimated for the MGCR preliminary design heat balance. Adjustments have been made by increasing some of the main coolant pipe sizes. The main coolant piping is summarized in Table 2. 2 . 
Table 2.2

SIZE AND WALL THICKNESS OF MAIN COOLANT PIPING

\begin{tabular}{|c|c|c|c|}
\hline & $\begin{array}{c}\text { Nominal } \\
\text { Size } \\
(\text { in. })\end{array}$ & $\begin{array}{l}\text { Wall Thickness } \\
\text { (in.) }\end{array}$ & Comments \\
\hline $\begin{array}{l}\text { Low-pressure turbine, } \\
\text { regenerator shell }\end{array}$ & 28 & 1.261 & Nonstandard \\
\hline $\begin{array}{l}\text { Regenerator shell, precooler } \\
\text { Precooler, low-pressure }\end{array}$ & 22 & 0.625 & \\
\hline compressor & 20 & 0.593 & \\
\hline $\begin{array}{l}\text { Low-pressure compressor, } \\
\text { intercooler }\end{array}$ & 18 & 0.719 & \\
\hline $\begin{array}{l}\text { Intercooler, high-pressure } \\
\text { compressor }\end{array}$ & 18 & 0.719 & \\
\hline $\begin{array}{l}\text { High-pressure compressor, } \\
\text { regenerator tube }\end{array}$ & 14 & 0.750 & Two in parallel \\
\hline Regenerator tube, outer duct & 16 & 0.843 & Two in parallel \\
\hline Outer duct of concentric duct & 30 & 1.493 & Nonstandard \\
\hline Inner duct of concentric duct & 20 & 0.500 & $\begin{array}{l}\text { Less thermal } \\
\text { barrier }\end{array}$ \\
\hline Low-pressure turbine bypass & 10 & 1.125 & \\
\hline
\end{tabular}

SHIELDING STUDIES (R. Gulino and A. C. McClure)

This work is concerned with the design of primary and secondary shielding for the prototype plant. It is anticipated that the shielding will incorporate means for testing several primary shield configurations.

The specific activity of the primary coolant under abnormal conditions is currently being calculated for the case of fuel-pin failures. Current assumptions are that $0.1 \%$ of the fuel pins in the core will rupture simultaneously and that fission products with boiling points below $1,500^{\circ} \mathrm{F}$ will be released into the coolant stream instantaneously.

Coolant activity along the primary coolant lines will depend on the degree and manner of fission-product plating out. Coolant activity will be calculated for each of the following cases:

1. No plating out of fission products. 
2. Plating out occurs instantly and completely when the temperature of the duct or component is below the boiling point of the nuclide.

3. All fission products with boiling points below the temperature of the first flow path disturbance (elbow, valve, turbine, etc.) plate out at the point of disturbance.

The operating histories to be used for the studies are 1,500 hr, $300 \mathrm{hr}$, and $50 \mathrm{hr}$ at full power.

The IBM Type 704 gamma-shielding program for 6-Mev gamma sources has been modified so that the dose rate due to fission-product gamma sources may be computed. The modified program is now being checked for possible errors. Work has begun on the preparation of computer codes for designing primary shields. There will be separate codes for neutron and gamma attenuation. Many neutron computer codes are available; those currently being prepared for use include:

1. WANDA, a few-group multiregion diffusion equation program.

2. SIMPL, a multigroup multiregion transport equation program.

3. FLIP, a one-group multiregion transport equation program.

4. MUFT IV, a 54-group calculation which gives the neutron spectrum and fast-neutron parameters.

The gamma shielding code will be a new one, written and programmed at the Electric Boat Division. Currently, geometry considerations are being studied.

STRUCTURAL STUDIES (I. H. Kabler and A. C. MCClure)

The objectives of this work were to prepare the structural designs and to make analyses of the rotating machinery foundations.

A series of designs for the machinery foundations has been prepared. Longitudinal girders will support the turbocompressor unit and the power turbine. These girders can be supported in several ways, but the most promising is to attach them to the after shield bulkhead and to columns near the forward end of the turbomachinery. This attachment will maintain 
the alignment between the power turbine and reduction gear, or power absorber. It is also possible to attach the forward end of the girders to the primary shield tank in addition to the columns. The use of two-point support in conjunction with deep girders ensures turbocompressor shaft alignment (in shipboard installation) by divorcing the girders from "panting" or "flexing" of the main structure. A bed-plate design proposed by Westinghouse has, with modifications, served as a basis for the main machinery foundation study. 


\section{ROTATING MACHINERY}

PRELIMINARY DESIGN (F. E. MCDona'd, R. W. Carver, A. Kazarinov, and A. C. McClure)

The greater part of the development work for the rotating machinery is assigned to Westinghouse Electric Corporation under subcontract. This subcontract includes aerodynamic and mechanical development of turbines and compressors, as well as start-up and control analysis. The subcontract also includes Westinghouse work in metallurgy, reported in the section on Materials Development, and work on sealing and lubrication systems, reported in this section.

Work at Electric Boat in connection with the rotating machinery consists of monitoring the Westinghouse effort in aerodynamic and mechanical development, coordinating this work with other parts of the program, studying machinery performance, and assisting in cycle and control analysis in relation to turbomachinery performance.

Initial effort has been concentrated on design of the high-pressure turbine and the high-pressure compressor. These two units are combined into one rotor with two support bearings. It has been previously reported that the low-pressure compressor would be separately supported on two bearings and would be coupled with appropriate flexibility to the highpressure compressor shaft. The low-pressure turbine is an entirely separate unit with its own support and thrust bearings.

It was apparent early in the program that the high-pressure turbinecompressor rotor would be a controlling factor in the design of the entire machine. The helium machine tends to be long and slender and consequently to have a low critical speed. A comprehensive parametric study of this portion of the machine has been prepared. With this as a basis, preliminary V. Proscino, et al. Maritime Gas Cooled Reactor Project: Engineering Report on High Pressure Rotor Component Selection, Westinghouse Electric Corporation Report GTM-55, March 31, 1959. 
designs of blading, inlet and outlet hoods, rotor, and casing were prepared. Compressor and turbine experimental models were then designed.

The compressor test model will represent the ninth, tenth, eleventh, and twelfth stages of the 21-stage high-pressure compressor. Procurement of the blades was initiated, and the detailed design of the model was begun following approval of preliminary design. The turbine test model will consist of two high-pressure turbine stages, with annulus divergenc. corrected for air. Design and procurement of the turbine test model are proceeding in parallel with those for the compressor.

The high-pressure turbine inlet scroll is a critical portion of the machine, both because of its effect on turbine performance and because of its effect on the length of the rotor and hence on critical speed.

The model tests of the scroll have accordingly been scheduled first in the development program for the hood and diffuser. Tests will be conducted on inexpensive wooden models, using the Westinghouse laboratory air supply and exhausting to atmosphere.

The first test model will be a compact scroll having cross-sectional areas one-half as great as the inlet pipe on the inlet side, and one-fourth as great on the opposite side. The second model will have area ratios of one and of one-half, respectively.

Drawings of these two turbine inlet scrolls have been approved, and procurement has been initiated. It is expected that a third test model will be designed from the results of the first two tests.

Studies of the low-pressure turbine have continued. There is an optimum combination of turbine and marine-type reduction gear such that lower turbine cost, as a result of higher turbine speed, results in a cheaper turbine, but this is balanced by an increased cost of the reduction gear. In order to select this optimum, a series of turbines with speeds ranging from 6,000 to $10,000 \mathrm{rpm}$ is being studied. Difficulty has been experienced in designing machines which operate below the firstcritical speed. Since the high-speed 
rotor has received major emphasis during this quarter, the low-pressure turbine has not yet been given sufficient attention. If required, a solution to this problem is expected during the following quarter.

Casing studies have indicated that horizontal joints will be satisfactory in most sections of the machine from the standpoints of tightness, strength, and total length of joint. This construction is greatly preferred for reasons of access and assembly. The high-pressure compressor and high-pressure turbine are combined in a horizontally split section of casing. A design has been worked out to avoid four-corner joints but still to provide access to all parts of the machine. The low-pressure compressor and low-pressure turbine retain vertically split, or barrel-type, casings except at the bearings.

The effects of piping reactions on the machinery casing were studied. Several piping runs were changed to reduce end reactions, and a generally satisfactory piping arrangement was developed.

Turbine and compressor designs were checked at Electric Boat with the aid of IBM 704 computer programs. The programs also facilitated a preliminary study of reactor shutdown cooling. A rotor critical-speed study by Electric Boat demonstrated the effect of bearing and seal diameters on critical speed. Four-inch-diameter bearings with 5- or 6-in.-diam shafting at the seal labyrinths will provide satisfactory stiffness.

Compressor and turbine model design and procurement will take place during the third quarter of calendar 1959, with experimental work :ommencing in the fourth quarter. Turbine inlet scroll tests will begin during the third quarter.

BEARINGS, SEALS, AND LUBRICANTS (C. P. de Carlo, A. E. Holmes, and A. C. McClure)

The development of efficient bearings, seals, and associated systems for application to the prototype gas turbine, and the selection of the lubricating oil best suited to the particular working conditions of this machine are part of the over-all work on rotating machinery. Bearing and seal tests 
and investigations are being performed at Electric Boat Division, in close cooperation with Westinghouse. The results will form a basis for selection of the seals and bearings to be adopted for mockup testing by Westinghouse Electric Corporation.

Westinghouse has prepared a series of lubricating and sealing system diagrams depicting systems using high-pressure and low-pressure oil supply and saturated and degassed oil supply. A detailed description of the operation of the systems was also prepared to aid in evaluating the different concepts.

A decision was made that attention would be directed toward the system using low-pressure (approximately atmospheric) oil supply reservoirs and employing degassing in the system. Deaeration will be obviated by use of contact-type end seals arranged to seal oil at 2 to 5 psi above atmospheric pressure. Therefore, only normal filtering and extraction of helium will be required.

Sealing systems will incorporate a buffer gas system supplied from the main coolant purification system to ensure that helium mixing with the oil is free of radioactive contamination.

These lubricant and seal system studies by Electric Boat and Westinghouse aid in planning the seal experimental development program and provide information needed for machinery preliminary design.

\section{Seal Test Program: First Series}

The last quarterly report (GA-1030) described the initial checkout runs on the bearing and seal test stand and the general arrangement of the test stand. During this quarter, the test on the first series configuration (Koppers Company seals) was completed.

The test shaft is driven at speeds up to $20,500 \mathrm{rpm}$ by a $200-\mathrm{hp} \mathrm{dc}$ motor through a 5-to-1 speed increaser and high-speed gear coupling. Oil is supplied to the unit at 500 psi by a gear pump taking suction from a 100-gal reservoir at atmospheric pressure. 
The test housing, instrumented with thermocouples and thermometers, is shown at the center of Fig. 3.1. Pump and drive motor, oil cooler, and reservoir are at the left. At the upper left is the $\mathrm{T}$-shaped separator for separation of face-seal leakage gas from the drain oil. The speed increaser and high-speed coupling and guard are at the right. Figure 3.2 shows the instrument panel and drive motor control.

In the first series of tests, bushing seals and carbon-ring face-contact seals designed and manufactured by Koppers Company were installed in the test housing. The 3 -in. -diam shaft is run at speeds necessary to produce surface speeds equivalent to those that will occur in the prototype gas turbine. Figure 3.3 is the assembly drawing showing the installation of the seals in the test housing.

The original intent was to perform a 50- to 100-hr wear-in run on the face seals, followed by a 500-hr life test in order to predict operating life of the seals. However, unsatisfactory performance of both types of seals prevented running of the planned life test for the face seals. The following tests were completed:

1. A 38-hr wear-in run at 15,000 rpm with single rotation locking pin on bushing seals,

2. A 50-hr run at $14,000 \mathrm{rpm}$ with a two-pin design of rotation locking pins on bushing seals,

3. A 35-hr run at 15,000 rpm with diametral clearance of bushings increased to 6 mils,

4. A 15-hr run at 14,000 rpm with bushing seals alone, with the normal diametral clearance of 3 to $4 \mathrm{mils}$ and closer run-out tolerance.

Some basic data are included in Tables 3.1 and 3.2. Test numbers refer to test No. 1 above. These are preliminary data. Final data on the first series of tests will be given in a subsequent report.

The abrupt increase in face-seal leakage between test No. 1 and the 


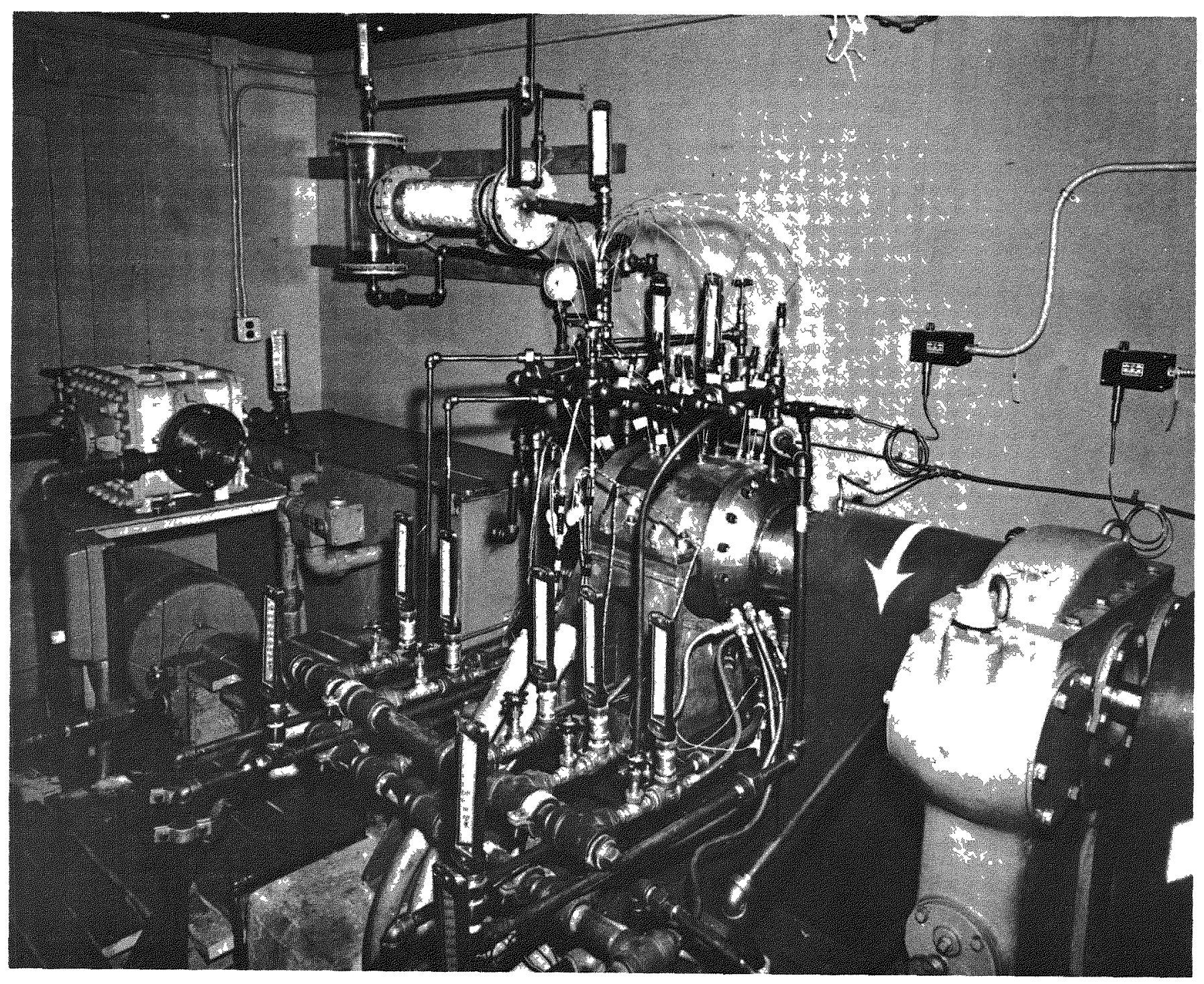

Fig. 3.1--Test assembly for first seal test series 


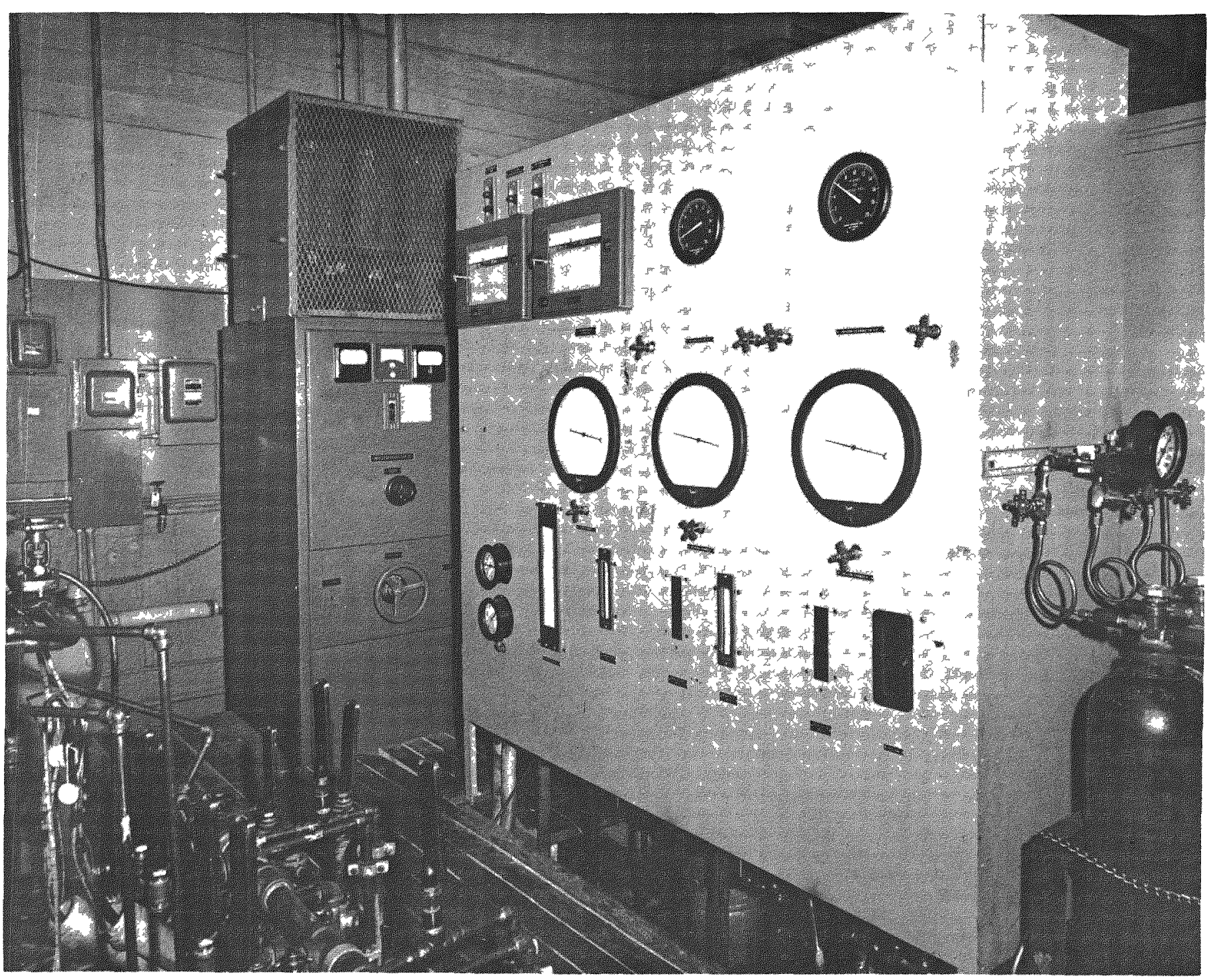

Fig. 3.2--Instrument panel and drive motor control for first seal test series 


\section{-}

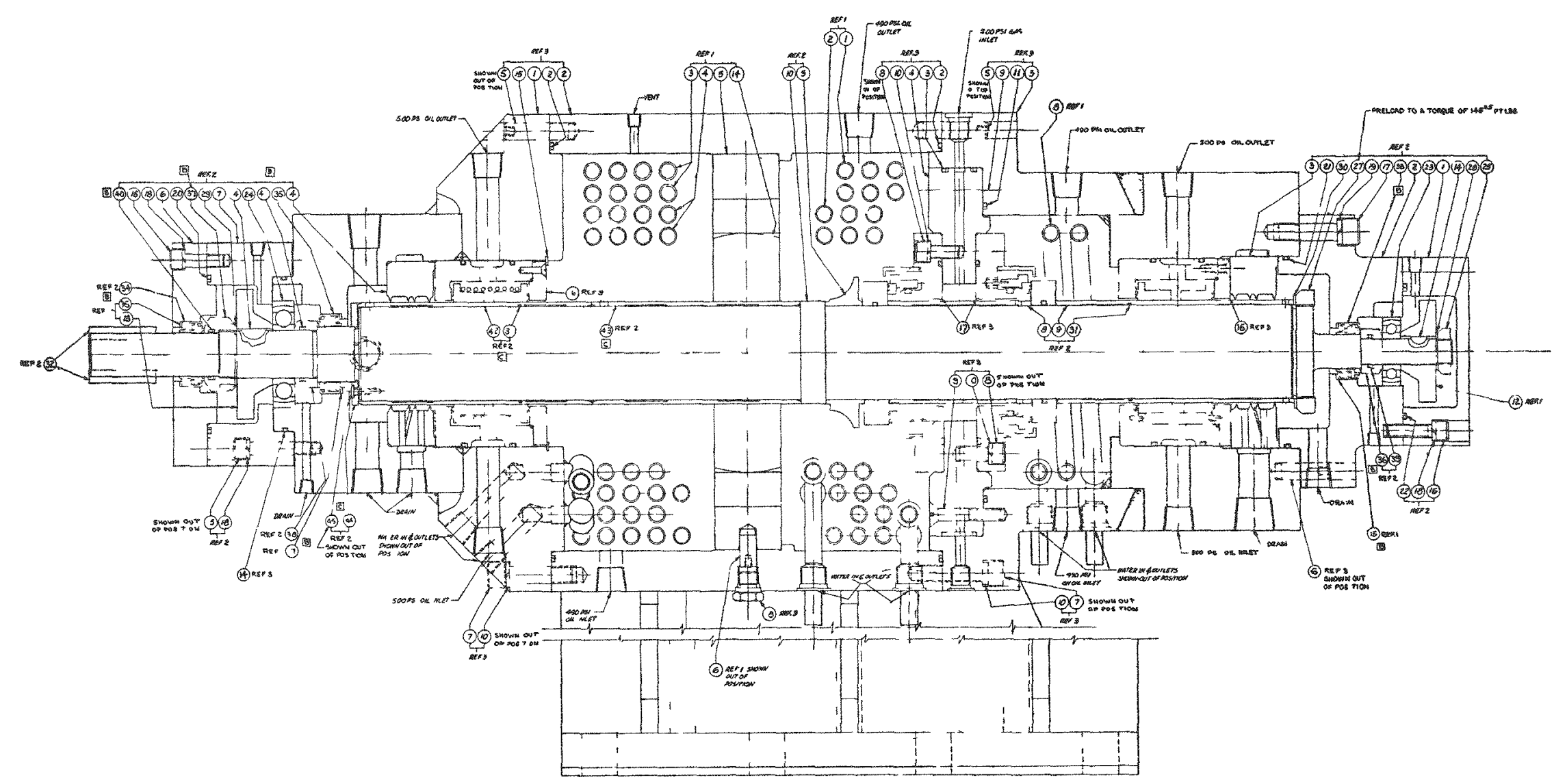

Fig. 3.3--Assembly drawing for installation of seals in test housing 
DATA FOR KOPPERS BUSHING SEALS

\begin{tabular}{|c|c|c|c|c|c|c|c|c|c|c|}
\hline \multirow[b]{2}{*}{$\begin{array}{l}\text { Test } \\
\text { No. }\end{array}$} & \multirow{2}{*}{$\begin{array}{c}\text { Pressure } \\
\text { Difference } \\
\text { across } \\
\text { Outboard } \\
\text { Seals } \\
\text { (psi) }\end{array}$} & \multirow{2}{*}{$\begin{array}{l}\text { Shaft } \\
\text { Speed } \\
\text { (rpm) }\end{array}$} & \multicolumn{2}{|c|}{$\begin{array}{c}\text { Diametral } \\
\text { Clearance } \\
\text { (in.) }\end{array}$} & \multicolumn{2}{|c|}{$\begin{array}{c}\text { Average } \\
\text { Leakage Flow } \\
\text { (gpm) }\end{array}$} & \multirow{2}{*}{$\begin{array}{c}\text { Oil } \\
\text { Supply* } \\
\text { Temperature } \\
\text { ( F } F)\end{array}$} & \multicolumn{2}{|c|}{$\begin{array}{c}\text { Average } \\
\text { Oil Drain } \\
\text { Temperature } \\
\left({ }^{\circ} \mathrm{F}\right)\end{array}$} & \multirow{2}{*}{$\begin{array}{l}\text { Average } \\
\text { Horsepower } \\
\text { per Bushing }\end{array}$} \\
\hline & & & $\begin{array}{l}\text { Drive } \\
\text { End }\end{array}$ & $\begin{array}{l}\text { Free } \\
\text { End }\end{array}$ & $\begin{array}{c}\text { Drive } \\
\text { End }\end{array}$ & $\begin{array}{l}\text { Free } \\
\text { End }\end{array}$ & & $\begin{array}{c}\text { Drive } \\
\text { End }\end{array}$ & $\begin{array}{l}\text { Free } \\
\text { End }\end{array}$ & \\
\hline $\begin{array}{l}1 \\
2\end{array}$ & $\begin{array}{l}210 \\
250\end{array}$ & $\begin{array}{l}15,000 \\
14,000\end{array}$ & $\begin{array}{l}0.0031 \\
0.0028\end{array}$ & $\begin{array}{l}0.0037 \\
0.0037\end{array}$ & $\begin{array}{l}0.3 \\
0.4\end{array}$ & $\begin{array}{l}0.5 \\
0.8\end{array}$ & $\begin{array}{l}120 \\
123\end{array}$ & $\begin{array}{l}200 \\
200\end{array}$ & $\begin{array}{l}178 \\
200\end{array}$ & -- \\
\hline 3 & 250 & 15,000 & 0.0058 & 0.0060 & 1.2 & 2.4 & 120 & 185 & $\ldots$ & - \\
\hline 4 & 495 & 14,000 & 0.0031 & 0.0035 & 0.75 & 1.6 & 113 & 220 & 180 & 11 \\
\hline
\end{tabular}

* Teresso 43 oil was used.

Table 3.2

DATA FOR KOPPERS FACE SEALS USING NITROGEN

\begin{tabular}{|c|c|c|c|c|c|c|}
\hline \multirow{2}{*}{$\begin{array}{l}\text { Test } \\
\text { No. }\end{array}$} & \multirow[t]{2}{*}{$\begin{array}{c}\text { Pressure } \\
\text { Difference } \\
\text { across } \\
\text { Seal } \\
\text { (psi) }\end{array}$} & \multirow{2}{*}{$\begin{array}{l}\text { Gas } \\
\text { Pressure } \\
\text { (psi) }\end{array}$} & \multirow[t]{2}{*}{$\begin{array}{l}\text { Minimum } \\
\text { Nitrogen } \\
\text { Leakage for } \\
\text { Two Seals } \\
\text { (sctm) }\end{array}$} & \multirow{2}{*}{$\begin{array}{l}\text { Duration } \\
\text { of } \\
\text { Test } \\
\text { (hr) }\end{array}$} & \multicolumn{2}{|c|}{$\begin{array}{c}\text { Average Wear at Four } \\
\text { Circumferential } \\
\text { Locations } \\
\text { (in.) }\end{array}$} \\
\hline & & & & & Seal No. 1 & Seal No. 2 \\
\hline 1 & 23 & 220 & 0.3 & 38 & $\ldots-\infty$ & $-\infty-\infty$ \\
\hline 2 & 20 & 250 & 3.0 & 50 & $\begin{array}{l}0.0001 \\
\text { to } 0.0002\end{array}$ & 0.0001 \\
\hline 3 & 19 & 60 & 1.5 & 35 & 0.0001 & $<0.0001$ \\
\hline
\end{tabular}


later tests was apparently due to one of the carbon seals not contacting all the way around its circumference. At the termination of test No. 1, the polished mating rings had a more uniform appearance, suggesting a better contact than was obtained in subsequent tests.

Extreme care was taken to ensure similarity in the face-seal installations for all tests. The variation in leak rate gives an indication of the sensitivity of these seals to subtle variations in installation.

The excessive gas leakage rates of the face seals tested makes them less worthy of consideration, since their chief advantage normally is low leakage.

The bushing seals were expected to be relatively trouble-free devices, but did not prove to be so by test. Throughout the testing period, the bushing-seal rings suffered damage at the rotation locking point during high-speed operation.

Typical examples of this damage may be seen in Figs. 3.4 and 3.5. Seal ring $\mathrm{A}-1$ in Fig, 3.4 is undamaged and has the normal milled slot in the flange in which the steel rotation lock pin rides to prevent rotation of the ring with the shaft. The slot in A-2 is in an initial stage of damage; rings $B-1$ and $U M$ in Fig. 3.5, which were run at $16,000 \mathrm{rpm}$ for $38 \mathrm{hr}$, display an advanced degree of damage with the slot enlarged to nearly a $90^{\circ}$ arc length.

The abrasion of the slots was of a vibratory nature, the damage progressing more or less linearly with running time. Possible sources of abrasion which have been investigated include:

1. Vibration due to rotor imbalance,

2. Foundation resonance,

3. Coupling misalignment,

4. Shaft run-out,

5. Oil whip or other film instability,

6. Ball bearing faults (ball bearings support the shaft in this assembly),

7. Oil film turbulence. 


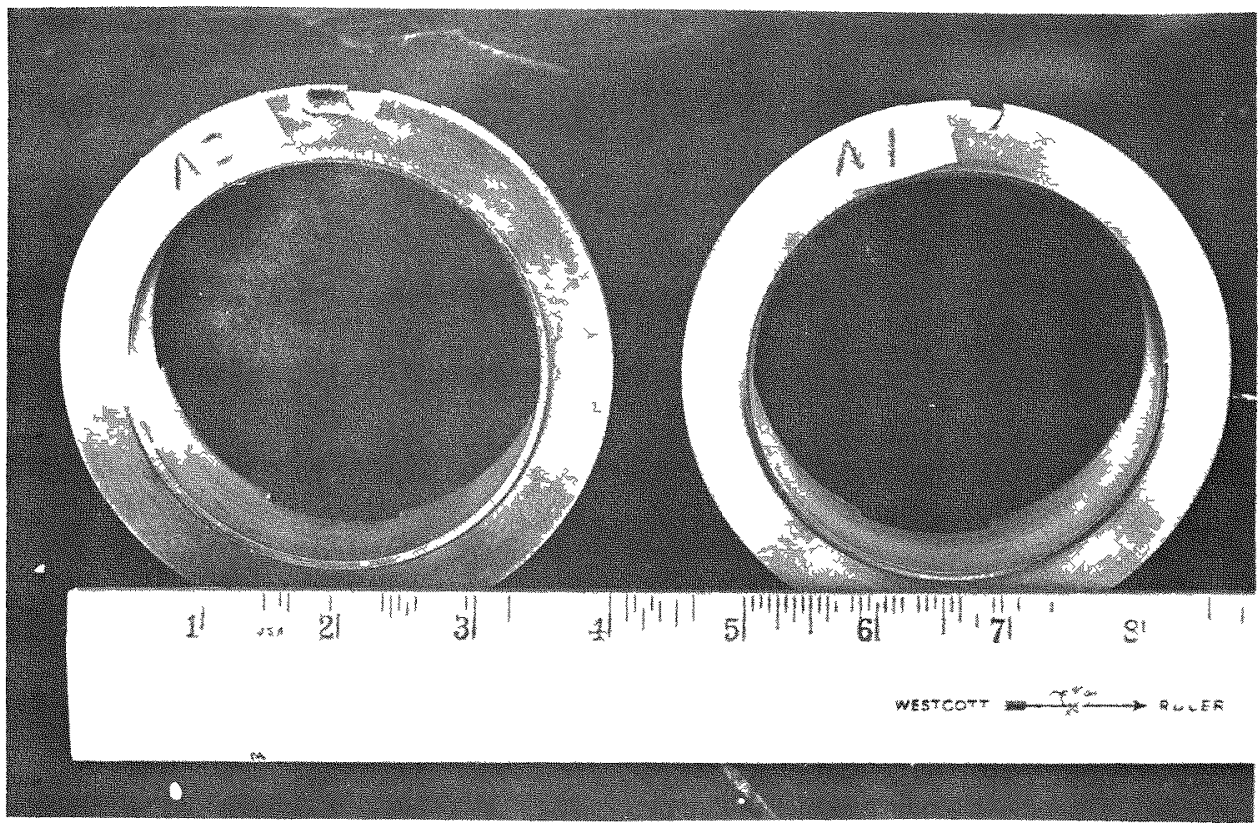

Fig. 3.4--Undamaged seal ring (A-1) and example of initial stage of slot damage $(A-2)$

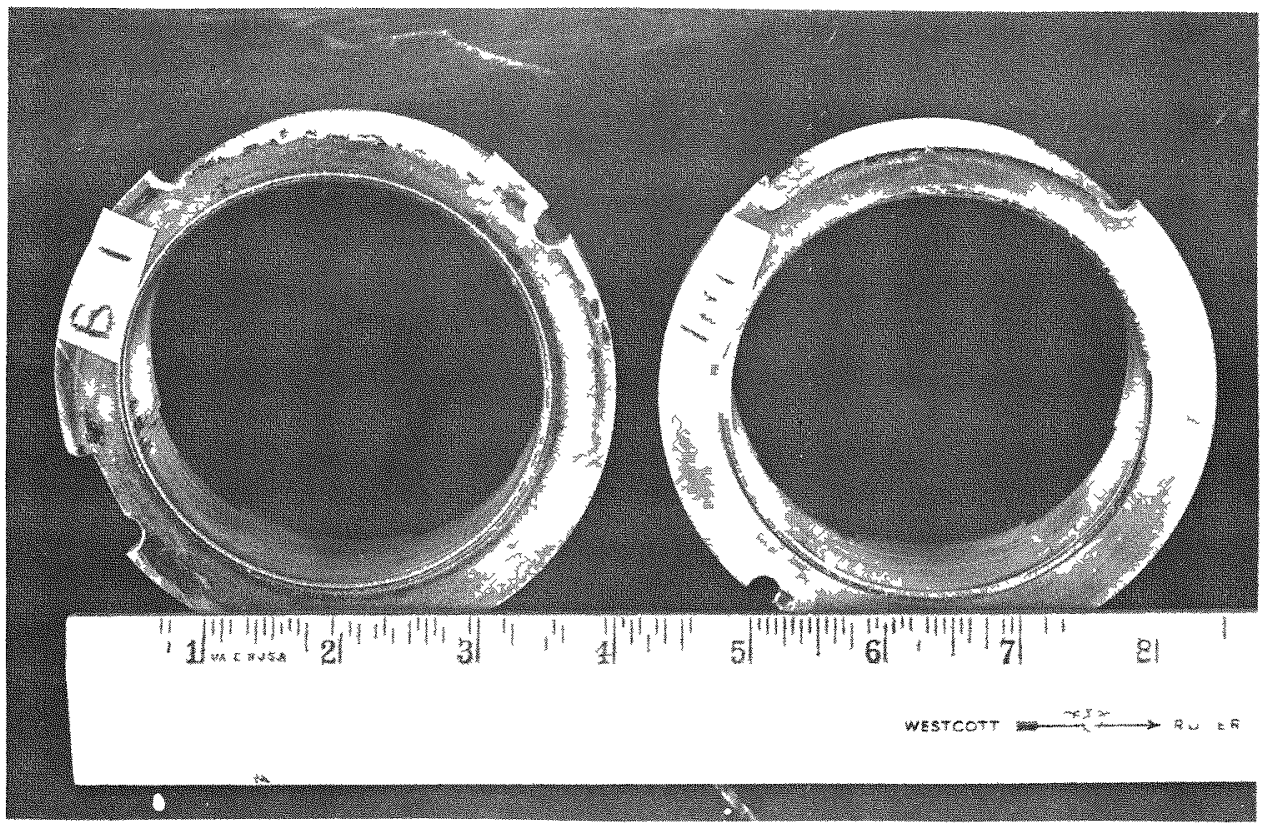

Fig. 3.5--Examples of advanced degree of slot damage in seal rings 
Of the above, all except the last three have been eliminated as the source of the trouble. Studies of the last three are continuing.

Since the floating bushing seal must receive further consideration, the requirements for its proper installation will have to be determined by additional testing at the running speeds of the turbine.

\section{Bearings and Seal Tests: Second Series}

The second series of tests involves a simpler sealing system, incorporating plain journal bearings which perform the added function of oil seals. The sealing configuration is shown in the test housing assembly drawing, Fig. 3.6, and the diagram, Fig. 3.7. Oil at 500-psi pressure is fed into the cavity between the journal bearing and floating seal. The oil flows outward through the journal bearing clearance to atmosphericpressure drain lines and inward through the oil side of the floating seal to the central drain groove, which is held at a pressure about 5 psi below the oil supply pressure. Similarly, gas at 500 psi flows across the other side of the seal and to the drain groove, where it mixes with the oil and drains to the coolers and oil-gas separators. Gas leakage through the floating seal clearance is limited by the orifices downstream from the separators. The diaphragm control valves sense gas pressure within the housing and maintain oil pressure nearly equal to gas pressure. Luring the test the gas pressure level will be varied, simulating load changes in the gas turbine. Pumping head for circulation of the gas in the closed loop will be supplied by a shaft-mounted centrifugal viscosity pump.

Various types of oil-gas separators will be tested to determine the optimum design. Journal bearing stability and performance with deliberately imposed misalignment will be investigated. At least three combinations of seal designs will be tested.

Lubricant Study (H. W. Allman and I. Huppert)

The initial work in the study of lubricants was the tabulation of pertinent physical properties of various lubricating oils, as furnished by 


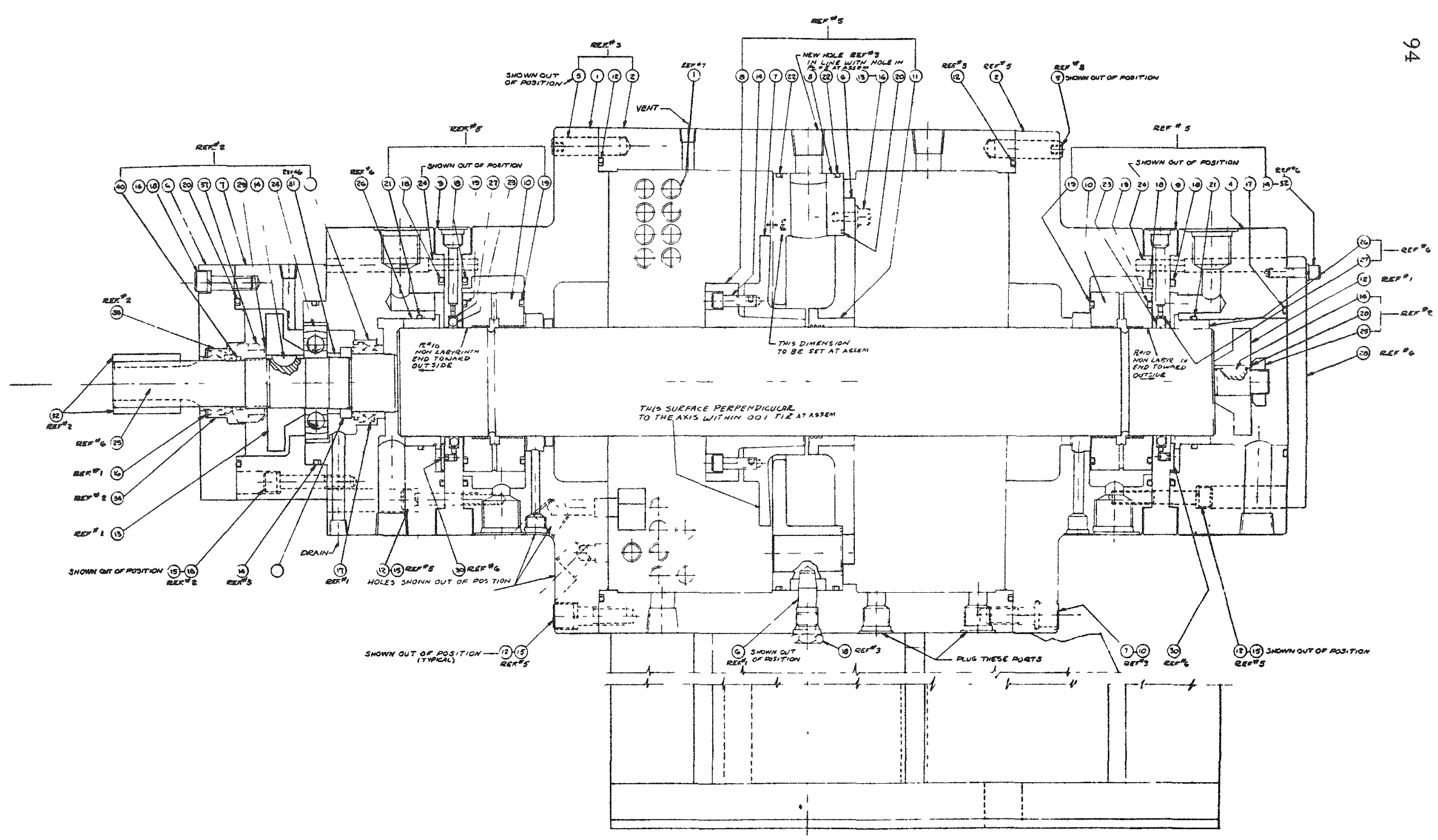

Fig. 3.6--Assembly drawing of sealing configuration for second series of bearings and seal tests 


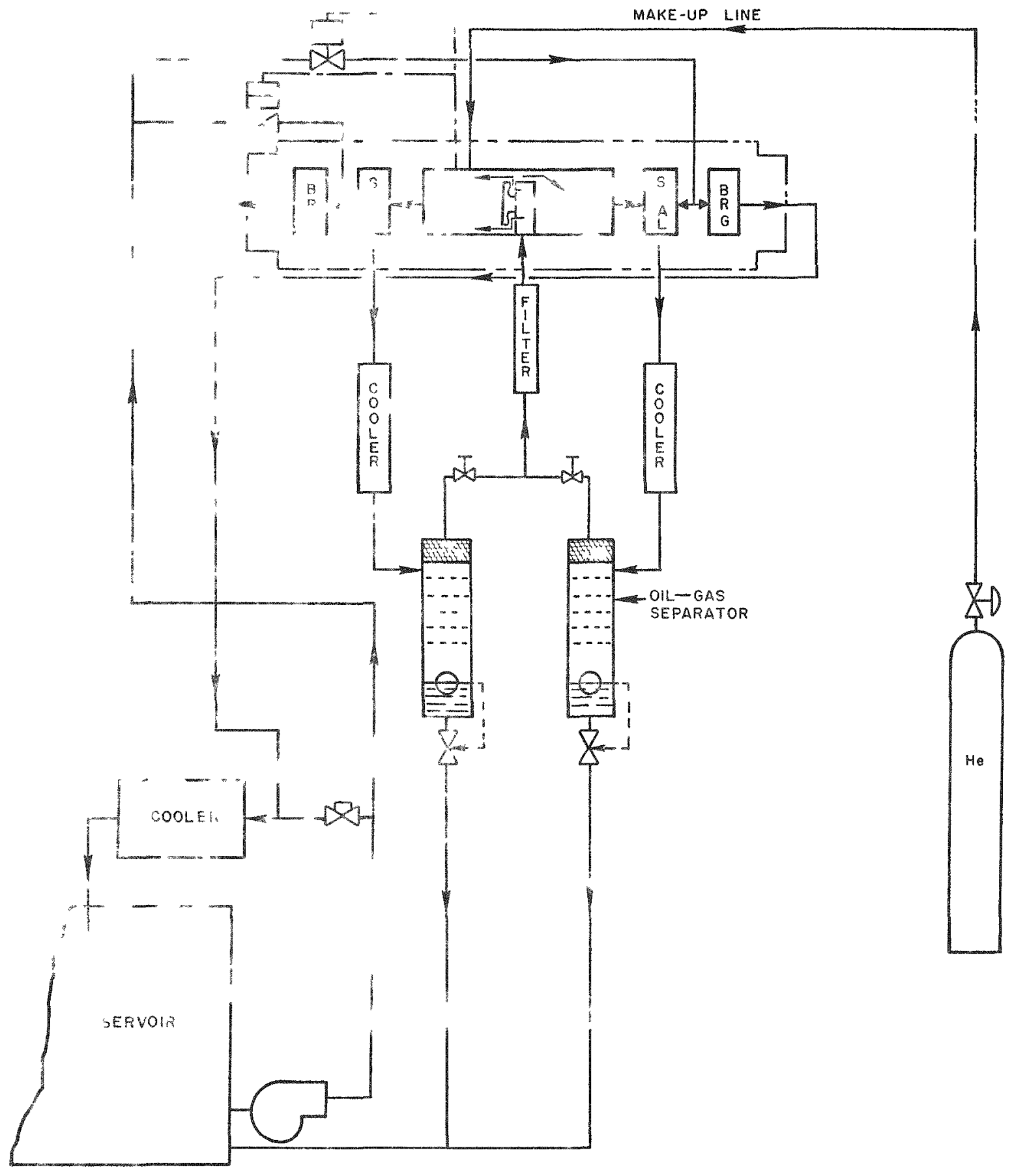

Fig. 3.7--Hiping diagram for second series of tests 
their manufacturers. In some instances, the reported properties for similar oils differed. In all instances, the effect on properties of using the oils in a helium environment was unknown.

In order to resolve discrepancies in the reported data and to determine the effect of helium on the properties, a lubricating oil test program has been initiated.

The testing program will include the following work:

1. The effect of dissolved helium on oil viscosity,

2. Helium solubility as a function of temperature and pressure,

3. Oil evaporation rates as a function of time and temperature at atmospheric pressure,

4. Oil vapor pressure as a function of temperature,

5. The foaming characteristics of oil on the release of helium pressure.

All equipment necessary to perform the test program has been ordered and is currently being fabricated.

Oil viscosity will be measured with a specially designed rolling-ball viscosimeter, after its calibration with Bureau of Standards oils. Duplicate samples of the five oils under test have been sent to two laboratories for vapor pressure tests. Evaporation rate tests, currently being run at Electric Boat Division, will supplement the vapor pressure data. Solubility and foam data will be obtained at Electric Boat Division by use of a pressure bomb adapted.for these purposes. The oils which are being evaluated are Teresso 43, Mobil Oil DTE-797, Texas Regal A (R and O), Esso Turbo 35, and UCON DLB-200 EX. They were chosen after consideration of their reported viscosity, vapor pressure, composition of base oil, nature of additives, radiation stability, and price.

Testing should be completed by October, 1959, and data correlations and recommendations by November. 
CYCLE ANALYSIS (D. R. Olding and A. C. MCClure)

Cycle analysis performed includes the specification of the preliminary design heat balance and the determination of the steady-state performance of the plant under off-design conditions.

Full-load Analysis

No change in the preliminary full-load cycle was made during this quarter.

The revision of the electrical load analysis which was performed in this quarter has an increase in the electrical load of the shipboard fullpower design from 600 to $800 \mathrm{kw}$. Additionally, new heat-transfer and pressure-drop correlations will soon be available from the heat exchanger test loop.

When these correlations are available, the changes will be included in a new optimization of heat-exchanger surface and pressure-drop distributions, and a revised design of the full-load cycle will be issued.

Part-load Analysis

A revised version of the digital computer program used to predict off-design plant performance was completed. Provisions now exist for determining part-load performance with two bleed flows, power turbine bypass, and a steam generator. The part-load performance characteristics for the plant arrangement were generated using the program. Figure 3.8 shows the estimated basic cycle efficiency at part load. Basic cycle efficiency is plotted against shaft horsepower, with reactor outlet temperature and fraction of design inventory as parameters. The curve on which the plant will operate under normal inventory control is indicated on this plot.

The feasibility of plant operation at $1,500^{\circ} \mathrm{F}$ was investigated, using the part-load program. The following modifications were considered:

1. Reblading the high-pressure turbine to maintain design speed and present design points on the compressor characteristics, 


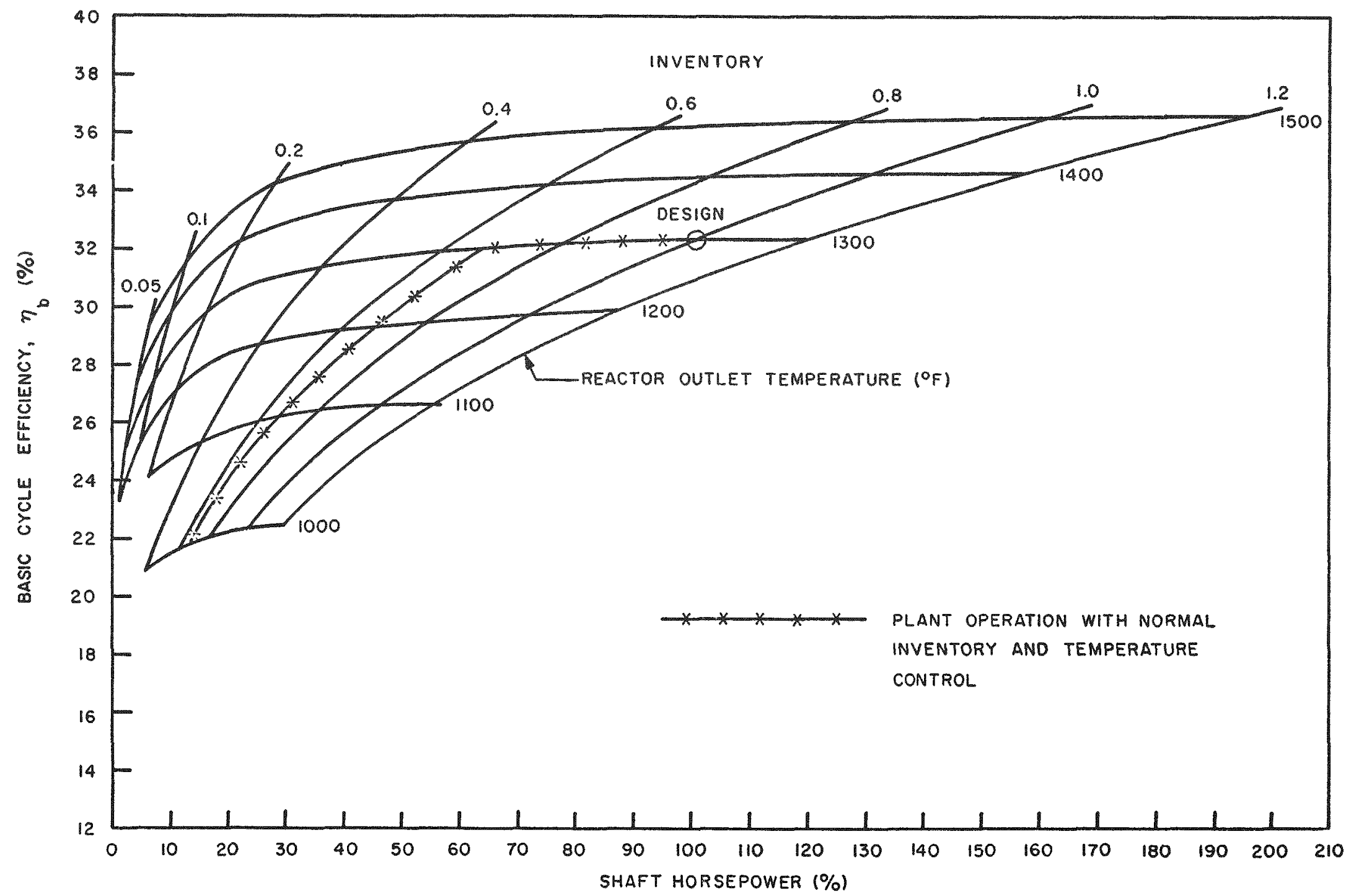

Fig. 3.8--Estimated basic cycle efficiency at part load 
2. Reblading the low-pressure turbine to maintain design speed,

3. Bleeding from the high-pressure compressor discharge to the lowpressure compressor inlet to maintain design speed,

4. Throttling the low-pressure discharge to maintain design speed,

5. Increasing rotational speed.

The operating point for each of the se modifications is shown in Fig. 3.9. In each case, inventory is adjusted to maintain 22,000 shp. Accordingly, low-pressure turbine speed remains constant.

The prediction of turbine operating life for each of the above cases will be made, and the results will be given in a subsequent report.

A comparison was made of basic cycle efficiency under two different modes of electrical power generation:

1. With the electrical generator on the turbine shaft,

2. With a steam turbine and a steam turbine-generator set.

It is assumed that the steam plant operates at $17 \%$ efficiency, a reasonable value for the steam conditions and power output anticipated. The study showed that at an electrical load of $800 \mathrm{kw}$, a gain of about $0.8 \%$ in basic cycle efficiency is predicted if the generator is mounted on the compressor shaft and the reduction gear efficiency is $95 \%$. Further study is in progress to determine performance at various electrical loads and power levels. 


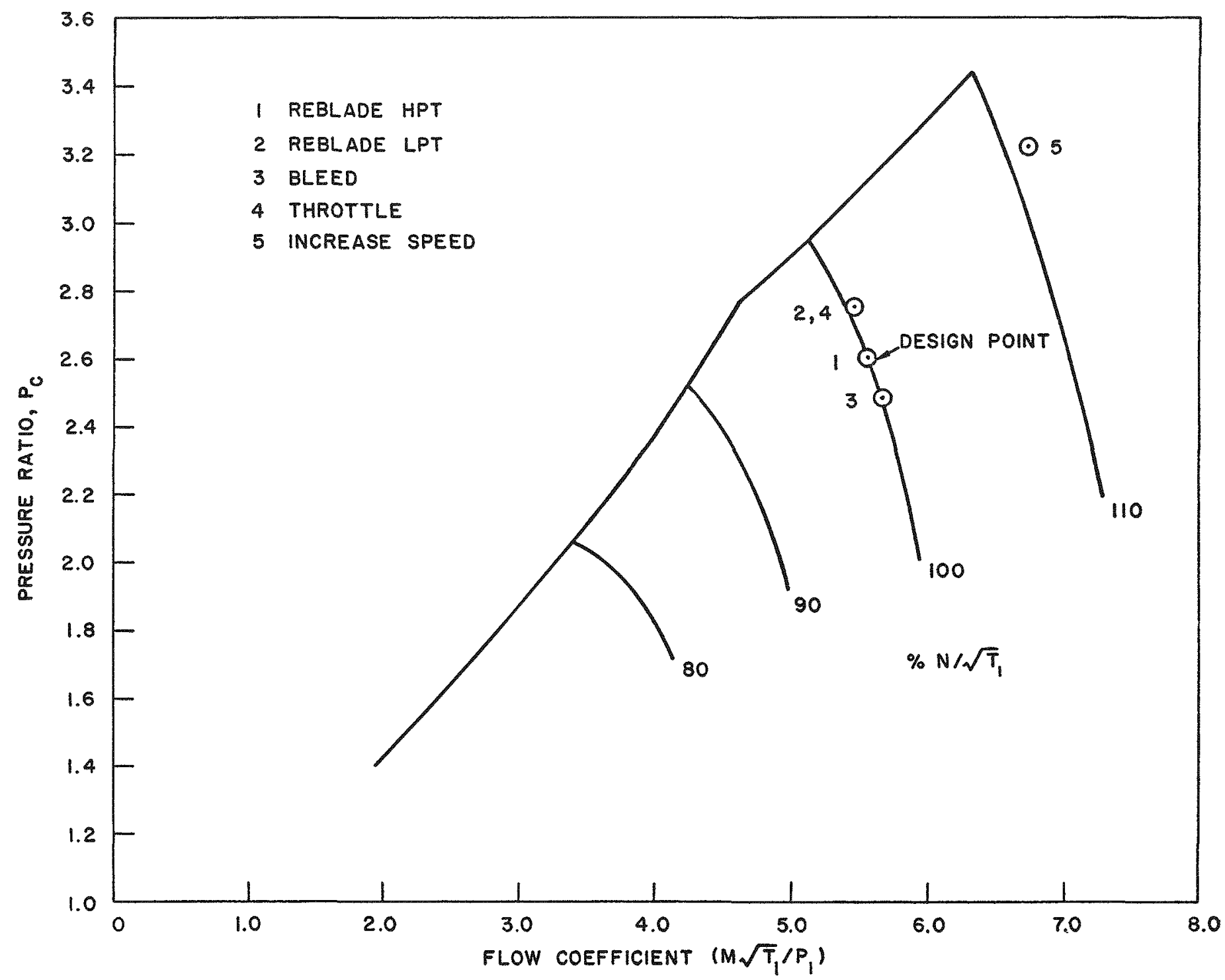

Fig. 3.9--Operating points for various plant modifications to permit operation at $1,500^{\circ} \mathrm{F}$ 


\section{REACTOR PHYSICS}

DESIGN OF REACTOR CORE (J. M. Stein, H. A. Vieweg, and B. W. Roos) Nuclear Design

Based on the established design parameters, a semihomogeneous graphite core was developed to be equivalent to the present preliminary design for the heterogeneous core. The equivalence was based on maintaining essentially the same ratio of heat-transfer surface and void volume for the semihomogeneous design and the present heterogeneous design.

Table 4.1 gives the compositions of the cores with aluminum oxide diluent. In all cases, the basic cell size is 7 by 7 in., and fuel rods are $0.250 \mathrm{in.} \mathrm{OD.}$

Reactivity, burnup, and fuel-cycle cost estimates were obtained for the equivalent semihomogeneous core for comparison with the current heterogeneous design. In making the estimates, a semiempirical relation was used to obtain the resonance escape probability for the semihomogeneous design. The disadvantage factor was evaluated analytically. Results are given in Tables 4.2 and 4.3, along with information for BeO systems, discussed below.

For the most expeditious comparison, the initial $\mathrm{U}^{235}$ loading and hot, clean excess reactivity were made the same in the semihomogeneous design as in the preliminary heterogeneous core design. Although for the same $U^{238}$ loading the resonance escape probability would be lower in the semihomogeneous core than in the heterogeneous design, the significantly lower disadvantage factor and the lower steel content permit an increase of $20 \%$ in $U^{238}$ inventory of the semihomogeneous reactor for the same initial excess reactivity. This results in a fuel cycle cost $13 \%$ lower in the semihomogeneous design. No attempt was made to explore other fuel loadings and obtain lower fuel cycle costs. 
Table 4.1

COMPOSITIONS OF PRELIMINARY CORES

\begin{tabular}{|c|c|c|c|c|c|c|}
\hline & \multicolumn{2}{|c|}{ Volume Per Cent of Core } & \multirow[b]{2}{*}{$\begin{array}{c}\text { Ratio of } \\
\text { Semihomogeneous } \\
\text { to Heterogeneous }\end{array}$} & \multicolumn{2}{|c|}{ Volume Per Cent of Core } & \multirow[b]{2}{*}{$\begin{array}{c}\text { Ratio of } \\
\text { Semihomogeneous } \\
\text { to Heterogeneous }\end{array}$} \\
\hline & \begin{tabular}{|c|} 
New \\
Heterogeneous
\end{tabular} & $\begin{array}{c}\text { New } \\
\text { Semihomogeneous }\end{array}$ & & \begin{tabular}{|c|} 
Preliminary \\
Design \\
Heterogeneous
\end{tabular} & $\begin{array}{c}\text { Equivalent } \\
\text { Semihomogeneous }\end{array}$ & \\
\hline $\mathrm{vO}_{2}$ plus diluent & 7.48 & 4.41 & 0.590 & 5.85 & 3.25 & 0.556 \\
\hline Fuel-coolant void & 7.08 & 7.85 & 1. 109 & 5.71 & 6.31 & 1.105 \\
\hline Stainless steel & 1.45 & 0.81 & 0.559 & 1.36 & 0.73 & 0.537 \\
\hline Graphite & 81.59 & 85.19 & 1.044 & 85.11 & 87.75 & 1.031 \\
\hline Other void & $\frac{2.40}{100.00}$ & $\frac{1.74}{100.00}$ & 0.725 & $\frac{1.97}{100.00}$ & $\frac{1.96}{100.00}$ & 0.995 \\
\hline Heat transfer surface & $3485.4 \mathrm{ft}^{2}$ & $3269.9 \mathrm{ft}^{2}$ & 0.938 & $2788.3 \mathrm{ft}^{2}$ & $2616.1 \mathrm{ft}^{2}$ & 0.938 \\
\hline
\end{tabular}


Table 4.2

REACTIVITY AND BURNUP INFORMATION FOR GRAPHITE AND BEO CORES

\begin{tabular}{|c|c|c|c|c|}
\hline & $\begin{array}{c}\text { Heterogeneous } \\
\text { Graphite }\end{array}$ & $\begin{array}{c}\text { Semihomogeneous } \\
\text { Graphite }\end{array}$ & $\begin{array}{c}\text { Heterogeneous } \\
\text { BeO }\end{array}$ & $\begin{array}{c}\text { Semihomogeneous } \\
\text { BeO }\end{array}$ \\
\hline $\begin{array}{l}\text { Initial } \mathrm{U}^{235} \text { Loading }(\mathrm{kg}) \\
\text { Initial } \mathrm{U}^{238} \text { Loading }(\mathrm{kg}) \\
\mathrm{K}_{\text {eff }} \text {, hot clean } \\
\mathrm{K}_{\text {eff, initial hot poisoned }} \\
\text { Lifetime at } 49.7 \mathrm{Mw} \\
\text { Days } \\
\text { Years } \\
\mathrm{U}^{235} \text { burned (kg) } \\
\mathrm{U}^{238} \text { burned (kg) } \\
\text { Plutonium at end of life (kg) } \\
\text { Initial conversion ratio } \\
\text { Initial enrichment }(\%) \\
\text { Final enrichment }(\%) \\
\text { Operating life } \\
\text { Days } \\
\text { Years } \\
\text { Shp-hr } \times 10^{-9}\end{array}$ & $\begin{array}{l}128.3 \\
500.0 \\
1.136 \\
1.097 \\
572 \\
1.57 \\
35.0 \\
10.3 \\
7.0 \\
0.354 \\
20.4 \\
16.0 \\
657 \\
1.80 \\
0.2746\end{array}$ & $\begin{array}{l}128.3 \\
606.0 \\
1.134 \\
1.095 \\
666 \\
1.83 \\
39.3 \\
14.7 \\
9.4 \\
0.392 \\
17.5 \\
13.1 \\
766 \\
2.10 \\
0.3197\end{array}$ & $\begin{array}{l}128.3 \\
3900 \\
1.139 \\
1.105 \\
812 \\
2.22 \\
45.9 \\
23.8 \\
15.3 \\
0.623 \\
3.2 \\
2.8 \\
933 \\
2.56 \\
0.3898\end{array}$ & $\begin{array}{l}128.3 \\
680.0 \\
1.140 \\
1.104 \\
848 \\
2.32 \\
45.5 \\
27.3 \\
15.8 \\
0.618 \\
15.9 \\
11.3 \\
975 \\
2.67 \\
0.4070\end{array}$ \\
\hline
\end{tabular}


Table 4.3

FUEL CYCLE COST ESTIMATES FOR GRAPHITE AND BeO CORES

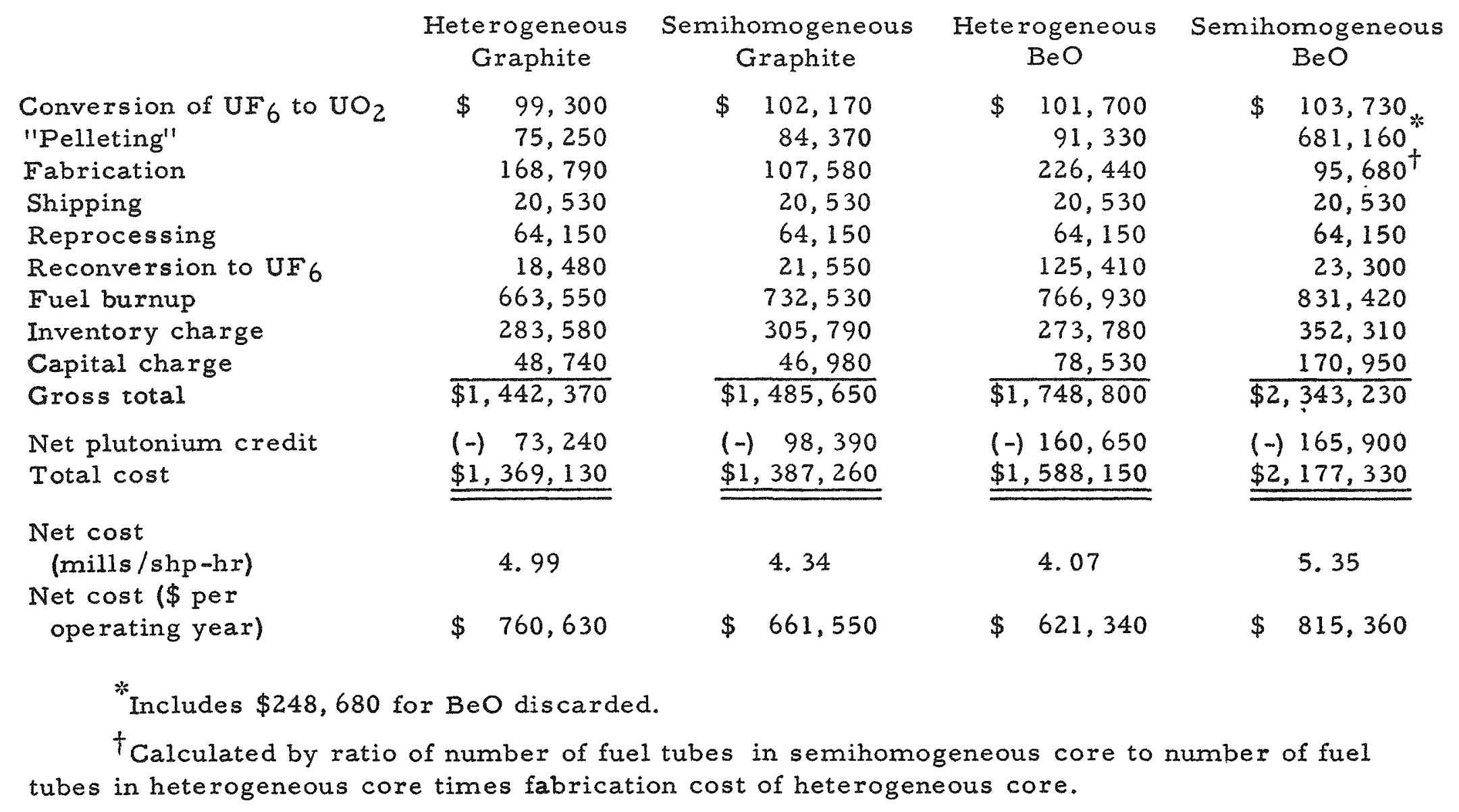


Preliminary calculations were made to investigate the potential gains in performance from the use of $\mathrm{BeO}$ as a moderator in future maritime reactors. Two BeO systems were considered, the first being the same as the preliminary design for the heterogeneous core with a direct substitution of $\mathrm{BeO}$ for graphite. The second $\mathrm{BeO}$ design is a semihomogeneous one with $\mathrm{BeO}$ and $\mathrm{UO}_{2}$ intimately mixed in 0.788-in.-diam tubes, with 19 tubes arranged in a bundle surrounded by a BeO shroud. One-third of the total $\mathrm{BeO}$ volume in the core is mixed with fuel; $87 \%$ of the core is occupied by $\mathrm{BeO}$ and fuel, $2 \%$ is steel, and the remainder is coolant and control-rod void.

Here again, for the quickest comparison with the preliminary heterogeneous graphite reactor, the initial $\mathrm{U}^{235}$ loading was maintained the same and the $U^{238}$ loading was adjusted to yield the same hot, clean excess reactivity. Reactivity, burnup, and fuel cycle cost estimates are given in Tables 4.2 and 4.3 .

For the heterogeneous BeO core, the greatly improved moderating properties and lower disadvantage factor far offset the increased absorption by the moderator and permit an increase from $500 \mathrm{~kg}$ to $3,900 \mathrm{~kg}$ of $\mathrm{U}^{238}$. Core lifetime is $42 \%$ higher and fuel cycle cost $18.5 \%$ lowe $r$ than in the graphite heterogeneous design.

The $\mathrm{BeO}$ results are believed to be conservative because the $(n, 2 n)$ fast reaction in beryllium was ignored. With this effect included and an optimization undertaken, the $\mathrm{BeO}$ semihomogeneous design might achieve a lower fuel cycle cost than the heterogeneous graphite core.

\section{Control Rods}

Resonance parameters ${ }^{*}$ were used to compute absorption cross sections for dysprosium, gadolinium, and samarium isotopes; the initial curves obtained were without the effects of Doppler broadening.

*D. J. Hughes and R. B. Schwartz, Neutron Cross Sections, Brookhaven National Laboratory Report BNL-325, 2d ed., July 1, 1958. 
Calculations are presently under way to obtain Doppler-broadened absorption cross sections for the potential control-rod materials at room and operating temperatures. Completion of the Doppler-broadened curves and major development of the analytical technique for obtaining resonance group cross sections is expected during the next period. When completed, these cross sections will be used in an analytical treatment for calculating selfshielding and flux depression as a function of energy to yield effective resonance group cross sections.

Cell Calculations

To compare the relative accuracy of the different cell calculation codes available, a program was initiated to test the se codes on fuel-cell configurations of the MGCR heterogeneous and semihomogeneous designs. The group of codes to be tested will include a Monte Carlo code and the $S_{n}$ and SNG codes. During this period, careful attention was given to preparing input data for these calculations.

Thermal Shields

Preliminary calculations are under way to modify thermal-shield, pressure-vessel heating curves previously obtained to permit evaluation of a core support plate consistung essentially of laminations of steel and water. An analytical treatment is being employed to determine the effect of the water layers on the fluxes. In performing the calculations, it is assumed that borated sheets are used to prevent thermal neutron leakage from the core to the support plate, and to prevent leakage of the rmal neutrons from the water layers into the upper or lower steel plates of the support structure.

BIOLOGICAL SHIELDING (J.M. Stein and H. A. Vieweg)

The effect on MGCR shielding caused by the recently recommended revisions to the AEC's 'Standards for Protection Against Radiation" was 
investigated. It was disclosed that the guidelines being followed by the Electric Boat Division were already based on the lower maximum permissible dose rates being recommended.

During this period, clarification of the shielding program was obtained from the AEC. It has been decided that shipboard operation will be simulated only where such simulation is not an undue complication to the prototype plant. Under these circumstances, our shielding program for the future will concentrate on the design of a land-based prototype shield, with only a modest effort on the problems peculiar to shipboard application.

Preliminary estimates are being made of the weight of the shielding cask for fuel element removal for both the heterogeneous and semihomogeneous designs. For purposes of comparison, it is assumed that both cores will be operated for an infinite length of time at a power level of 49.7 Mw. Because the major shielding required is to attenuate fissionproduct gammas, this assumption gives only slightly higher shielding requirements than the assumption of a core life of $1-1 / 2$ or 2 years.

For the semihomogeneous design, the cask is assumed to accommodate one complete fuel element ( 7 by $7 \mathrm{in.}$ ); for the heterogeneous design, the cask is assumed to accommodate a single fuel-rod bundle. The estimates are expected to be available before the middle of the next period.

CRITICAL FACILITY (J. M. Stein, H. A. Vieweg, L. Amyot, A. D. McWhirter, and A.J. Goodjohn)

Hazards Analysis

The main problem associated with the hazards analysis was the attainment of some kind of inherent shutdown mechanism which would limit the magnitude of the excursion following a credible accident. To keep the critical assembly flexible enough for studies of a wide range of fuel and poison concentrations, it was evident that physical separation of 
the constituents (i.e., fuel, poison, and moderator) was required. As a result, the usual shutdown mechanisms, such as those due to temperature coefficients and void coefficients, could not be relied upon to terminate a power excursion.

It was decided that melting of the fuel plates, which are made of uranium-aluminum alloy, into a less reactive configuration within the core was the only inherent shutdown mechanism available for the flexible critical facility. Calculations were made to determine the magnitude of the expected shutdown coefficient and to decide on an optimum loading pattern for fuel and poison in the core (independent of actual concentrations) which would yield the maximum shutdown coefficient and minimum energy release following an accidental excursion.

The second important aspect concerning the hazards analysis was the classification of all possible accidents. The consideration of melting as a shutdown mechanism, without ultimate vaporization of part or all of the fuel in the core, required that the design of the critical assembly be such that large step changes in reactivity could not be accidentally inserted into the core. In fact, any accidental change in reactivity must be such that the resulting asymptotic reactor period would be long enough to permit adequate time for the fuel plates to melt and slump to the less reactive configuration and thereby shut down the reactor before vaporization would proceed. Melting of part or all of the core would result in very high radioactivity of the core, but the activity would be essentially contained within the critical assembly building. Only the gaseous fission products and those fission products which were volatile at the temperature of the molten fuel would be released to the atmosphere. Since most of even the gaseous and volatile fission products would remain in the molten fuel, primarily because of occlusion, it was estimated conservatively

*G. W. Parker and G. E. Creek, "Experiments on the Release of Fission Products from Molten Reactor Fuels," Proceedings of the Second United Nations International Conference on the Peaceful Uses of Atomic Energy, United Nations, Geneva, 1958, Vol. 11, p. 171. 
that the atmospheric-type radiation hazard would be no more than $1 \%$ of the hazard if all of the fuel was vaporized at the same fission energy content and was released to the atmosphere.

The boundary line between accidents in which vaporization would or would not occur appeared to be at periods close to the period corresponding to prompt criticality. The design of the critical assembly has therefore emphasized the requirement that the maximum reactivity worth of any one package of fuel, poison, or moderator which may accidentally be inserted into, or removed from, the assembly be significantly less than the reactivity corresponding to prompt criticality. Only the worth of the safety rods violates this requirement, and the withdrawal rates on these rods have been so adjusted that for an accident in which all scram mechanisms fail the assembly will reach a power level and energy content sufficient to melt the fuel and shut down the assembly long before it goes prompt critical. All other credible accidents involve long periods that correspond to small reactivity changes.

The fission energy content of the core as a result of accidents in which melting terminates the excursion has been conservatively estimated on the basis of melting of the total fuel load and slumping to the less reactive configuration in a time corresponding to the free-fall time after the fuel is in the completely molten state. On this basis, the maximum energy content will be no more than $400 \mathrm{Mw}-\mathrm{sec}$; for most of the core setups required in the flexible critical facility, the energy content at the termination of the excursion would be considerably less. The radiation hazard is therefore associated with an assembly that would retain at least $99 \%$ of the resulting radioactive fission products and would release to the atmosphere no more than $1 \%$ of the total activity.

Another consideration has been possible accidents that would involve very long reactor periods, corresponding to very small reactivity additions. If melting were the only ultimate shutdown mechanism, such accidents might involve considerable heat transfer to the remainder of 
the core and subsequently a much higher fission energy content before melting. Therefore, the design has incorporated a built-in manual safety rod and automatic $\mathrm{BF}_{3}$ fuses of the expanding-gas type. The use of these devices effectively eliminates the possibility of a serious accident following very small accidental reactivity additions.

Seismology of the Site

Because of both the poor structural properties of an unrestrained graphite assembly and the California location of the critical assembly site, a great deal of attention was paid to the investigation of earthquake hazards.

Professor Perry Byerly and Dr. William Quaide of the University of California, Berkeley, under contract with General Atomic, made a detailed study of the seismology of the area. They concluded that although the region is one of only moderate earthquakes, construction should be such as to resist an earthquake of intensity VIII on the modified Mercalli scale. Intensity VIII is described as producing considerable damage to weak masonry, a general construction category appropriate for a pile of loose graphite blocks. Intensity VIII is associated with a horizontal acceleration of 0.25 of gravity and would accompany waves with periods of 0.1 to $0.3 \mathrm{sec}$.

The frequency of occurrence of such strong earthquakes in the San Diego area is very low indeed. Since the written records began in 1769, only two shocks (in 1800 and 1894) have been rated as high as intensity VIII.

No geological faults were found in the General Atomic property. The nearest fault, the Rose Canyon fault, lies $5 \mathrm{mi}$ from the General Atomic site. There is no geologic evidence for recent movements on the fault, but location of epicenters on its trace indicates that it is still active.

Other active faults lie at considerable distances from the site. The closest on land lies $40 \mathrm{mi}$ to the northeast in the northeastern part of 
San Diego County, a seismically active area. Active faults in Baja California are still farther from the site. Areas offshore are seismically active, and although faults cannot be mapped, submarine topography indicates their presence.

\section{Earthquake Resistance of the Pile}

Basically, resistance to earthquake is a problem in motion. But, for most construction purposes, it is sufficient to use a static approach, the structure being designed to resist certain lateral forces correlated experimentally with the intensity scale. On this basis, as mentioned above, intensity VIII would correspond to a horizontal acceleration approximately 0.25 of gravity.

The reason for this extreme simplification is that the study of earthquake-induced motion is such a complex problem that it does not appear feasible to make a precise dynamic-stress analysis. Damage due to earthquake vibration is related not only to the peak acceleration, but also to the duration of this peak, to the resonant frequencies of the structure, to the dominant frequencies in the seismic wave spectrum, and to the degree of damping in the structure.

The prime consideration in the present case is not so much mechanical stability of the assembly as avoldance of more reactive configurations after a possible collapse. Because accurate theoretical prediction is not possible, it was felt that rigidity should be achieved by generous bracing and clamping.

After consultation with other groups in the field, it became apparent that vertical displacement would also be important, typical values of the order of $1 \mathrm{in}$. of ground motion being quoted. However, it was deemed sufficient to restrain only the central region of the pile against vertical motion. This would not hinder future changes in the physical size of the as sembly, but it would prevent dangerous configurations.

A system of tuelve 3/4-1n. -diameter prestressed aluminum bars 
held vertically in tension between the base plate and a rib structure resting on top of the pile should achieve our purpose.

Horizontal constriction is effected by extruded aluminum spacing bars running through the length of the pile. The designed system should be able to resist horizontal forces up to $800 \mathrm{lb}$ per linear foot of channel.

Thermal Insulation of Fuel Elements

The negative Doppler coefficient of $U^{238}$ would effectively act as a brake on the emergency shutdown mechanism by slowing down the rise of fuel temperature and delaying the meltdown. Also, the channels and the $\mathrm{U}^{238}$ would form heat sinks and prevent accumulation of heat in the fuel. In order to establish the magnitude of these effects, the form factor of the temperature distribution through the $U^{238}$ foils was determined by assuming perfect contact between the fuel elements and the $U^{238}$ foils and neglecting heat transfer to the ambient air. The fuel temperature was first considered to increase exponentially. Under these conditions, it was found that for all values of the period larger than $1 \mathrm{sec}$ and after a transient variation of the order of $0.2 \mathrm{sec}$, the temperature would be uniform throughout the $U^{238}$ foils. The same conclusion would be true of reactivity changes obeying a ramp function, as long as the period did not become smaller than 1 sec. It was verified that the assumption of negligible heat transfer to the ambient air was justified for all periods shorter than 1 sec.

Thus, if good thermal contact is maintained at the fuel boundaries, meltdown could be delayed until the period becomes dangerously small.

The simplest way of providing the required amount of insulation between the fuel elements and the aluminum channels is to maintain air gaps by using metallic projections on the channel walls. The thermal conductivity is then a strong function of the total width of aluminum ridges bridging the air gaps. To ensure point contact only, the ridges are made cylindrical in shape. The heat transfer from the fuel to the channel and 
to the $U^{238}$ foils was estimated by assuming a steady state and negligible conduction to the graphite. As mentioned above, a large portion of the heat may be conducted to the graphite during slow transients, and a fuse must be provided to take care of inadvertent periods larger than 1 sec. It was not thought desirable to provide the $U^{238}$ foils or the fuel elements with ridges similar to those on the channel walls, and thermal insulation at the fuel- $U^{238}$ boundary must be provided by some other means. A sheet of insulating material, such as asbestos cloth or fiberglass, will be fastened on each $U^{238}$ foil. The thickness will not have to exceed $0.003 \mathrm{in}$. in order to satisfy the requirements for thermal insulation. Heat Transfer from Molten Fuel

On the basis of reactor kinetic calculations, assuming flat power distribution in the core, it is estimated that before the fuel assumes the less reactive slumped configuration, it will be superheated to $150^{\circ} \mathrm{F}$. To arrive at this estimate, it is supposed, conservatively, that the fuel will stand as a column of viscous fluid until all the excess aluminum is molten (at $350 \mathrm{Mw}-\mathrm{sec}$ ) and then suddenly will slump in a time interval of twice the free-fall time, i.e., $200 \mathrm{msec}$. If it is assumed that all the heat transferred to the channel is absorbed homogeneously, the channels will have been brought to an average temperature of $450^{\circ} \mathrm{C}$ by the time the fuel has solidified from an initial temperature of $810^{\circ} \mathrm{C}\left(150^{\circ} \mathrm{C}\right.$ superheat).

The actual flux distribution is likely to peak in the reflector and it is conceivable that the amount of superheat in the fuel elements adjacent to the core-reflector interface will be two or three times as high as $150^{\circ} \mathrm{C}$. If no containment were provided, the fuel could then melt through the aluminum channels and spread into a highly reactive configuration. In order to prevent this effect, a 0.003-in. stainless steel container will be placed around the outside of the aluminum channel. 
Radiation Level

In connection with the critical experiment safeguards report, dose rates from the operating and shutdown critical as sembly have beencalculated and are shown in Figs. 4. 1 through 4.4. These curves show attenuation for direct radiation only.

An attempt was made to calculate the radiation that is due to gamma scattering from the atmosphere. In this calculation, the gamma photon was assumed to undergo a single collision. For simplicity, the differential scattering cross section was assumed to be constant for all angles, the energy degradation was assumed constant, and the source (the core in this case) was assumed to be a point source of $2-\mathrm{Mev}$ photons. The constant values of scattering cross section and energy degradation were calculated by using the Klein-Nishina formula and the Compton effect for a scattering angle of $34^{\circ}$. This angle happens to be the most acute angle for single scattering that is permitted by the geometry of the problem. To further simplify the integration, only scattering that occurred in a semi-infinite slab lying between the center of the core and the detector point (the control console) was considered. The resultant dose due to "skyshine" was $1.7 \%$ of the direct gamma-radiation dose. The conservative value of $10 \%$ was used in the safeguards report for computing skyshine at any point of interest.

As an appendix to the critical experiment safeguards report, a section on emergency procedures was drafted. Possible incidents involving the critical experimentwere classifiedas major incidents and minor incidents. The distinction was made that a minor incident affects, at the most, property and personnel actually within the fenced area of the critical assembly. A major incident was defined as an incident in which radioactive material escapes into the atmosphereand thus necessitates evacuation of Laboratory personnel and possibly residents in the area surrounding 


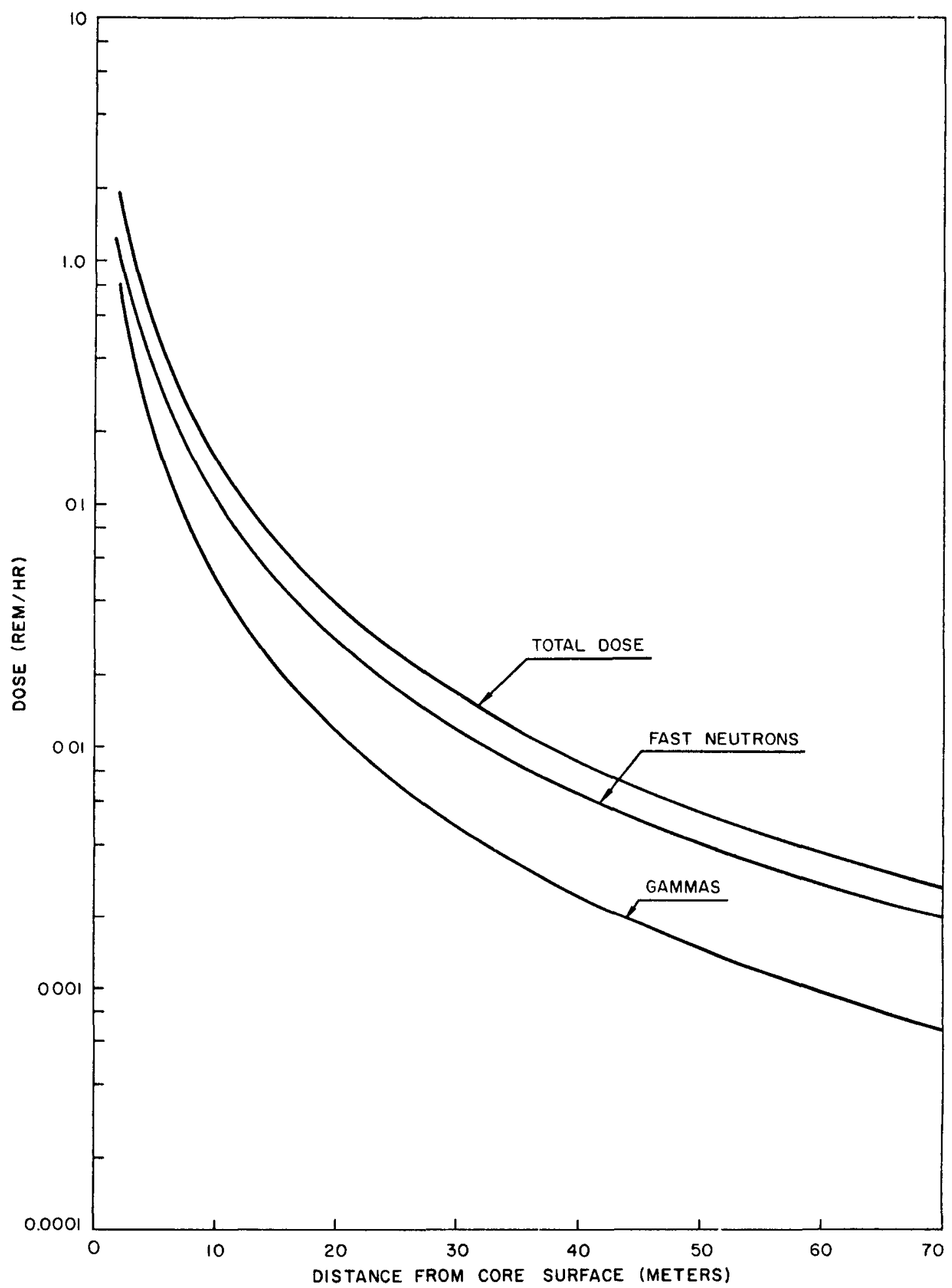

Fig. 4.1--Dose from direct radiation as a function of distance from core surface during continuous operation at $30 \mathrm{w}$ 


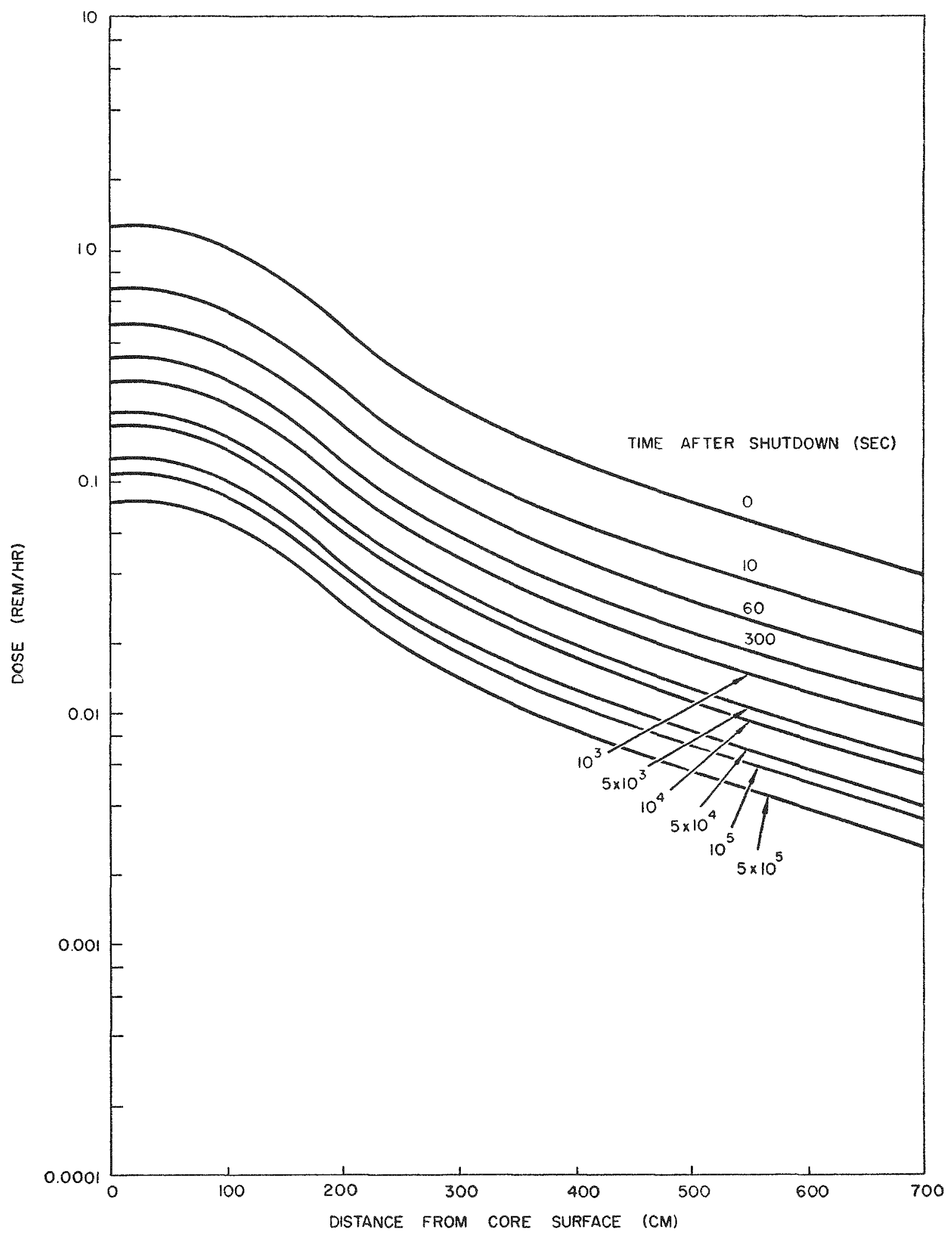

Fig. 4.2--Decay-gamma dose as a function of distance from core surface after infinite operation at $30 \mathrm{w}$ 


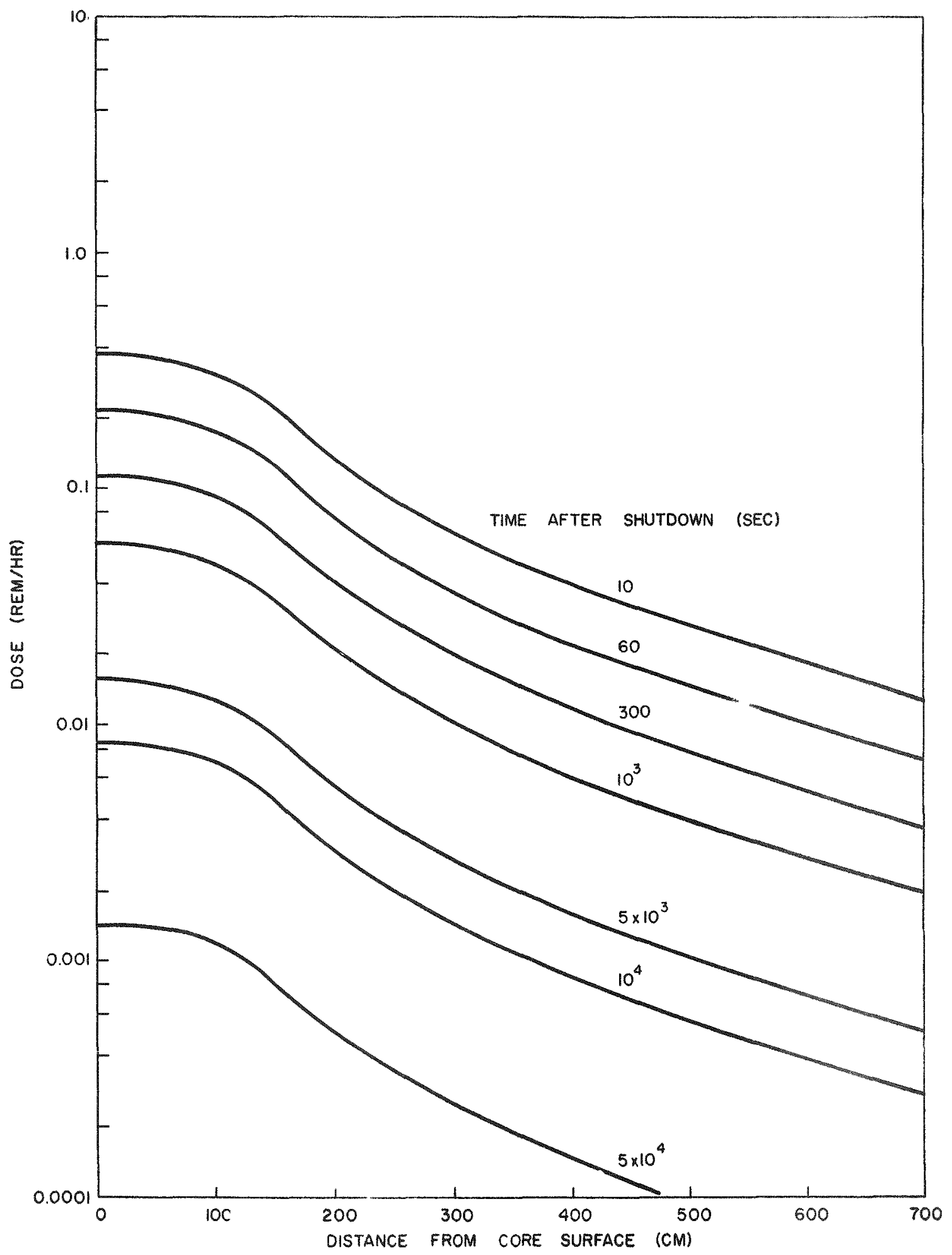

Fig. 4.3--Decay-gamma dose as a function of distance from core surface after operation at $30 \mathrm{w}$ for $1 \mathrm{hr}$ 


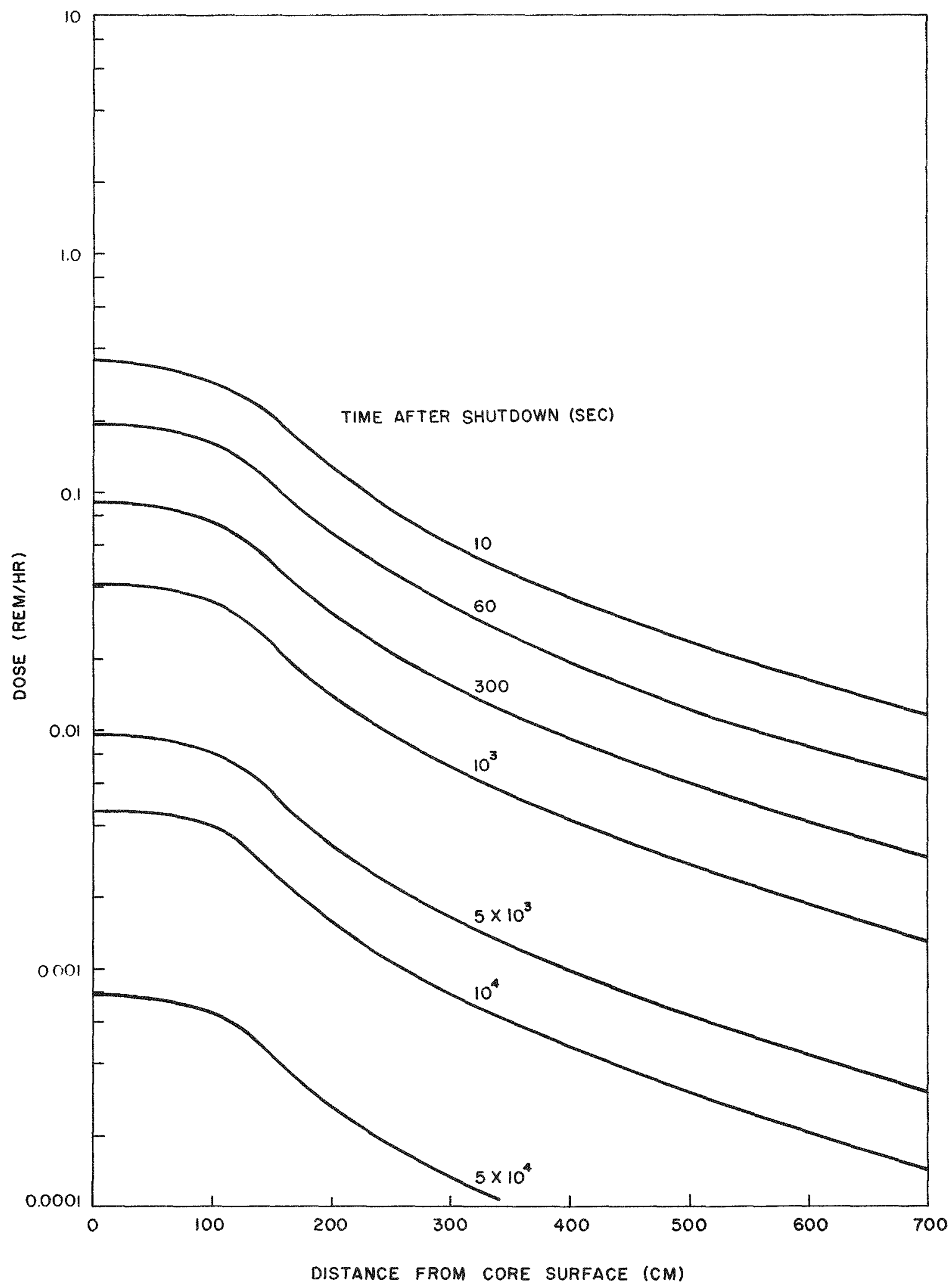

Fig. 4.4--Decay-gamma dose as a function of distance from core surface after operation at $30 \mathrm{w}$ for $30 \mathrm{~min}$ 
the General Atomic site. The philosophy of the procedure was that minor incidents can be brought under control by taking some well-defined action, whereas major incidents are of such a nature that no preventive measures are practical, and evacuation in the most sensible manner may be the only action that can be taken immediately. 


\section{MATERIALS DEVELOPMENT}

MATERIALS FOR THE REACTOR (W. P. Wallace)

Control-rod Materials (B. Turovlin and J. R. Lindgren)

Twenty compacts have been made, each of which contained $25 \mathrm{vol}-\% \mathrm{ZrO}_{2}(-150$ to $+200 \mathrm{mesh})$ and the remainder a stainless steel powder mixture $(-150$ to $+200 \mathrm{mesh})$. These were assembled into a cruciform and placed in a mild steel can, and were then extruded to a 25:1 reduction in area at Harvey Aluminum Company. For economic and safety reasons, zirconium oxide was used to make the simulated control rods instead of a rare-earth oxide. An evaluation of these extrusions is in progress.

Fuels Development (D. Johnson, J. Tobin, A. Miller, F. Lofftus, B. Czech, N. Baker, and R. LaPorte)

It is anticipated that the fuel bodies for the MGCR will consist of a mixture of particles of the fuel phase dispersed in a nonfissionable phase. The fuel materials under consideration are $\mathrm{UO}_{2}, \mathrm{UC}$, and $\mathrm{UC}_{2}$. The materials under consideration as matrix materials are $\mathrm{BeO}, \mathrm{Al}_{2} \mathrm{O}_{3}$, and graphite. The fuel materials may occupy up to $20 \%$ of the fuel-rod volume and will be present in the form of particles of a size to be determined.

The work at General Atomic was primarily directed toward the fabrication of $\mathrm{UO}_{2}$-containing alumina bodies. Some preliminary studies of methods for the fabrication of graphite bodies were also made. The work at Battelle Memorial Institute (BMI) was directed toward the development of fabrication techniques for bodies consisting of $\mathrm{UO}_{2}$ particles in $\mathrm{BeO}$, $\mathrm{UC}$ particles in graphite, and $\mathrm{UC}_{2}$ particles in graphite.

As reported last quarter in GA-1030, a study of the sintering behavior of alumina in a hydrogen atmosphere was conducted. During the present 
quarter, a study was made of the effect on the sintering behavior of compacts when several impurities were added to high-purity alumina. The variable investigated was the pellet density after sintering for $2 \mathrm{hr}$ at $1,700^{\circ} \mathrm{C}$. The alumina powder that was used contained less than $100 \mathrm{ppm}$ total impurities before sintering and before the additions were made. The results obtained are noted in Table 5. 1. The density values for the pellets were determined by a water-immersion technique; the values reported are the averages for ten pellets.

From these data, it was concluded that titania is the most effective of the sintering aids investigated. Additions of soda appear to have an adverse effect on the density of alumina after sintering in hydrogen. Additions of magnesia to alumina resulted in an increase in the sintered density, but surface blisters were formed on the pellet surfaces. Additions of silica resulted in excessive porosity. Additions of zirconia and nickel oxide were only moderately effective under the conditions used.

Thirty pellets consisting of a homogeneous mixture of fully enriched $\mathrm{UO}_{2}$ powder and finely divided $\mathrm{Al}_{2} \mathrm{O}_{3}$ powder were fabricated for use in a capsule irradiation experiment in the TRIGA reactor. The composition of the pellets was $40.7 \mathrm{wt}-\% \mathrm{UO}_{2}$ and $59.3 \mathrm{wt}-\% \mathrm{Al}_{2} \mathrm{O}_{3}$. By a waterimmersion technique, the average density for the pellets was determined to be $96.3 \%$ of theoretical density.

Three experiments were performed to obtain a rough estimate of the ability of alumina pellets and of a simulated semihomogeneous fuel assembly to withstand thermal stresses and stresses induced by differential thermal expansion. A cross section is shown in Fig. 5. 1.

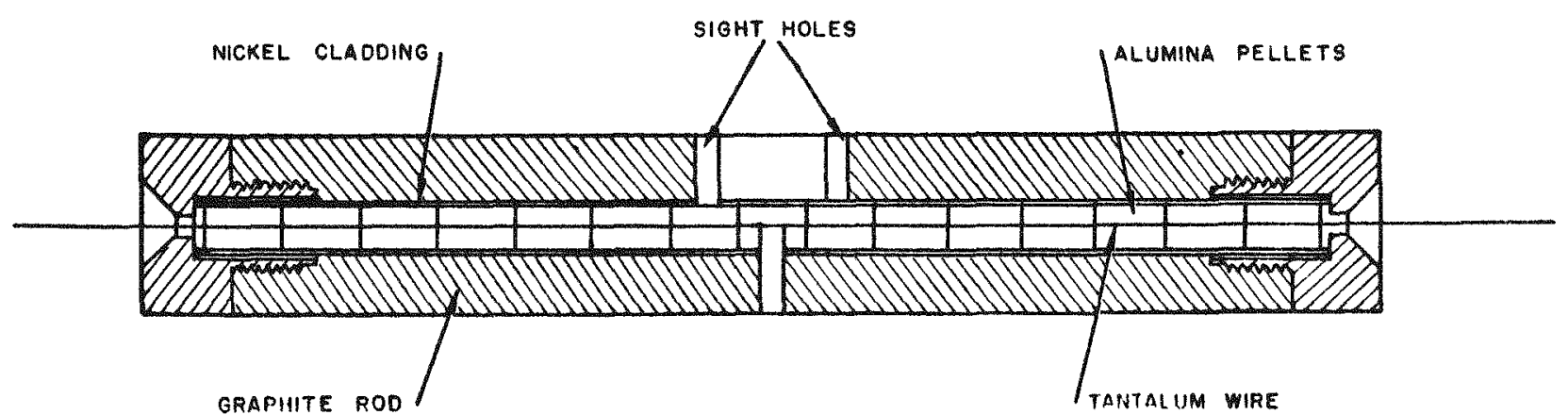

Fig. 5. 1--Cross section of experimental as semblv 
Table 5. 1

SINTERED DENSITY OF ALUMINA PELLETS, CONTAINING KNOWN IMPURITIES, AFTER SINTERING IN HYDROGEN

\begin{tabular}{|c|c|c|c|}
\hline $\begin{array}{l}\text { Impurity } \\
\text { Addition }\end{array}$ & $\begin{array}{c}\text { Impurity } \\
\text { Concentration } \\
(w t-\%)\end{array}$ & $\begin{array}{l}\text { Density } \\
\left(\mathrm{g} / \mathrm{cm}^{3}\right)\end{array}$ & Comments \\
\hline \multirow[t]{3}{*}{ None } & $\ldots$. & 3.69 & \\
\hline & 0.01 & 3.68 & \\
\hline & 0.01 & 3.74 & \\
\hline \multirow{6}{*}{$\mathrm{TiO}_{2}$} & 0.1 & 3.75 & \\
\hline & 0.1 & 3.74 & \\
\hline & 1.0 & 3.78 & Pellets were grey \\
\hline & 5.0 & 3.9 & Pellets were black \\
\hline & 0.017 & 3.67 & All samples \\
\hline & 0.02 & 3.70 & were porous \\
\hline \multirow{4}{*}{$\mathrm{SiO}_{2}$} & 0.05 & 3.73 & and densities \\
\hline & 0.1 & 3.71 & are therefore \\
\hline & 1.0 & 3.66 & approximate. \\
\hline & 0.01 & 3.65 & \\
\hline \multirow{5}{*}{$\mathrm{Na}_{2} \mathrm{O}$} & 0.1 & 3.65 & \\
\hline & 1.0 & 3.63 & \\
\hline & 5.0 & 3.46 & \\
\hline & 0.02 & 3.8 & Most of the \\
\hline & 0.05 & 3.8 & pellets containing \\
\hline \multirow[t]{4}{*}{$\mathrm{MgO}$} & 0.1 & 3.8 & magnesia exhibited \\
\hline & 0.5 & 3.8 & surface blisters \\
\hline & 1.0 & 3.8 & \\
\hline & 0.01 & 3.74 & \\
\hline \multirow[t]{4}{*}{$\mathrm{NiO}$} & 0.1 & 3.72 & \\
\hline & 1.0 & 3.74 & \\
\hline & 5.0 & 3.81 & \\
\hline & 0.01 & 3.74 & \\
\hline \multirow{3}{*}{$\mathrm{ZrO}_{2}$} & 0.1 & 3.65 & \\
\hline & 1.0 & 3.70 & \\
\hline & 5.0 & 3.78 & \\
\hline
\end{tabular}


The test assemblies were mounted in the vacuum bell-jar system. The pressure in the bell jar was maintained at well below $1 \mu$ for all tests. The assemblies were heated by passing electric current through the axial tantalum heating filament. The temperature of the wire and of the pellet surface were measured with an optical pyrometer. Some of the temperatures achieved were: wire temperature, $2,140^{\circ} \mathrm{C}$; pellet surface temperature, $1,450^{\circ} \mathrm{C}$; cladding surface temperature, $700^{\circ}$ to $750^{\circ} \mathrm{C}$ (estimated); and graphite surface temperature, $700^{\circ} \mathrm{C}$ (estimated). These values do not include corrections for the effect of the glass bell jar on the pyrometer readings.

The temperatures of the nickel cladding and of the graphite cladding were estimated from the color of the respective surfaces. Subsequent metallographic examination of the alumina pellets did not reveal any radial cracks or other defects that could be attributed to thermal stress or thermal shock. Visual examination of the graphite sleeve did not reveal any cracks or other failures.

Work on the development of fabrication techniques for the production of $\mathrm{UO}_{2}$-bearing beryllia bodies was continued.

Brush Beryllium Company beryllia, Type LOH, is being used at BMI in their work on fuel-fabrication development for the MGCR. The reasons given were that (1) BMI personnel are familiar with methods for handling this material, (2) it is fairly easy to produce bodies that exhibit high densities from the LOH-grade beryllia powder, and (3) this beryllia powder is readily available. However, it is known that the LOH-grade beryllia powder contains about $2 \%$ impurities; the predominant impurities are sodium, calcium, magnesium, silicon, and aluminum. UOX-grade beryllia powder is of much higher purity but cannot presently be sintered to the same high densities. Another sponsor is financing a program to study the effect of impurities on the sintering behavior of beryllia powder at BMI, but no definite trends have been observed to date.

It was reported by $\mathrm{BMI}$ that the $\mathrm{UO}_{2}-\mathrm{BeO}$ specimens that were irradiated in the first capsule exhibited a density of about $89 \%$ of theoretical. 
Subsequent experiments have resulted in pellets with a density of about $98 \%$ of theoretical.

Neutron activation tests have been initiated to study the fissionproduct retention properties of representative fuel bodies.

Under contract to General Atomic, Battelle Memorial Institute is developing techniques for the fabrication of graphite bodies containing uranium dicarbide in the concentrations of interest for the MGCR.

The uranium-carbide-graphite fuel bodies made to date have exhibited relatively low graphite densities (in the region of $1.3 \mathrm{~g} / \mathrm{cm}^{3}$ ). Reasonably uniform distributions of the carbide particles in the graphite have been obtained, but some difficulty with breakage of the uranium carbide particles during mixing has been encountered. When compacts containing uranium monocarbide are heated to temperatures above $2,350^{\circ} \mathrm{F}$, some conversion of the monocarbide to a higher carbide occurs.

The primary effort in the fabrication development of uranium-carbidegraphite fuels is now being directed toward improving the density of the graphite matrix and toward determining if the release of fission products from uranium-monocarbide-graphite compacts is accelerated by conversion of the monocarbide to a higher carbide. The use of several starting materials and variations in processing techniques are being explored in an effort to improve the density of the graphite matrix and to reduce the rate of fracture of the carbide particles. Neutron activation and post-irradiation annealing techniques are being used to determine if the conversion of the monocarbide results in an increased rate of fission-product release. It is also planned to use neutron-activation techniques for comparing the fission-product release behavior of compacts containing the monocarbide with those containing the dicarbide. The annealing temperatures to be used in these experiments are listed in Table 5. 2.

Fuel-materials Chemistry (U. Merten, L. Dykstra, P. Winchell, and J. Dixon). In order to understand the chemistry of fuel systems containing uranium and oxygen, the ternary system of aluminum-ruanium- 
Table 5.2

ANNEALING TEMPERATURES

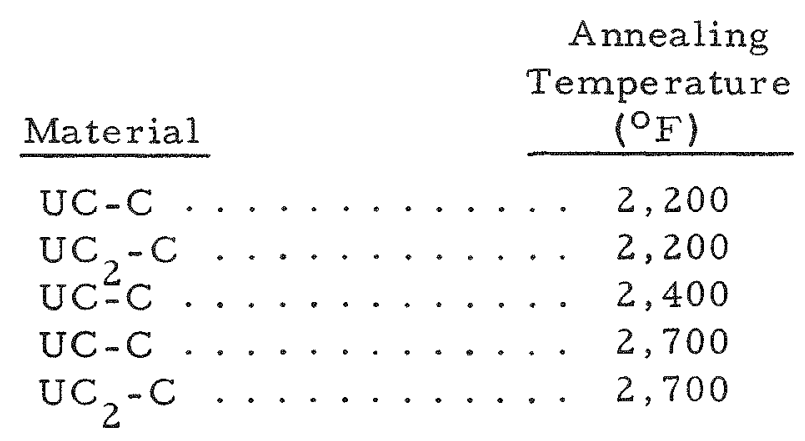

oxygen is being studied. Previously published work is limited to an investigation of the binary $\mathrm{Al}_{2} \mathrm{O}_{3}-\mathrm{UO}_{2}$ system. $\mathrm{Al}_{2} \mathrm{O}_{3}-\mathrm{UO}_{2}$ pressed pellets were annealed at $1,600^{\circ}$ to $1,900^{\circ} \mathrm{C}$ in vacuum. X-ray examination of samples at room temperature confirmed the results of previous investigators-there is no reaction and no miscibility of the two phases. Specimens cooled from the melt showed the same results. Because decomposition might have occurred during cooling, quenching a melt and high-temperature $\mathrm{X}$-ray diffraction are bing considered.

Our principal investigations have been concerned with that portion of the system in which the oxygen content is greater than in the $\mathrm{UO}_{2}-\mathrm{Al}_{2} \mathrm{O}_{3}$ binary. It has been suggested that the solution of $\mathrm{Al}_{2} \mathrm{O}_{3}$ in $\mathrm{UO}_{2}$ might be favored by an excess of oxygen. Also, the reaction between $\mathrm{Al}_{2} \mathrm{O}_{3}$ and $\mathrm{UO}_{3}$ at $450^{\circ}$ to $600^{\circ} \mathrm{C}$, with formation of a uranate, has been reported. A suitable uranium compound to use an alloying material in this region of the diagram would be $\mathrm{UO}_{3}$. Unfortunately, commercial $\mathrm{UO}_{3}$ has been found to be the monohydrate, and our efforts to dehydrate it have always resulted in simultaneous loss of oxygen. Attempts to prepare the most stable crystalline form of $\mathrm{UO}_{3}$ by methods reported in the literature have so far failed. Despite these difficulties, an attempt was made to prepare the reported $\mathrm{Al}_{2} \mathrm{O}_{3}-\mathrm{UO}_{3}$ compound by pressing pellets of the $\mathrm{UO}_{3}$ hydrate and $\mathrm{Al}_{2} \mathrm{O}_{3}$ and heating in air at about $550^{\circ} \mathrm{C}$; no reaction except dehydration 
and oxygen loss was observed. Further experiments to produce $\mathrm{UO}_{3}$ and to react it with $\mathrm{Al}_{2} \mathrm{O}_{3}$ are in progress. Oxygen pressures up to $25 \mathrm{~atm}$ are being employed to prevent reduction of the $\mathrm{UO}_{3^{\circ}}$

A start has also been made on an investigation of the low-oxygen content portion of the U-Al-O system. The compounds $\mathrm{UAl}_{2}$ and $\mathrm{UAl}_{3}$ have been prepared and oxidized to varying degrees. These experiments are still in progress.

Fission-product Retention by Fuel Bodies (A. Miller, D. Johnson, J. Tobin, and B. (zech). The release of Xe $\mathrm{X}^{133}$ from 15 samples of sintered $\mathrm{UO}_{2}$ and from samples of fused $\mathrm{UO}_{2}$ was studied; the samples were crushed and sieved before being irradiated in the TRIGA reactor for $1 \mathrm{hr}$ at $100 \mathrm{kw}$. The samples were annealed at $1,400^{\circ} \mathrm{C}$ and the xenon was collected and monitored in an apparatus described more fully in GA-1030. A rate meter and a recorder have been added to permit continuous recording of the collected xenon.

The results that have been obtained to date for the work on the release of fission products from particles of sintered and of fused $\mathrm{UO}_{2}$ are summarized in Fig. 5.2. The amount of xenon released was found to be inversely related to the particle diameter for the conditions of the experiment (anneal for $20 \mathrm{hr}$ at $1,400^{\circ} \mathrm{C}$ ). One per cent of the xenon was released from unsintered submicron size $\mathrm{UO}_{2}$ powder; this represents an upper limit of release.

It is planned to conduct similar experiments at a higher temperature $\left(1,600^{\circ} \mathrm{C}\right)$ with $\mathrm{UO}_{2}$ particles and then to study the release of fission products from alumina bodies which contain particles of $\mathrm{UO}_{2}$. The construction of a tantalum-filament furnace for use in the study of the release of fission products from fuel materials and from ceramic bodies that contain fuel is about $95 \%$ complete.

Specimens were prepared to permit an evaluation of the fissionproduct retention characteristics of alumina as prepared and sintered in our laboratory. A series of fuel-bearing wafers of three types were 


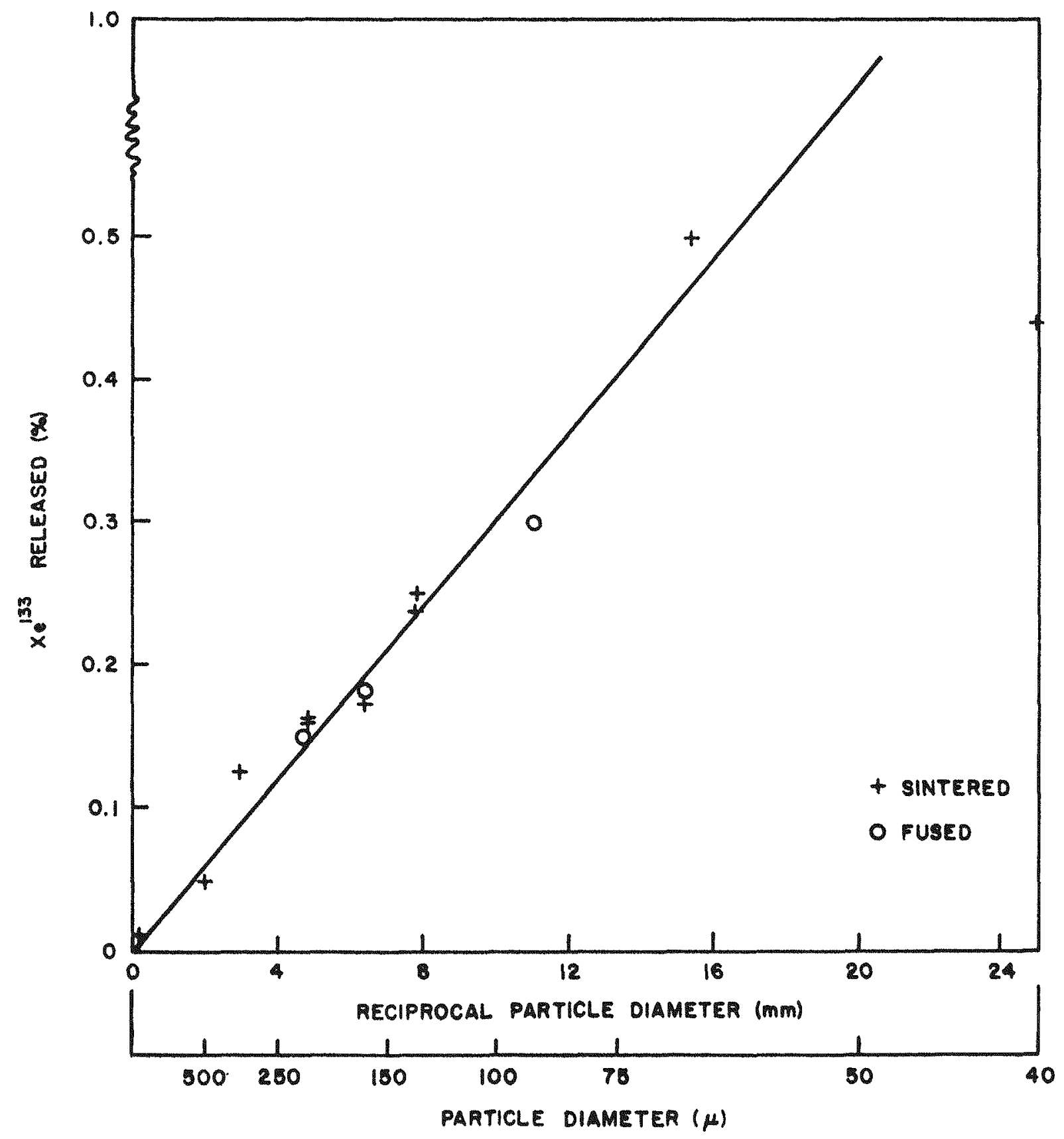

Fig. 5.2--Release of $\mathrm{Xe}^{133}$ from sintered and fused $\mathrm{UO}_{2}$ as a function of particle size $\left(20-\mathrm{hr}\right.$ anneal at $\left.1,400^{\circ} \mathrm{C}\right)$ 
prepared for this experiment. The first type contained only $\mathrm{UO}_{2}$, the second was a homogeneous mixture of very fine $\mathrm{UO}_{2}$ and ball-milled alumina, and the third was a wafer of $\mathrm{UO}_{2}$ completely surrounded by dense alumina. The alumina-clad $\mathrm{UO}_{2}$ wafers (third type) were heated to $600^{\circ} \mathrm{C}$ in an oxygen atmosphere. The alumina cladding ruptured, which indicated that oxygen had diffused through a defect, oxidizing (and thereby expanding) the $\mathrm{UO}_{2}$. These wafers released the same xenon as unclad $\mathrm{UO}_{2}$ wafers.

Alumina-clad $\mathrm{UO}_{2}$ spheres manufactured by BMI were also heated to $600^{\circ} \mathrm{C}$ in oxygen; these did not rupture.

Irradiation Stability of MGCR Fuel Materials (D. Johnson and J. Tobin). The first MGCR fuel irradiation capsule was inserted into the BRR and irradiation began on April 8. The irradiation of the capsule was completed and the capsule was removed from the reactor on June 1, 1959. No unusual behavior of the capsule occurred during irradiation. The capsule was opened and the specimens were examined during June. The types of specimens irradiated and their locations in the capsule are shown in Table 5.3.

Table 5.3

LOCATIONS AND TYPES OF IRRADIATED SPECIMENS

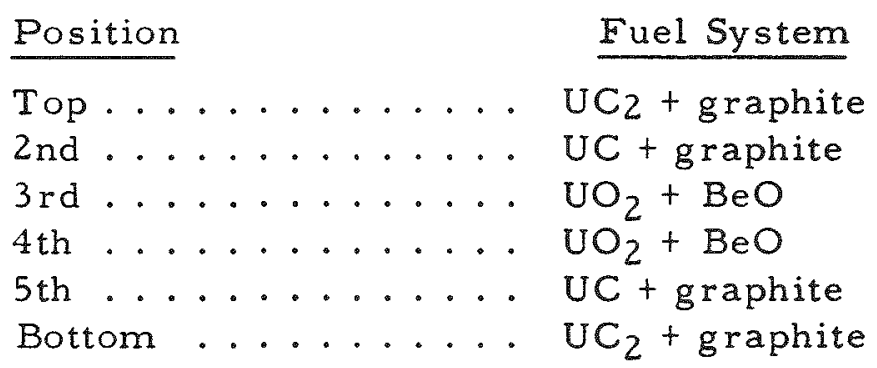

The specimens were 0.220-in.-diam,0.250-in.-OD pellets clad with Type 316 stainless steel. Four 1/2-in. -long pellets were contained in each specimen. Two specimens each of three fuel materials were irradiated.- $-\mathrm{UO}_{2}$ in $\mathrm{BeO}, \mathrm{UC}$ in graphite, and $\mathrm{UC}_{2}$ in graphite. It was 
intended that the fuel bodies contain about 20 vol-\% of the fuel phase, but the pellets fabricated contained about 24 vol-\%. The fuel phase contained fully enriched uranium in each case. Pertinent data on the fuel bodies are noted in Table 5. 4.

Table 5.4

DATA ON SPECIMENS IN THE FUEL IRRADIATION CAPSULE

\begin{tabular}{|c|c|c|c|c|c|}
\hline Specimen & Material & $\begin{array}{l}\text { Fuel Loading } \\
\left(\mathrm{g} \text { of } \mathrm{U}^{235}\right)\end{array}$ & $\begin{array}{c}\text { Clad Surface } \\
\text { Temperature } \\
\text { Estimated } \\
\left({ }^{\circ} \text { F) }\right.\end{array}$ & $\begin{array}{c}\text { Surface } \\
\text { Heat Flux } \\
\text { Btu/(hr) }\left(\mathrm{ft}^{2}\right)\end{array}$ & $\begin{array}{c}\text { Burnup } \\
\left(\% \text { of } \mathrm{U}^{235}\right. \\
\text { atoms) }\end{array}$ \\
\hline 5 & $\mathrm{UC}_{2}-\mathrm{C}$ & 1.46 & 1,520 & 204,000 & 1.58 \\
\hline 9 & $U C-C$ & 1. 44 & 1,560 & 198,000 & 1.56 \\
\hline 3 & $\mathrm{UO}_{2}-\mathrm{BeO}$ & 1.35 & 1,550 & 179,000 & 1.50 \\
\hline 1 & $\mathrm{UO}_{2}^{2}-\mathrm{BeO}$ & 1.35 & 1,510 & 165,000 & 1.39 \\
\hline 8 & $U C-C$ & 1. 44 & 1,430 & 156,000 & 1.23 \\
\hline 4 & $U C_{2}-C$ & 1. 46 & 1,270 & 132,000 & 1.01 \\
\hline
\end{tabular}

The post-irradiation measurements included dimensional determination of the fuel claddings, density determination of the clad specimens, dimensional measurement of the individual fuel pellets, collection and analysis of the fission gas that had accumulated in the several claddings, and metallography of the fuel pellets and of the pellet claddings.

Micrometer measurements and density determinations of the clad specimens indicated that no detectable change in the cladding dimensions occurred during irradiation. No detectable change in the dimensions of the $\mathrm{UO}_{2}-\mathrm{BeO}$ pellets from specimen No. 1 occurred during irradiation. The diameter of the UC-C pellets from specimens No. 8 and 9 decreased about $1-1 / 2 \%$ during irradiation. The diameter of the $\mathrm{UC}_{2}-\mathrm{C}$ pellets from specimen No. 4 decreased slightly more than $1 \%$ during irradiation. The pellets from the remaining $\mathrm{UO}_{2}-\mathrm{BeO}$ specimen and from the $\mathrm{UC}_{2}-\mathrm{C}$ specimen were broken when the claddings were punctured to collect the fission gases. 
The metallographic examination of the Type 316 stainless steel cladding from a $\mathrm{UO}_{2}-\mathrm{BeO}$ specimen did not reveal evidence of radiation effects in the stainless steel. The metallographic examination of individual fuel pellets and the analysis of the gas samples that were collected have not been completed.

Threeadditional capsules have been fabricated. These capsules are scheduled for irradiation in the MTR beginning about July 1, 1959 (MTR cycle No. 125). One capsule is scheduled for $12 \%$ burnup of the $U^{235}$ and the remaining two capsules are scheduled for about $20 \%$ burnup of the $\mathrm{U}^{235}$. It is planned that essentially the same types of fuel specimens would be irradiated in the MTR as were irradiated in the BRR, except that the enrichment would be adjusted for the higher flux. The fuel used for the MTR irradiation specimens was $30 \%$ enriched.

Work on the sweep-gas capsule program at BMI has consisted primarily of the design of the experimental equipment and capsules, and procurement of the apparatus. It is anticipated that the first sweep-gas capsule may be ready for insertion into the BRR in October.

Work on the diffusion of fission products through metallic claddings has consisted in developing the techniques for assembling the specimens and in some preliminary exploratory work on the impregnation of metallic surfaces with argon by a cathodic bombardment technique.

Graphite-Metal Reactions (J. Bokros, J. Barry, W. Ellis, D. Guggisberg, and C. Mungle)

Strength Tests. Two experiments to determine the influence of precipitated carbon on the ductility of Monel and " $A$ " nickel are almost complete. Twelve tensile specimens were machined from 0.031-in. sheets of each material and saturated with carbon by pack carburizing in graphite $+5 \% \mathrm{BaCO}_{3}$ for $500 \mathrm{hr}$ at $1,700{ }^{\circ} \mathrm{F}$. Control specimens were heated in vacuum to the carburizing temperature for the same time. Two carburized and two control samples of each material were tensile tested at room temperature. Carburized samples of each material were aged in vacuum 
at $600^{\circ}, 800^{\circ}, 1,000^{\circ}$, and $1,200^{\circ} \mathrm{F}$ for $1,000 \mathrm{hr}$ to precipitate the carbon from solid solution and subsequently tensile tested at room temperature. The resulting stress-strain curves are plotted in Figs.5.3 and 5.4. The curves for "A" nickel show an increase in strength of $39 \%$ due to carburization, but show no accompanying decrease in ductility. Aging at $600^{\circ}$ and $800^{\circ} \mathrm{F}$ in vacuum for $1,000 \mathrm{hr}$ resulted in a further increase in strength. The samples annealed at $1,000^{\circ}$ and $1,200^{\circ} \mathrm{F}$ over-aged and thus exhibited strengths below those of the carburized specimen, but above the control specimen. Aging did not in any case significantly decrease the ductility of carburized nickel.

Carburization of Monel caused an increase in strength of $19 \%$ without a loss in ductility. Aging at $600^{\circ}, 800^{\circ}, 1,000^{\circ}$, and $1,200^{\circ} \mathrm{F}$ for $1,000 \mathrm{hr}$ resulted in a further increase of about $18 \%$ without a $10 \mathrm{ss}$ in ductility (Fig。 5。4). The metallographic examination to determine the size and distribution of precipitated carbon is not complete. Results of tests on nickel and nickel-copper alloys show them to be preferred as a graphite cladding material for temperatures as high as $1,700^{\circ} \mathrm{F}$.

Cycling Tests. Hexagonal test fuel-element assemblies containing six simulated 1/4-in.-OD, 4-in。-long nickel-clad simulated fuel pins are being cycled from room temperature to $1,700^{\circ} \mathrm{F}$ in 500 to $1,000 \mathrm{psi}$ helium to determine the mechanical stability of an assembly of this type and to further check material compatibility. An assembly of this type is shown in Fig. 5.5, and the thermal cycle is shown in Fig. 5。6.

Two types of simulated fuel are being used. One hexagon contains 1/2-in.-long alumina pellets clad with 0.010 in. of "A" nickel and the other contains six graphite pins clad with 0.010 in. of "A" nickel. The results for these two types are presented here:

1. Results for nickel-clad graphite. The hexagon containing six graphite pins clad with 0.010 in of "A" nickel was removed after 47 cycles. The chemical analysis of the helium after the test is shown in Table 5. 5. Each pin was checked with a helium leak detector for tightness--all six 


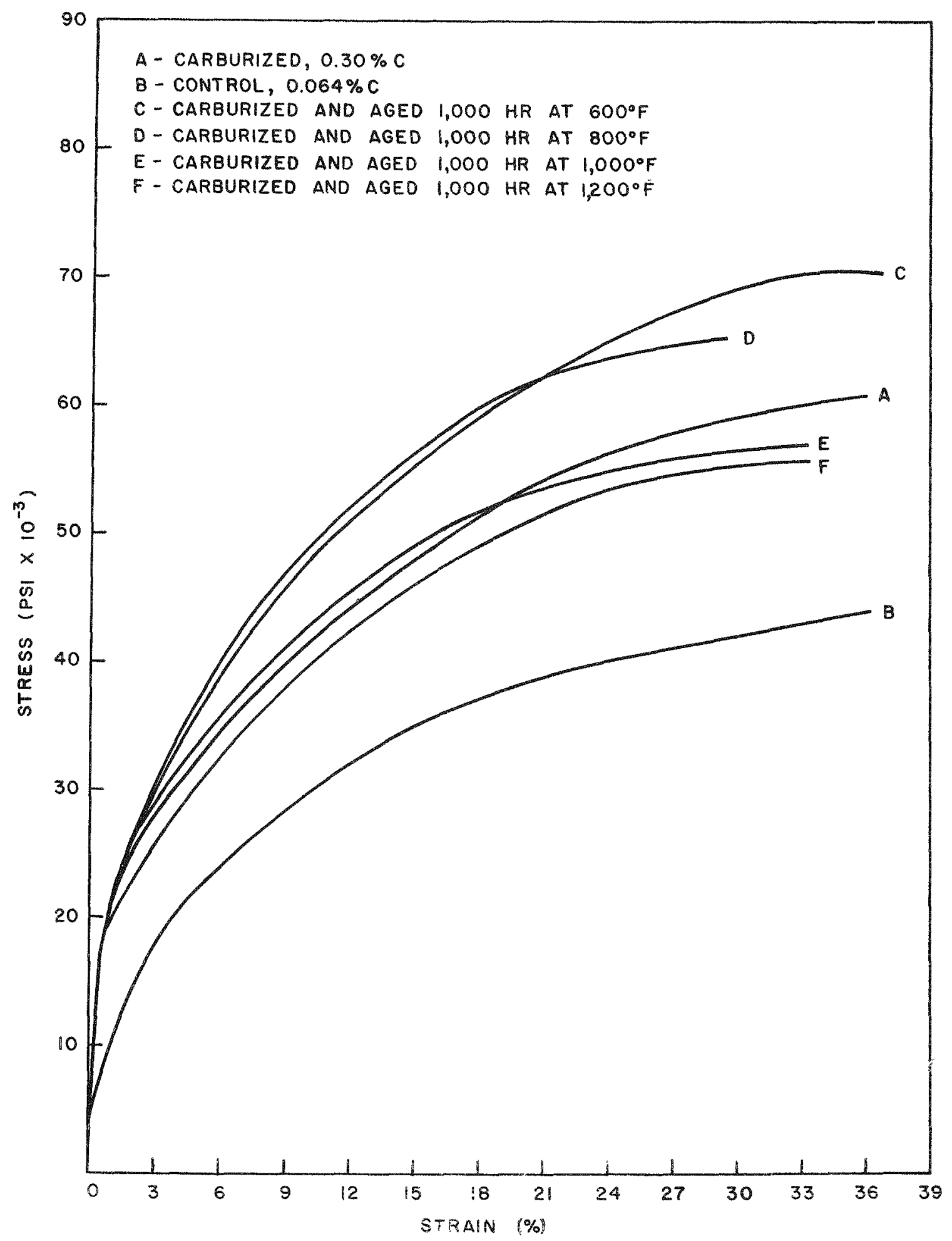

Fig. 5.3--Room temperature stress-strain curve for "A" nickel 


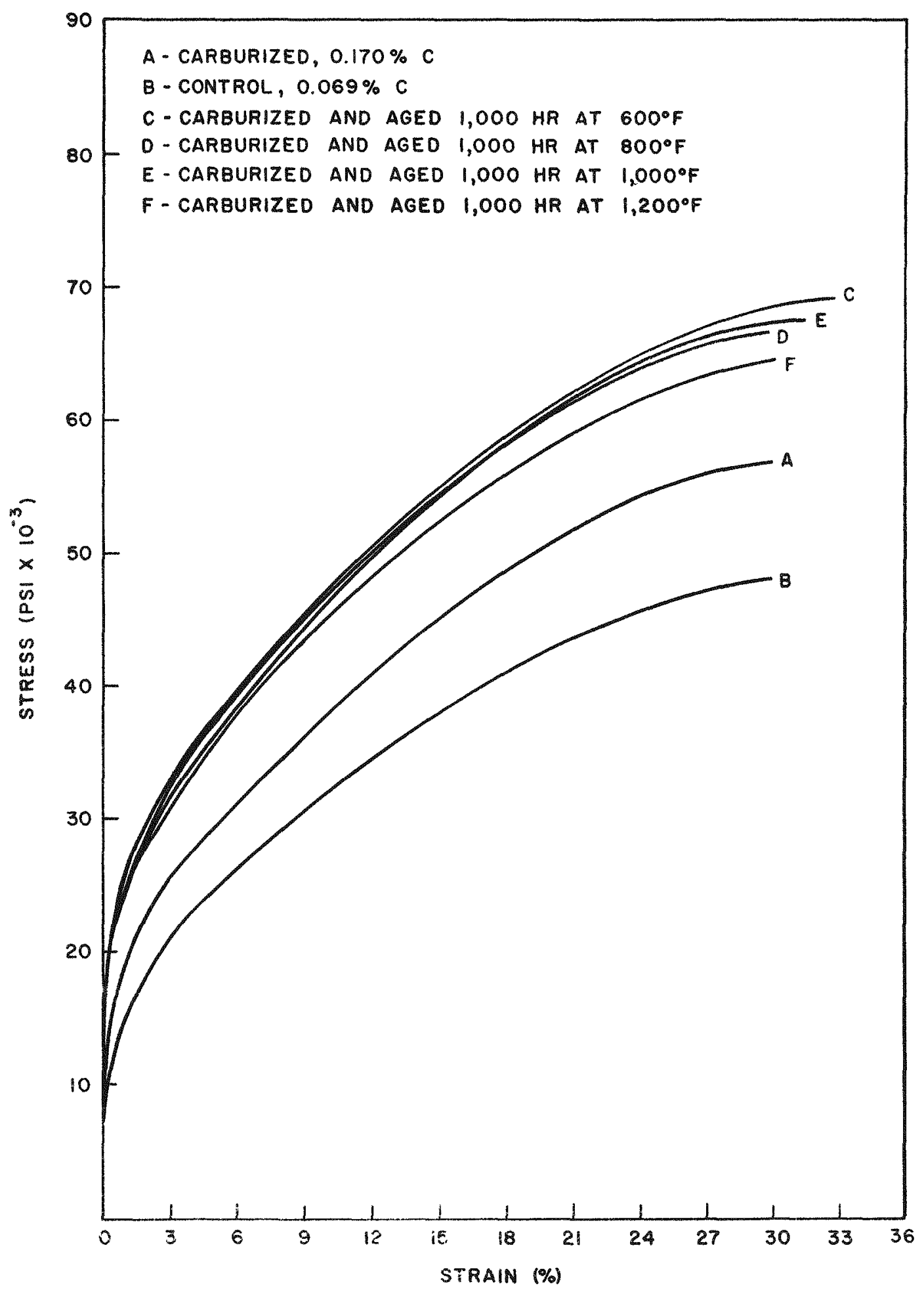

Fig. 5.4...Room temperature siress-strain curve for Monel 


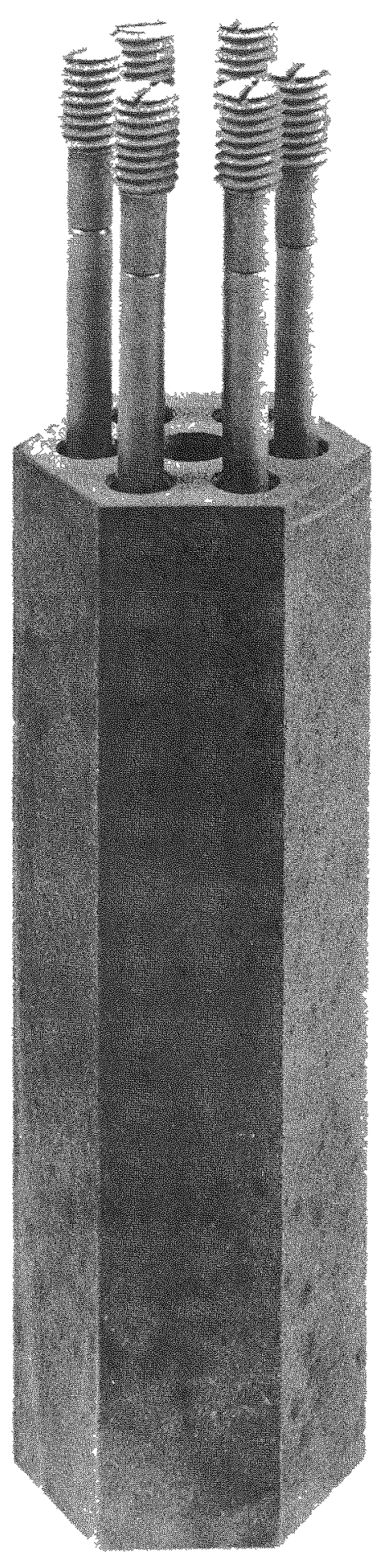

Fig. 5.5--Test fuel-element assembly used in thermal cycling tests (1X) 


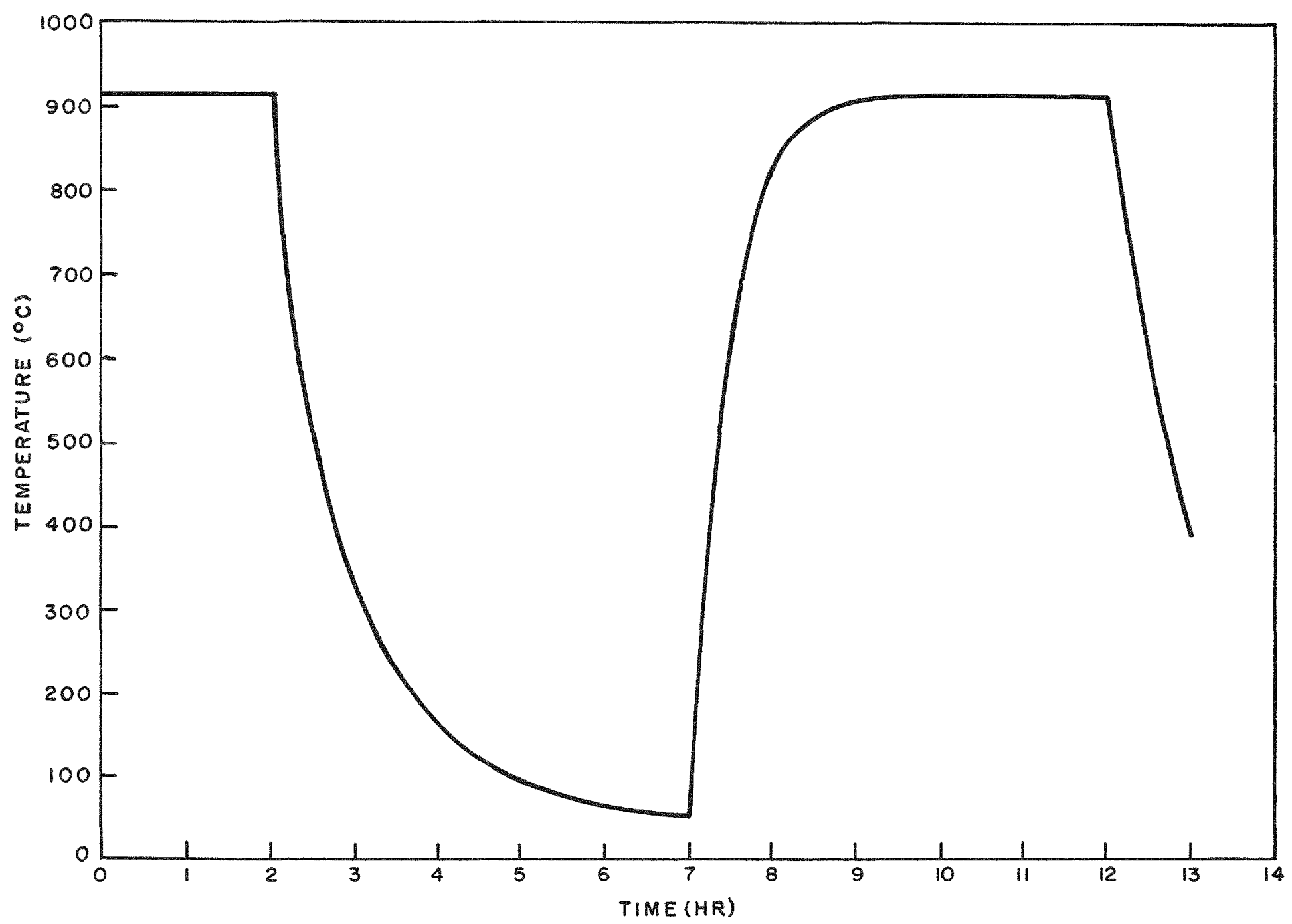

Fig. 5. 6--Thermal cycle used in high-pressure helium thermal cycling tests 
Table 5.5

CHROMATOGRAPHIC ANALYSIS OF HELIUM IN WHICH NICKEL-CLAD GRAPHITE TEST FUEL ASSEMBLY WAS CYCLED

\begin{tabular}{c|c|c}
\hline Impurity & After 47 cycles & After 107 cycles \\
\hline $\mathrm{H}_{2}$ & 0.070 & $\ldots .$. \\
$\mathrm{O}_{2}$ & 0.0025 & trace \\
$\mathrm{N}_{2}$ & 0.0107 & trace \\
$\mathrm{CH}_{4}$ & 0.0023 & $\ldots .$. \\
$\mathrm{CO}$ & 0.0700 & 0.0187 \\
$\mathrm{CO}_{2}$ & 0.0035 & $\ldots .$. \\
\hline
\end{tabular}

pins were leak-tight. A macrophotograph of the pins is shown in Fig. 5.7. A metallographic examination of one of these pins revealed the presence of small spheroids of graphite, about 0.0002 to $0.0003 \mathrm{in}$. in diameter, which had developed in the nickel microstructure. Photomicrographs of this cladding are shown in Figs.5.8a and 5.8b magnified 100 and 500 times, respectively. These spheroids do not affect the room-temperature ductility.

The remaining pins were cycled an additional 28 times and were removed for examination. All five were leak-tight. Macrophotographs of the pins after 75 cycles are shown in Fig. 5.9, and a cross section of one of these pins is shown in Fig. 5.10. The microstructure of the nickel cladding revealed the same graphite sphercids, and the diameter was not significantly larger than that observed after the 47 cycles $<0.0005$ in. diam).

The four remaining pins were cycled an additional 32 times for a total of 107 cycles without failure; they are shown in Fig. 5.11. Metallographic results on one of these pins are not complete. The remaining three pins have been re-inserted in the autoclave for further cycling.

2. Results for nickel-clad alumina pins. The assembly containing six alumina pins clad with 0.010 in. of "A" nickel was cycled 30 times from room temperature to $1,700^{\circ} \mathrm{F}$. Chemical analysis of the helium 

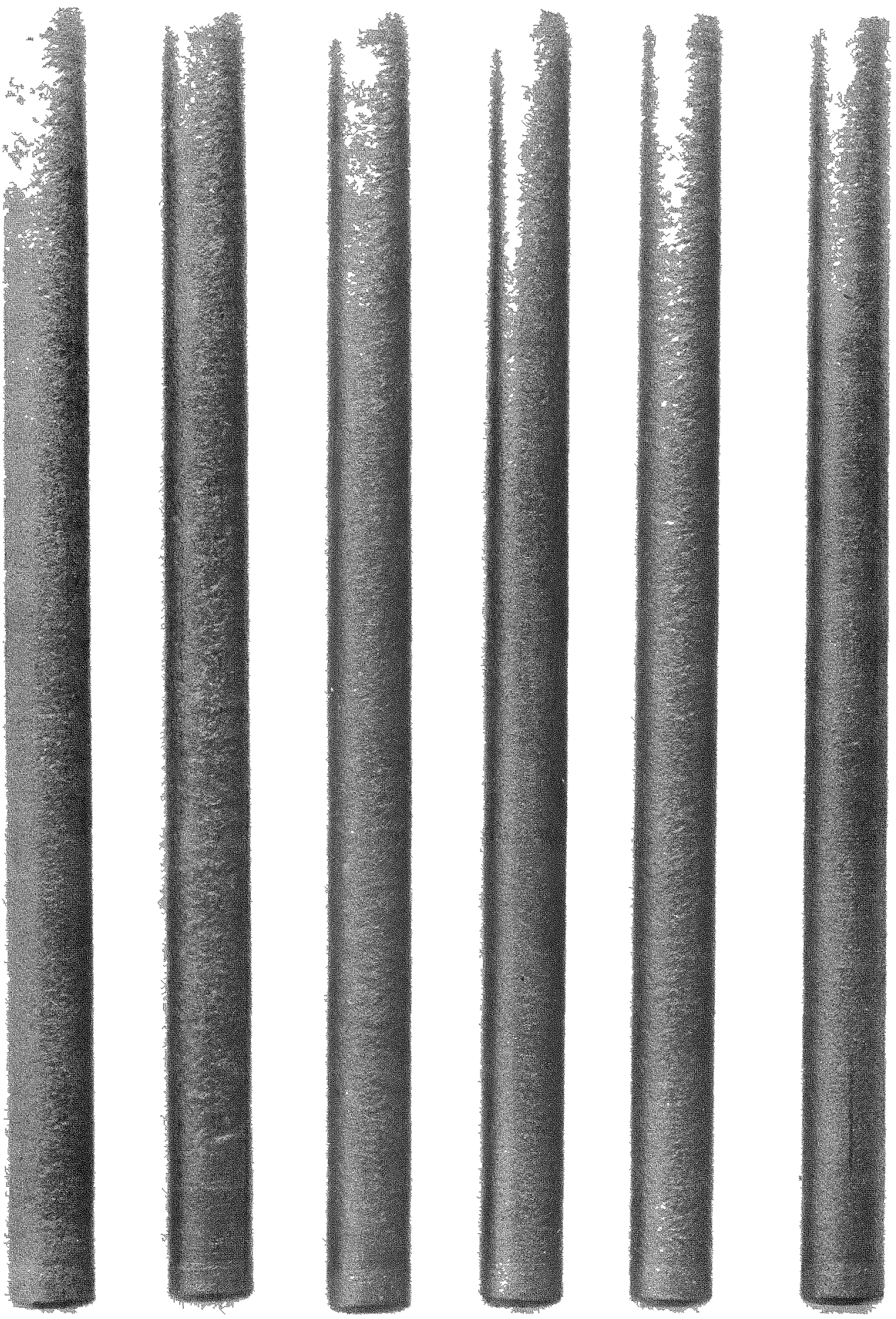

Fig. 5.7--Nickel-clad graphite pins cycled 47 times from room temperature to $1,700^{\circ} \mathrm{F}$ in 500 to $1,000 \mathrm{psi}$ helium 

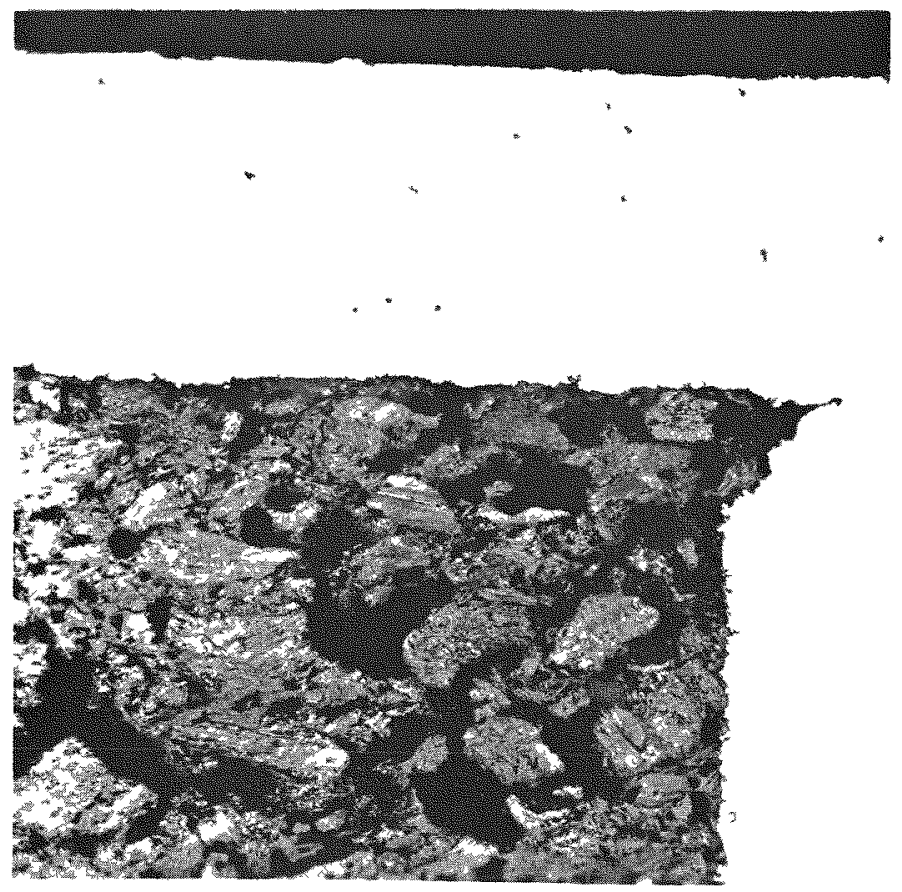

$(100 X)$
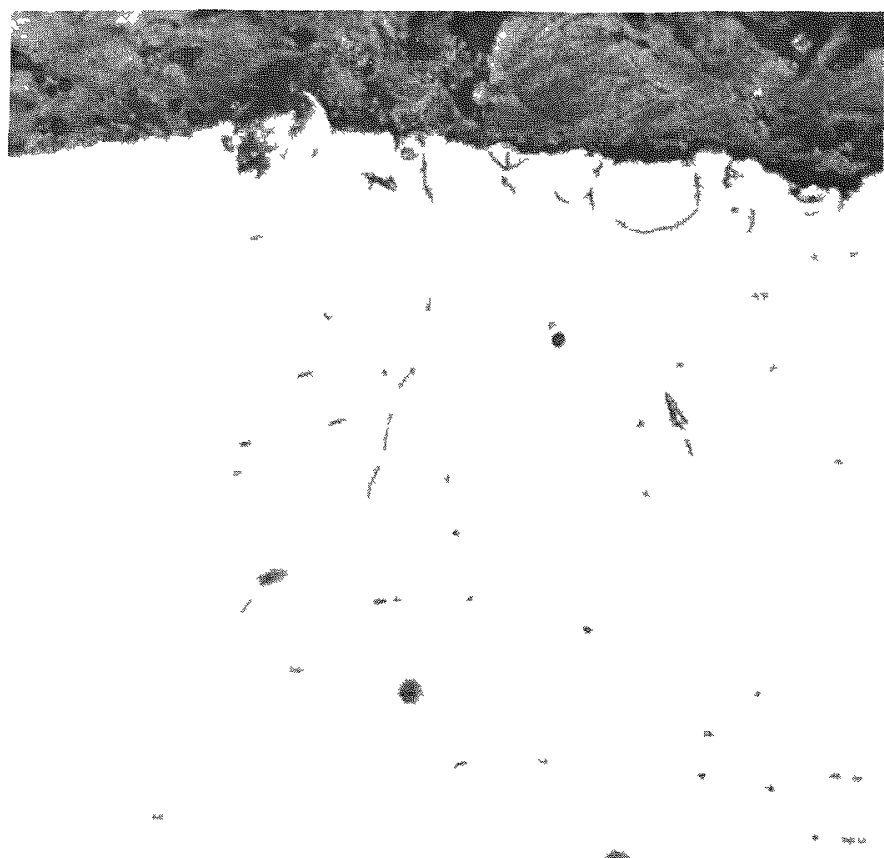

$(500 X)$

Fig. 5.8--Photomicrographs of nickel cladding on graphite after 47 cycles from room temperature to $1,700^{\circ} \mathrm{F}$ in 500 to 1,000 psi helium 

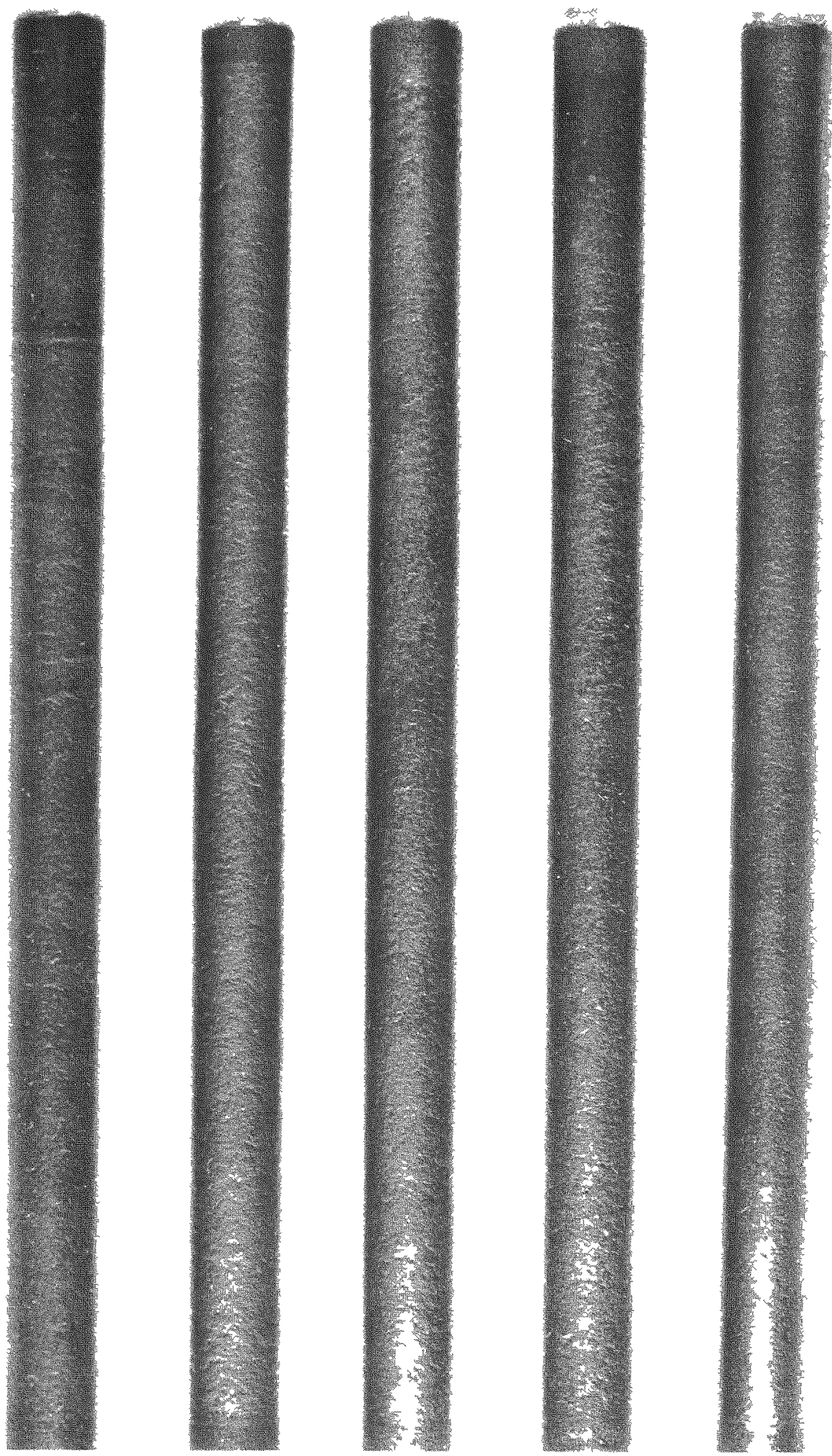

Fig. 5.9--Nickel-clad graphite pins after 75 cycles from room temperature to $1,700^{\circ} \mathrm{F}$ in 500 to 1,000 psi helium 


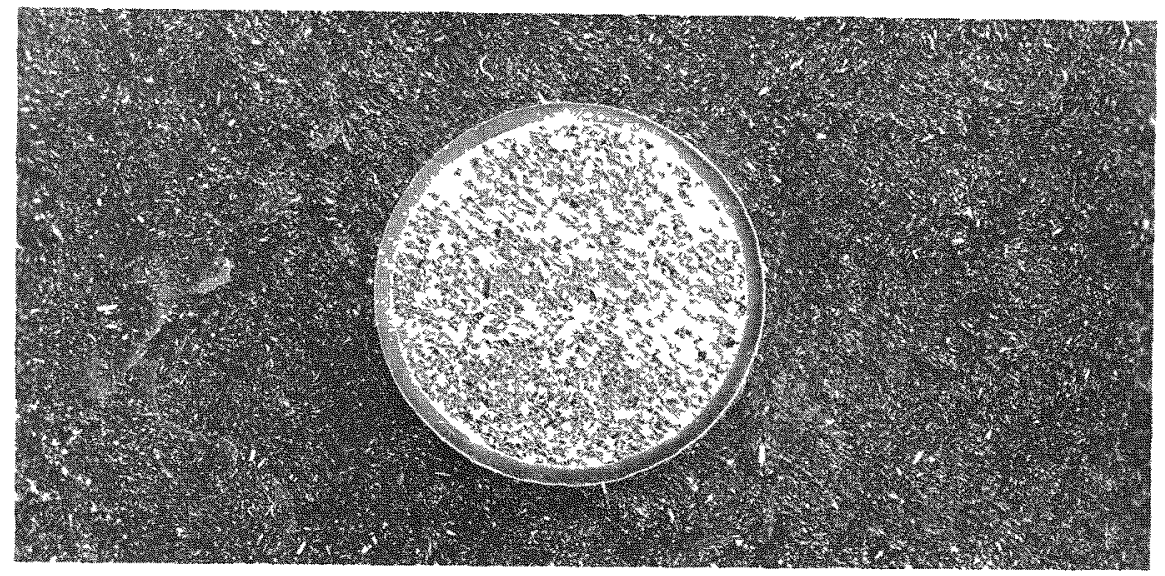

Fig. 5. 10--Cross section of a nickel-clad graphite pin after 75 cycles from room temperature to $1,700^{\circ} \mathrm{F}$ in 500 to 1,000 psi helium

after cycling is shown in Table 5.6. None of these pins leaked. A macrophotograph of the fuel pins after cycling is shown in Fig. 5. 12. The cavity

Table 5.6

CHROMATOGRAPHIC ANALYSIS OF HELIUM IN WHICH NICKEL-CLAD ALUMINA TEST EUEL ASSEMBLY WAS CYCLED

\begin{tabular}{l|c|c}
\hline Impurity & After 30 cycles & After 91 cycles \\
\hline $\mathrm{H}_{2}$ & 0.165 & 0.0036 \\
$\mathrm{O}_{2}$ & 0.0071 & 0.0155 \\
$\mathrm{~N}_{2}$ & 0.0174 & $\cdots-.$. \\
$\mathrm{CH}_{4}$ & 0.0008 &..-- \\
$\mathrm{CO}$ & 0.1450 & 0.0524 \\
$\mathrm{CO}_{2}$ & 0.0023 &..-- \\
\hline
\end{tabular}

in the third pin from the left was caused by the collapse of the cladding around a clipped alumina pellet. Macrophotographs of a sectioned pin are shown in Fig. 5. 13. A 0.020-in. gap was left between one of the end pellets shown in the sectioned view of Fig. 5.13; despite this gap, the cladding did not fail. Photomicrographs of the end cap and junction 


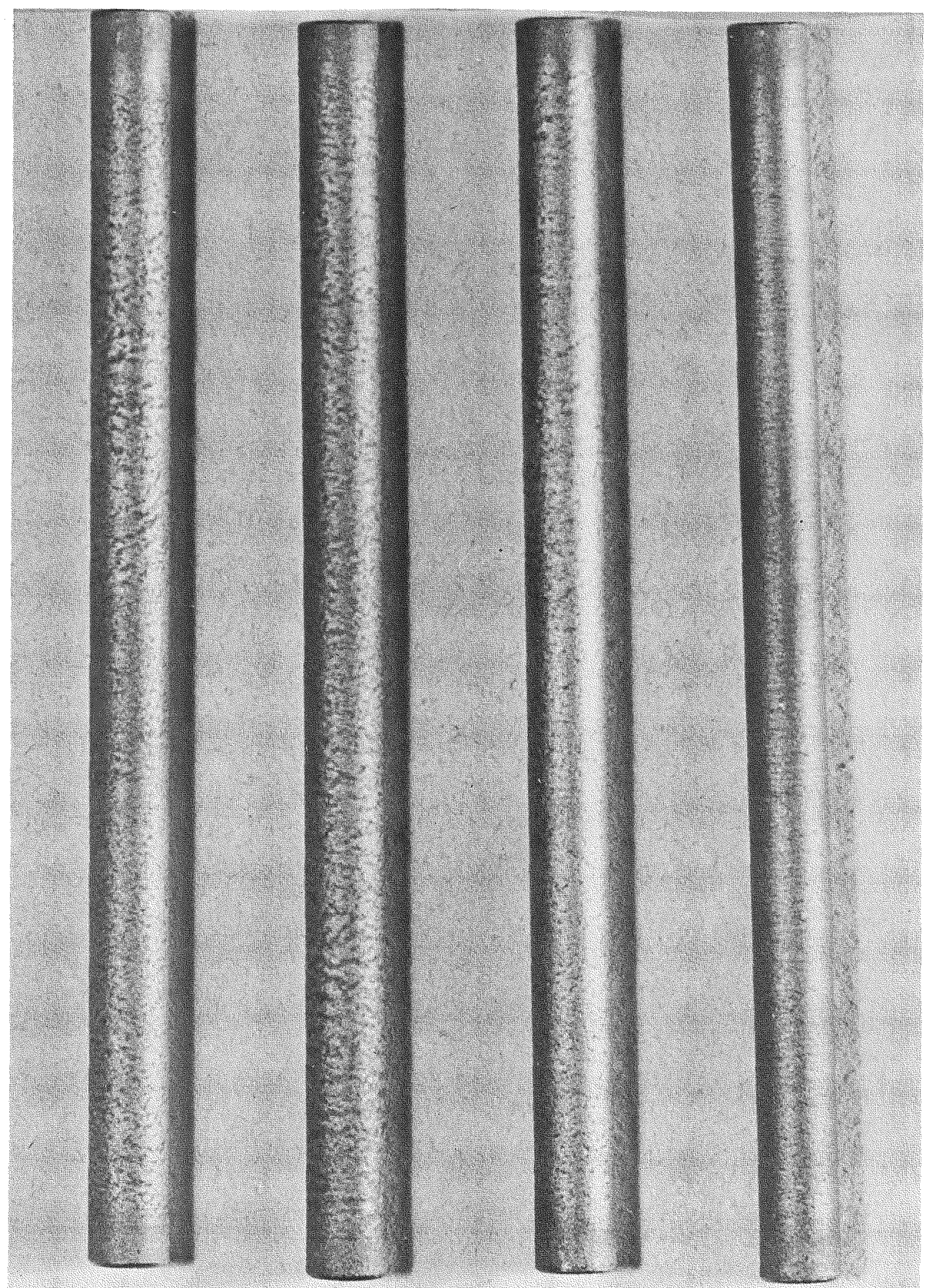

Fig. 5.11--Nickel-clad graphite pins after 107 cycles from room temperature to $1,700^{\circ} \mathrm{F}$ in 500 to $1,000 \mathrm{psi}$ helium 


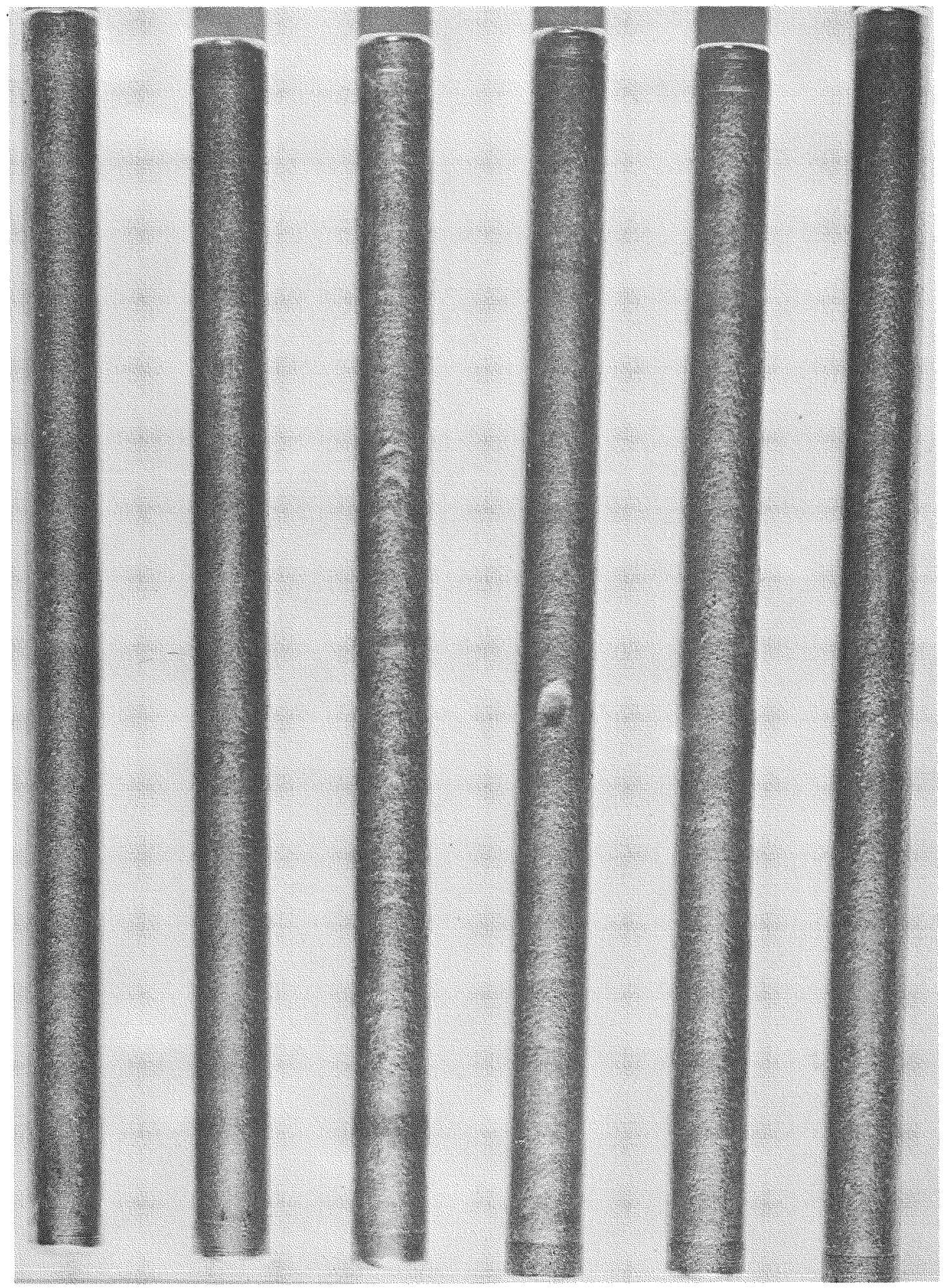

Fig. 5.12--Nickel-clad alumina pins after 30 cycles from room temperature to $1,700^{\circ} \mathrm{F}$ in 500 to 1,000 psi helium 

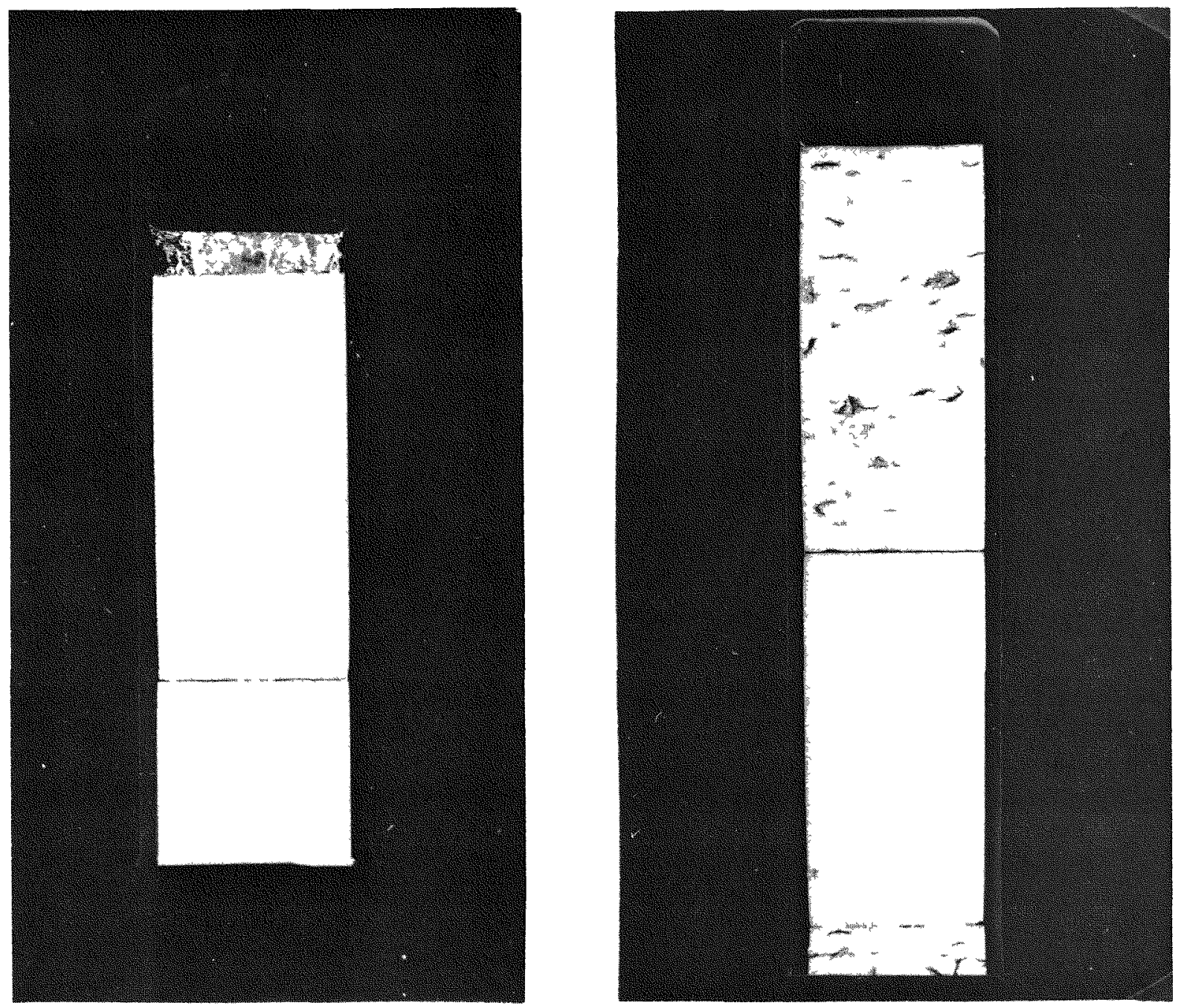

Fig. 5.13--Sections of a nickel-clad alumina pin after 30 cycles from room temperature to $1,700^{\circ} \mathrm{F}$ in 500 to $1,000 \mathrm{psi}$ helium 


\section{4}

between two alumina pellets are shown in Fig. 5.14. The small black dots in the photomicrographs are graphite spheroids similar to those observed in the nickel-clad graphite pins.

The remaining five pins were cycled an additional 61 times (total 91) and removed for examination. One of them (second from left in Fig. 5. 15) had a very small leak barely detectable with the helium leak detector. Metallographic results for the pin containing the leak are not complete. Moderator-Coolant Compatibility (W. Kosiba and C. Mungle)

Seven AGOT graphite samples, $1 / 8$ in. diam, 2 in. 1ong, and weighing approximately $650 \mathrm{mg}$ each, were placed in a quartz tube in a furnace at $1,500^{\circ} \mathrm{F}$. Helium was passed over the graphite samples at a nominal flow rate in a one-pass-through system. Before the system was brought to temperature, it was pumped and flushed with helium several times. At the completion of each run, helium was allowed to flow through until the system cooled. Between runs the graphite specimens were stored in an evacuated desiccator.

The graphite samples were weighed before and after each run and the results are summarized in Table 5.7.

Table 5.7

WEIGHT LOSS OF GRAPHITE SAMPLES

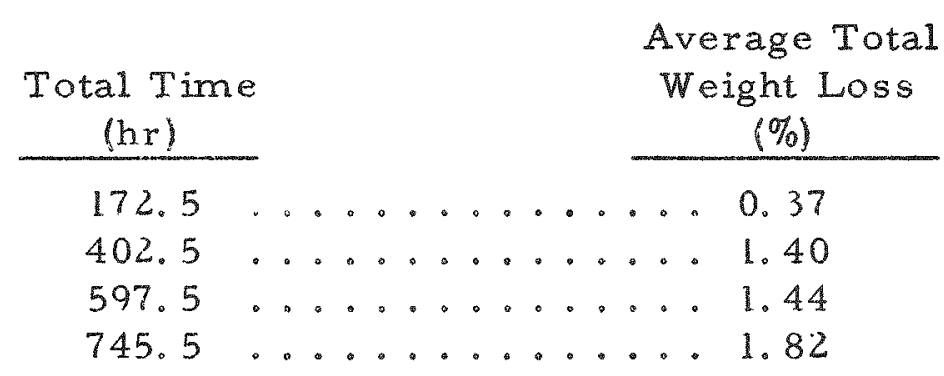

The inlet helium gas was found to contain less than $0.005 \mathrm{~mol}-\%$ impurities. A black deposit appeared on the walls of the quartz tube in 


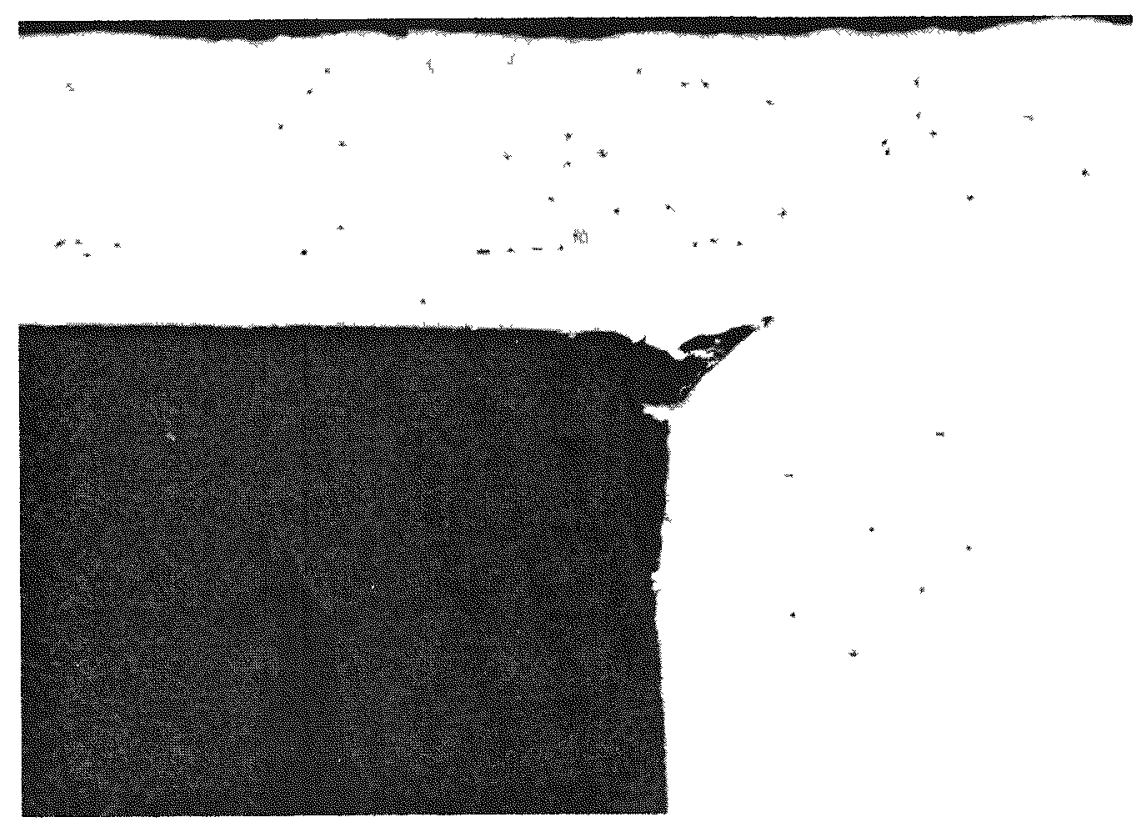

End cap region
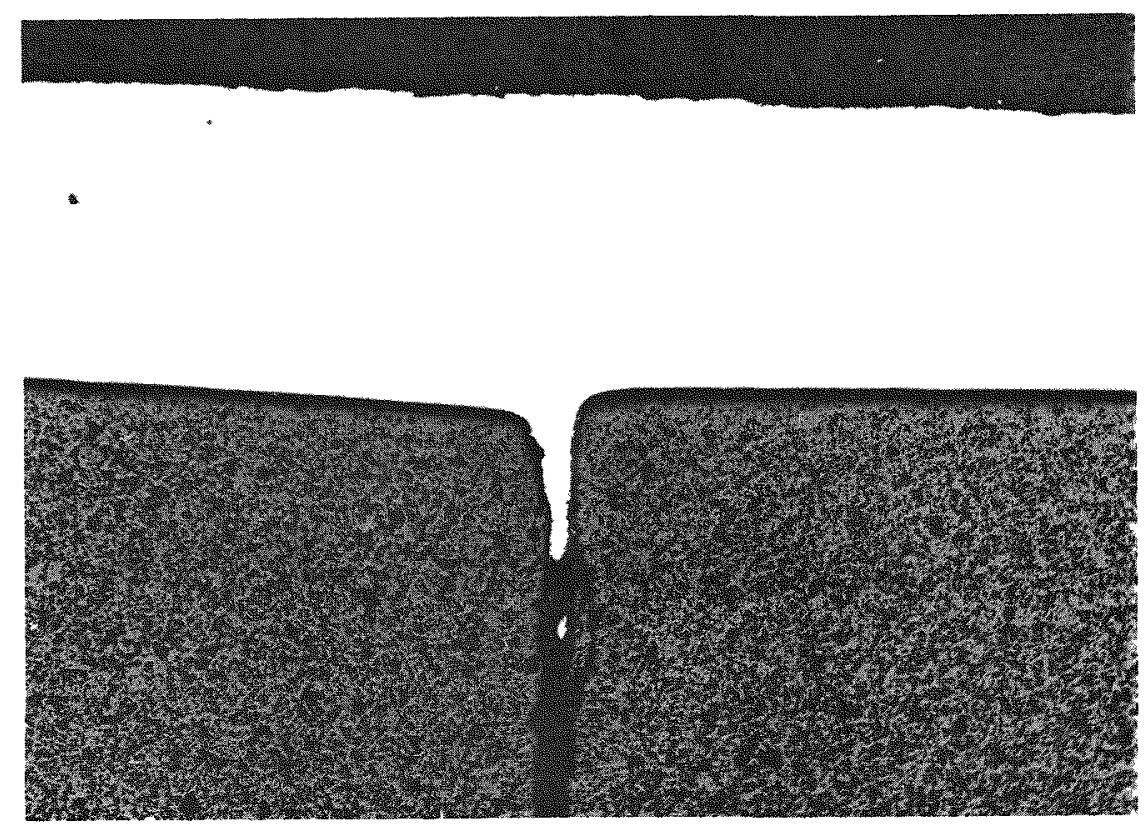

Junction between two alumina pellets (100X)

Fig. 5.14--Photomicrograph of a nickel-clad alumina pin after 30 cycles from room temperature to $1,700^{\circ} \mathrm{F}$ in 500 to 1,000 psi helium 


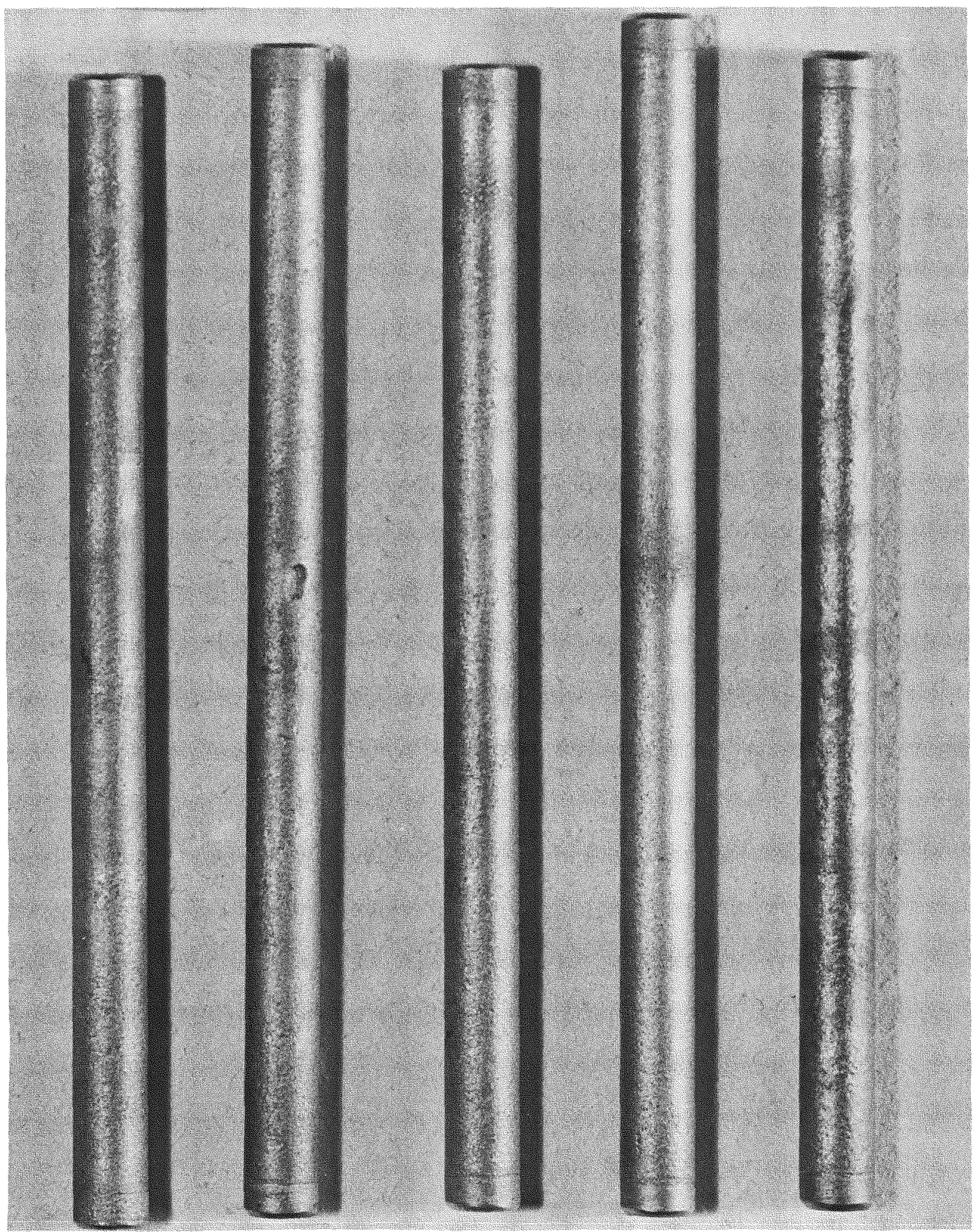

Fig. 5.15--Nickel-clad alumina pins after 91 cycles from room temperature to $1,700^{\circ} \mathrm{F}$ in 500 to $1,000 \mathrm{psi}$ helium. Second pin from left leaked 
each run. The amount of the deposit was considerably less after the third run than in the two preceding runs. Although it was not possible to weigh the deposit, it is possible that it accounts for the major portion of the weight loss. The above table shows that a significant weight loss took place during the first two runs. This is probably due to the release of the binder from the graphite and to the reaction between the graphite and the oxidizable impurities initially adsorbed in the graphite. The weight-loss rate leveled off, but it increased after approximately $600 \mathrm{hr}$. At present no explanation is offered for this increase.

The present experiment will be continued to establish the weight loss versus time curve. Additional systems are being prepared to run similar experiments in which the concentration of impurities in the helium stream will be varied.

Strength and Oxidation-resistance of Fuel Cladding Materials ( $\mathrm{J}$. Bokros and D. Guggisberg)

Tensile specimens of Type $430 \mathrm{~T}$ stainless steel, an alloy being considered for graphite cladding, were aged in the temperature range $600^{\circ}$ to $1,200^{\circ} \mathrm{F}$ to determine the extent of " $885^{\circ} \mathrm{F}$ " embrittlement in this alloy. Room-temperature stress-strain curves obtained on aged, asreceived, and annealed material are shown in Figs.5.16 and 5.17. The stress-strain curves for the control specimens and for specimens aged at $600^{\circ}, 1,000^{\circ}$, and $1,200^{\circ} \mathrm{F}$ for $1,000 \mathrm{hr}$ are grouped together, and these specimens show ultimate tensile strengths of 71,000 to 76,000 psi and elongations of $21 \%$ to $24 \%$. The specimens aged at $800^{\circ} \mathrm{F}$, on the other hand, exhibited ultimate strengths of 104,000 to 106,500 psi and elongation of $13 \%$ and $15 \%$. Twenty-four specimens of this material are being aged at $885^{\circ} \mathrm{F}$ and will be used to determine the transition temperature for the embrittled material. 


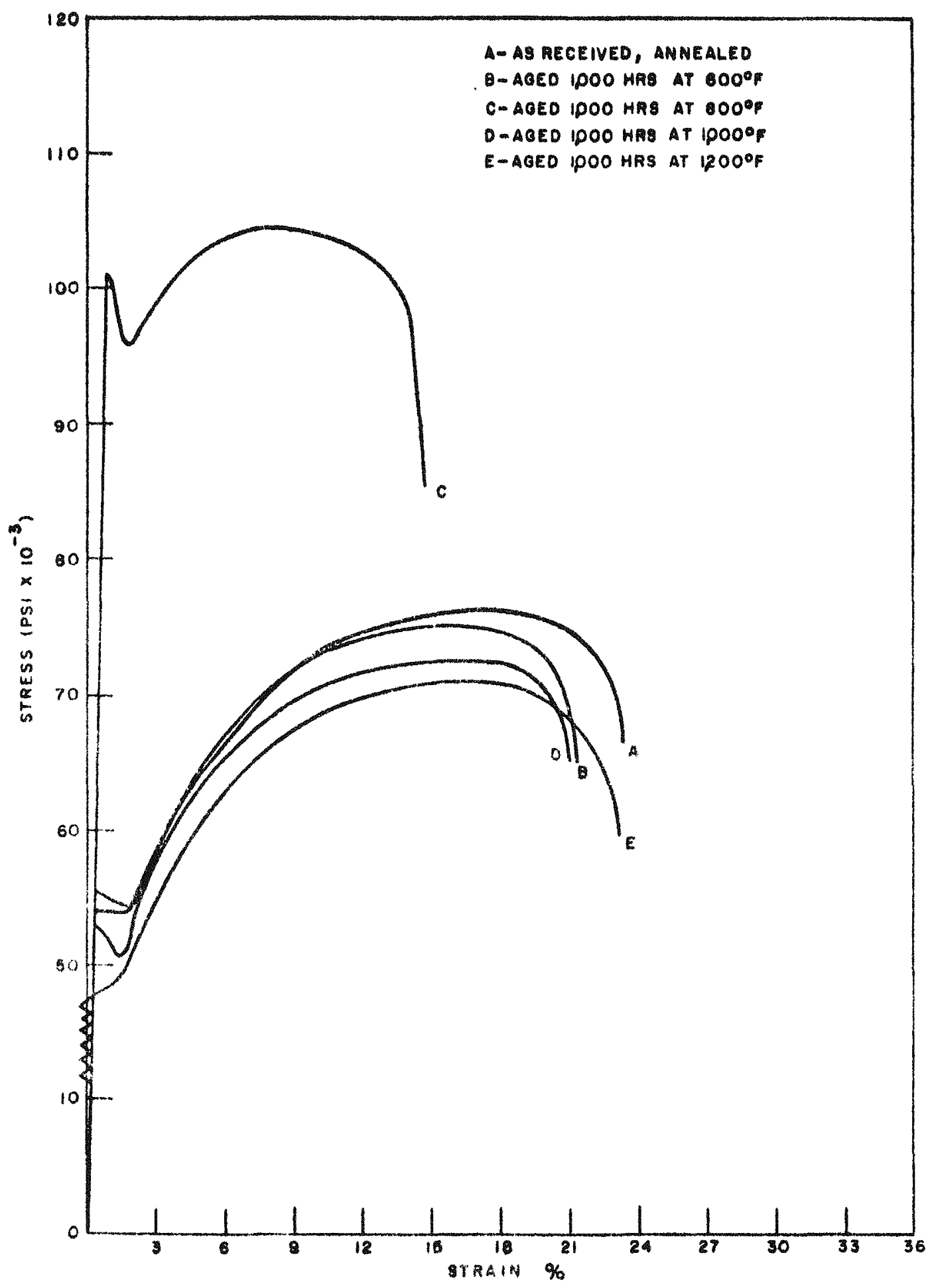

Fig, 5.16--Room-temperature stress-strain curves for Type $430 \mathrm{~T}$ stainless steel, annealed, as-received, and aged 


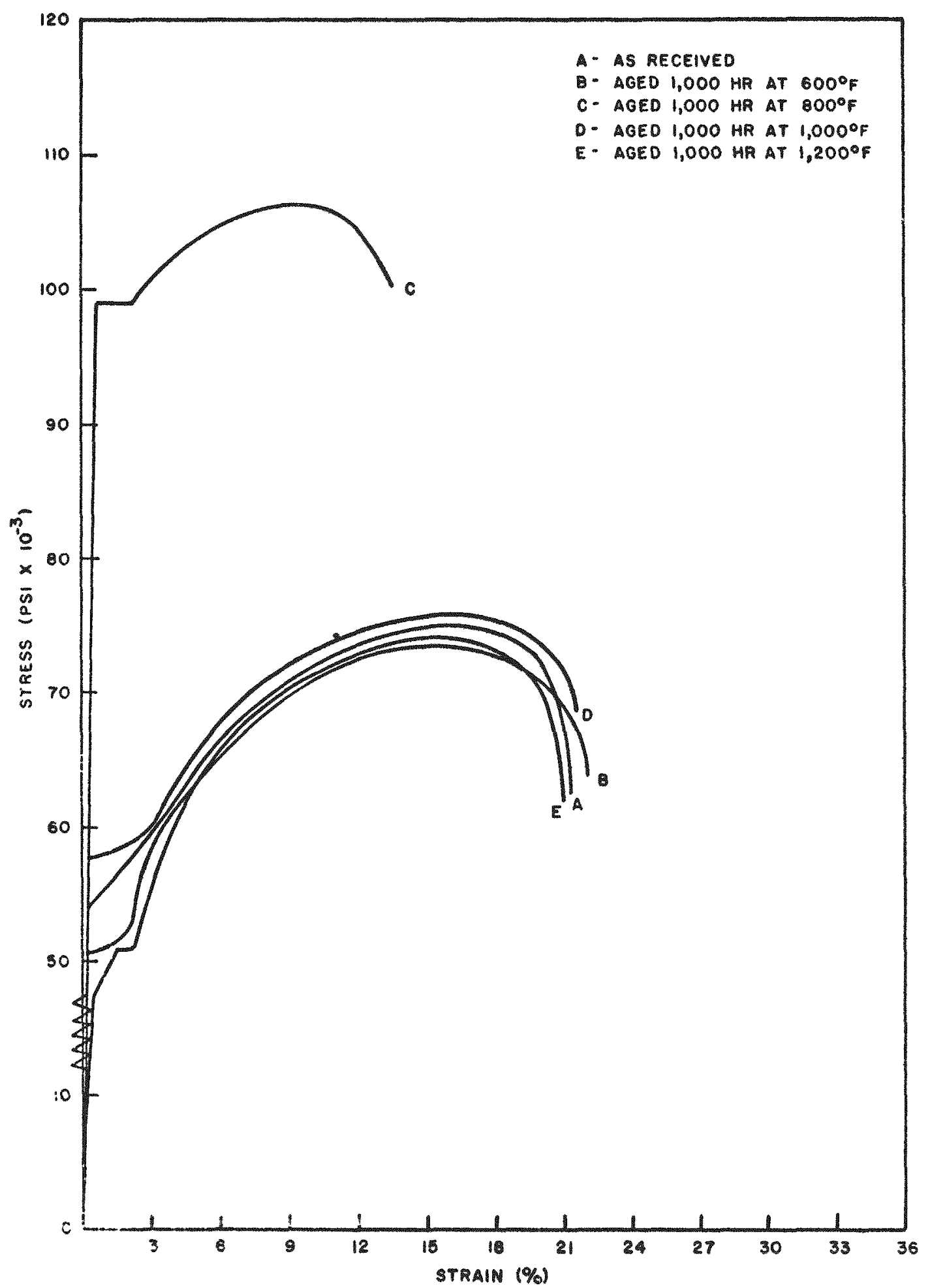

Fig. 5.17--Room-temperature stress-strain curves for Type $430 \mathrm{~T}$ stainless steel, as - received, and aged 
MATERIALS FOR THE PROPULSION PLANT (W P Wallace)

Creep, Stress-rupture, and Fatigue of Turbine and Piping Materials (J. Bokros, D. Guggisberg, and W Ellis)

A number of creep curves for " $A$." nickel are being prepared from tests performed in vacuum in the temperature range $1,000^{\circ}$ to $1,600^{\circ} \mathrm{F}$ These tests are being conducted to check the vacuum and the gas-handling systems on the creep equipment The results will serve as a guide in selecting stress-temperature combinations in the future testing program Properties of Coolant Gas ( $\mathrm{M}$ P Wilson, Jr)

Cycle analyses require that the thermodynamic and transport properties of the coolant be known in the range of temperatures and pressures which exist in the plant A literature search indicated that knowledge of these properties at temperatures above $600^{\circ} \mathrm{F}$ was inadequate for project use An experimental and analytical program was therefore undertaken to determine the necessary properties in the temperature and pressure range of interest

The following ten charts were prepared (1) temperature-entropy diagram, (2) enthalpy-entropy diagram, (3) compressibilıty factor, (4) constant volume-specific heat, (5) constant pressure-specific heat, (6) specific heat ratio, (7) velocity of sound, (8) absolute viscosily, (9) thermal conductivity, and (10) Prandtl number

The temperature range covered was from $0^{\circ}$ to $1,600^{\circ} \mathrm{F}$ and the pressure range was from atmospheric 108,000 psia The data are well substantiated by experiment and calculation, except for thermal conductivity

The experimental determination of the thermal conductivity of helium being carried out, under subcontract, by Professor B Vodar of Bellevue, France, continued during this quarter. Results of his experiment will be reported subsequently 
Effect of Coolant and Impurities in Coolant on Materials (J. Bokros, H. Shoemaker, and R. Earle)

The corrosion products formed on metal specimens exposed to $2 \times 10^{-4}$ atm $\left(\mathrm{P}_{\mathrm{CO}}+2 \mathrm{P}_{\mathrm{CO}_{2}}\right)$ at $1,500^{\circ}$ and $1,700^{\circ} \mathrm{F}$ have been identified by $\mathrm{X}$-ray diffraction. These results have been tabulated in Table 5.8 . The significance of the metal position, $\dot{1}_{0} e_{0}$, Zone 1, 2, 3, or 4, was explained in the previous progress report (GA-1030). Briefly, Zones 1 through 4 contain decreasing amounts of $\mathrm{CO}_{2}$, in that order. The small letters $s, m$, and $w$ following the corrosion product indicate strong, medium, or weak X-ray patterns. The spinel pattern refers to a family of face-centered cubic oxides having the formula $M_{1}\left(M_{2}\right)_{2} \mathrm{O}_{4}$, where $M_{1}$ and $\mathrm{M}_{2}$ for these alloys can be 1 ron, chromium, or nickel. Results of carbon analysis obtained on these samples are reported in Figs. 5.18 through 5. 26. The maximum oxide penetration and hardness data are summarized in Table 5.9.

Niobium and niobium $+1 \% \mathrm{Zr}$ formed the carbides $\mathrm{NbC}$ and $\mathrm{Nb}_{2} \mathrm{C}$ at $1,500^{\circ}$ and $1,700^{\circ} \mathrm{F}\left(\right.$ Table 5.8). At $1,700^{\circ} \mathrm{F}$, the average carbon concentration in niobium increased from $0.005 \%$ to $0.035 \%$ to $0.045 \%$ in $500 \mathrm{hr}$. At $1,500^{\circ} \mathrm{F}$ the carbon content of the niobium increased by a factor of 2 to 3 in $500 \mathrm{hr}$ (Fig. 5.20). The carbon pickup occurred as a thin layer of $\mathrm{NbC}$ and $\mathrm{Nb}, \mathrm{C}, 0.1$ to 0.3 mil thick. The two niobium specimens in Zones 1 and 2 at $1,500^{\circ} \mathrm{F}$ became brittle in 400 to $500 \mathrm{hr}$; the presence of the carbides and the two oxides, $\mathrm{NbO}$ and $\mathrm{NbO}_{2}$ (Table 5.5), was detected by $\mathrm{X}$-ray diffraction. A metallographic examination revealed large pits 6 to 8 mils deep (Fig. 5.27) on these two specimens. The hardness results for all of the samples at $1,500^{\circ} \mathrm{F}$ are indicative of oxygen contamination.

The results for the alloy, niobium $+1 \% \mathrm{Zr}$, were similar to those obtained for niobium. The two carbides formed on the specimens at $1,500^{\circ}$ and $1,700^{\circ} \mathrm{F}$ and the specimen in Zone 1 at $1,500^{\circ} \mathrm{F}$ became very brittle in $500 \mathrm{hr}$. The hardness data (Table 5.9) indicate that oxygen 
Table 5.8

CORROSION PRODUCTS TORMED ON ALLOYS

$$
2 \times 10^{-4} \mathrm{man}\left(\mathrm{CO}^{+28} \mathrm{co}\right.
$$

\begin{tabular}{|c|c|c|c|c|c|}
\hline Matertal & 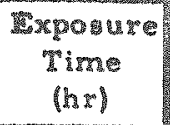 & 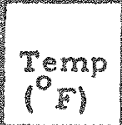 & Zone & Corrotion Product & Remary \\
\hline \multirow[t]{6}{*}{ Niobium $(\mathrm{C} . \mathrm{P}}$. & 94 & 1.500 & 1 & $\left(\mathrm{Nb}_{2} \mathrm{Clm} \cdot \mathrm{NbC} w\right.$ & \multirow{6}{*}{ Drotete } \\
\hline & 606 & 1.500 & 8 & $\left(\mathrm{Nb}_{2} \mathrm{C}\right) \cdot(\mathrm{NBC}) \cdot(\mathrm{NbO}),\left(\mathrm{NbO}_{2}\right)^{\mathrm{w}}$ & \\
\hline & 500 & 1.500 & 4 & $\left(\mathrm{NB}_{2} \mathrm{Cl}\right) \cdot \mathrm{NbCl}$ & \\
\hline & $9 \sqrt{2}$ & 1.700 & $\$$ & $\left.(\mathrm{NBC}), \mathrm{NB}_{2} \mathrm{C}\right)$ & \\
\hline & 406 & 1.700 & 1 & $\left(\mathrm{Nb}_{2} \mathrm{C}\right), \mathrm{MbC} / \mathrm{s}$ & \\
\hline & 500 & 1.700 & 4 & 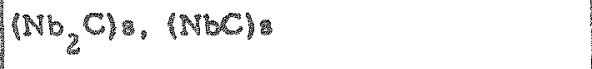 & \\
\hline \multirow{6}{*}{ Nobíuma $+1 \%$ Z } & 96 & 1.500 & 1 & 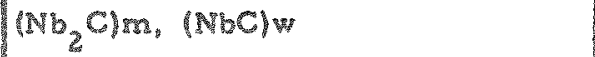 & \multirow{6}{*}{ 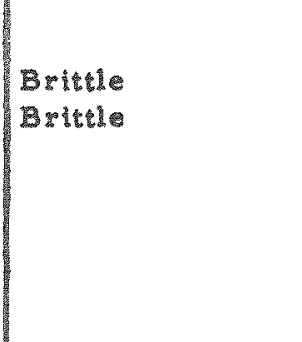 } \\
\hline & 406 & 1.500 & 1 & $\left(\mathrm{Nb}_{2} \mathrm{C}\right),(\mathrm{NBC}) \mathrm{m}$ & \\
\hline & 500 & 1.500 & 4 & $\left(\mathrm{Nb}_{2} \mathrm{C}\right) \cdot \mathrm{MBC} / \mathrm{m}$ & \\
\hline & 94 & 1.700 & 2 & $\left(\mathrm{Nb}_{2} \mathrm{C}\right) \mathrm{mm},(\mathrm{NbC}) \mathrm{m}$ & \\
\hline & 806 & 1.200 & 1 & $\left(\mathrm{Nb}_{2} \mathrm{C}\right) \mathrm{a},(\mathrm{NbC})$ & \\
\hline & 500 & 1.700 & $d_{a}$ & $\left(\mathrm{NbC} / \mathrm{s},\left(\mathrm{Nb}_{2} \mathrm{C}\right)\right.$ & \\
\hline \multirow[t]{4}{*}{ Inconel } & 406 & 1.500 & 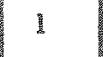 & $\left(\mathrm{C}_{2} \mathrm{O}_{3}\right)$ (spinel)m & \\
\hline & 500 & 1.500 & 4 & $\left(\mathrm{Cor}_{2} \mathrm{O}\right) w,($ spinel)w & \\
\hline & 406 & 1.700 & 4 & $\left(\mathrm{Cr}_{2} \mathrm{O}_{3}\right.$ & \\
\hline & 500 & 1,700 & 1 & $\left(\mathrm{Cr}_{2} \mathrm{O}\right) \mathrm{w}$ & \\
\hline \multirow[t]{4}{*}{ Inconed $\mathrm{x}$} & 406 & 1,500 & 1 & $\left(1 \mathrm{Cr}_{2} \mathrm{O}_{3}\right):($ apinelim & \\
\hline & 500 & 1.500 & 4 & $\left(\mathrm{C}_{2} \mathrm{O}_{3}\right)$ & \\
\hline & 406 & 1.700 & 6 & $\left(\mathrm{Cr}_{2} \mathrm{O}_{3}\right)$, (spinel/w & \\
\hline & 500 & 1,700 & 1 & $\left(\mathrm{C}_{2} \mathrm{O}_{3}\right) w_{s}(\mathrm{splnel}) \mathrm{w}$ & \\
\hline \multirow[t]{4}{*}{43095} & 406 & 1,500 & $\perp$ & $\left(\mathrm{C}_{7} \mathrm{C}_{3}\right)$, (apinells & \\
\hline & 500 & 1.500 & 4 & hamellom & \\
\hline & 406 & 1.700 & 4 & (spinel)s, $\left(\mathrm{Cr}_{2} \mathrm{O}_{3}\right) \mathrm{w}$ & \\
\hline & 500 & 1.700 & 1 & (apirella, $\left(\mathrm{Cr}_{2} \mathrm{O}_{3}\right),\left(\mathrm{Cr}_{7} \mathrm{C}_{3}\right) w$ & \\
\hline \multirow[t]{4}{*}{$316 \mathrm{SS}$} & 406 & 1.500 & 1 & (apinella, $\left(\mathrm{Cm}_{7} \mathrm{C}_{3}\right) w$ & \\
\hline & 500 & 3.500 & 4 & (apiral)xn & \\
\hline & 406 & 1.700 & 4 & Irginells: $\left.1 \mathrm{Cr}_{2} \mathrm{O}_{3}\right)$ & \\
\hline & 500 & 1.700 & 1 & Ispinells: $\left(\mathrm{C}_{2} \mathrm{O}_{3}\right) \cdot\left(\mathrm{C}_{7} \mathrm{C}_{3}\right)$ & \\
\hline Mone! & & & & None & Surface bright \\
\hline "A" Nickel & & & & None & Sugriace bright \\
\hline Duranickel. & & & & Wone & Surface tarnished \\
\hline
\end{tabular}




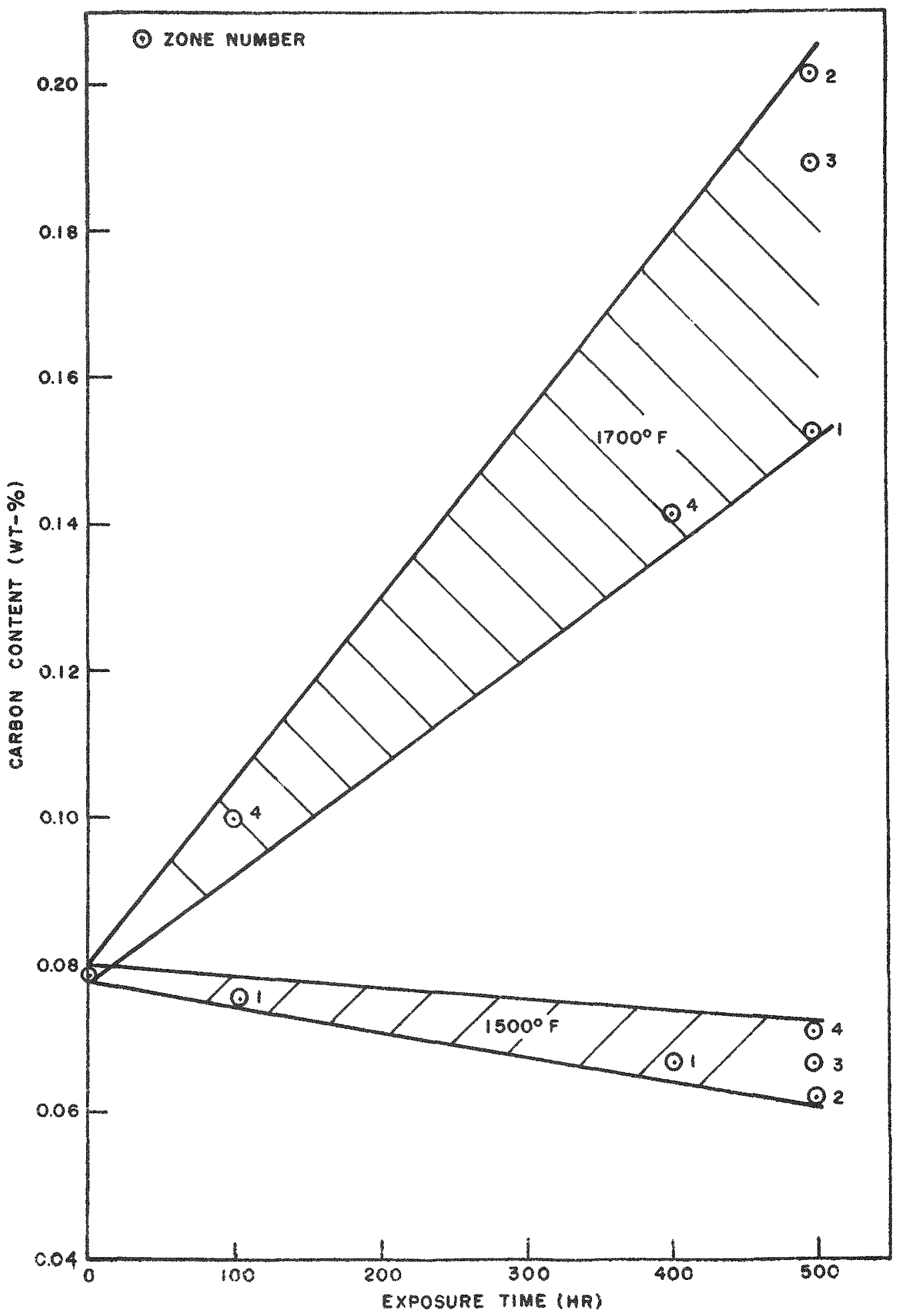

Fig. 5.18--Carbon content versus time for Type 430 stainless steel exposed to $2 \times 10^{-4} \mathrm{~atm}\left(\mathrm{P}_{\mathrm{CO}}+2 \mathrm{P} \mathrm{CO}_{2}\right)$ 


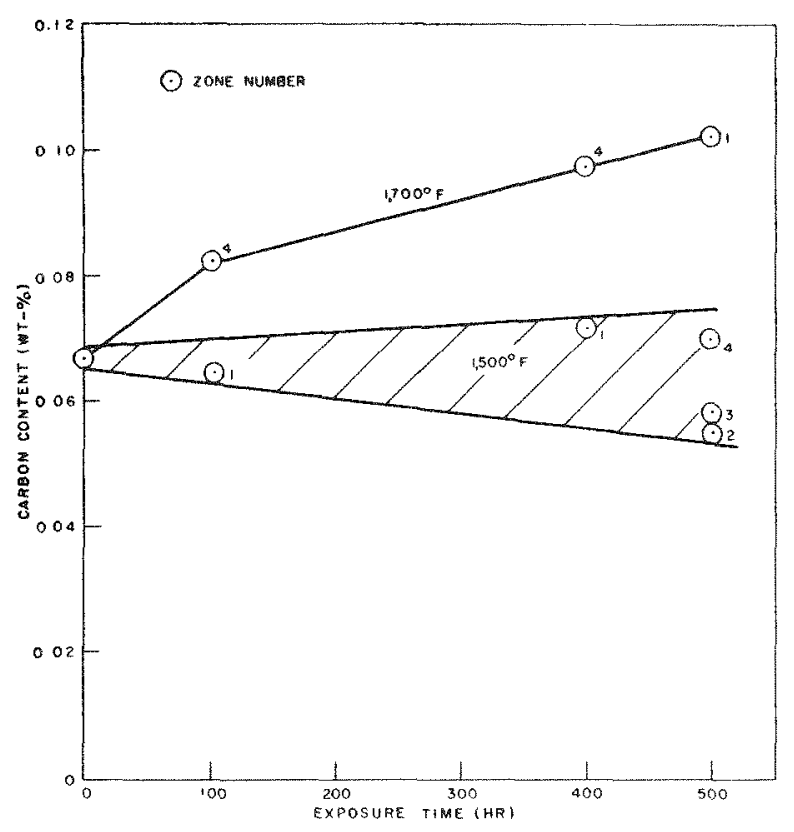

Fig. 5.19--Carbon content versus time for Type 316 stainless steel exposed to $2 \times 10^{-4}$ atm ( $\left.\mathrm{PCO}^{+2 \mathrm{P}} \mathrm{CO}_{2}\right)$

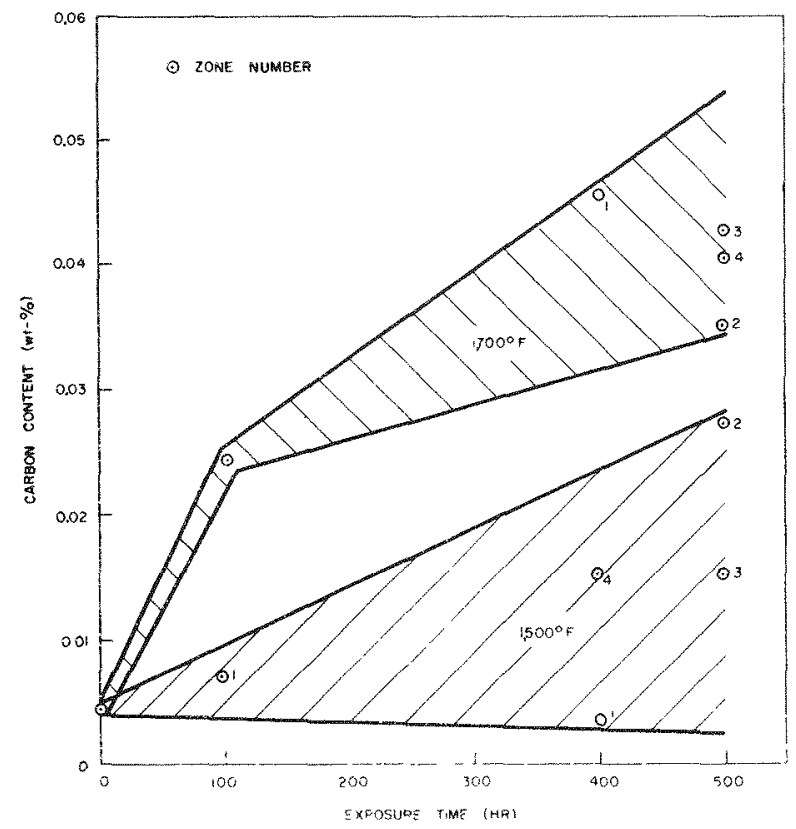

Fig. 5.21--Carbon content versus time for niobium $+1 \% \mathrm{Zr}$ exposed to $2 \times 10^{-4}$ atm ( $\mathrm{PCO}+2 \mathrm{P}_{\mathrm{CO}_{2}}$ )

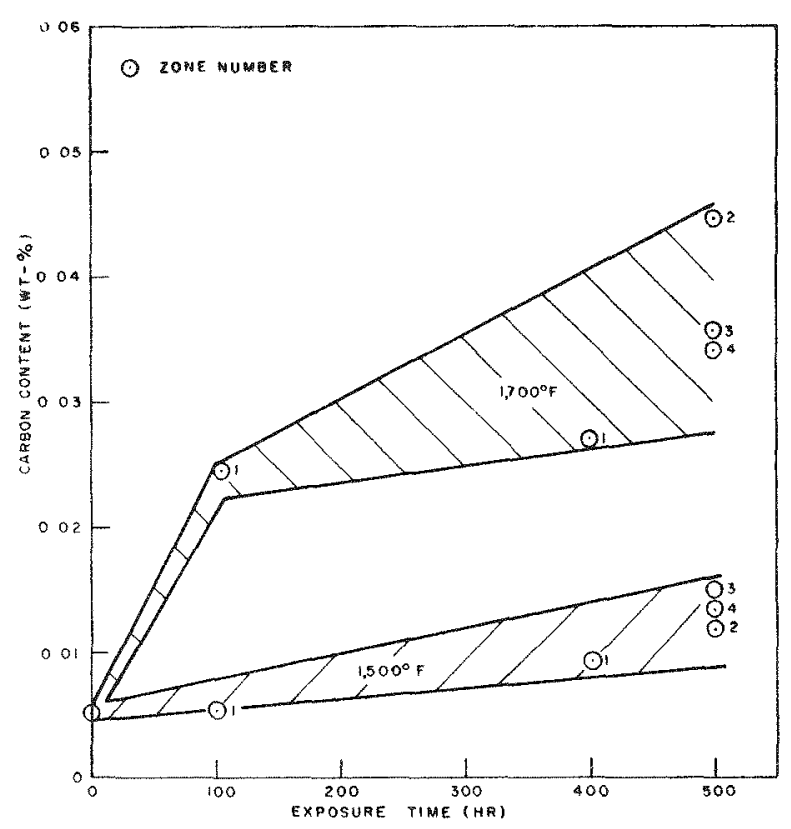

Fig. 5.20--Carbon content versus time for niobium $+1 \% \mathrm{Zr}$ exposed to $2 \times 10^{-4}$ atm $\left(\mathrm{PCO}+2 \mathrm{P}_{\mathrm{CO}_{2}}\right)$

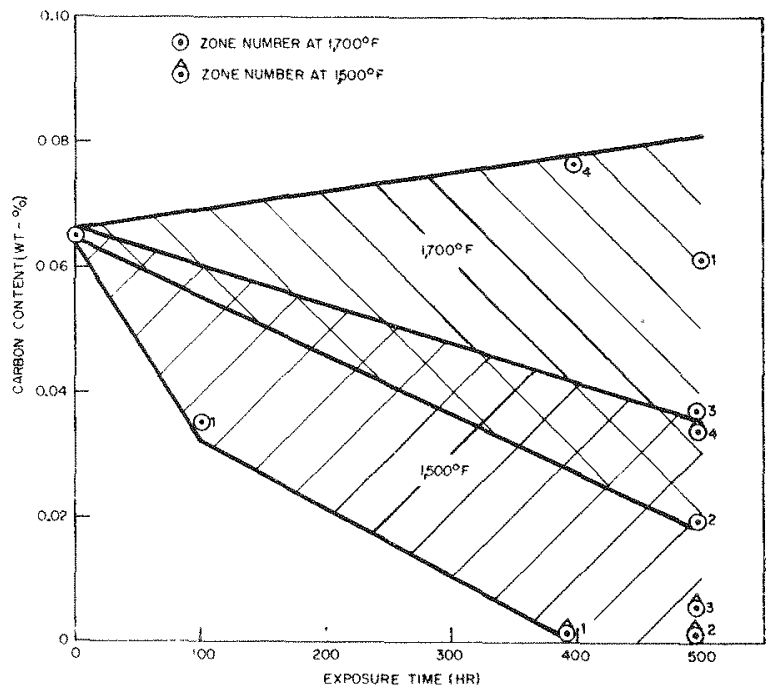

Fig. 5.22--Carbon content versus time for "A" nickel exposed to $2 \times 10^{-4} \mathrm{~atm}\left(\mathrm{PCO}+2 \mathrm{P}_{\mathrm{CO}_{2}}\right)$ 


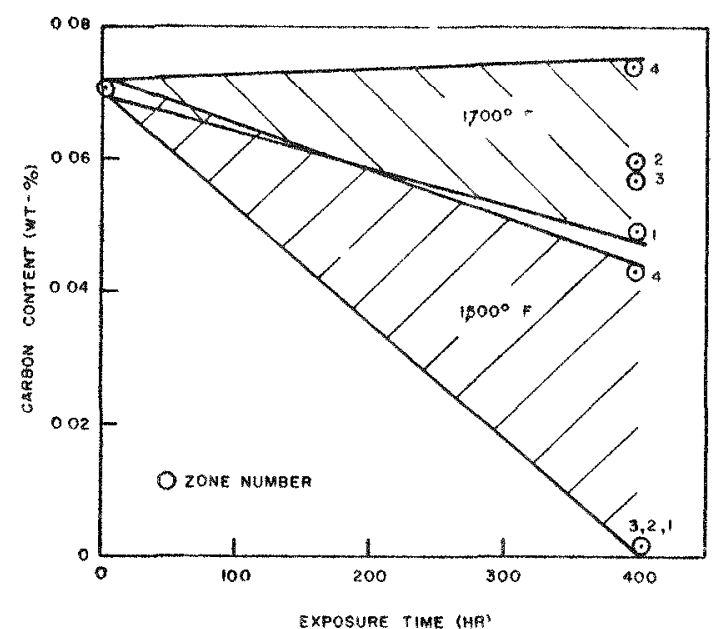

Fig. 5.23--Carbon content versus time for Monel exposed to $2 \times 10^{-4}$ atm $\left(\mathrm{P}_{\mathrm{CO}}+2 \mathrm{P}_{\mathrm{CO}_{2}}\right)$

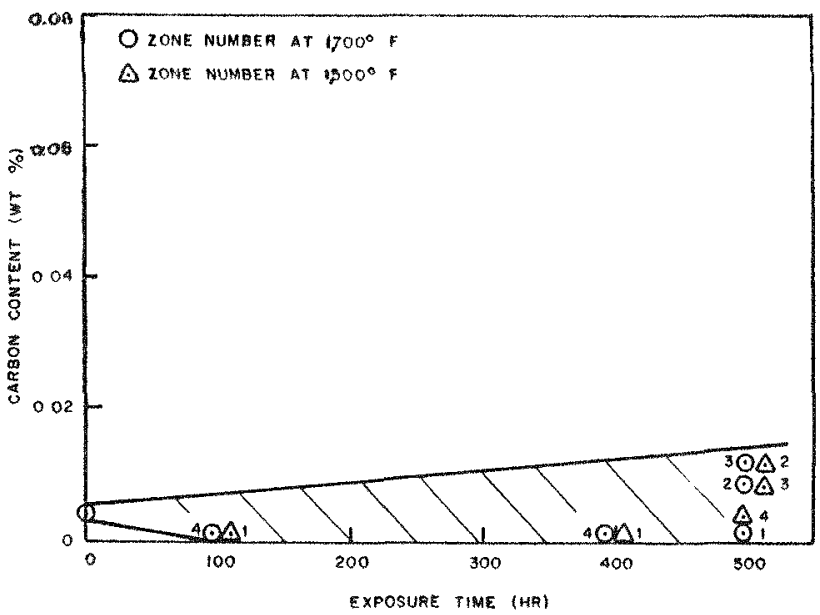

Fig. 5.24-. Carbon content ver sus time for Inconel exposed to $2 \times 10^{-4} \mathrm{~atm}$

$$
\left(\mathrm{PCO}+2 \mathrm{P}_{\mathrm{CO}_{2}}\right)
$$

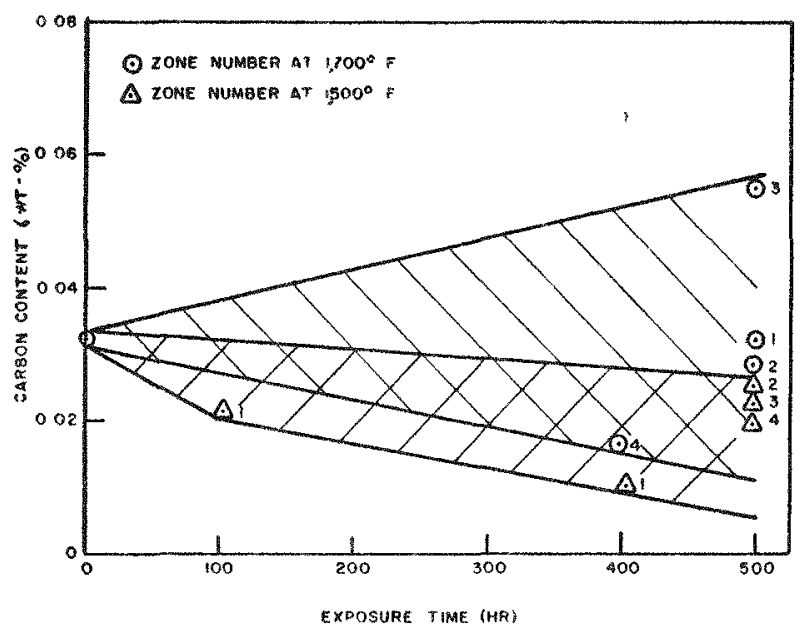

Fig. 5.25--Carbon content versus time for Inconel $X$ exposed to

$2 \times 10^{-4} \mathrm{~atm}\left(\mathrm{PCO}+2 \mathrm{P} \mathrm{CO}_{2}\right)$

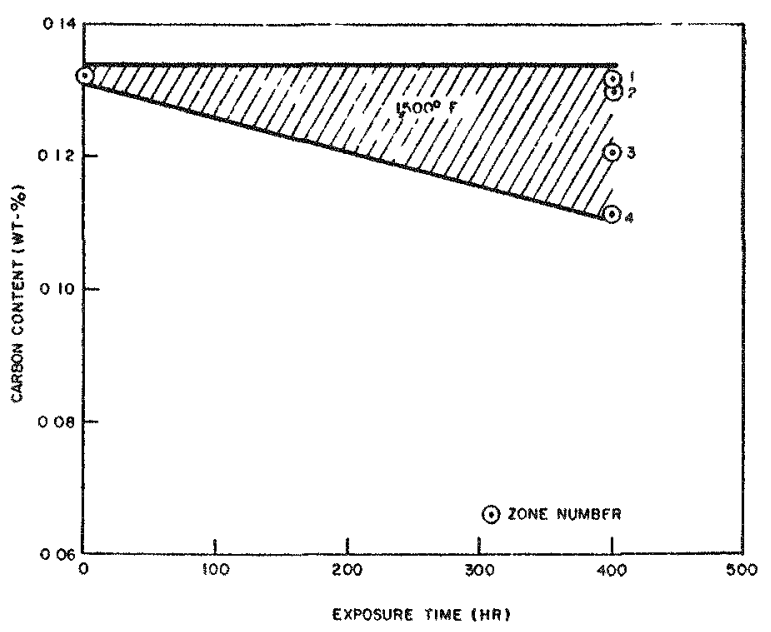

Fig.5.26- Carbon content versus time for Duranickel exposed to $2 \times 10^{-4} \mathrm{~atm}\left(\mathrm{PCO}_{\mathrm{CO}}+2 \mathrm{P} \mathrm{CO}_{2}\right)$ 
Table 5.9

SUMMARY OF METALLOGRAPHIC RESULTS OBTAINED FOR METALS AND ALLOYS EXPOSED TO $2 \times 10^{-4}$ ATM ( $\left.\mathrm{PCO}^{+}{ }^{2} \mathrm{P}_{\mathrm{CO}_{2}}\right)$

\begin{tabular}{|c|c|c|c|c|c|c|c|}
\hline \multirow[b]{3}{*}{ Material } & \multicolumn{2}{|c|}{ Exposure } & \multirow[b]{3}{*}{ Zone } & \multirow{3}{*}{$\begin{array}{l}\text { Maximum } \\
\text { Oxide } \\
\text { Penetration } \\
\text { (mils) }\end{array}$} & \multirow{2}{*}{\multicolumn{2}{|c|}{$\begin{array}{l}\text { Hardness } \\
\text { DPH }\end{array}$}} & \multirow[b]{3}{*}{ Remarks } \\
\hline & \multirow{2}{*}{$\begin{array}{c}\text { Time } \\
(\mathrm{hr})\end{array}$} & \multirow{2}{*}{$\begin{array}{l}\text { Temp. } \\
\left({ }^{\circ} \mathrm{F}\right)\end{array}$} & & & & & \\
\hline & & & & & Edge & Center & \\
\hline \multirow[t]{8}{*}{$430 \mathrm{SS}$} & 100 & 1500 & 1 & 0.1 & 154 & 160 & \\
\hline & 500 & 1500 & 4 & 0.1 & 205 & 197 & \\
\hline & 500 & 1500 & 3 & 0.1 & 151 & 166 & \\
\hline & 100 & 1700 & 4 & 0.1 & 173 & 179 & Carburized \\
\hline & 406 & 1700 & 4 & 0.5 & 197 & 181 & Carburized \\
\hline & 500 & 1700 & 1 & 0.8 & 245 & 190 & Carburized \\
\hline & 500 & 1700 & 3 & 0.7 & 343 & 202 & Carburized \\
\hline & 500 & 1700 & 2 & 0.7 & 277 & 212 & Carburized \\
\hline \multirow[t]{9}{*}{$316 \mathrm{SS}$} & 100 & 1500 & 1 & 0.1 & 170 & 179 & \\
\hline & 406 & 1500 & 1 & 0.2 & 294 & 325 & \\
\hline & 500 & 1500 & 3 & 0.1 & 197 & 193 & \\
\hline & 500 & 1500 & 4 & 0.1 & 238 & 205 & \\
\hline & 100 & 1700 & 4 & 0.1 & 174 & 180 & \\
\hline & 406 & 1700 & 4 & 0.2 & 157 & 182 & \\
\hline & 500 & 1700 & 3 & 0.4 & 183 & 190 & \\
\hline & 500 & 1700 & 2 & 0.2 & 156 & 192 & \\
\hline & 500 & 1700 & 1. & 0.2 & 172 & 185 & \\
\hline \multirow{8}{*}{ Inconel } & 100 & 1500 & 1 & 0.1 & 149 & 147 & \\
\hline & 406 & 1500 & 1 & 0.4 & 298 & 268 & \\
\hline & 500 & 1500 & 4 & 0.5 & 306 & 271 & \\
\hline & 500 & 1500 & 3 & 0.4 & 288 & 262 & \\
\hline & 500 & 1500 & 2 & 0.2 & 206 & 245 & \\
\hline & 406 & 1700 & 4 & 0.2 & 155 & 170 & \\
\hline & 500 & 1700 & 3 & 0.7 & 165 & 182 & \\
\hline & 500 & 1700 & 2 & 0.3 & 162 & 158 & \\
\hline \multirow[t]{7}{*}{ Inconel $X$} & 100 & 1500 & 1 & 0.5 & 261 & 262 & \\
\hline & 406 & 1500 & 1 & 0.7 & 379 & 406 & \\
\hline & 500 & 1500 & 3 & 0.6 & 381 & 355 & \\
\hline & 100 & 1700 & 4 & 0.1 & 341 & 341 & \\
\hline & 406 & 1700 & 4 & 0.2 & 351 & 388 & \\
\hline & 500 & 1700 & 2 & 0.2 & 349 & 381 & \\
\hline & 500 & 1700 & 3 & 0.6 & 321 & 374 & \\
\hline \multirow[t]{4}{*}{ "A" Nicke1 } & 100 & 1500 & 1 & 0.1 & 111 & 116 & \\
\hline & 406 & 1500 & 1 & 0.5 & 107 & 124 & $\begin{array}{l}\text { Fine grain-boundary } \\
\text { precipitate }\end{array}$ \\
\hline & 500 & 1500 & 3 & 0.1 & 103 & 122 & $\begin{array}{l}\text { Fine grain-boundary } \\
\text { precipitate }\end{array}$ \\
\hline & 500 & 1500 & 4 & 0.1 & 122 & 131 & \\
\hline
\end{tabular}


Table 5.9--Contmued

\begin{tabular}{|c|c|c|c|c|c|c|c|}
\hline \multirow[b]{3}{*}{ Material } & \multicolumn{2}{|c|}{ Exposure } & \multirow[b]{3}{*}{ Zone } & \multirow{3}{*}{$\begin{array}{l}\text { Maximum } \\
\text { Oxide } \\
\text { Penetration } \\
\text { (mils) }\end{array}$} & \multirow{2}{*}{\multicolumn{2}{|c|}{$\begin{array}{l}\text { Hardness } \\
\text { DPH }\end{array}$}} & \multirow[b]{3}{*}{ Remarks } \\
\hline & \multirow{2}{*}{$\begin{array}{l}\text { Time } \\
(\mathrm{hr})\end{array}$} & \multirow{2}{*}{$\begin{array}{l}\text { Temp } \\
(O F)\end{array}$} & & & & & \\
\hline & & & & & Edge & Center & \\
\hline \multirow[t]{6}{*}{$\begin{array}{l}\text { "A" Nickel } \\
\text { (contined) }\end{array}$} & 500 & 1500 & 2 & 1.0 & 140 & 138 & $\begin{array}{l}\text { Fine grain-boundary } \\
\text { precipitate }\end{array}$ \\
\hline & 100 & 1700 & 4 & 0.1 & 126 & 128 & \\
\hline & 406 & 1700 & 4 & 0.1 & 124 & 126 & \\
\hline & 500 & 1700 & 2 & 0.1 & 150 & 161 & \\
\hline & 500 & 1700 & 3 & 0.1 & 130 & 141 & \\
\hline & 500 & 1700 & 1 & 0.1 & 112 & 130 & \\
\hline \multirow[t]{2}{*}{ Duranickel } & 406 & 1500 & 4 & 01 & 293 & 278 & \\
\hline & 406 & 1500 & 1 & 0.5 & 178 & 253 & \\
\hline \multirow[t]{8}{*}{ Monel } & 406 & 1500 & 4 & 0.1 & 230 & 134 & \\
\hline & 406 & 1500 & 3 & 0.1 & 128 & 137 & \\
\hline & 406 & 1500 & 2 & 0.5 & 181 & 171 & Intergranular attack \\
\hline & 406 & 1500 & 1 & 2. 0 & 206 & 180 & Intergranular attack \\
\hline & 406 & 1700 & 4 & 0.1 & 142 & 139 & \\
\hline & 406 & 1700 & 3 & 0.1 & 135 & 139 & \\
\hline & 406 & 1700 & 2 & 0.1 & 137 & 138 & \\
\hline & 406 & 1700 & 1 & 0.1 & 135 & 138 & \\
\hline \multirow[t]{10}{*}{ Niobium } & 100 & 1500 & 1 & 0.1 & 200 & 202 & Carbide surface layer \\
\hline & 406 & 1500 & 1 & 8.0 & 205 & 240 & Oxide pits, brittle \\
\hline & 500 & 1500 & 2 & 6.0 & 278 & 269 & Oxide pits, brittle \\
\hline & 500 & 1500 & 3 & 0.2 & 296 & 275 & Carbide surface layer \\
\hline & 500 & 1500 & 4 & 0.2 & 224 & 239 & Carbide surface layer \\
\hline & 100 & 1700 & 1 & 0.2 & 130 & 131 & Carbide surface layer \\
\hline & 406 & 1700 & 1 & 0.1 & 171 & 181 & Carbide surface layer \\
\hline & 500 & 1700 & 2 & 0.2 & 168 & 149 & Carbide surface layer \\
\hline & 500 & 1700 & 3 & 0.3 & 162 & 142 & Carbide surface layer \\
\hline & 500 & 1700 & 4 & 0.1 & 206 & 190 & Carbide surface layer \\
\hline \multirow{10}{*}{$\begin{array}{c}\text { Niobium }+ \\
1 \% \mathrm{Zr}\end{array}$} & 100 & 1500 & 1 & 0.3 & 202 & 128 & Carbide surface layer \\
\hline & 406 & 1500 & 1 & 0.1 & 310 & 401 & Carbide surface layer \\
\hline & 500 & 1500 & 2 & 0.1 & 381 & 415 & Carbide surface layer \\
\hline & 500 & 1500 & 3 & 0.1 & 317 & 231 & Carbide surface layer \\
\hline & 500 & 1500 & 4 & 0.1 & 269 & 255 & Carbide surface layer \\
\hline & 100 & 1700 & 1 & 0.1 & 202 & 128 & Carbide surface layer \\
\hline & 406 & 1700 & 1 & 0.5 & 201 & 167 & Carbide surface layer \\
\hline & 500 & 1700 & 2 & 0.1 & 190 & 151 & Carbide surface layer \\
\hline & 500 & 1700 & 3 & 0.2 & 161 & 150 & Carbide surface layer \\
\hline & 500 & 1700 & 4 & 0.3 & 189 & 160 & Carbide surface layer \\
\hline
\end{tabular}




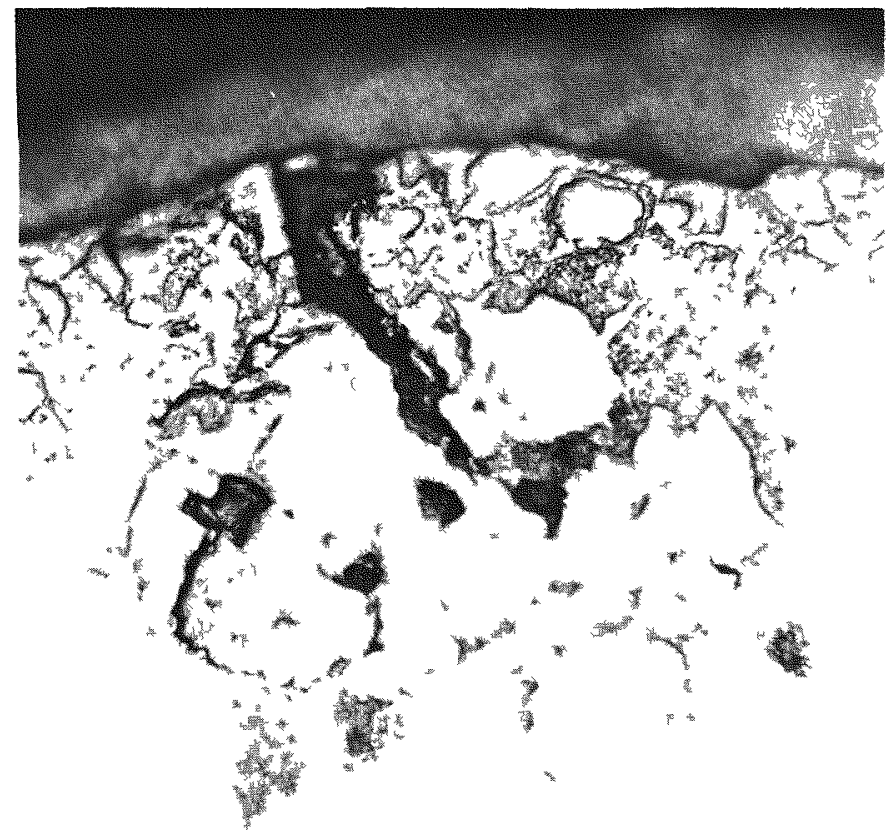

Fig. 5.27--Photomicrograph of niobium exposed to $2 \times 10^{-4} \mathrm{~atm}\left(\mathrm{P}_{\mathrm{CO}}+2 \mathrm{P}_{\mathrm{CO}_{2}}\right)^{\prime}$

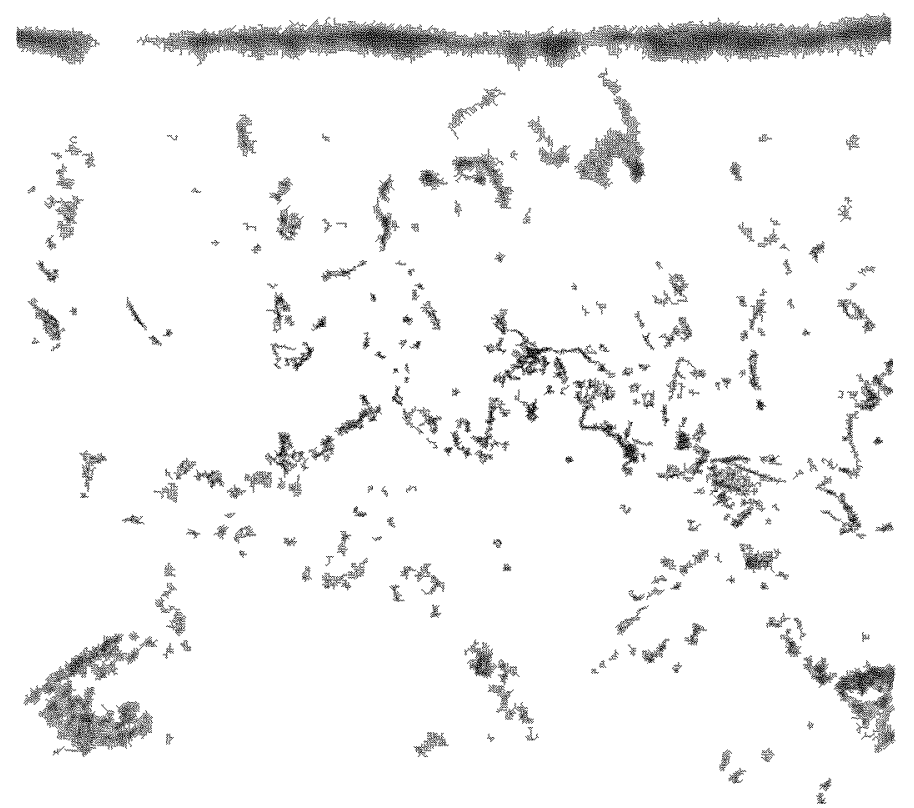

Fig. 5.28--Photomicrograph of carburized Type 430 stainless steel exposed to $2 \times 10^{-4}$ atm $\left(\mathrm{P}_{\mathrm{CO}}+2 \mathrm{P}_{\mathrm{CO}_{2}}\right)$ 
contamination occurs at $1,500^{\circ}$ and $1,700^{\circ} \mathrm{F}$.

The data obtained indicate that $2 \times 10^{-4}$ atm of $\left(\mathrm{P}_{\mathrm{CO}}+2 \mathrm{P}_{\mathrm{CO}_{2}}\right)$ is too high for niobium and niobium $+1 \% \mathrm{Zr}$. This partial pressure corresponds to 4 vol-ppm in a 750-psi system.

The Types 430 and 316 stainless steels are oxidized by this atmosphere, forming spinel and $\mathrm{Cr}_{2} \mathrm{O}_{3}$ at $1,500^{\circ}$ and $1,700^{\circ} \mathrm{F}$. The maximum oxide penetration in all cases is less than 1.0 mil (Table 5.6). The carbon analysis shown in Figs. 5.18 and 5.19 indicates that these steels carburize at $1,700^{\circ} \mathrm{F}$ in this environment. Both steels behave satisfactorily at $1,500^{\circ} \mathrm{F}$. Figure 5.28 shows the extensive carburization which occurred in Type 430 stainless steel in $500 \mathrm{hr}$ at $1,700^{\circ} \mathrm{F}$.

Inconel and Inconel $X$ formed surface oxides less than 1 mil thick at $1,500^{\circ}$ and $1,700^{\circ} \mathrm{F}$ (see Fig. 5.29). Carbon analysis in ticates that little, if any, carburization occurred at $1,500^{\circ} \mathrm{F}$.

" $A$ " nickel formed no surface reaction product in this atmosphere. It decarburized in all positions at $1,500^{\circ} \mathrm{F}$ and decarburized in Zones 1 , 2 , and 3 in $500 \mathrm{hr}$ at $1,700^{\circ} \mathrm{F}$ (see Fig. 5. 22). Metallographic examination revealed no significant attack.

The behavior of Monel was similar to that observed for nickel. All specimens decarburized at $1,500^{\circ} \mathrm{F}$ and the specimens in Zones 1,2 , and 3 decarburized at $1,700^{\circ} \mathrm{F}$ (see Fig. 5. 23). The specimen in Zone 4 carburized slightly at $1,700^{\circ} \mathrm{F}$. Metallographic examination revealed intergranular attack to a maximum depth of 2 mils on samples exposed in Zones 1 and 2 (oxidizing end) for $406 \mathrm{hr}$ at $1,500^{\circ} \mathrm{F}$. Figure 5.30 shows the nature of this attack. The white layer is a nickel plate put on to preserve the surface during metallographic preparation.

Studies of Disproportionation of $\mathrm{CO}$ in Helium $+1 \%$ Carbon Monoxide (H. Shoemaker, D. Ragone, and R. Earle)

Two tubes of materials were run for $100 \mathrm{hr}$ in this series. Tube No. 1 contained niobium and niobium-zirconium alloy and was heated to 

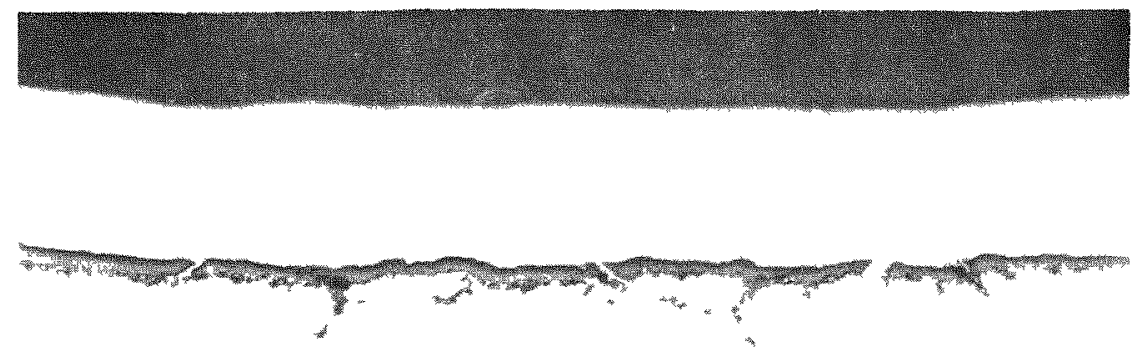

Fig. 5.29--Photomicrograph of oxide (spinel plus $\mathrm{Cr}_{2} \mathrm{O}_{3}$ ) formed on Inconel $\mathrm{X}$ exposed to $2 \times 10^{-4} \mathrm{~atm}$ $\left(\mathrm{P}_{\mathrm{CO}}+2 \mathrm{P}_{\mathrm{CO}_{2}}\right)$
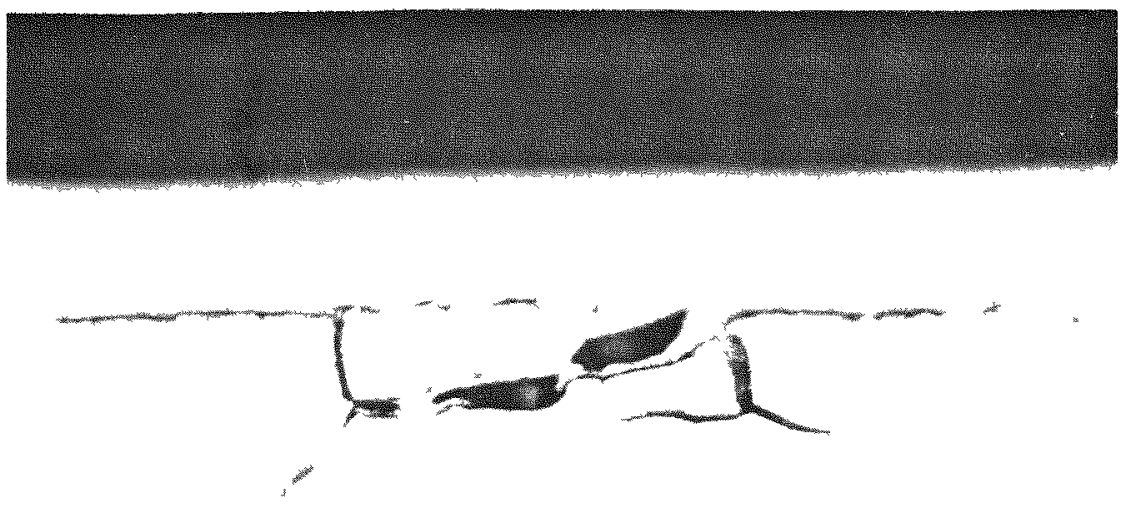

Fig. 5.30--Photomicrograph of $\mathrm{Monel}$ exposed to $2 \times 10^{-4}$ atm $\left(\mathrm{PCO}_{\mathrm{CO}}+2 \mathrm{PCO}_{2}\right)$ for $406 \mathrm{hr}$ at $1,500^{\circ} \mathrm{F}$ in Zone 2. Intergranular attack 1.5 mils deep (500X) 
$1,700^{\circ} \mathrm{F}$. The gas (helium plus $0.6 \pm 0.2 \% \mathrm{CO}_{2}$ ) was passed through perforated graphite plugs and over graphite plates as it entered the system, in order to form the carbon monoxide required in the test. Analysis of the exhaust showed $20 \%$ of the impurity to be $\mathrm{CO}_{2}$, which indicated either disproportionation of carbon monoxide when cooled and/or incompletion of the reaction

$$
\mathrm{CO}_{2}+\mathrm{C} \cdots 2 \mathrm{CO}
$$

The linear fiow rate in the chamber was about $4 \mathrm{in} / \mathrm{min}$ Visual examination showed considerable reaction, but no elemental carbon deposit. Weight changes were as follows:

$$
\begin{array}{ll}
\text { Graphite } & -2 \mathrm{mg} / \mathrm{cm}^{2} \\
\text { Niobium } & +5 \mathrm{mg} / \mathrm{cm}^{2} \\
\text { Niobium }+1 \% \mathrm{Zr} & +10 \mathrm{mg} / \mathrm{cm}^{2} \\
\text { Niobium }+5 \% \mathrm{Zr} & +7 \mathrm{mg} / \mathrm{cm}^{2}
\end{array}
$$

Tube No. 2 contained graphite, stainless steels, and nickel alloys. Some samples were extended from the $1,700^{\circ} \mathrm{F}$ test region into the exhaust temperature gradient region of the tube in order to determine the low temperature limit of reaction; the gas was introduced as in Tube No. 1. Samples were tested for $100 \mathrm{hr}$ and the weight changes were noted, then the samples were tested for an additional $400 \mathrm{hr}$. Pure carbon monoxide was used as the $1 \%$ impurity addition for the 400 hr test. The exhaust gases showed no detectable $\mathrm{CO}_{2}$. Table 5.10 shows the weight changes for materials at $100 \mathrm{hr}$ and $500 \mathrm{hr}$.

Studies of Disproportionation of CO in 1 Atm Carbon Monoxide (H. Shoemaker, D. Ragone, and R. Earle)

Two tubes of materıals were run in this series. Both were run for $100 \mathrm{hr}$, examined, and then run for an additional $400 \mathrm{hr}$. In both tubes the carbon monoxide flow rate was $0.25 \mathrm{scf} / \mathrm{hr}$. The gas was $99.8 \%$ carbon monoxide with $0.2 \%$ nitrogen. Both tubes were operated in a 
Table 5. 10

WEIGHT CHANGES IN MATERIALS IN TUBE NO. 2

\begin{tabular}{l|c|c|c}
\hline Sample & $\begin{array}{c}\text { Temp. } \\
(\mathrm{OF})\end{array}$ & $\begin{array}{c}\text { Weight Change } \\
\text { at } 100 \mathrm{hr} \\
\left(\mathrm{mg} / \mathrm{cm}^{2}\right)\end{array}$ & $\begin{array}{c}\text { Weight Change } \\
\text { at } 500 \mathrm{hr} \\
\left(\mathrm{mg} / \mathrm{cm}^{2}\right)\end{array}$ \\
\hline Graphite & 1700 & -5 &.--- \\
Inconel & 1700 & +0.3 & +0.4 \\
316 SS & 1700 & +0.3 & +0.3 \\
Inconel X & 1700 & +0.9 & +1.4 \\
Monel & 1700 & -0.1 & -0.1 \\
Nickel & 1700 & -0.07 & +0.01 \\
Inconel X & 1300 & +0.3 & +1.0 \\
Inconel X & 600 & Slight loss & 0 \\
316 SS & 1400 & +0.3 & +0.7 \\
316 sS & 800 & 0 & +0.07 \\
\hline
\end{tabular}

temperature gradient with the hottest specimen at about $1,700^{\circ} \mathrm{F}$ and the coolest at $200^{\circ} \mathrm{F}$.

Tube No. 3 contained niobium alloys. The 100-hr weight changes are shown in Table 5.11 .

Table 5.11

WEIGHT CHANGES IN NIOBIUM ALLOYS

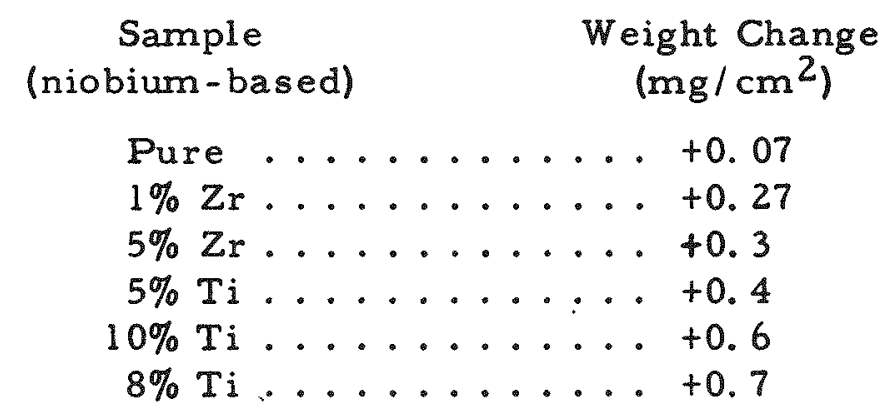

No carbon deposit was observed except on a piece of Inconel used in the supporting rack. The exhaust gas showed no $\mathrm{CO}_{2} \cdot \mathrm{X}$-ray diffraction 
examination of the samples showed carbide formation in all of the above samples.

Tube No. 4 contained stainless steels and nickel alloys. The materials tested were: Types 316 and 430 stainless steel, Inconel, Inconel X, nickel, Monel, Croloy, carbon $+1 / 2 \%$ Mo steel, $1-1 / 4 \% \mathrm{Cr}$ steel, $2-1 / 4 \% \mathrm{Cr}$ steel, $5 \% \mathrm{Cr}$ steel, ana $9 \% \mathrm{Cr}$ steel.

All of the samples were covered with carbon at $1,700^{\circ} \mathrm{F}$. Since some of the carbon flaked off, weight gain was not considered a significant parameter. Inconel $X$ showed the least catalytic activity. Nickel and Monel gave very adherent carbon deposits. An X-ray diffraction examination was made of the carbon produced. The carbon deposited on nickel and Monel showed fairly well-developed graphite structures even at decomposition temperatures of $1,300^{\circ} \mathrm{F}$. Except for preoxidized Type 316 stainless steel, little carbon was deposited below $1,100^{\circ} \mathrm{F}$. This is somewhat inconsistent with the literature, which gives the maximum decomposition rate over iron at about $900^{\circ} \mathrm{F}$, and the maximum rate over nickel at $1,300^{\circ} \mathrm{F}$.

An interesting observation in the paper by Baukloh and Henke is that the oxides of $\mathrm{Al}, \mathrm{Ti}, \mathrm{Si}, \mathrm{Cr}, \mathrm{V}$, and many other oxides, are catalytically inert to carbon monoxide decomposition. This could well be the explanation for the superior performance of Inconel $X$, which contains $\mathrm{Ti}$ and Al. These two elements could readily form surface oxides under these conditions. Gaseous impurities also seem to have some effect. It has been observed" that hydrogen greatly accelerates the decomposition of carbon monoxide over iron.

An approximation of the carbon that will be deposited in the cooler portion of the reactor system may be made by considering the composition of the gas surrounding experimental Tube No. 4, the flow rate in the tube,

\footnotetext{
W. Baukloh and C. Henke, Metallwirtshaft 19, 463-70 (1940).

W. Baukloh and E. Spetzler, Archiv. für das Eisenhottenwesen 13, 223-6 (1939).
} 
and the area of metal exposed. The exhaust gas contained $1 \% \mathrm{CO}_{2}$ with an over-all flow rate of $0.25 \mathrm{scf} / \mathrm{hr}$. Approximately $1 \mathrm{ft}^{2}$ of metal was exposed in the system.

Chufarov and Antonova " have shown that the rate of decomposition is linearly proportional to carbon monoxide pressure in the range of 2 to $200 \mathrm{~mm} \mathrm{Hg}$ in the temperature range $350^{\circ}$ to $750^{\circ} \mathrm{C}$. If the temperature distribution in the test approximates that in the reactor system, then the decomposition "constant" can be given as $8.3 \times 10^{-5} \mathrm{lb}$ of carbon per $h r / \mathrm{ft}^{2} / \mathrm{P} \mathrm{CO}$ atm. Assuming the exposed metal area of the reactor to be $100 \mathrm{ft}^{2}$ and the pressure of carbon monoxide to be $10^{-4} \mathrm{~atm}$, a carbon deposit rate of $7.2 \times 10^{-3} \mathrm{lb} / \mathrm{yr}$ would result. Experiments will be conducted to verify the decomposition "constant" at various temperatures on various materials in order to give a more reliable estimate of the carbon monoxide decomposition.

Effects of Irradiation on Corrosion by Coolant or Coolant-carried Impurities (W. Kosiba, and C. Mungle)

In an attempt to determine the possible effects of radiation on the mass transport of carbon, the following experiment was devised. Four quartz tori containing specimens were constructed and assembled in one capsule for irradiation. A drawing of a "thermal convection torus" is shown in Fig. 5.31. The detailed dimensions and the method of achieving a temperature differential in the two arms of each torus were described in quarterly report GA-1030.

The capsule containing four quartz tori was inserted in the BRR, core position CP-12, on May 5, 1959, the first day of a two-day reactor shutdown period. During this shutdown, the heaters on the cool and hot arms of the tori were raised to $750^{\circ} \mathrm{F}$ and $1,500^{\circ} \mathrm{F}$, respectively, for a short period of time. Satisfactory heater performance was achieved.

G. I. Chufarov and M. F. Antonova, Biell. Acad. Sci. URSS, Classe Sce. Tech. (1947) 381-5 (Chem. Abs. 42:3648). 

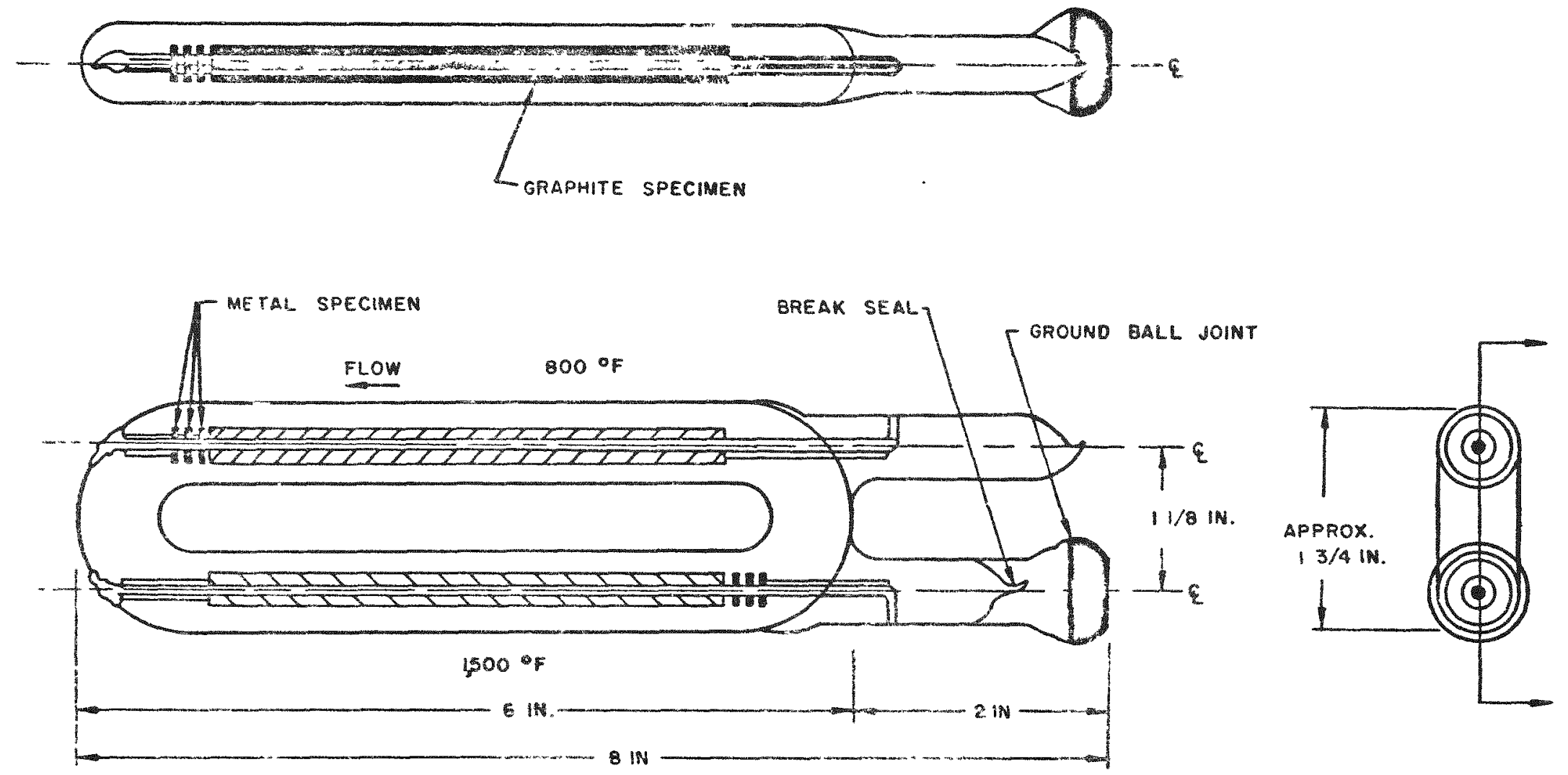

Fig. 5. 31--Diagram of quat tz tre rmal convection torus 
On May 6, the BRR was brought to $2 \mathrm{Mw}$. After $3 \mathrm{hr}$ of operation, the capsule heaters established the following temperature pattern in the capsule: The seven heaters on the hot arm, operating at $80 \%$ of capacity, produced a temperature of $1,500^{\circ} \mathrm{F}$ in the hot arms. With no power supplied to the heaters on the cool arms, the temperature of the latter was $960^{\circ} \mathrm{F}$. The $1,500^{\circ} \mathrm{F}$ and $960^{\circ} \mathrm{F}$ temperatures did not change more than $\pm 10^{\circ} \mathrm{F}$ during the entire irradiation period, which ended when the reactor was shut down, May 18.

Reactor shutdowns totaling $45 \mathrm{hr}$ occurred, thus reducing the irradiation time to $243 \mathrm{hr}$. During shutdowns, the temperatures of the hot and cool arms were in the range $1,410^{\circ}$ to $1,470^{\circ} \mathrm{F}$ and $670^{\circ}$ to $720^{\circ} \mathrm{F}$, respectively.

The neutron and gamma-ray intensities during this experiment can be estimated from dosimetry measurements completed in core position CP-12 before the capsule was inserted. Neutron and gamma-ray intensities are listed below. These values do not show the observed change of radiation intensity with location of the tori in the capsule.

Total fast-neutron flux

(fission spectrum) ............ $5 \times 10^{13}$ neutrons $/ \mathrm{cm}^{2}-\mathrm{sec}$ Thermal-neutron flux ...... $4 \times 10^{13}$ neutrons $/ \mathrm{cm}^{2}$-sec Adsorbed dose rate in graphite (fast neutron plus gamma) ... $2 \times 10^{8} \mathrm{rads} / \mathrm{hr}$ Ratio of fast-neutron dose rate to gamma dose rate ....... 1

A duplicate set of tori were constructed at General Atomic and subjected to the same temperature history in the absence of radiation as the irradiated capsule containing the tori was in the BRR. For purposes of indentification,

Torus I contained graphite only.

Torus II contained graphite and zirconium getter. 
Torus III contained graphite and the metal specimens (Ni, Monel, $\mathrm{Nb}+1 \mathrm{wt}-\% \mathrm{Zr}$ ).

Torus IV contained graphite, metal specimens, and the zirconium getter.

The four irradiated tori were broken during their removal from the capsule. The heat barrier holding the tori could not be slipped out of the capsule, and during a strong pull, the tori were broken into several pieces, but, in general, the torus geometry was maintained. There was no evidence that torus breakage or fracture had occurred during the irradiation. Torus breakage, of course, prevented the collection and analysis of torus helium, and the zirconium foil from Torus II was not recovered. There was no evidence of carbon deposit on the few pieces of quartz examined.

The unirradiated capsule remained intact and gas samples were collected and analyzed after exposure at temperature. As in the irradiated capsule, there was no evidence of carbon deposit on the walls of the quartz. The graphite, metal specimens, and zirconium getters were recovered. Table 5.12 summarizes the results obtained thus far.

The graphite specimens were intact after removal from the capsule and were indistinguishable in appearance from unexposed specimens. The only visual change in the metal specimens was a slight discoloration when compared with the unexposed specimens. There is certainly no visual evidence of severe attack on the metals, however, metallography of a few graphite specimens, and all of the metal specimens, is needed to determine the exact depth of attack. Until metallogralphic results are available, the weight changes of the metal specimens cannot be easily interpreted. However, the relatively large weight changes for nickel in irradiated Torus III and Torus IV at $1,500^{\circ} \mathrm{F}$ and the weight changes for $\mathrm{Nb}+1 \mathrm{wt}-\% \mathrm{Zr}$ in the irradiated Torus III at $960^{\circ}$ and $1,500^{\circ} \mathrm{F}$ indicate a possible radiation effect.

The weight losses in the graphite are probably not significant. Weight losses as small as 1 to $3 \mathrm{mg}$ in a 5.8 graphite sample are probably the result of outgassing of the graphite during the experiments. The gas 
Table 5.12

SUMMARY OF DATA ON IRRADIATED AND UNIRRADIATED CAPSULES

\begin{tabular}{|c|c|c|c|c|c|c|c|c|}
\hline \multirow[b]{2}{*}{ Specimen } & \multirow[b]{2}{*}{ Torus } & \multicolumn{3}{|c|}{ Irradiated Capsule } & \multicolumn{4}{|c|}{ Unirradiated Capsule } \\
\hline & & $\begin{array}{c}\text { Pre-irrad. } \\
\text { Weight } \\
(g)\end{array}$ & $\begin{array}{c}\text { Post-irrad. } \\
\text { Weight } \\
\text { (g) }\end{array}$ & $\begin{array}{c}\text { Weight } \\
\text { Change } \\
\text { (mg) }\end{array}$ & $\begin{array}{c}\text { Pre-expos. } \\
\text { Weight } \\
\text { (g) }\end{array}$ & $\begin{array}{c}\text { Post-expos. } \\
\text { Weight } \\
(g)\end{array}$ & $\begin{array}{l}\text { Weight } \\
\text { Change } \\
\text { (mg) }\end{array}$ & $\begin{array}{l}\text { Temp. } \\
(\mathrm{OF})\end{array}$ \\
\hline \multirow[t]{8}{*}{ Graphite } & I & 5.4896 & 5.4898 & +0.2 & 5.3851 & 5.3859 & +0.8 & 960 \\
\hline & I & 5.5260 & 5.5249 & -1.1 & 5.3788 & 5.3812 & +2.4 & 1500 \\
\hline & II & 5.5241 & 5.5229 & -1.2 & 5.4234 & 5.4251 & +1.7 & 960 \\
\hline & II & 5.5149 & 5.5131 & -1.8 & 5.3857 & 5.3886 & +2.9 & 1500 \\
\hline & III & 5.5142 & 5.5133 & -0.9 & 5.4031 & 5.4028 & -0.3 & 960 \\
\hline & III & 5.5034 & 5.5024 & -1.0 & 5.4164 & 5.4161 & -0.3 & 1500 \\
\hline & IV & 5.5430 & 5.5416 & -1.4 & 5.4932 & 5.4946 & +1.4 & 960 \\
\hline & IV & 5.5316 & 5.5303 & -1.3 & 5.3435 & 5.3450 & +1.5 & 1500 \\
\hline \multirow[t]{4}{*}{ Nickel } & III & 0.1248 & 0.1250 & +0.2 & 0.1318 & 0.1344 & +2.6 & 1500 \\
\hline & III & 0.1376 & 0.1294 & -8.2 & 0.1304 & 0.1312 & +0.8 & 960 \\
\hline & IV & 0.1294 & 0.1297 & +0.3 & 0.1220 & 0.1232 & +1.2 & 1500 \\
\hline & IV & 0.1377 & 0.1282 & -9.5 & 0.1325 & 0.1334 & +0.9 & 960 \\
\hline \multirow[t]{4}{*}{ Monel } & III & 0.1324 & 0.1326 & +0.2 & 0.1282 & 0.1299 & +1.7 & 1500 \\
\hline & III & 0.1315 & 0.1320 & +0.5 & 0.1270 & 0.1278 & +0.8 & 960 \\
\hline & IV & 0.1321 & 0.1323 & +0.2 & 0.1285 & 0.1295 & +1.0 & 1500 \\
\hline & IV & 0.1304 & 0.1305 & +0.1 & 0.1261 & 0.1270 & +0.9 & 960 \\
\hline \multirow{7}{*}{$\begin{array}{l}\mathrm{Nb}+ \\
1 \mathrm{wt}-\% \mathrm{Zr}\end{array}$} & III & 0.1370 & 0.1384 & +7.4 & 0.1367 & 0.1393 & +2.6 & 1500 \\
\hline & III & 0.1376 & 0.1332 & -4.4 & 0.1315 & 0.1332 & +1.7 & 960 \\
\hline & IV & 0.1372 & 0.1381 & +0.9 & 0.1341 & 0.1354 & +1.3 & 1500 \\
\hline & IV & 0.1377 & 0.1382 & +0.5 & 0.1285 & 0.1294 & +0.9 & 960 \\
\hline & II & 0.2158 & Not & & & & & \\
\hline & & & recovered & $\ldots$ & 0.1635 & 0.1671 & +3.6 & 1500 \\
\hline & IV & 0.2460 & 0.2470 & +1 & 0.0930 & 0.0954 & +2.4 & 960 \\
\hline
\end{tabular}


analyses for the tori in the unirradiated capsule are being completed and will be reported at a later date.

Investigation and Test of Nonreactor Structural Materials (C. Webster, R. G. Shepheard, and B. Lund)

This work is being conducted to ensure proper selection and handling of nonreactor structural alloys and the selection of safe design stresses. These alloys will be employed in the construction of high-temperature helium ducts, rotating machinery casings, pressure vessels, heat exchangers, and valves. The most suitable materials seem to be 1-1/4 Cr-1/2 Mo steel and 2-1/4 Cr-1 Mo steel for temperatures up to $1,000^{\circ} \mathrm{F}$, and Type $31 \mathrm{~h}$ stainlesa steel and Inconel $\mathrm{X}$ (under subcontract) for temperatures above $1,000^{\circ} \mathrm{F}$.

Creep-rupture Tests. These materials are undergoing elevated temperature creep-rupture tests in high purity helium to determine its effect on their strength properties. If it is found that the strength is affected, it will be necessary to establish the severity and to resolve the maximum allowable design stresses.

A number of creep-rupture tests were first performed in air on these materials to establish a suitable comparison datum for the helium test. Typical creep-rupture test stands are shown in Fig. 5. 32.

Specimens taken from 1/2-in. vendor-heat-treated Cr-Mo steel plates and tested in air at $1,000^{\circ} \mathrm{F}$ had much shorter rupture lives than predicted. This also occurred, to a lesser degree, for specimens from a 1/2-in. Type $316 \mathrm{~L}$ stainless steel plate when tested at $1,200^{\circ} \mathrm{F}$. It became necessary to find the cause for this condition and to eliminate it before proceeding with the helium tests. A notch-plain, creep-rupture test specimen is shown in Fig. 5.33.

Various normalizing and tempering treatments and two annealing treatments produced little hardness variation in $1-1 / 4 \mathrm{Cr}-1 / 2 \mathrm{Mo}$ steels, and affected the microstructure only by size and distribution of the carbide phase. Similar treatments of 2-1/4 Cr-1 Mo steel showed signiticant 


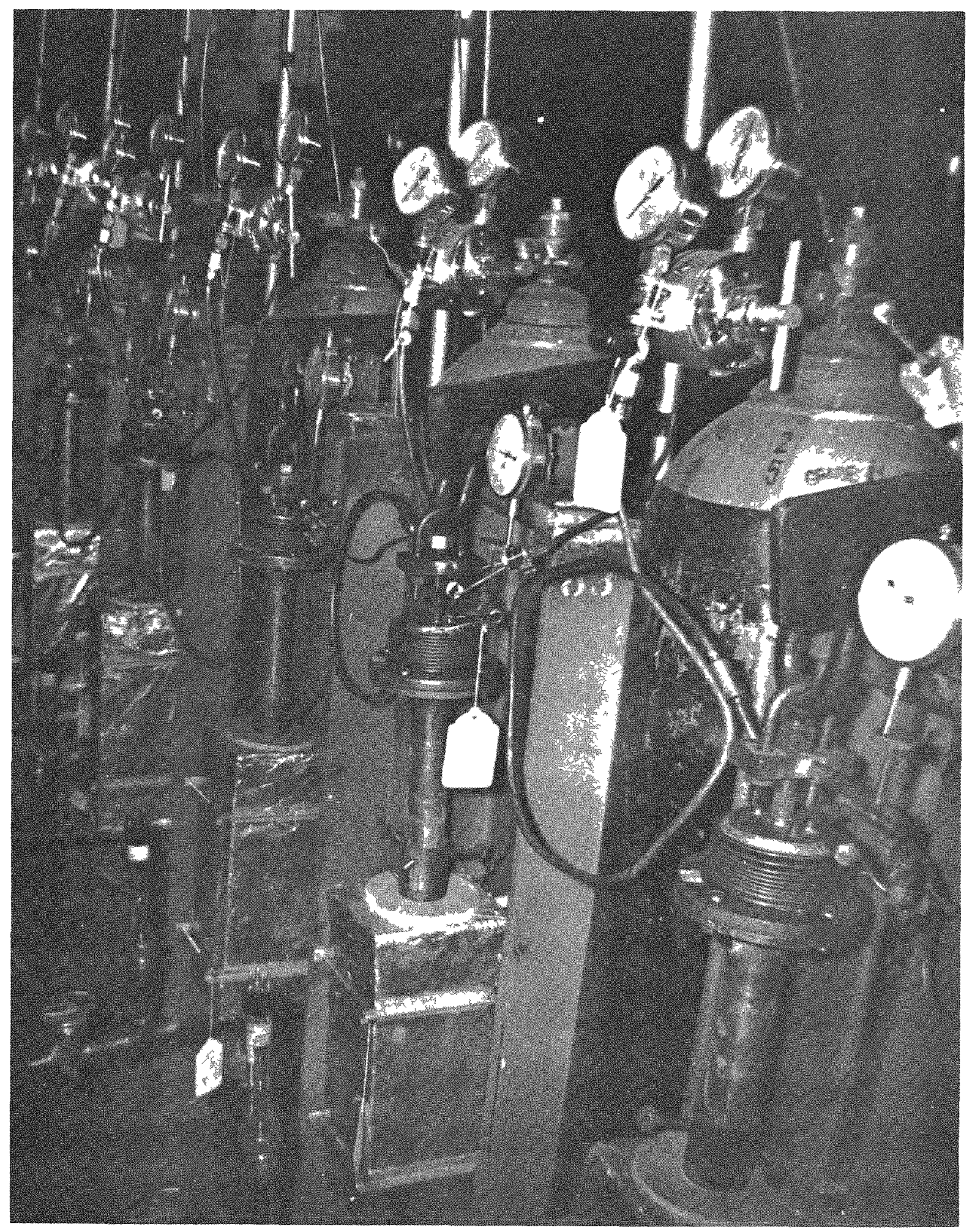

Fig. 5.32--Typical materials creep-rupture test stands 


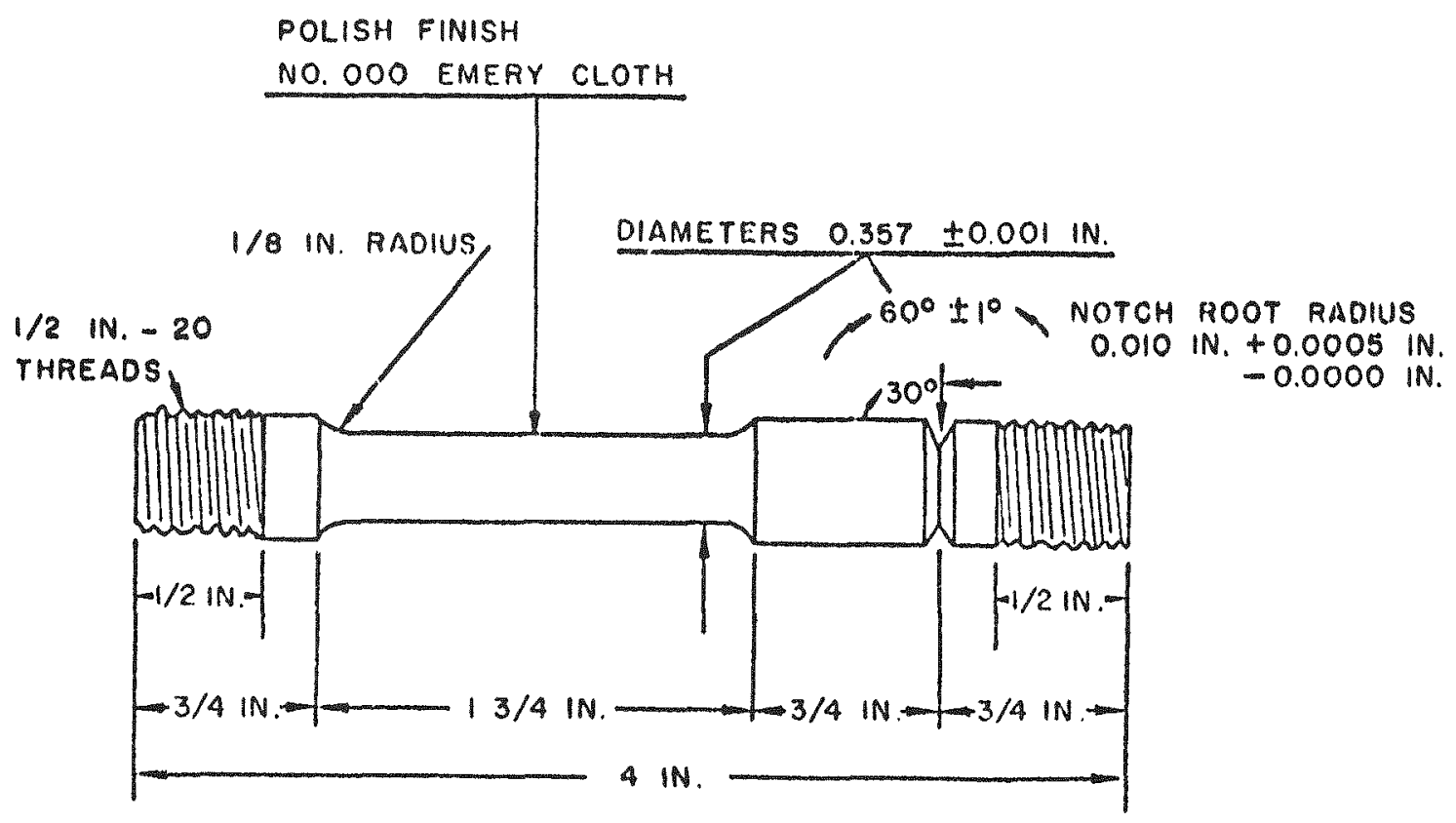

Fig. 5. 33--Notch-plain creep-rupture test specimen

hardness and microstructure changes. Normalizing at $1,750^{\circ} \mathrm{F}$ and tempering at $1,150^{\circ} \mathrm{F}$, for each of these alloys, produced 100 -fold increases in time to rupture at $30,000 \mathrm{psi}$ and $1,000^{\circ} \mathrm{F}$ over the as-received material. Likewise, rough (dial gauge) creep measurements indicated the smalleat creep rates with this heat treatment. All specimens for testing in helium will be heat treated in this manner. Results of the air tests are summarized in Figs. 5. 34, 5.35, and 5.36.

Solution heat treatment of the Type 316L stainless steel plate at $2,150^{\circ} \mathrm{F}$, followed by water quenching, did not cause the rupture life to differ from that of the as-received condition. A mixed grain structure and a large concentration of inclusions were, however, found near the center of the plate. Another plate of more uniform microstructure was obtained and solution heat treated at 2,150 $\mathrm{F}$. All specimens for helium tests were taken from this plate.

It is important to en ure that variations in the purity of the helium environment are limited to avoid obscuring the effects of the controlled 


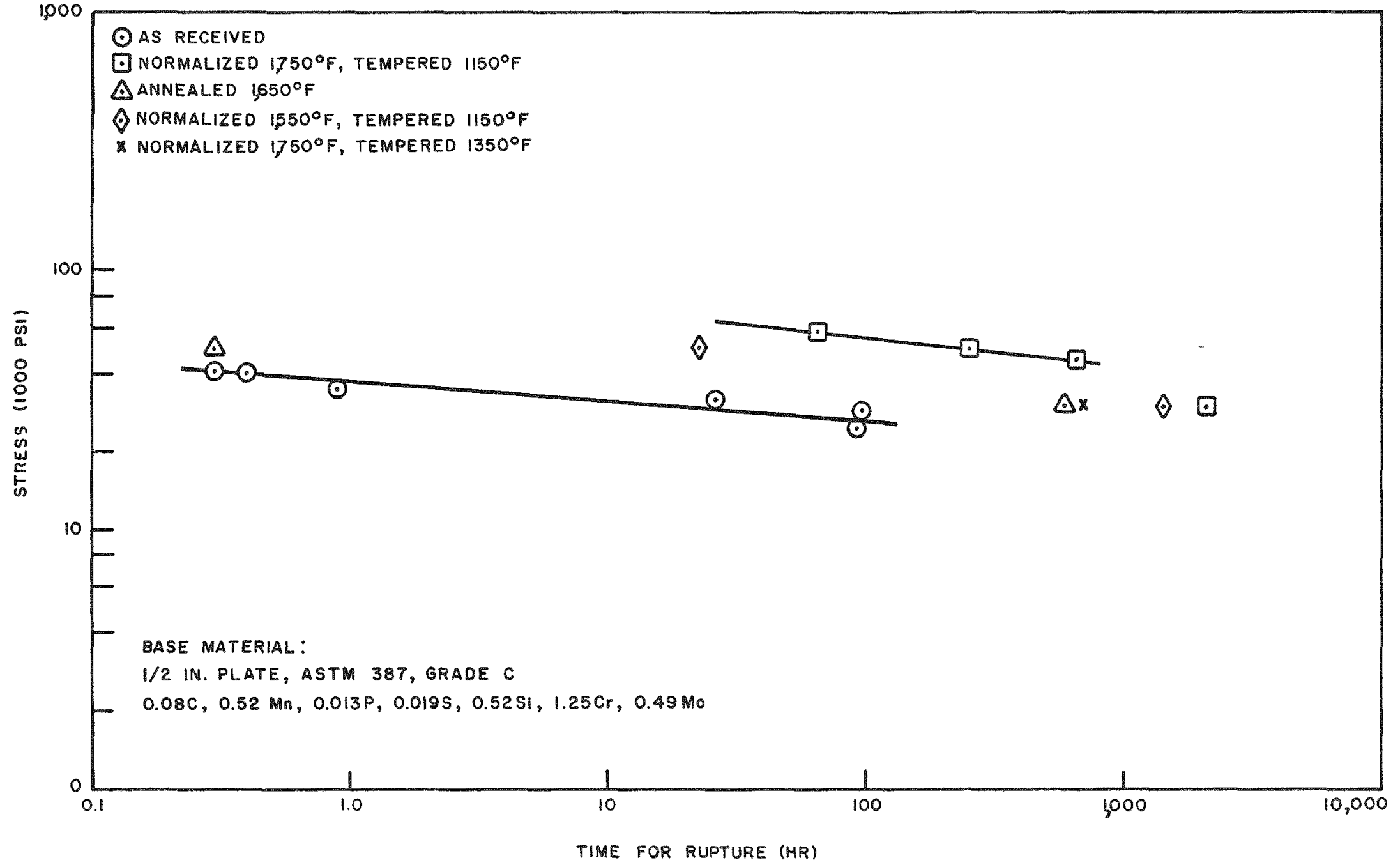

Fig. 5.34--Effect of heat treatment on rupture life of $1-1 / 4 \mathrm{Cr}-1 / 2$ Mo steel at $1,000^{\circ} \mathrm{F}$ in air 


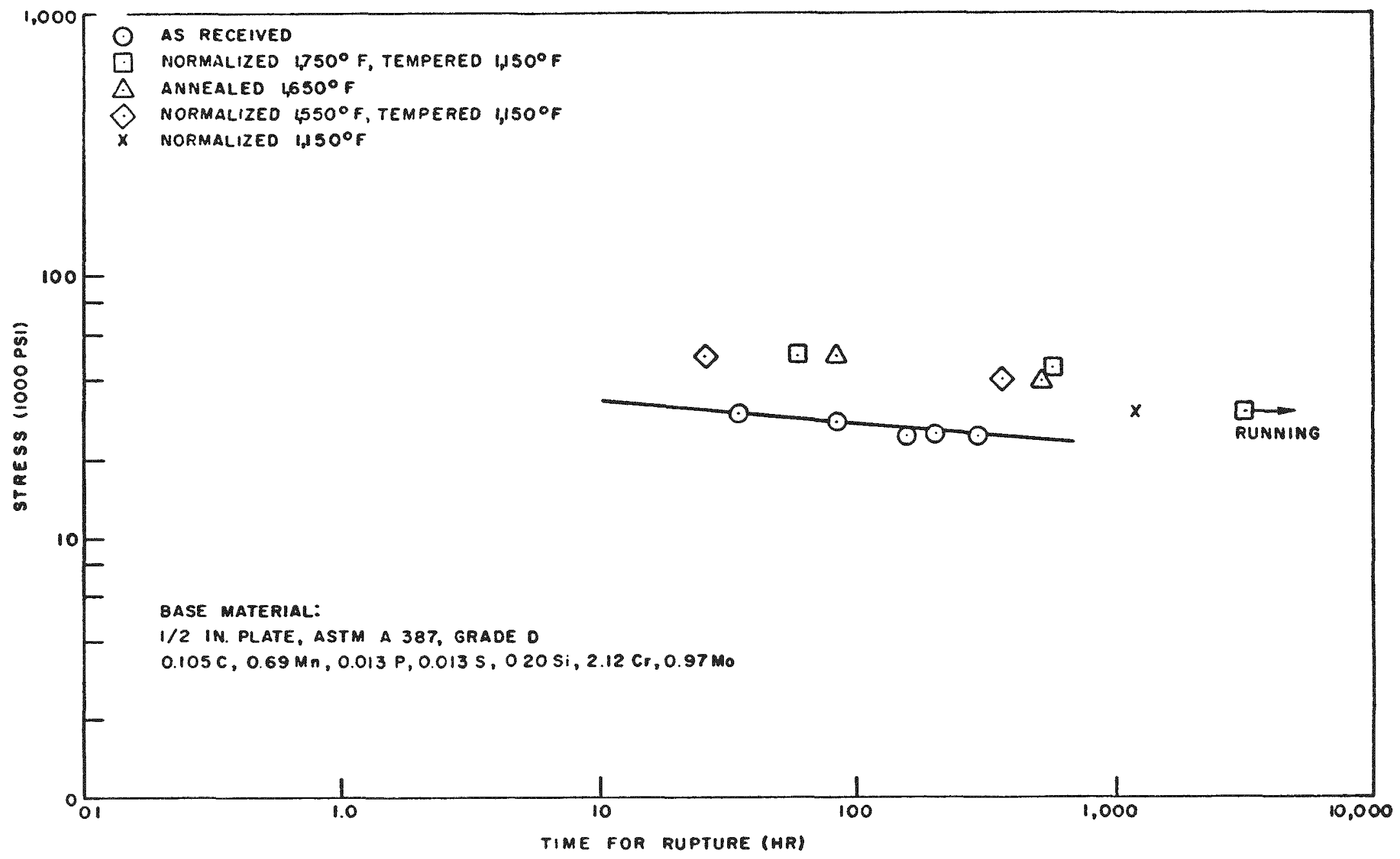

Fig. 5.35--Effect of heat treatment on rupture life of $2-1 / 4 \mathrm{Cr}-1$ Mo steel at $1,000^{\circ} \mathrm{F}$ in air 


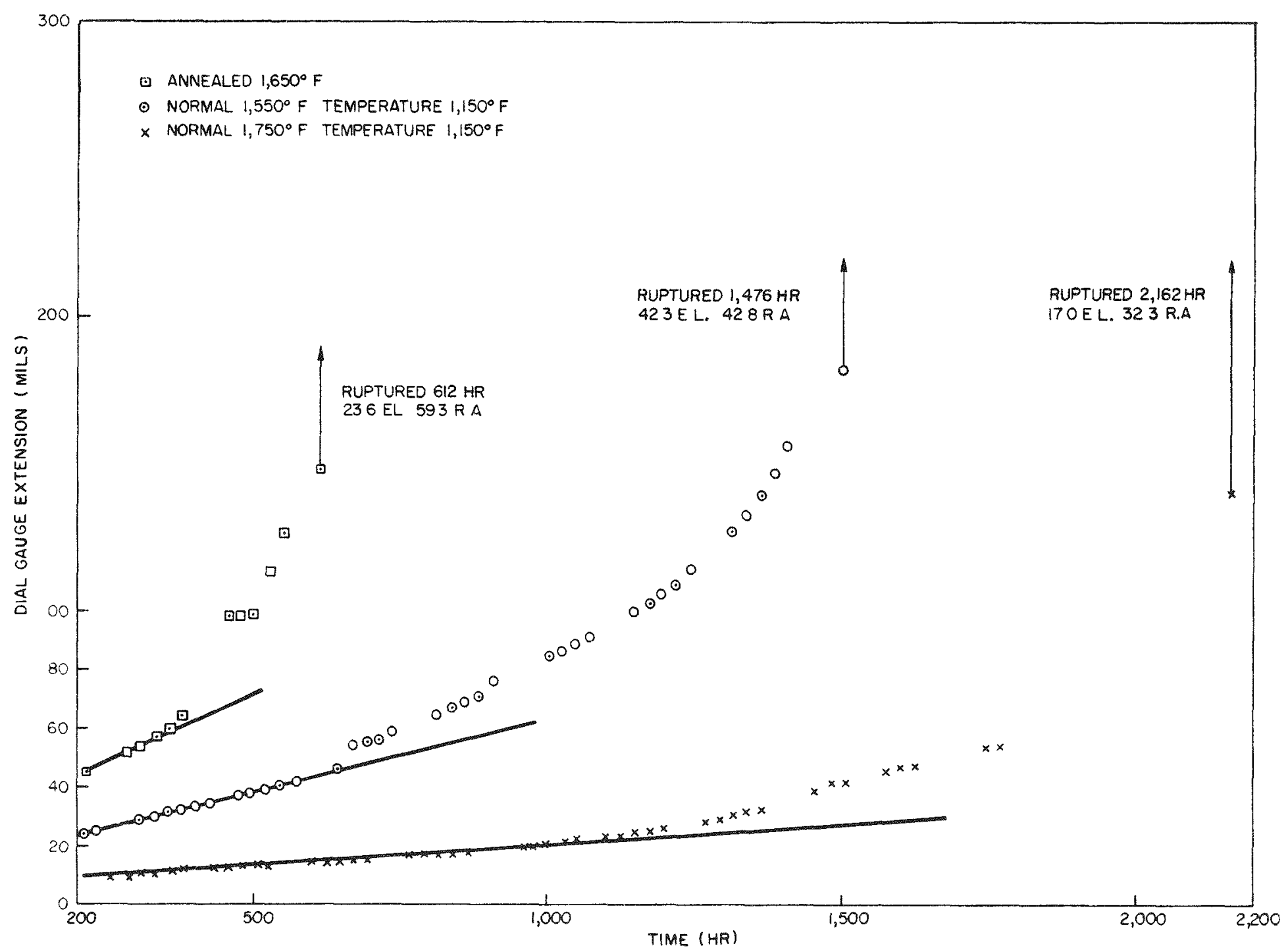

Fig. 5. 36--Dial gauge extension versus time for $1-1 / 4 \mathrm{Cr}-1 / 2$ Mo steel at $1,000^{\circ} \mathrm{F}, 30,000 \mathrm{psi}$ in air 
variables of the tests. It $1 \mathrm{~s}$, furthermore, considered possible that the lowest rupture lives will occur in the purest helium. Helium bottled at Bu-Mines, Amarillo, Texas, was adopted as the standard environment for the tests, and rigid procedures were established to prevent contamination of this helium by the test apparatus.

The first two specimens of Type 316 stainless steel tested in helium at $1,300^{\circ} \mathrm{F}$ (up to approximately $100 \mathrm{hr}$ ) did not indicate any environmental effect, as shown in Fig 5 37. One specimen of 1-1/4 Cr-1/2 Mo steel ruptured after $19.6 \mathrm{hr}$ in helium, at $1,000^{\circ} \mathrm{F}$ and $58,000 \mathrm{psi}$; the corresponding air specimen lasted 69.0 hr. The data on helium tests are shown in Table 5.13.

A procedure has been established for evaluating the effects of controlled amounts of carbon monoxide and hydrogen impurities on the creep-rupture properties of the above materials in helium The gasmixing apparatus is being constructed and it is expected that these experiments will start in September, 1959.

Welding Tests. The program for welding studies on $1-1 / 4 \mathrm{Cr}-1 / 2 \mathrm{Mo}$ steel was finalized and the preparation of specimens began in June, 1959, With the following objectives:

1. To develop procedures for producing sound, crevice-free welds in normalized and tempered $1-1 / 4 \mathrm{Cr}-1 / 2$ Mo steels for shop welding and field welding of high-temperature piping and pressure vessels. The Electric Boat Division consumable insert weld technique will be used.

2. To resolve whether the elevated temperature creep-rupture properties are adversely influenced in the heat-affected zone of of the weld. Creep-rupture specimens will be removed from welded pipe to compare joint strength with base-metal strength.

Helium Contaınment Tests. An experiment was performed to determine whether helium penetrates through the walls of $1-1 / 4 \mathrm{Cr}-1 / 2$ Mo steel 


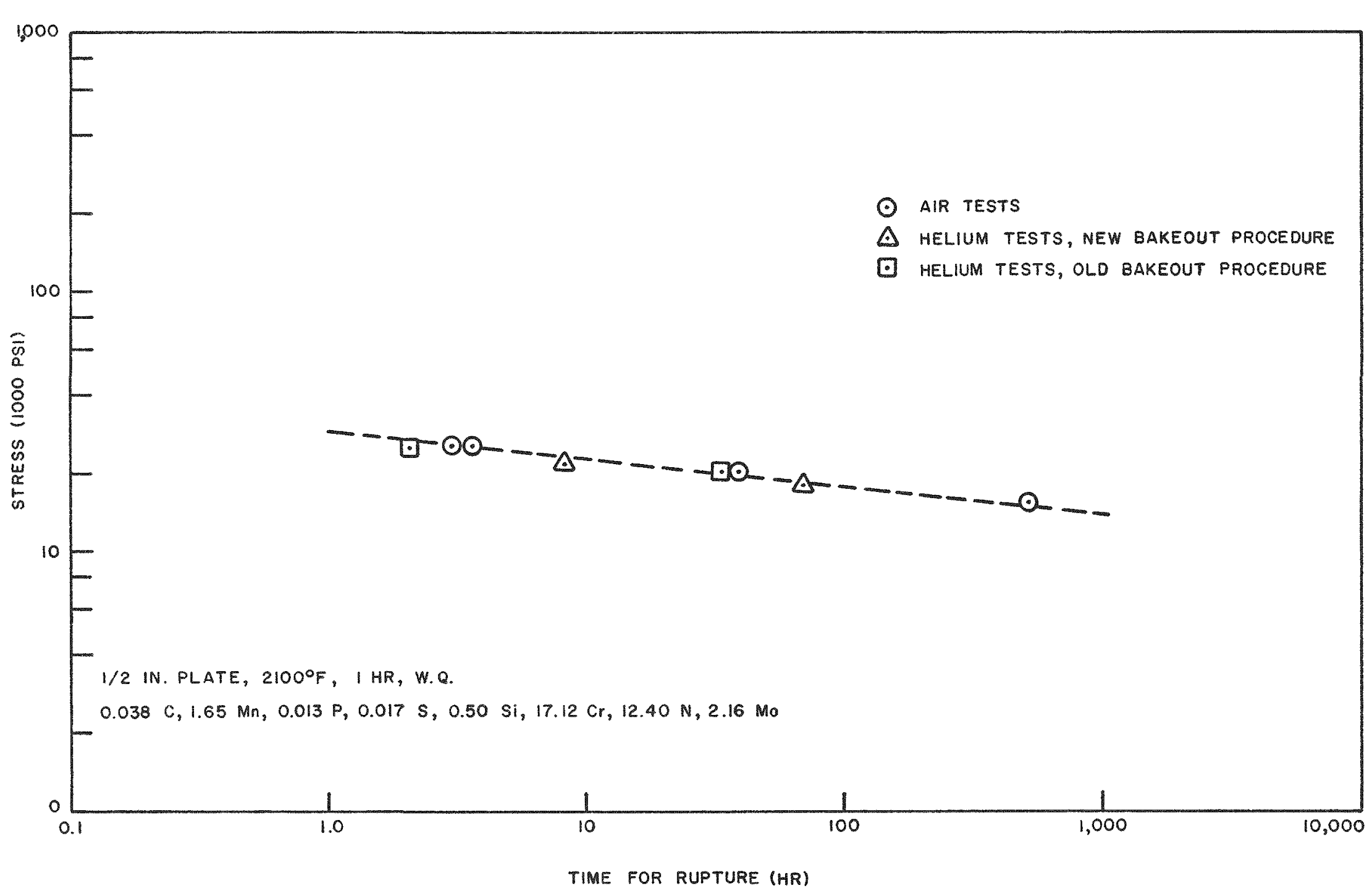

Fig. 5.37--Stress versus rupture time for Type 316 stainless steel at $1,300^{\circ} \mathrm{F}$ 
Table 5.13

HELIUM CREEP-RUPTURE TEST DATA

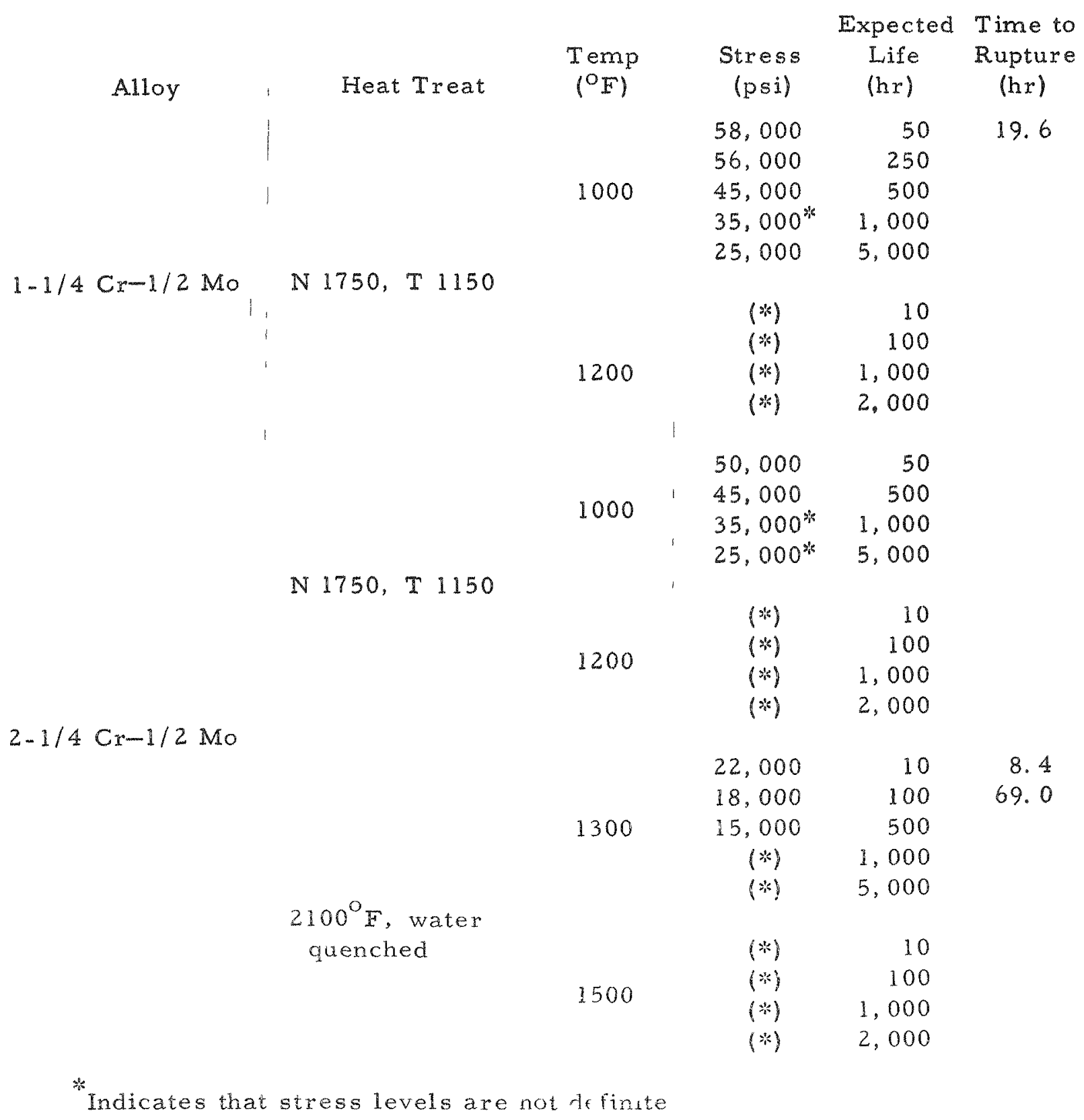


piping. The experimental test system is shown in Fig. 5.38. A 4-in.-diam pipe of approximately 1/4-in. wall thickness, Fig. 5.39, was heated to $1,000^{\circ} \mathrm{F}$ and pressurized internally to 1,000 psig with helium. An annular collecting chamber surrounding this pipe wàs maintained under vacuum. Helium penetration could not be detected, within the sensitivity limits of the vacuum decay measurements and a mass spectrometer leak detector. This instrument can detect one part of helium in 200,000 parts of air and measure the flow of helium through a leaking vessel in the order of $10^{-9} \mathrm{~cm}^{3} / \mathrm{sec}$.

Seizing and Wear in Helium at Elevated Temperatures. The objective in this area of investigation was to establish the scope of work needed to determine the galling, fretting, and self-welding aspects of the materials intended for use in the MGCR propulsion plant. This is of particular importance with regard to the seating surfaces and mechanisms of high-temperature helium valves, and it is also important for establishing designs for flanges and other members in contact in a helium atmosphere at high temperature. The Crane Company has submitted a list of materials to be considered for use in the construction of the concentric duct valves.

Information obtained from the Pratt and Whitney CANEL Laboratory indicated that the following materials are successful combinations for an unlubricated rotating seal:

1. Carboloy $44 \mathrm{~A}$ with Carboloy $44 \mathrm{~A}$.

2. Carboloy $44 \mathrm{~A}$ with Carboloy 907.

3. Kennametal K96 with Kennametal K162B.

A seizure and wear testing program will be finalized during July, 1959 , and it is expected that experiments will begin in August, 1959. 

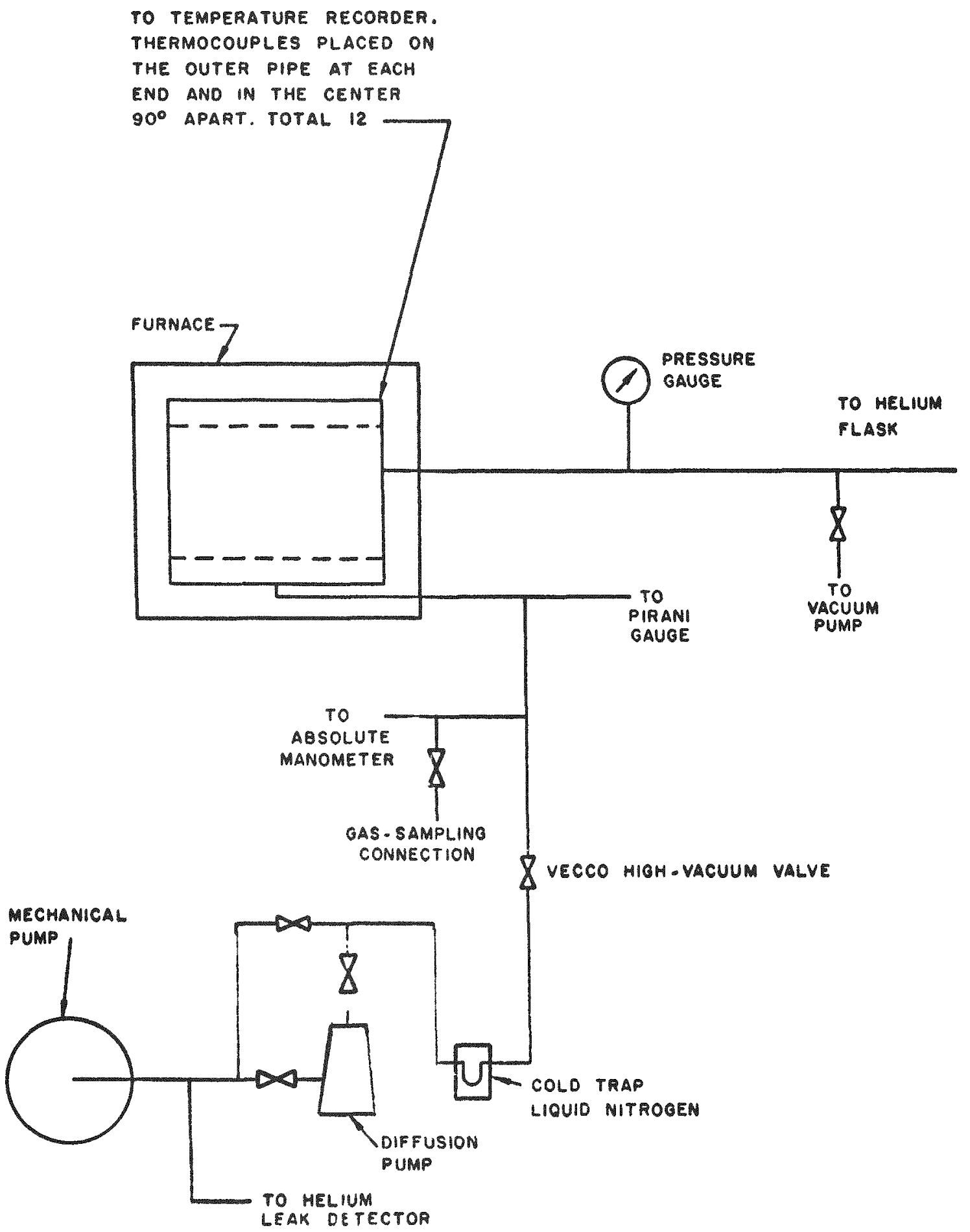

Fig. 5.38--Schematic diagram of helium containment materials tost systom 


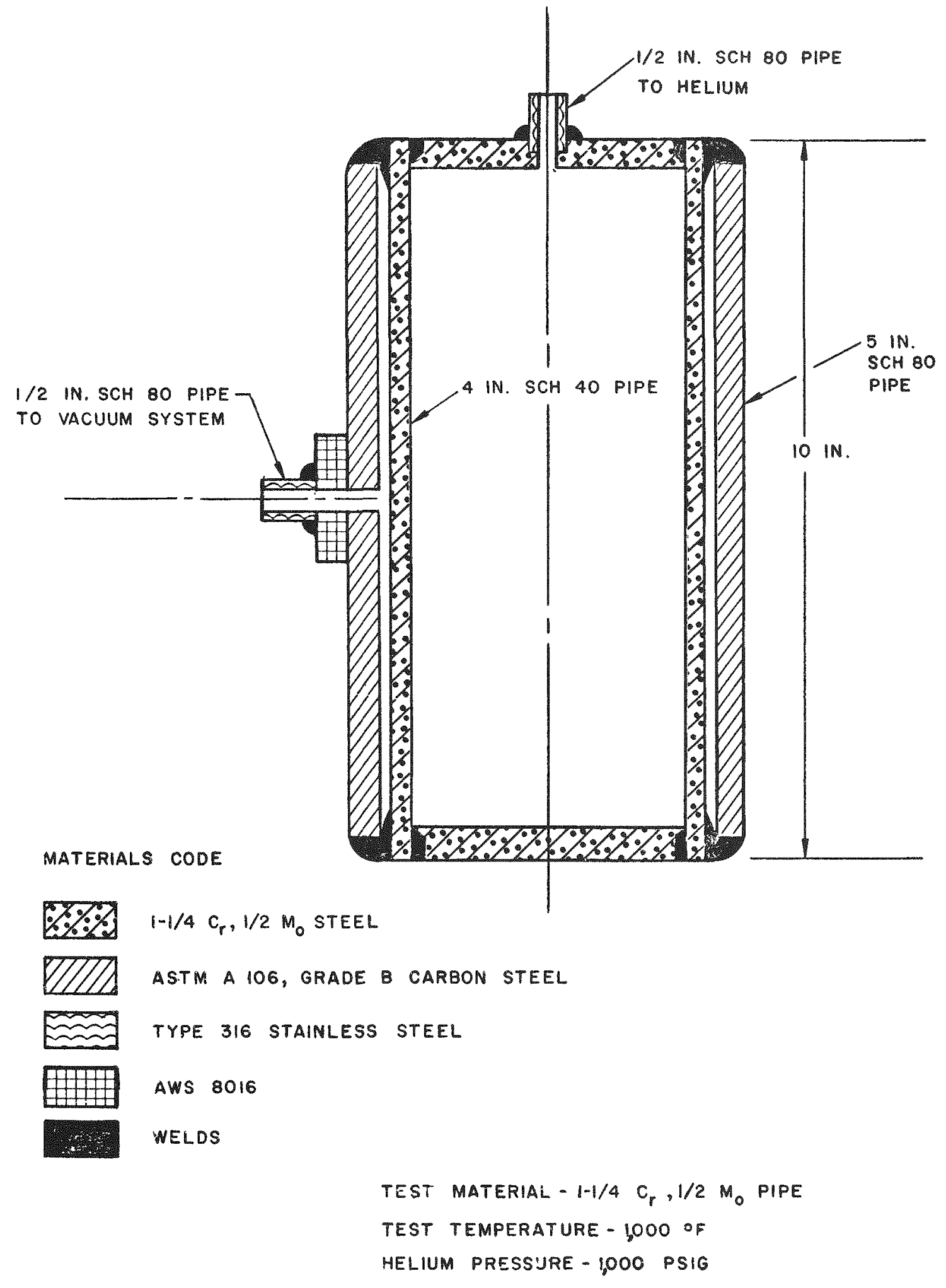

Fig. 5.39--Diagram of vessel for helium containment tests 